Routledge Studies in Media, Communication, and Politics

\title{
GENERATIONAL GAPS IN \\ POLITICAL MEDIA USE AND CIVIC ENGAGEMENT
}

FROM BABY BOOMERS TO GENERATION Z

Kim Andersen, Jakob Ohme, Camilla Bjarnøe, Mats Joe Bordacconi, Erik Albæk, and Claes de Vreese

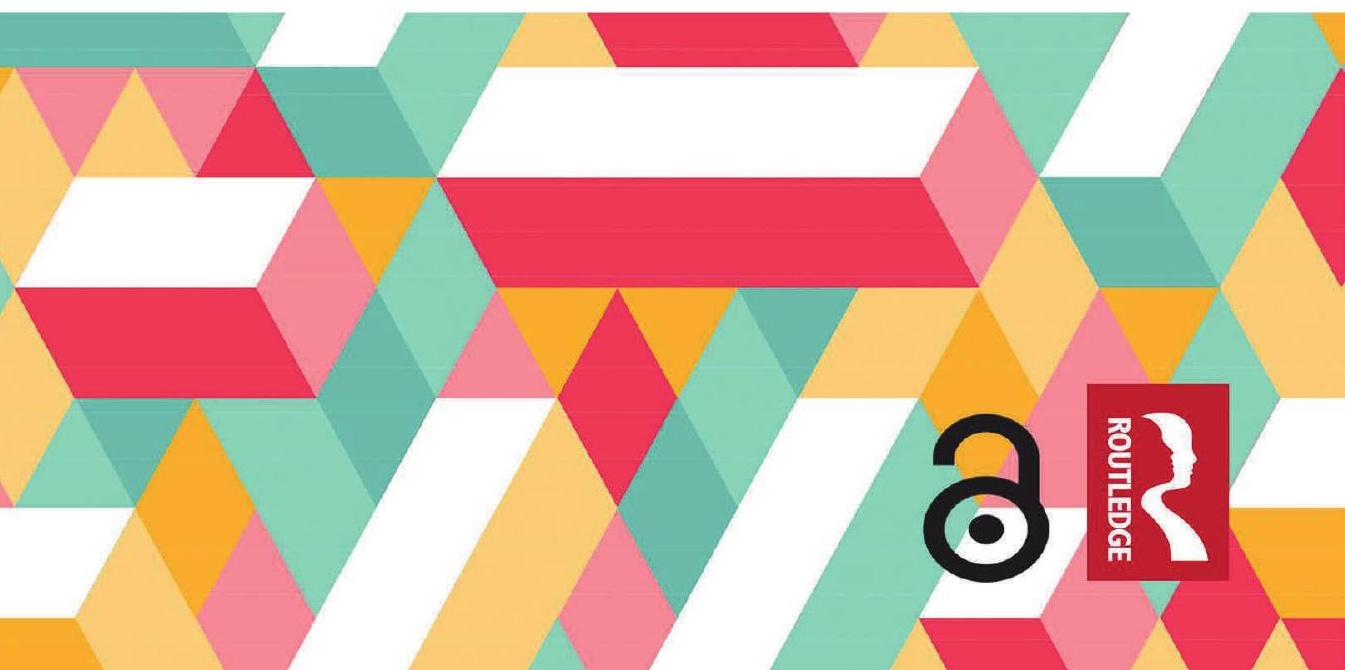


This impressive book introduces a new model for studying media use and political participation. The authors introduce an original research design that combines generational analysis of media preferences with a compelling framework for mapping a broad spectrum of political participation. The resulting analyses shows how different generations of citizens are defined by their media habits, and how those communication preferences offer different pathways into politics.

Lance Bennett Professor of Political Science and Ruddick C. Lawrence Professor of Communication, Emeritus University of Washington, Seattle, USA

Rich in data and full of big ideas, Generational Gaps in Political Media Use and Civic Engagement tells the story of remarkable differences in patterns of media use and political engagement across five generations. The authors paint a largely hopeful portrait of the continued importance of news use in democracy, while offering warnings to us all of the potential dangers posed by our increasingly fragmented, personalized media environment. The book is a must for anyone who cares about safeguarding the political voice of emerging generations.

Kjerstin Thorson

Associate Professor, Michigan State University

With the changing media landscape creating new patterns of information consumption and opportunities for a great number of actors to express themselves and reach others in ways that were previously impossible, understanding the effects of exposure to political information on political participation is critical for assessing the health of our democracy. Theoretically innovative and conceptually rich, Generational Gaps in Political Media Use and Civic Engagement, brings together three different types of data collection to explore the interplay between information consumption, participation and engagement by the young and the elderly. Providing new insights about how a variety of types of exposure experienced by five generations affect different types of input to the political system, Andersen and colleagues' book adds important new empirical evidence for understanding participation and active citizenship in a changing political information environment.

Yannis Theocharis

Professor of Media and Communication

University of Bremen 
$\because$ Taylor \& Francis

Taylor \& Francis Group

http://taylorandfrancis.com 


\section{Generational Gaps in Political Media Use and Civic Engagement}

This book investigates news use patterns among five different generations in a time where digital media create a multi-choice media environment.

The book introduces the EPIG model (Engagement-ParticipationInformation-Generation) to study how different generational cohorts' exposure to political information is related to their political engagement and participation. The authors build on a multi-method framework to determine direct and indirect media effects across generations. The unique dataset allows for comparison of effects between legacy and social media use and helps to disentangle the influence on citizens' political involvement in nonelection as well as during political campaign times. Bringing the newly of-age Generation $\mathrm{Z}$ into the picture, the book presents an in-depth understanding of how a changing media environment presents different challenges and opportunities for political involvement of this, as well as older generations.

Bringing the conversation around political engagement and the media up to date for the new generation, this book will be of key importance to scholars and students in the areas of media studies, communication studies, technology, political science, and political communication.

Kim Andersen is Assistant Professor in the Centre for Journalism at the University of Southern Denmark.

Jakob Ohme is Postdoctoral Researcher at the Amsterdam School of Communication Research (ASCoR) at the University of Amsterdam.

Camilla Bjarnøe is Postdoctoral Researcher in the Centre for Journalism at the University of Southern Denmark.

Mats Joe Bordacconi is Analyst at The National Olympic Committee and Sports Confederation of Denmark.

Erik Albæk is Professor in the Centre for Journalism at the University of Southern Denmark.

Claes de Vreese is Professor and Chair of Political Communication at the Amsterdam School of Communication Research (ASCoR) at the University of Amsterdam. 
Routledge Studies in Media, Communication, and Politics

Digitizing Democracy

Edited by Aljosha Karim Schapals, Axel Bruns, and Brian McNair

Communicating Populism

Comparing Actor Perceptions, Media Coverage, and Effects on Citizens in Europe

Edited by Carsten Reinemann, James Stanyer,

Toril Aalberg, Frank Esser, and Claes H. de Vreese

Human Rights, Iranian Migrants, and State Media

From Media Portrayal to Civil Reality

Shabnam Moinipour

Threat Communication and the US Order after 9/11

Medial Reflections

Edited by Vanessa Ossa, David Scheu and Lukas R.A. Wilde

Rhetoric, Fantasy, and the War on Terror

Vaheed Ramazani

Generational Gaps in Political Media Use and Civic Engagement From Baby Boomers to Generation Z

Kim Andersen, Jakob Ohme, Camilla Bjarnøe,

Mats Joe Bordacconi, Erik Albak, and Claes de Vreese 


\section{Generational Gaps in Political Media Use and Civic Engagement}

From Baby Boomers to Generation Z

Kim Andersen, Jakob Ohme, Camilla Bjarnøe, Mats Joe Bordacconi, Erik Albæk, and Claes de Vreese 
First published 2021

by Routledge

2 Park Square, Milton Park, Abingdon, Oxon OX14 4RN

and by Routledge

52 Vanderbilt Avenue, New York, NY 10017

Routledge is an imprint of the Taylor \& Francis Group, an informa business

(C) 2021 Kim Andersen, Jakob Ohme, Camilla Bjarnøe, Mats Joe

Bordacconi, Erik Albæk, and Claes de Vreese

The right of Kim Andersen, Jakob Ohme, Camilla Bjarnøe, Mats Joe Bordacconi, Erik Albæk, and Claes de Vreese to be identified as authors of this work has been asserted by them in accordance with sections 77 and 78 of the Copyright, Designs and Patents Act 1988.

The Open Access version of this book, available at www.taylorfrancis. com, has been made available under a Creative Commons AttributionNon Commercial-No Derivatives 4.0 license.

Trademark notice: Product or corporate names may be trademarks or registered trademarks, and are used only for identification and explanation without intent to infringe.

British Library Cataloguing-in-Publication Data

A catalogue record for this book is available from the British Library

Library of Congress Cataloging-in-Publication Data

Names: Andersen, Kim (Professor of journalism), author.

Title: Generational gaps in political media use and civic engagement : from baby boomers to Generation Z / Kim Andersen [and five others].

Description: Abingdon, Oxon ; New York, NY : Routledge, 2021. I Series: Routledge studies in media, communication, and politics I Includes bibliographical references and index.

Identifiers: LCCN 2020029579 (print) | LCCN 2020029580 (ebook) | ISBN 9780367629328 (hardback) I ISBN 9781003111498 (ebook)

Subjects: LCSH: Communication in politics. I Political participation. I Conflict of generations-Political aspects. I Mass media and older people-Political aspects. I Mass media and youth-Political aspects. I Older people-Political activity. I Youth-Political activity.

Classification: LCC JA85 .A64 2021 (print) I LCC JA85 (ebook) I DDC 302.23/10840973-dc23

LC record available at https://lccn.loc.gov/2020029579

LC ebook record available at https://lccn.loc.gov/2020029580

ISBN: 978-0-367-62932-8 (hbk)

ISBN: 978-1-003-11149-8 (ebk)

Typeset in Sabon

by Apex CoVantage, LLC 


\section{Contents}

List of figures

List of tables

viii

xi

1 Times are changing

2 The EPIG model-political information exposure and political involvement in a generational perspective

3 A multi-methods research design

4 Being exposed to political information in the media

5 Getting interested in, learning about, and feeling capable of participating in politics

6 Participation targeting the political system

7 Participation targeting the local community

8 Being politically motivated

9 Social media, political engagement, and participation

10 Election times: special times?

11 Are the kids alright?

Appendix 


\section{Figures}

1.1 News media use across generations 8

1.2 Political participation across generations 9

2.1 Antecedents of exposure to political information in the media 19

2.2 Effects of exposure to political information in the media 21

2.3 The relevance of cohort and life-cycle effects for explaining levels of - and relationships between-exposure to political information in the media and political involvement

2.4 The Engagement-Participation-Information-Generation $\begin{array}{ll}\text { (EPIG) model } & 27\end{array}$

3.1 Sample overview for online and mobile survey waves 31

3.2 Amount of political information across news outlets over time 36

4.1 Political information in the news media over time 45

4.2 Average political news exposure over time across generations $\quad 46$

4.3 Average political social media exposure over time across generations

4.4 Marginal effects of political interest on exposure to political information in the news media and on social media across generations

4.5 Marginal effects of political knowledge on exposure to political information in the news media and on social media across generations

4.6 Marginal effects of political efficacy on exposure to political information in the news media and on social media across generations

4.7 Marginal effects of political participation targeted at the political system (PP II) on exposure to political information in the news media and on social media across generations

4.8 Marginal effects of political participation targeted at the local community (PP III) on exposure to political information in the news media and on social media across generations

4.9 Marginal effects of politically motivated but non-political participation (PP IV) on exposure to political information in the news media and on social media across generations 
5.1 Average political interest over time across generations

5.2 Marginal effects of exposure to political information in the news media on political interest across generations

5.3 Average political knowledge over time across generations

5.4 Marginal effects of exposure to political information in the news media on political knowledge across generations

5.5 Average political efficacy over time across generations

5.6 Marginal effects of exposure to political information in the news media on political efficacy across generations

6.1 Frequency of participatory activities targeted at the political system (PP II) across generations

6.2 Average level of political participation targeted at the political system (PP II) over time across generations

6.3 Marginal effects of exposure to political information in the news media on political participation targeted at the political system (PP II) across generations

7.1 Frequency of participatory activities targeted at the local community (PP III) across generations

7.2 Average level of political participation targeted at the local community (PP III) over time across generations

7.3 Marginal effects of exposure to political information in the news media on political participation targeted at the local community (PP III) across generations

8.1 Frequency of participation in non-political but politically motivated behaviours (PP IV) across generations

8.2 Average level of participation in non-political but politically motivated behaviours (PP IV) over time across generations

8.3 Marginal effects of exposure to political information in the news media on non-political but politically motivated participation (PP IV) across generations

9.1 Average levels of political engagement across generations in mobile survey subsample

9.2 Marginal effects of exposure to political information on social media on political interest across generations

9.3 Marginal effects of exposure to political information on social media on political knowledge across generations

9.4 Marginal effects of exposure to political information on social media on political efficacy across generations

9.5 Average levels of political participation across generations in subsample

9.6 Share of participation types of total political participation across generations in subsample

9.7 Marginal effects of exposure to political information on social media on political participation targeted at the political system (PP II) across generations 
9.8 Marginal effects of exposure to political information on social media on political participation targeted at the local community (PP III) across generations

9.9 Marginal effects of exposure to political information on social media on non-political but politically motivated participation (PP IV) across generations

10.1 Levels of campaign participation across generations

10.2 Frequency of campaign participation across generations

10.3 Marginal effects of exposure to political information in the news media on campaign participation

10.4 Marginal effects of exposure to political information on social media on campaign participation

A3.1 Search string for political information in the news media

A3.2 Questionnaire of Audio-Page-Stream measurement

A3.3 Results of the confirmatory factor analysis of four types of political participation 


\section{Tables}

3.1 Age span and number of respondents per generation 40

6.1 Indirect effects of exposure to political information in the news media on political participation II

7.1 Indirect effects of exposure to political information in the news media on political participation III

8.1 Indirect effects of exposure to political information in the news media on political participation IV

9.1 Indirect effects of exposure to political information on social media on political participation II

9.2 Indirect effects of exposure to political information on social media on political participation III

9.3 Indirect effects of exposure to political information on social media on political participation IV

10.1 Indirect effects of exposure to political information in the news media on campaign participation

10.2 Indirect effects of exposure to political information on social media on campaign participation

11.1 Main findings across generations

A3.1 Comparison of gender, age, and region for general population sample $(18+)$ and population (pct.)

A3.2 Comparison of education for general population sample $(18+)$ and population $(20-60)$ (pct.)

A3.3 Descriptive statistics

A3.4 Political knowledge questions 150

$\begin{array}{ll}\text { A3.5 Political efficacy statements } & 151\end{array}$

A3.6 Frequencies of political participation activities 151

A3.7 Frequencies of (intended) campaign participation activities 154

A4.1 Effects of political engagement antecedents on exposure to political information in the news media

A4.2 Effects of political engagement antecedents on exposure to political information on social media

A4.3 Effects of political participation antecedents on exposure to political information in the news media 
A4.4 Effects of political participation antecedents on exposure to political information on social media

A5.1 Effects of exposure to political information in the news media on political interest

A5.2 Effects of exposure to political information in the news media on political knowledge

A5.3 Effects of exposure to political information in the news media on political efficacy

A6.1 Effects of exposure to political information in the news media on political participation II

A7.1 Effects of exposure to political information in the news media on political participation III

A8.1 Effects of exposure to political information in the news media on political participation IV

A9.1 Effects of exposure to political information on social media on political interest

A9.2 Effects of exposure to political information on social media on political knowledge

A9.3 Effects of exposure to political information on social media on political efficacy (1-5)

A9.4 Effects of exposure to political information on social media on political participation II

A9.5 Effects of exposure to political information on social media on political participation III

A9.6 Effects of exposure to political information on social media on political participation IV

A10.1 Effects of exposure to political information in the news media on campaign participation

A10.2 Effects of exposure to political information on social media on campaign participation 


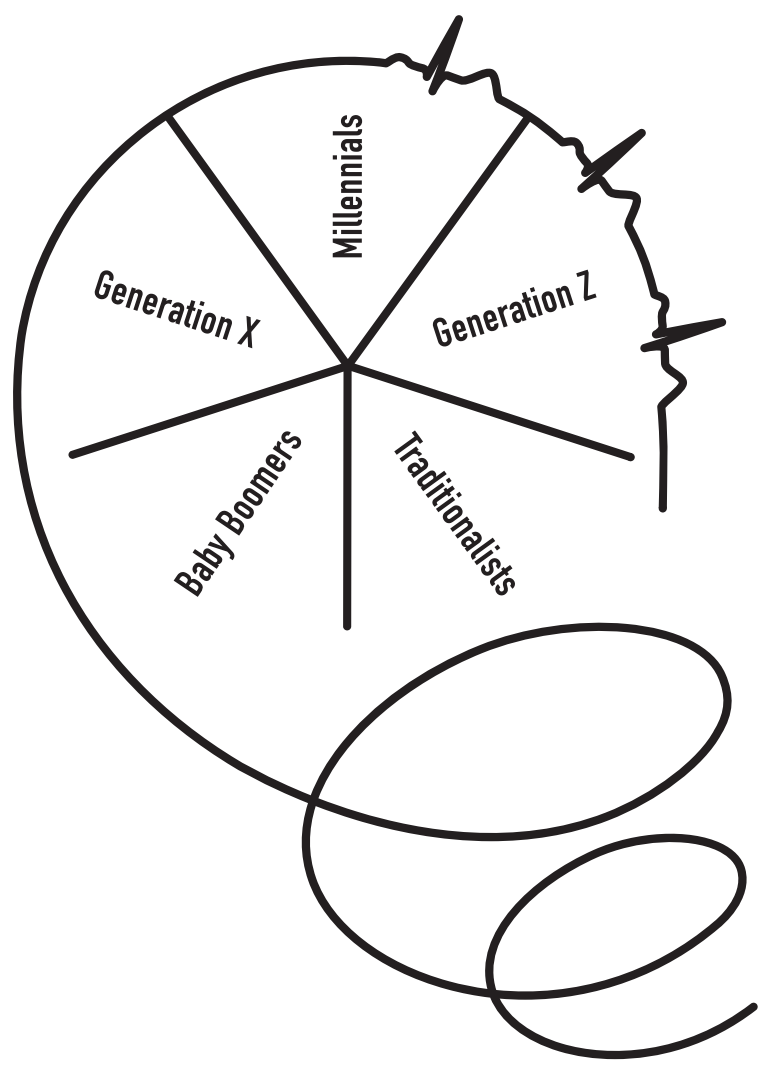


$\because$ Taylor \& Francis

Taylor \& Francis Group

http://taylorandfrancis.com 


\section{Times are changing}

Saturday morning at a family breakfast table: as the eating winds down, father Peter picks up the printed broadsheet newspaper. The family have been subscribers to the same morning newspaper for years, the same paper that Peter's and mother Sarah's parents read when Peter and Sarah were kids. An independent business owner, Sarah quickly skims through the paper's business section on her tablet, using the newspaper's app, then checks her fitness app and departs for a yoga class. Their three children each have their smartphones out. The youngest, age 11, is picking up a game that was paused when breakfast started. The middle child, 13 , is in a lengthy Snapchat session. The oldest, 17, is scrolling through a long stream of Instagram posts. Before taking off for field hockey, in response to an Instagram post, she comments on how much water is needed to produce a kilo of meat.

The scene is a snapshot of the rapidly changing information ecology. The way in which-and the degree to which-citizens in today's democracies consume and expose themselves to political information is fundamentally different from how things were only a couple of decades ago. Younger generations grow up in a high-choice environment that would have been inconceivable to their parents. Parents in their 40s today were children of black and white television, landline telephones, nightly television news programmes, free print newspapers, and-in their late youth-the arrival of the internet and its initial affordances. They are typically avid users of Facebook. Their teenage children, born after 2000, however, have grown up in the mobile and visual age: cell phones, smartphones, tablets, media hybridity, and social media platforms. Social media to them means WhatsApp, Instagram, and Snapchat.

The generations each have their own set of opportunities to inform themselves. At the same time, each cycle of life comes with a different set of 


\section{Times are changing}

opportunities. Parents of today grew up in newspaper households. Typically, they engaged less with newspapers during the adolescent years before becoming newspaper users themselves, albeit at a much lower level than their own parents. These 'media life histories' illustrate the fundamental change in the information ecology. The supply of political information has never been bigger, the time spent with media has never been longer, and at the same time, it has never been easier to avoid political information while still being connected.

The changing media landscape has offered a new opportunity structure for citizens; as the media landscape has changed, so has the opportunity for citizens to engage and express themselves and to participate politically. Political involvement is of key importance in a well-functioning democracy, and in this book, we argue that news media use is vital to understand how people are involved politically. The changing environment for media use and political participation, with the changing opportunity structures that follow, needs to be unpacked. How do these changes affect the way that citizens engage in society and politics? We approach this key question from a generational perspective: what are the consumption, engagement, and participation patterns across different generations? And is the impact of exposure to political information different for citizens in different cycles of life? In this chapter we first unpack the changing media landscape and the new opportunities for political involvement. We then focus specifically on the generational perspective in understanding the relationship between media use and political involvement. Finally, we outline the structure of the book's remaining chapters.

\section{Understanding political information consumption in today's communication ecology}

The supply side of political information has changed. Research spanning decades shows that the supply of news has increased in traditional media like television (see Esser et al., 2012) and newspapers, with more free newspapers entering the market (e.g., Bakker, 2008). At the same time, the online presence of traditional news organizations has burgeoned, and new information brokers have become popular. Platforms like Facebook and Twitter are now central to the news ecology, and personal messaging services like WhatsApp are also increasingly important for understanding the political information landscape. In addition, traditional genre-determined boundaries have shifted, resulting in a wider mix of different types of content, often combining harder, factual news with softer entertainment features. As a consequence, citizens can easily create their own personal media diets with varying degrees of political information based on individual preferences (Arceneaux \& Johnson, 2013; Prior, 2007). 
The demand side has also changed. Subscriptions to newspapers have been decreasing for years. Some groups have become political news junkies, while sizeable parts of the electorate are opting out of news consumption (Bos, Kruikemeier, \& de Vreese, 2016). Yet others have migrated towards relatively brief news encounters, almost 'news snacking,' thanks to generators and social media sites. These changes in the demand side vary significantly across generations, with younger news consumers, for example, consuming most of their news online only (Newman, Fletcher, Kalogeropoulos, Levy, \& Nielsen, 2018).

These developments in the media landscape, on both the supply and the demand sides, are not linear or uniform across generations. They represent a general development in the past two decades, but recent data show additional nuances and even, in some cases, reversals. The 2018 Reuters report (Newman et al., 2018) notes that the use of social media is falling for the first time in years, whereas the use of messaging apps (like WhatsApp) is increasing. This change might suggest a migration from more public platforms to more private platforms when it comes to political information, but it is still too soon to tell. Another example is the increasing number of digital newspaper subscriptions in the past couple of years. This increase breaks the curve of virtually across-the-board decline. Again, however, it is too early to determine whether this reversal is temporary and what it looks like across countries. Likewise, we do not know if this development has been brought about by traditional news consumers-who in the past tuned out of paying for news but have now returned-or by new and younger news consumers. Whether we look at long-term trends or some of the more recent fluctuations, in all cases we see differences between generations.

Underlying some of these user data are more structural transformations in the news ecology, being part of larger changes in political communication altogether (see Van Aelst et al., 2017). These changes do not apply only to supply and demand but also to discussions about the quality and trustworthiness of news; the value of information and the ongoing misinformation crisis; the increasing concentration of media ownership; increasing audience fragmentation and polarization of political attitudes; increasing relativism and questioning of authority, truth, and authenticity; and the increasing inequality in political knowledge between news users and non-users. Such tendencies also capture the concerns of misinformation and limited media literacy in today's media landscape. These larger changes form the backdrop against which we study political information exposure and address the questions of whether consumption patterns are different across generations and whether different generations are affected differently by political information. 


\section{Changing political involvement?}

'More than 15,000 litres of water for a kilo of beef?' The family looks up from their newspapers and smartphones when the 11-year-old expresses surprise about the number that the older sibling has just picked up on an Instagram post. A friend shared this post, in which an NGO calls for signing a petition against factory farming. The 13-yearold responds with rolling eyes and feels supported in her decision to boycott meat for the past three years. 'We should eat less meat,' one of their parents mumbles. 'That would still not change the conditions in which most animals are held,' the oldest child responds. 'Such factories will change only if we stand right in front of their doors and demonstrate for the rights of animals.' The other parent now joins the debate: 'These farmers are only doing their job within the framework that politics gives them. If you really want to change something, you should join a party that aims at changing the relevant legislation.'

As citizens' opportunity structure-in terms of both political information supply and demand-has changed so too have patterns of political participation. Citizen participation in political processes is at the core of all conceptions of liberal democracies (Strömbäck, 2005). Central scholars like Schumpeter (1942) and Schattschneider (1975) all emphasize the importance of citizen participation. They diverge, however, in their conception of how much and what type of participation is needed in a healthy democracy.

Competitive democracy is seen as a means to aggregate voters' individual preferences when competing elites supply policy packages on the political market and voters buy their preferred package with their votes (Held, 1987). This model of representative democracy presupposes multiple elites that, through competition, keep each other at bay. Citizens' political participation is linked to turnout at elections but is neither needed nor desirable between electionsfor instance, during the formulation of party policies. The normative role of the mass media in a competitive democracy is to provide information to citizens on central political and social challenges, on how political parties have performed since the last election, and on what their policy packages consist of in order that citizens can make informed vote choices (Strömbäck, 2005).

At the other end of the scale, so to speak, participatory democracy considers citizens' active participation not only a means to obtain authoritative decisions for society but also a goal in itself: besides influencing political decisions, popular participation has an educational function in that it teaches citizens how to take part in public debate, how to form opinions on societal problems, and how to solve conflicts on mutual matters, thus turning them into politically competent citizens. These arguments are used, among others, by Alexis de Tocqueville (Sharpe, 1970, p. 161) and John Stuart Mill (1912) in defence 
of local government, which gives citizens a chance to learn the skills necessary to run a well-functioning democracy. Participatory democracy does not imply that free elections are obsolete but rather that citizens must constantly act out democracy. Just think of recent examples like the Fridays of Future, Black Lives Matter, or \#MeToo movements, where protest participation is changing not only the public debate but also current legislation in many countries. What happens between elections thus becomes of utmost importance for the well-being of democracy (Held, 1987). Equally important, in a wellfunctioning democracy, all parts of the citizenry participate politically-not only the elderly but also the youth. Just as in a competitive democracy, the media in a participatory democracy are normatively obliged to provide political information to citizens in a manner that enables them to make informed choices. In addition, the media are also obliged to encourage the greatest possible participation by citizens not only in public debate but also in democratic decision-making in all its forms (Strömbäck, 2005).

The normative literature diverges both on how much citizens are to participate in a healthy democracy and on how they are to participate. Some argue that deliberation is key to democracy and therefore put a premium on collectivistic activities with some element of deliberation-for instance, membership of a political party or participation in election meetings or demonstrations. However, in recent decades, many new forms of more individualistic political activities without active deliberation have emerged, for instance, signing of online petitions, crowdfunding, or boycotting of products. Both collectivistic and individualistic forms of participation create a political 'we' that is intended to influence authoritative decisions- the former, primarily through deliberation (a collectivistic 'we'), the latter, primarily through aggregation of interests (an individualistic 'we'). In sum, assessing the amount and type of political participation in healthy democracies and whether the media performs its democratic role satisfactorily depends on the normative democratic standards applied.

Generally speaking, the empirical study of political participation is of continuous importance since it is an indicator of the quality of democracy (Theocharis \& van Deth, 2016). As opportunity structures in the media landscape change, so do opportunity structures for political participation. The ways in which citizens can express opinions, show political engagement, and participate in decision-making processes are constantly evolving. In the past 20 years, opportunity structures have changed rapidly. New participatory activitiessuch as supporting crowdfunding campaigns or signing online petitions-are now part of the mainstream participation repertoire. Indeed, some of the most important new ways of participation are digital (Theocharis, 2015).

Our aim in this book is to offer a new perspective, in the broadest sense, on the relationship between exposure to political information in the media and political involvement, with a specific focus on generational differences. Our task implies a further reflection on the conceptualization and ultimately the measurement of political participation. We supply definitions in more detail in Chapter 2, but suffice it to say for now that we intend the concept 
of political participation to be inclusive and to reflect digitally networked or other more recent forms of participation. Since voting turnout is remarkably high and stable in Denmark, the case country of this book, we have chosen to focus on other types of political participation for which the opportunity structures of participation have changed, both in non-election times and in times of election campaigns. Again, our core interest will be how these different types of participation relate to political information exposure in the media, most importantly, whether these aspects are different between generations and whether specific generations are more susceptible to media effects than others.

\section{Why the youth?}

Scholars often argue that the world is changing —and not for the better. One particular group of citizens, the youth, has caught a noticeable amount of scholarly attention. On the one hand, some scholars-often focusing exclusively on traditional participation opportunities such as voting behaviourpaint a pessimistic picture of the future and of the young generation. After all, young people turn away from traditional news media and focus on online or digital platforms (Mindich, 2005). They drop out of society rather than participating in it-at least traditionally (Putnam, 2000). On the other hand, other scholars take a more optimistic approach and suggest that the young generation use other types of media to obtain information, most notably social media (Xenos, Vromen, \& Loader, 2014). They participatebut differently - and particularly on social media platforms. The question is whether today's youth are inherently different or simply use other sources and platforms in these changing times.

In our analysis of the generation factor, we consider both generational effects and life-cycle effects. On the one hand, it might be a nonconsequential truism that younger people participate less than older groups and that they have different political information habits. They are simply concerned with receiving an education, finding a place to live, and starting a career and a relationship-just like younger generations of the past. Soon, they will start to behave like the older generations. This life-cycle perspective, however, is challenged by the generational perspective that assumes that each generation is composed differently, has a different formative experience, and will ultimately behave differently.

We focus on differences regarding media consumption and the type and level of participation as well as how media exposure affects participation and vice versa. The book's core starting point is thus to ask, how different are younger generations compared to older generations in regard to media use and political involvement? While asking this question, we think hard about the best way to conceive and to tap political information exposure in the media and different forms of political participation, all from a generational comparative perspective. 
In Chapter 2, we elaborate more on our classification of generations. Different studies have applied different starting and cut-off points. Broadly speaking, we distinguish five generations: Traditionalists (born between 1922 and 1944), Baby Boomers (1945-59), Generation X (1960-79), Millennials (i.e., Generation Y; 1980-94), and the emerging Generation Z (born after 1995). We have a specific interest in the younger generations and are keen not to study them in isolation but to offer a comparative perspective to their attitudes and behaviour.

\section{Generational differences in opportunity structures}

Earlier, we outlined opportunities for obtaining information about politics via the news media expanding beyond traditional media outlets to online platforms with an infinite number of news outlets as well as new social media platforms, which may direct citizens to-or away from-the news media. We now start by getting a better sense of media consumption. We focus on Denmark, where our elaborate multi-wave panel study is situated (see Chapter 3).

Looking at Danish data from the Reuters 2016 Digital News Report (Newman, Fletcher, Levy, \& Nielsen, 2016), we find that Baby Boomers, Traditionalists, and, almost to the same extent, Generation X consume news a lot; they access it daily, and most of them even do so multiple times per day. Millennials and Generation $\mathrm{Z}$ also score relatively high on news consumption but access news less frequently, and a sizeable group (about onefifth) consume news only once a week or less frequently. In terms of news interest, Millennials and members of Generation $\mathrm{Z}$ are typically 'somewhat interested' in news, while older generations are very to extremely interested in news. This pattern is also found for interest in political news, in particular, though the level of interest is lower across generations.

Turning to specific media, we observe some interesting generational differences. Only half of the younger generations (Millennials and Generation Z) watch television news, whereas the vast majority (73 to 86 percent) of older generations do so. Printed newspapers are used mostly by Traditionalists and Baby Boomers (57 and 44 percent, respectively), while Generation X are at 25 percent, Millennials at 13 percent, and Generation $Z$ at 18 percent. The slightly higher number for Generation $\mathrm{Z}$ is most likely due to this generation continuing to live at home (with Generation $X$ parents) in newspaper-subscribing households.

Looking at television or radio news websites, we see no generational differences, indicating that audio-visual online news content is equally appealing across generations. Finally, looking at social media usage, we see a reverse linear trend, with two-thirds (66 percent) of Generation $\mathrm{Z}$ accessing news via social media compared to a still noticeable 39 percent of Traditionalists at the other end of the spectrum. In sum, we see a news consumption pattern that is largely affected by generational differences. Older generations 


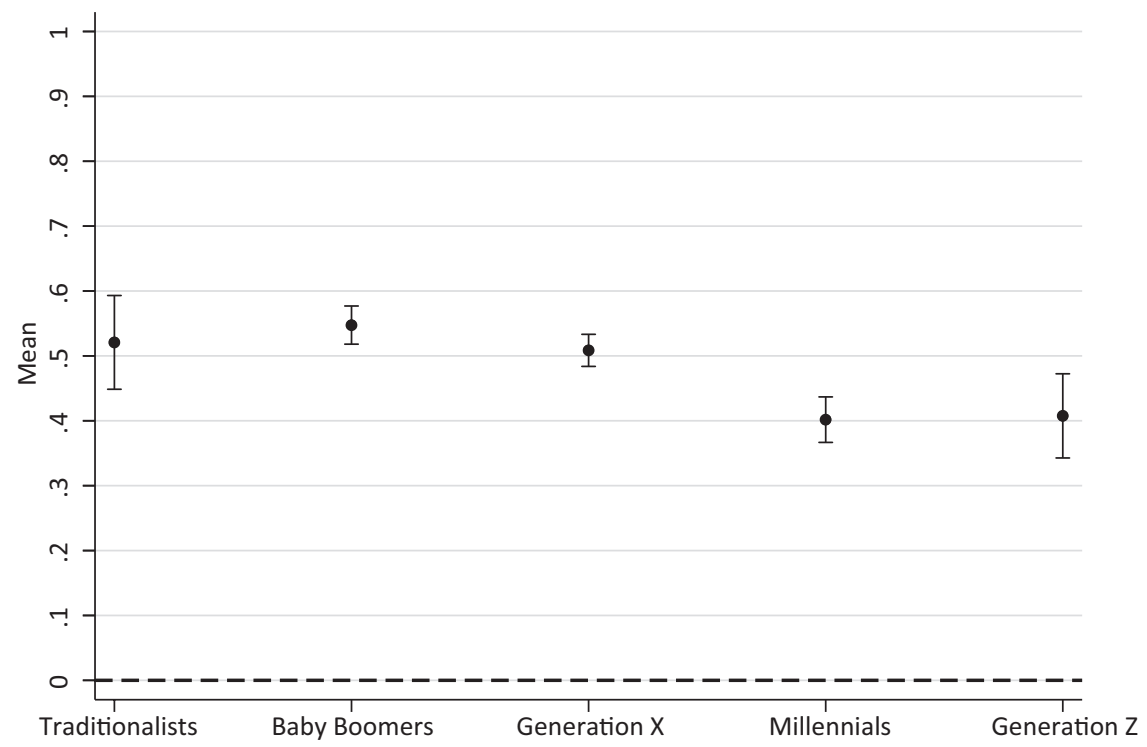

Figure 1.1 News media use across generations

Source: Reuters Institute Digital News Report 2016 (Newman et al., 2016)

Notes. Respondents were asked if they had used the following sources to access news in the last week: television news bulletins or programmes; printed newspapers; websites/apps of newspapers; websites/apps of TV and radio companies. The Y-axis shows the mean media use during the past week, where $0=$ they have not used any of the sources and $1=$ they have used all of the sources. The estimates are displayed with a 95 percent confidence interval. N: Traditionalists $=96$, Baby Boomers $=579$, Generation $X=819$, Millennials $=407$, Generation $Z=119$, Total $=2,020$.

simply turn to the news more, almost regardless of the medium (see the summary scores in Figure 1.1). Newspaper reading is mostly found in older generations. Television news usage is relatively high across the board but is also tilted towards the older generations. Social media usage, however, is much more pronounced among the younger generation. These descriptive findings give more than good reason to examine the effect of different news consumption patterns on political participation.

We take a broad and inclusive approach to understanding not only media consumption but also political participation. As outlined earlier, in some models of democracy, voting behaviour is key; in others, political participation is more than simply voting behaviour. What does political participation in Denmark look like?

At first glance (Figure 1.2) generations in Denmark do not look so different when we examine the general frequency of participating in different political activities, based on data from the European Social Survey 2014. A 


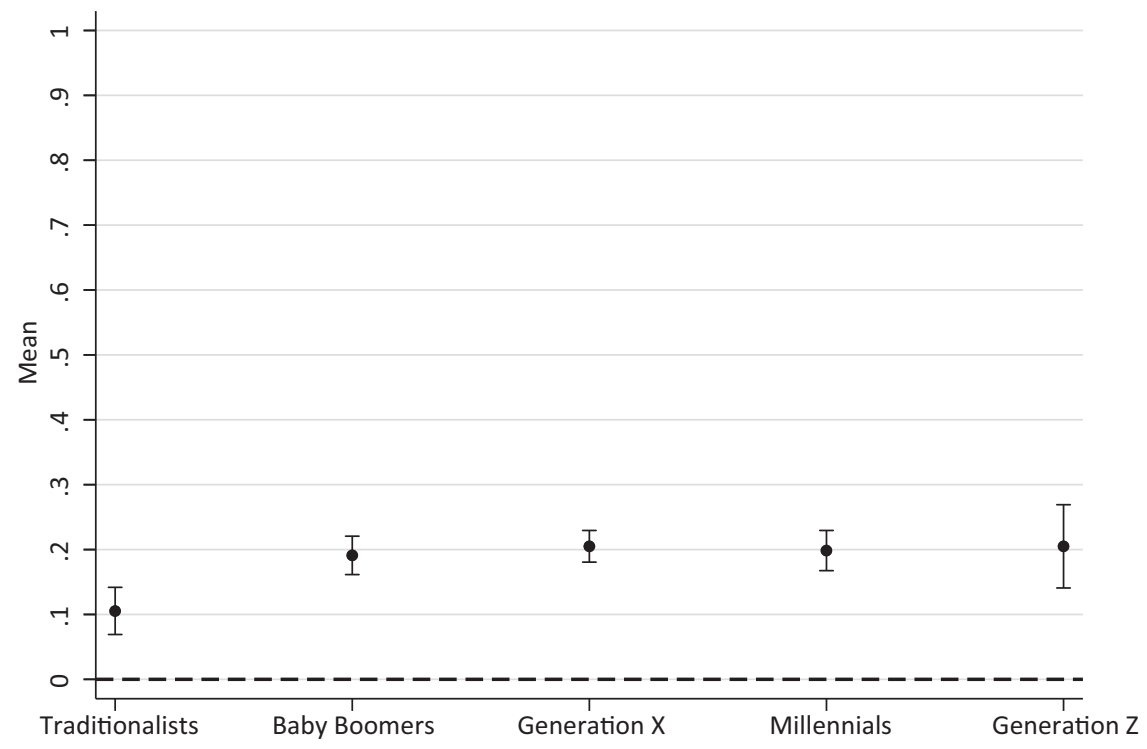

Figure 1.2 Political participation across generations

Source: European Social Survey 2014

Notes. Respondents were asked if they conducted any of the following political activities during the past 12 months: contacted politician or government official; worn or displayed campaign badge/sticker; signed a petition; taken part in lawful public demonstration; boycotted certain products. The Y-axis indicates the mean political participation during the past 12 months, where $0=$ they did not conduct any of the activities and $1=$ they conducted all the activities. The estimates are displayed with a 95 percent confidence interval. N: Traditionalists $=211$, Baby Boomers $=369$, Generation X $=499$, Millennials $=305$, Generation $\mathrm{Z}=58$, Total $=1,442$.

closer look at some of these activities, however, reveals greater generational differences. Generation Z (9 percent) and Millennials (15 percent) contact politicians less often than do, for example, the Baby Boomers (24 percent). Boycotting products for political reasons is less common among Traditionalists and Generation Z, compared to Baby Boomers, Generation X, and Millennials. Generation $\mathrm{Z}$ are the cohort that signed petitions in the last 12 months most often (44 percent), with numbers declining linearly for each generation, ending with 15 percent for Traditionalists. The same patterns evolve when looking at participation in lawful demonstrations, with 18 percent of Generation $\mathrm{Z}$ reporting to have done so, whereas the numbers for all other generations range between two and eight percent.

Clearly, different generations find distinct ways of becoming politically active. However, we look at only a small number of ways that participation takes place today. We therefore assess political participation among different generations in an inclusive-yet theoretically distinct-way that helps 


\section{Times are changing}

us to examine the meaning of participation patterns in different models of democracy. In doing so, we also investigate how generational differences in news consumption and political participation are related.

\section{Outline of the book}

Our starting point is the changing media landscape and the changing opportunity structures for political involvement today. In Chapter 2, we develop a generational perspective on the relationship between exposure to political information in the media and political involvement. We outline a theoretical model that guides our further inquiry. In Chapter 3, we describe the empirical basis for our book. This chapter, though sometimes somewhat technical, is an important one. It highlights our unique design and the nature and quality of our data.

In Chapter 4, we examine who gets exposed to political information and what the key determinants of that (non-)exposure are. In Chapter 5, we look at the consequences of exposure in terms of political interest, political knowledge, and feeling politically efficacious. In Chapters 6, 7, and 8, we turn to the relationship between political information exposure and participation targeting the political system (Chapter 6), the local community (Chapter 7), and other activities done for politically motivated reasons (Chapter 8). In all chapters, we look specifically at generational similarities and differences.

In Chapter 9, we focus more specifically on the role and affordances of social media vis-à-vis different generations. In Chapter 10, we delve more deeply into the periods around an election. These times are arguably special in a democracy and might reveal other communication and participation patterns for different generations.

In Chapter 11, we conclude by summarizing our key findings and ask whether the youth are different or not. We also relate our findings to broader changes in the information ecology and define an agenda for research going forward. 


\section{The EPIG model-political information exposure and political involvement in a generational perspective}

Political engagement and participation are potential outcomes and/ or the antecedents of exposure to political information in the news media or on social media. Taking a generational perspective to this two-sided relationship is beneficial if we want to achieve an in-depth understanding of the democratic dynamics that follow recent changes in both media consumption and political involvement. A generational perspective enables us to explore differences in levels of - and relationships between-exposure to political information in the media and political involvement. It enables us to assess how the future might look for mobilizing citizens to take part in democracy through the media. In order to facilitate such an examination, we define key concepts and relationships and present the Engagement-Participation-InformationGeneration (EPIG) model.

The ways in which citizens consume political information on the one hand and involve themselves in politics on the other hand are both in flux (see Chapter 1). With the technological transformation of society in the past several decades, the availability of news media outlets has proliferated (e.g., Williams \& Delli Carpini, 2011). In addition, social media platforms, such as Facebook and Twitter, have become key sources of information about politics (Newman et al., 2018). As a consequence, citizens can easily create their own personal media diets with varying degrees of political information based on individual preferences (Arceneaux \& Johnson, 2013; Prior, 2007). Political involvement has likewise been transformed. For example, political participation no longer includes only traditional activities, such as voting or attending public demonstrations (e.g., Zukin, Keeter, Andolina, Jenkins, \& Delli Carpini, 2006). Instead, political participation has broadened in scope and takes place both offline and online (Gibson \& Cantijoch, 2013). These current transitions in news consumption and 


\section{The EPIG model}

in political involvement raise highly pertinent questions about the future functioning of our democracies: How does the shift in news consumption from traditional news media outlets to social media affect the mobilizing role of the media? How do new forms of-and opportunities forpolitical participation alter this role? And do new opportunities lead to smaller or greater gaps in democratic behaviour? Answering such questions will allow us to understand whether the consequences are favourable or unfavourable for democracy and whether we should push for changes in certain directions rather than others.

In order to better understand the consequences of these changes, we need to take a comprehensive model of engagement, participation, and political information through the media into account, and we must do so by applying a generational perspective. This approach will provide valuable insights into the relationships between news consumption and political participation and the way they manifest themselves in contemporary Western democracies, enabling us to access the participatory status of such societies. In a well-functioning democracy, all parts of the citizenry participate politically - not only the elderly but also the youth. All generations need to voice their opinions, and by doing so, they participate in the society in which they live.

However, some scholars suggest that younger generations turn away from traditional news media (Blekesaune, Elvestad, \& Aalberg, 2012) and that they do not participate politically to the same extent as do older generations (Franklin, 2004). Others argue that the youth simply obtain political information in a different manner and participate differently in society (e.g., Kahne \& Bowyer, 2018; Loader, Vromen, \& Xenos, 2014). We want to contribute to this debate by exploring whether younger generations are exposed differently to political information and whether they engage and participate differently. Last but not least, we are also interested in whether the relationships between political information in the media and political involvement are different among younger compared to older generations.

In the following, we first provide detailed definitions of our key concepts. We then discuss existing models of the relationship between media consumption and political involvement and highlight how political engagement and participation can function as antecedents of exposure to political information in the media and, subsequently, as effects of this exposure. We therefore introduce the Engagement-Participation-Information (EPI) framework, which focuses on the interplay between these three elements. Lastly, we introduce the generational perspective, which we employ to study these key democratic behaviours and the relationship between them. The generational component extends the EPI framework, creating the EngagementParticipation-Information-Generations (EPIG) model, according to which we organize the work in this book. 


\section{Defining key concepts}

In order to present our theoretical framework, we begin by defining our key concepts: first, exposure to political information in the media and second, political involvement, which we use as a collective term for political engagement and political participation.

\section{Exposure to political information in the media}

Few citizens have first-hand experience with the political world. Instead, the vast majority are informed about politics through the media (Strömbäck, 2008; Zaller, 2003). In other words, politics is a mediated experience, traditionally dominated by newspaper and TV news consumption. However, with the changing media environment, citizens increasingly experience politics on social media platforms such as Facebook (Newman et al., 2018; see also Chapter 1). We therefore examine the roles of traditional news media (both offline and online) as well as social media because both provide political information. When doing so, we distinguish between exposure to political information in the news media-or political news exposure — and exposure to political information on social media—or political social media exposure.

This broad conceptualization of political information exposure covers a hybrid media ecology, where information comes in various forms and from a number of different actors. What counts as news and political information is therefore not easily defined (Edgerly \& Vraga, 2020). Nevertheless, journalists and audiences in general agree on what news is (Costera Meijer, 2007; Shoemaker \& Cohen, 2006), often conceptualizing it from the 'news-democracy narrative' (Woodstock, 2014), according to which news is a crucial component of a healthy democracy, enabling citizens to take an active part in society. Even in today's hybrid media ecology, where formerly distinct genres mix and the boundaries of news are blurring, what is communicated and by whom are still important factors in determining relevant information (Edgerly \& Vraga, 2020). In consequence, we will examine political information as it is disseminated by legacy news media but also examine political information on social media, which is likely becoming an increasingly important actor in fostering political involvement.

To distinguish political from non-political information, we follow Easton's (1953, p. 146) well-known definition of politics. He describes it as a situation in which somebody attempts to influence the authoritative allocation of values in a society, be they material or immaterial. This process includes not only politicians but also, for instance, interest organizations, firms, and ordinary citizens. Political information in the media refers to information that covers the political process. Political information may mobilize citizens to engage in society (Lemert, 1984; Schuck, Vliegenthart, \& de Vreese, 
2016; see also Druckman, 2005), and in this respect, the media may be seen as mobilizing agents (Norris, 2000).

\section{Political engagement}

Political engagement entails individual motivations, abilities, and attitudes that reflect citizens' involvement with politics. Political engagement may both influence and be influenced by exposure to political information. We focus on three key dimensions of political engagement-namely, political interest, political knowledge, and political efficacy. All three dimensions have received much scholarly interest, and studies have linked them to media exposure and political participation (e.g., Moeller, Kühne, \& de Vreese, 2018). Importantly, common for all dimensions, they are intrinsic in nature. That is, they manifest themselves within each individual and not necessarily by the individual interacting with his or her context. Being politically interested, knowledgeable, or efficacious is likely to lead to political participation in society but does not necessarily do so. Thus, in contrast to political participation, political engagement is not defined by actual behaviour.

Political interest is the degree to which politics arouses a citizen's curiosity. As such, political interest can be defined as 'an intrinsic motivation to pay attention to and engage in politics-not because of external pressures or as a means to achieve distinct outcomes, but for personal pleasure and the inherent satisfaction of doing so in itself' (Shehata \& Amnå, 2017, p. 3; see also Prior, 2018). Citizens with high political interest are more likely to both seek out political information and participate in politics. Thus, political interest is often seen as 'the most powerful predictor of political behaviours that make democracy work' (Prior, 2010, p. 747).

Political knowledge can be divided into knowledge about (1) the political system-often obtained through education-and (2) current political affairs knowledge-that is, knowledge about recent happenings in politics and society (Barabas, Jerit, Pollock, \& Rainey, 2014). We focus on the latter since current political affairs knowledge is more likely to be a product of media use and to influence subsequent political participation related to the topics about which knowledge is accumulated. For the sake of parsimony, however, we will use the more general term political knowledge to refer to current political affairs knowledge.

Political efficacy is normally defined as having an internal and an external dimension (Balch, 1974; Converse, 1964; Niemi, Craig, \& Mattei, 1991). Internal political efficacy refers to 'individuals' self-perceptions that they are capable of understanding politics and competent enough to participate in political acts,' while external political efficacy is defined as 'the feeling that an individual and the public can have an impact on the political process because government institutions will respond to their needs' (Miller, Goldenberg, \& Erbring, 1979, p. 253). Much research has already shown 
that internal political efficacy, in particular, is important to understand who participates and why (e.g., Moeller, de Vreese, Esser, \& Kunz, 2014), whereas external political efficacy can be translated less directly into either media consumption or political participation (e.g., Gil de Zúñiga, Weeks, \& Ardèvol-Abreu, 2017; Pollock, 1983). We therefore focus on internal political efficacy in our analyses. When doing so, for brevity we use the general term political efficacy.

\section{Political participation}

In contrast to political engagement, which refers to intrinsic motivations, abilities, and attitudes, political participation refers to an outreaching and behavioural component of political involvement. Political participation can be defined as activities that citizens perform when seeking to affect politics (van Deth, 2014, p. 351). More formally, political participation involves activities that have 'the intent or effect of influencing government actioneither directly by affecting the making and implementation of public policy or indirectly by influencing the selection of people who make these policies' (Verba, Schlozman, \& Brady, 1995, p. 38). Yet, how citizens participate in society is not stable, in terms of neither level nor type of activity. As Dalton (2008) has argued, 'the trends in political activity represent changes in the style of political actions, and not just changes in the level of participation' (p. 94). Just like the media environment has changed, forms of political participation have changed (see also Chapter 1). The opportunity structures for political participation have changed radically-for example, with the emergence of the internet-which provide new participation platforms that are less demanding and time consuming (e.g., 'liking' a politician on Facebook or signing an online petition) compared to more traditional participation (i.e., joining a demonstration). These changes have led to new debates about how to define and conceptualize political participation (e.g., Gibson \& Cantijoch, 2013).

Especially in the context of younger generations, participation is often used as a blanket term that is not sufficiently specified (Literat, KliglerVilenchik, Brough, \& Blum-Ross, 2018). Following Verba and Nie's (1972) understanding of political participation as multidimensional (for an overview, see also Fox, 2014), several empirical typologies have been developed. Bakker and de Vreese (2011), for example, address the observation that some political activities come at higher costs than others (see also Bode, 2017; Christensen, 2011; Morozov, 2009) by distinguishing between active versus passive participatory activities. Active participatory activities include contacting officials or attending demonstrations, whereas passive activities include visiting political websites or reading political books. Loader et al. (2014), in turn, distinguish between participation pursued individually or as a group. Individual engagement encompasses activities such as boycotting products or influencing others to vote, whereas joining or working 
for political groups is labelled collective engagement. The most prominent distinction in recent participation research is between activities conducted with the use of the internet and those conducted without. The online versus offline distinction for political participation has been proposed and applied by a number of recent studies (Gibson \& Cantijoch, 2013; Gil de Zúñiga, Jung, \& Valenzuela, 2012; Teorell, Torcal, \& Montero, 2007). It was further advanced by, for example, Visser and Stolle (2014), who differentiate between Facebook participation, other online participation and offline participation. Inglehart (1990, pp. 335-336) proposes what is perhaps the most comprehensive categorization by distinguishing between elite-directed activities (i.e., voting, party membership, other party-mediated activities, and union membership) and elite-directing activities (i.e., political discussion, participation in new social movements, and protest activities such as demonstrations, boycotts, signing petitions, occupations, and unofficial strikes).

We follow Van Deth's (2014) theory-driven conceptualization of four forms of political participation. Instead of classifying participation activities according to time-bound phenomena such as channels (e.g., online and offline) and activity costs (e.g., high and low), van Deth's classifications rely on three aspects of participation: the sphere, the target, and the intention of an activity. Political Participation I refers to activities within the political system (e.g., voting behaviour, party membership). Political Participation II refers to activities targeting the political system (e.g., citizens demonstrating for a political cause and trying to influence the political system) and comes close to institutionalized participation as framed by McLeod, Scheufele, and Moy (1999) or to elite-directed participation (Inglehart, 1990). Political Participation III refers to activities targeting the community, often referred to as civic participation, which approaches Easton's definition of politics (1953). Last but not least, Political Participation IV refers to politically motivated but non-political actions that take a more global approach and are only loosely tied to the mechanisms of a political system (e.g., expressing viewpoints in social media forums or wearing a badge for a specific cause). As discussed in Chapter 1, this book focuses on non-electoral participation and therefore includes Political Participation II, III, and IV, while leaving aside Political Participation I.

\section{The relationship between media consumption and political involvement}

Having defined our key concepts, we now turn to the relationships between exposure to political information in the media and political involvement. We are not the first to investigate these relationships. While political science often does not address the role of the media at all (as an example, see Grasso's [2016] recent comparative analysis), communication science has offered different perspectives and models in which the role of the media is theorized and tested but the generational perspective neglected. Often, 
studies focus on one generation-mostly the young-but do not include other age groups (Towner \& Muñoz, 2018). Before presenting our model, we therefore highlight three prominent models that have contributed to our understanding of the link between news media and political involvement: the Communication Mediation Model, the Orientations-Stimulus-ReasoningOrientations-Response (O-S-R-O-R) perspective, and the OpportunityMotivation-Ability (OMA) framework.

As media research began to view media effects as being indirect in nature, the Communication Mediation Model (Shah et al., 2017) gained in prominence. This model focuses particularly on political discussion as a variable mediating between political news and participation. The model 'places conversation in a mediating position between news consumption and civic engagement, theorizing that use of informational media does not directly influence citizen learning and participatory behaviours, but rather works through political discussion' (Shah et al., 2017, p. 492). A recent update of the model emphasizes citizens' capability to select politically congenial news. The new information ecology in combination with the ability to express oneself politically via social media lead the authors to conclude that 'rather than a pathway from news to talk, the relationship is now more clearly reciprocal and interdependent, with social media dynamics shaping news content and interpretation, just as news shapes social media reactions and discussion' (Shah et al., 2017, p. 493).

In a similar vein, Cho and colleagues (2009) introduced the O-S-R-O-R perspective as a model of indirect media effects on political engagement. The effect of news (S) on political engagement (second $R$ ) is influenced by initial orientations (first $\mathrm{O}$ ) that precede media use, which results in changes in attitudes (second $\mathrm{O}$ ) and thus behaviours. A reasoning process (first $\mathrm{R}$ ), consisting of interpersonal and intrapersonal communication, functions as a mediator between news use and cognitive- and behaviour-engagement outcomes.

Other research places a premium on the development of political knowledge as a stepping-stone towards political participation. The OMA framework focuses on citizens' opportunities, motivations, and abilities and highlights individual differences in the likelihood of involvement. As Prior (2007) and others have pointed out, changes in the media landscape in the past decade have increased citizens' opportunities to inform themselves, acquire knowledge, and ultimately participate in politics. However, in a high-choice environment, the degree of learning and participation depends largely on citizens' motivation and ability to learn and participate.

What unites the Communication Mediation Model, the O-S-R-O-R perspective, and the OMA framework is the understanding that media and communication are central to political engagement and participation. Moreover, the models acknowledge that the relationship is a process in which the selection of media and political information is one part of a relationship, and the potential effects are another. While the Communication Mediation 
Model and the O-S-R-O-R perspective provide a number of important entry points-such as the role of political talk and discussions-we build on their argument of indirect effects and combine this idea with the key roles played by individual predispositions. As such, we are not criticising these previous models. Instead, we use their general line of reasoning for building a model that captures media use and effects across generations-a perspective that is not captured by these models. In our model, we see political involvement (political engagement or participation) as both an antecedent and a consequence of exposure to political information in the media. When examining how exposure to political information in the media affects citizens' democratic involvement, it is crucial to account for the selection process that precedes the potential effects.

All these models, however, expect relationships between key concepts to be universal across different age groups. Building on research that describes the centrality of socialization experiences for citizens' media consumption and their political behaviours, in this book we integrate a generational perspective into a model that examines conditions and outcomes of news consumption. Only when we consider the antecedents and effects of exposure to political information in the media and distinguish between cohorts with different socialization experiences do we get closer to a full picture of the dynamics at stake.

\section{Antecedents of exposure to political information in the media}

It is costly to seek out political information in the media, and therefore not all citizens are equally likely to do so. Thus, citizens with higher political involvement are more likely to turn to the media to get informed about politics. The OMA framework (Luskin, 1990; Prior, 2007) can help explain this dynamic. It posits that any given behaviour is more likely to take place when citizens have many opportunities to engage in that behaviour and when their motivation and ability to do so are high.

However, according to Prior (2007), the role of motivation and ability in this regard is contingent on opportunities. In earlier times of limited media supply, citizens had no choice but to be exposed to political information if they used the media. Thus, motivation and ability did not play a crucial role in determining the extent to which citizens were exposed to political information in the media. However, in today's high-choice media environment, citizens have more opportunities than ever before to either seek or avoid political information. Given that today's media environment is characterized by tsunamis of not only political but various other information (including a lot of entertainment), motivation and ability are all the more important for seeking out information that corresponds to one's preferences. Different dimensions of political engagement and participation have thus become more important for explaining exposure to political information in the media (e.g., Strömbäck, Djerf-Pierre, \& Shehata, 2013). 


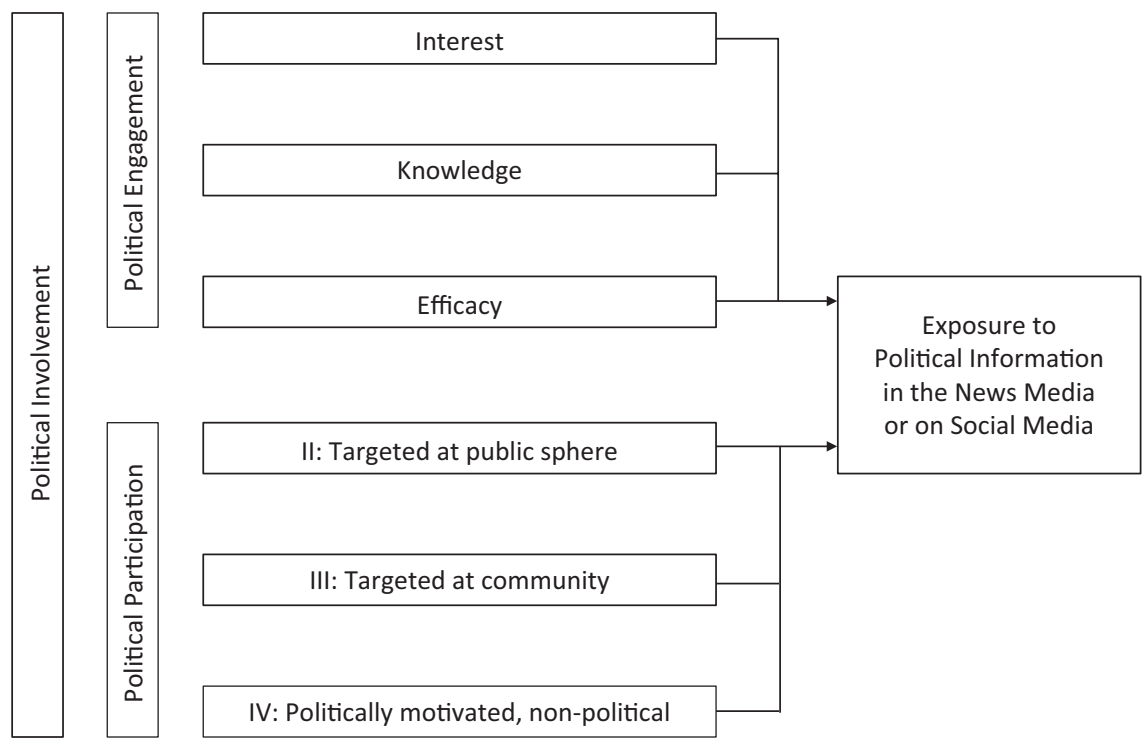

Figure 2.1 Antecedents of exposure to political information in the media

As a result of recent developments in the media environment, citizens with higher political involvement (both political engagement and political participation) will be more likely to seek out political information from the media since they have more motivation and abilities to do so. In other words, citizens who have a higher interest in politics, know more about politics, feel more capable of participating, and participate more in different political activities are more likely to turn to the media to get information about politics (Elenbaas, de Vreese, Schuck, \& Boomgaarden, 2014; Kruikemeier \& Shehata, 2017; Lecheler \& de Vreese, 2017; Prior, 2005, 2007; Reichert \& Print, 2019). These selection mechanisms are illustrated in Figure 2.1.

\section{Effects of exposure to political information in the media}

We now move from the antecedents of exposure to political information in the media to the subsequent effects of this exposure on political involvement. Considerable scholarly attention has been devoted to whether media consumption has a positive impact on political involvement. Focusing first on the consequences of general media use, it has been argued, on the one hand, that the media leave people inactive in front of TV sets (Putnam, 2000). This argument was based on relatively crude measures of time spent with media vis-à-vis other activities. On the other hand, it has been argued 
that the media play an important role by mobilizing citizens to become involved in politics (Norris, 2000). The explanation for these contradicting arguments seems to be that the specific content rather than the medium itself makes the difference. Thus, exposure to political information, often operationalized at news exposure, has been found to be positively related to different dimensions of political involvement (e.g., Norris, 2000; de Vreese \& Boomgaarden, 2006). In the following, we begin by discussing the potential effects of such exposure on political engagement before moving to effects on political participation.

A fundamental part of a well-functioning democracy is that its citizens have the necessary motivation, knowledge, and competence to understand and participate in politics (Dahl, 1989; Easton \& Dennis, 1967; Zaller, 1992). Citizens need to be knowledgeable in order to make informed decisions (Delli Carpini \& Keeter, 1996). And if citizens do not feel competent to participate, they may have little incentive to participate in politics (Abramson \& Aldrich, 1982). Thus, the decision about participating politically is ideally based on a sufficient level of political interest, knowledge about politics, and political efficacy (Delli Carpini \& Keeter, 1996). If a person is uninterested in politics, knows little about politics, or feels incapable of participating, it makes less sense for that person to act politically. In this way, political engagement can be seen as a crucial forerunner to political participation.

It is to be expected that exposure to political news increases political engagement. Thus, exposure to political information is likely to increase citizens' political interest as they become informed about different political issues (Boulianne, 2011; Kruikemeier \& Shehata, 2017; Lecheler \& de Vreese, 2017; Shehata \& Amnå, 2017; Strömbäck \& Shehata, 2010). Likewise, exposure to political information-which includes recent happenings in politics and society more broadly - will increase citizens' political knowledge (Barabas \& Jerit, 2009; Kenski \& Stroud, 2006; Moeller \& de Vreese, 2019; de Vreese \& Boomgaarden, 2006). Following the previous line of reasoning, exposure to political information is also likely to increase citizens' feeling of being capable of participating (Kenski \& Stroud, 2006; Moeller et al., 2014).

Just as exposure to political information is likely to foster political engagement, it is also likely to foster participation in different political activities. By increasing citizens' political engagement-through fostering political interest, knowledge, and efficacy - the media provide them with a valuable currency, which they can exchange for potential political influence through participation in various activities. Several previous studies have shown how the news media can have a positive impact on political participation (e.g., de Vreese \& Boomgaarden, 2006; Eveland \& Scheufele, 2000; McLeod et al., 1999; Newton, 1999).

Some literature on the news media's mobilizing role has explored potential indirect effects through political engagement on political participation more explicitly, in relation to political interest, knowledge, and efficacy (Andersen, Bjarnøe, Albæk, \& de Vreese, 2016; Cho et al., 2009; Corrigall-Brown 

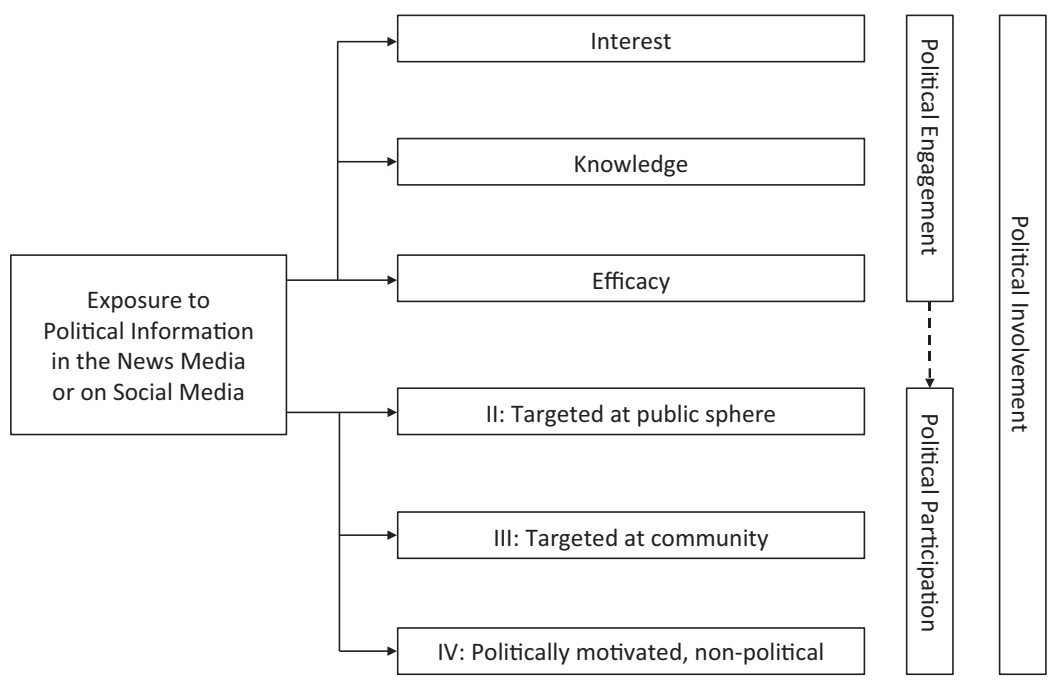

Figure 2.2 Effects of exposure to political information in the media

\& Wilkes, 2014; Jung, Kim, \& de Zúñiga, 2011; Kenski \& Stroud, 2006; McLeod et al., 1999; Moeller et al., 2014). We will also examine these potential indirect effects in our empirical studies. The effect of exposure to political information on political engagement and participation as well as the indirect effects are illustrated in Figure 2.2.

A few previous studies have simultaneously taken both selection and media effects into account, examining the potential reciprocity in the relationship between media use and various dimensions of political involvement (Eveland, Hayes, Shah, \& Kwak, 2005; Kruikemeier \& Shehata, 2017; Moeller \& de Vreese, 2019; Strömbäck \& Shehata, 2010, 2018). Though taking reciprocity into account in a more comprehensive fashion is valuable, our intention is to unfold the process and examine the selection effects and media effects in more detail. We therefore use a step-by-step approach, in order to gain a better understanding of how these processes play out across different generations. In our EPI framework, we first look at how engagement and participation are part of the selection mechanism of political information. We then look at how exposure to political information in the media affects engagement and participation.

\section{The G in EPIG: unpacking the generational perspective}

Knowing that engagement and participation are potential antecedents and outcomes of exposure to political information in the media, we return to the question whether differences in these mechanisms exist between different 


\section{The EPIG model}

generations. As outlined in Chapter 1, younger generations use different media to receive political information compared to older generations. They have access to more political information than any other generation before them and hence should be better equipped than older generations to act politically (Dalton, 2017). At the same time, the participation patterns of younger generations notably differ from those of older generations. These differences make it worth exploring whether generational differences in upbringing and media use are related to distinct participation patterns.

Previous research has mainly focused on the conditions for participation among the younger age cohorts (e.g., Bennett, 2008; Dalton, 2009; Loader et al., 2014). In contrast, we argue that a comparative perspective across all generations is valuable if we want to assess how the future might look for mobilizing citizens to take part in democracies in response to exposure to political information in the media. In this section we begin by discussing generational versus life-cycle effects and by defining how we perceive different generations. We move on to focus on how the generational perspective can be used to explore differences in the relationship between exposure to political information in the media and political involvement.

\section{Cohort versus life-cycle effects}

Research on political behaviour across age groups points to differences in terms of cohort effects and life-cycle effects (Grasso, 2016; Osborne, Sears, \& Valentino, 2011; Van der Brug \& Kritzinger, 2012). Both theories depart from the notion of age being the main determinant of differences in political behaviour. On the one hand, citizens have their first experiences with the political system during their adolescence, which leaves a permanent mark on their future political engagement. On the other hand, different stages in life also determine the levels and types of political behaviour among citizens. All generations might not use the new information environment or engage and participate similarly (e.g., Bhatti \& Hansen, 2012; Briggs, 2017; Franklin, 2004; Kleinberg \& Lau, 2019; Konzelmann, Wagner, \& Rattinger, 2012).

The life-cycle effects perspective points towards circumstances that change over the course of an individual's life as the main determinants of differential political participation across generations. Citizens' stage of life influences their political attitudes and behaviour. For instance, the frequency of participation increases from early adulthood onwards and only drops in the very last stages of life. In younger years, immediate life challenges, such as education, career planning, dating, and identity building, make political involvement less of a priority. When people take on the responsibilities of adulthood, such as starting a family, work, and paying taxes, political decisions become more relevant in their lives. Most people 
therefore start participating more frequently in politics (Dalton, 2017; Grasso, 2016).

The cohort effects perspective, in contrast, focuses on how sociohistorical events have a special influence on young citizens who are in their formative years compared to other generations (Mannheim, 1928). Citizens' levels of education, the norms and values of their time, and their political socialization create a 'generational imprint' that shapes their political participation throughout life. Lower levels of education, for example, may prevent older generations from participating in more resource-demanding political activities (Dalton, 2017). Growing up in times of high educational levels, affluence, and social security may increase the prominence of postmaterialistic and self-expressive values among generations that are coming of age, fuelling participation in expressive and elite-challenging political activities (Inglehart, 1990). As time goes by, their way of expressing themselves becomes habitual and defines the way a generation engages in politics (Wass, 2007). Early experiences with the political system will therefore leave a permanent mark on adolescents and young adults that affects their future political behaviour (Davis, 2004; Sears \& Valentino, 1997). This perspective thus acknowledges that each generation develops its own profile and culture and defines for itself what it sees as important, including in regard to politics (Quintelier, 2007).

It is beyond the purpose of this book to distinguish whether differences in exposure to political information and political involvement are driven by cohort or life-cycle effects. Generally, it is very difficult to distinguish between cohort and life-cycle effects in the absence of a truly long-term, longitudinal research design and long-term data collection (Stubager \& Hansen, 2013; Walczak et al., 2012). We will thus refrain from making any definitive conclusions on whether the differences in political behaviour between generations are due to cohort or life-cycle effects. Instead, we want to draw on both perspectives to argue why generation matters for the relationship between exposure to political information in the media and political involvement. This approach furthermore allows us to detect whether the new opportunity structures in media use and political participation introduce or shape inequalities for some generations more than for others (Thorson, Xu, \& Edgerly, 2018). Before we turn to these arguments, we will first look at what characterizes the different generations.

\section{The five generations}

In order to understand the benefit of the generational perspective, we need to understand how different generations have been brought up and hence how their socialization into society can be characterized. Defining the exact cut-off points for the years of birth for each generation is a challenge. Particularly for the younger generations, viewpoints vary on when one generation ends and the next one begins. Within the Western world, people 
are usually divided into four generations: Traditionalists, Baby Boomers, Generation X, and Millennials, also known as Generation Y (e.g., Howe \& Strauss, 2007). In addition to these four generations, we include the latest generation, Generation Z. In order to be at the forefront of determining potential differences among generations, this new generation is especially relevant to our examination. Thus, we look at five different birth cohorts: Traditionalists (born between 1922 and 1944), Baby Boomers (1945-64), Generation X (1965-79), Millennials (1980-94), and Generation Z (born 1995 and after). Below, we briefly outline the characteristics for each of these generations.

Traditionalists are defined as the birth cohort between 1922 and 1944. They experienced both the Second World War and the Great Depression and can generally be argued to respect authorities through values like obedience, diligence, and duty. Staying true to these values, they built a great deal of the societal structures that we still live in today (Mangelsdorf, 2014).

The Baby Boomers, being born at high birth rates between 1945 and 1964, are characterized as clear opposites to their parental generation: optimistic, collectivistic, and embracing the free expression of opinion. In contrast to the Traditionalists, they grew up in politically stable and economically prosperous times. This prosperity affects their societal engagement: they have been recognized as the first generation who used their newly won spare time for voluntary societal engagement (Howe \& Strauss, 2007; Mangelsdorf, 2014).

Generation X refers to citizens born between 1965 and 1979, who grew up in a highly modern world with less stable social structures, in which the individual has to choose his or her own education, job, sexuality, family type, lifestyle, friends, and so on, with no clear path to follow (Giddens, 1991). During these times, societal fault lines became more obvious: working families had less time to dedicate to the upbringing of their children, and a higher number of divorces and single parents challenged the traditional family image. Instead of respecting authorities, Generation X are characterized as independent and autonomous. They have less faith in political and economic promises and are known as the first generation to regard political protest as an appropriate means of political expression (Mangelsdorf, 2014). At the same time, they accept social diversity over uniformity.

Millennials, also known as Generation Y (or 'why?' due to their questioning nature), include citizens born between 1980 and 1994 (Hurrelmann \& Albrecht, 2014). Their coming-of-age years are characterized by media coverage about permanent threats: global warming, terror attacks, and school shootings. Hence, they do not take stability and economic well-being for granted but nonetheless decide to keep an optimistic pace in life. Their upbringing in a globalized world goes hand in hand with greater flexibility in life models (see Howe \& Strauss, 2007). They 
received strong support from their parents and, early on in life, became used to their opinions being heard during decision-making (see Mangelsdorf, 2014).

While Millennials were introduced slowly to the new media environment with online and digital platforms, Generation $Z$ were born into this new information age. Those citizens, born after 1995 (also the cut-off age used by the Pew foundation, for example), are oftentimes referred to as 'digital natives' (Prensky, 2001). Their upbringing in a digital media environment makes it especially easy for them to operate on social media platforms (Palfrey \& Gasser, 2010; Thomas, 2011). Growing up in the aftermath of the $9 / 11$ terror attacks and in the middle of the 2008 economic depression made them perceive the world as rather unsafe but at the same time sharpened their global awareness (Turner, 2015). This global connection through digital means feels natural to them and lets them believe in the power of the network, also when it comes to political participation and civic engagement.

\section{Potential differences across generations}

Two arguments can be made as to why exposure to political information in the media and political involvement as well as the relationships between these concepts could potentially vary across generations. First, drawing on the cohort perspective, different generations have experienced different societal changes in their formative stages of life. We argue that these differences may influence how citizens navigate the current information environment and how the information they receive influences their involvement in society. While older generations have been socialized to use more traditional media outlets to access political information, younger generations have been socialized to use new platforms, particularly social media sites, to access this information (see also Shah, McLeod, \& Yoon, 2001). The digital information age is likely to influence all generations but is perhaps more accessible and appealing to the youngest generations. Younger cohorts may also use the information available to them differently. For example, younger people tend to forget knowledge obtained by the media more quickly than older generations but make up for it through their skilled use of online source access (Kleinberg \& Lau, 2019). The same applies to political involvement. In particular, the changing forms of participation may be more easily accessible to the younger generations rather than the older ones, who were not brought up with similar participation opportunities.

Second, drawing on the life-cycle perspective, in their formative stages of life, young citizens are typically more curious and search for ways to express or promote themselves, which may influence both their search for political information and their reactions to this information. Further, since attitudes and behaviours are still under development, these younger citizens are likely 


\section{The EPIG model}

to be more susceptible to media information, whereas older citizens will have more stable habits and thus be less susceptible to changes in media use and political involvement (Valkenburg \& Peters, 2013).

In sum, one may think about the levels of-and relationships betweenexposure to political information in the media, political engagement, and political participation in the following way. Regarding levels, a life-cycle perspective provides the most likely explanation for differences in legacy news media consumption, political engagement, and more traditional forms of participation. For example, exposure to political information, engagement, and participation is likely to be higher among Traditionalists and Baby Boomers, who are in relatively established stages of their lives. By contrast, a cohort perspective more likely explains the higher uptake of political information on social media and newer, digitally driven forms of political participation among younger generations.

Regarding relationships between political involvement and exposure to political information in the media, the life-cycle perspective probably provides the most likely explanation for differences that run along generational lines. For instance, we may, ceteris paribus, expect younger individuals to be more malleable in their attitudes, implying that they are more likely to respond to- and be affected by- new political information. Cohortspecific relationships, in turn, would be evident, for instance, in the strong or weak reactions of the various generations to information from some media sources but not from others. The relevance of cohort and life-cycle effects for explaining levels of-and relationships between-exposure to political information in the media and political involvement is illustrated in Figure 2.3.

Following this argument, we aim at exploring whether exposure to political information and political involvement-and the relationship between these two-differ across generations. The generational perspective has been integrated into our EPI framework, resulting in the EPIG model, which is illustrated in Figure 2.4. We believe that examining the generational perspective is of crucial importance to understanding the current configuration of our democracies. In addition, it lays the groundwork for understanding what may lie ahead.

\begin{tabular}{lcc}
\hline & Cohort effects & Life-cycle effects \\
\hline Levels & $\mathrm{X}$ & \\
Relationships & & $\mathrm{X}$ \\
\hline
\end{tabular}

Figure 2.3 The relevance of cohort and life-cycle effects for explaining levels ofand relationships between-exposure to political information in the media and political involvement 


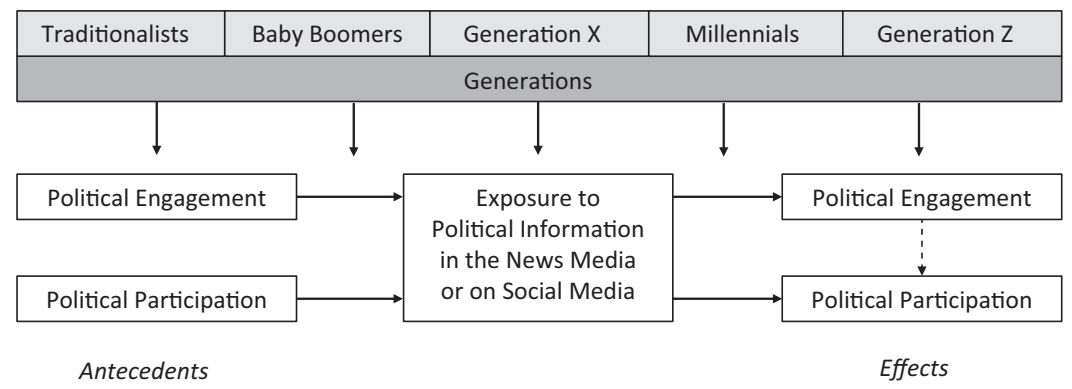

Figure 2.4 The Engagement-Participation-Information-Generation (EPIG) model Notes. The model illustrates the addition of the generational perspective to the levels of - and relationships between-exposure to political information in the media, political engagement, and political participation

\section{Summing up}

In this chapter we have presented the theoretical argument for the relationship between exposure to political information in the media and political involvement-understood as political engagement and political participation-across different generations. We have focused both on the antecedents that determine citizens' exposure to political information in the media and on the subsequent effects of this exposure on political involvement. We have used a framework that we dub the Engagement-ParticipationInformation-Generations-or EPIG—-model. Approaching these democratic behaviours and the relationships between them from a generational perspective enables us to explore questions of whether and how the youth, in particular, receive political information differently from the elderly and whether and how this exposure fosters political involvement in society differently across generations. 


\section{A multi-methods research design}

In order to examine how exposure to political information in the media affects political involvement across generations and vice versa, we rely on a comprehensive multi-methods design. In this chapter we describe how we combine a five-wave online survey and a three-wave smartphone-based survey, both of a large representative sample of a national population, with an automatic content analysis of the major news media. We also describe how we operationalize our key concepts and conduct our statistical analyses.

To address the question whether political information and young people's participatory behaviour today are different from those of other generations, a comprehensive research design is necessary. This chapter unravels the methodological approaches applied throughout the book and introduces the research design combining multi-wave online surveys and mobile panel surveys with content analysis. We provide readers with an overview of the data collection procedures and the operationalization of key variables. We also provide the information needed to understand our statistical analyses. Before doing so, we introduce the Danish case.

\section{The Danish case}

To comprehensively study the effect of exposure to political information in the media on political involvement across different generations, we focus on a mature democracy, namely Denmark, in which there is ample variation in the supply side of political information as well as in the opportunity to engage and participate in politics (see also Chapter 1).

In Denmark, which is characterized by a democratic corporative media system (Hallin \& Mancini, 2004), news media play an important role in informing the public about political affairs. In 2014, the year in which we started our data collection, Danes watched, on average, 173 minutes 
of television on a regular day, spent 117 minutes listening to the radio, and about 2 million out of 5.5 million Danes read a newspaper on a daily basis (Danish Ministry of Culture, 2015; Danmarks Radio, 2014; see also Chapter 1). The relatively high number of Danes consuming news via traditional media channels is an important precondition for the exploration of news-consumption effects on citizens' levels of political involvement since it allows media consumption to have an impact. With 96 percent of households having internet access and 83 percent of citizens using the internet on a daily basis in 2014, online media are evidently widely used in Denmark (Danish Ministry of Culture, 2015; World Bank, 2018). With more than one-third of citizens accessing news media in 2014 via social media platforms and almost 50 percent via mobile devices, Denmark can be described as a digital frontrunner (Danish Ministry of Culture, 2015; Newman, Levy, $\&$ Nielsen, 2015). Thus, Denmark is an ideal choice to study the effects of social media news consumption patterns on political involvement.

Denmark has two strong public service TV broadcasters (DR and TV 2), seven national daily newspapers (Politiken, Berlingske, Jyllands-Posten, Kristeligt Dagblad, Information, BT, and Ekstra Bladet), a number of local and regional newspapers, and a few specialized newspapers (e.g., the financial newspaper Børsen). As seen in other countries, younger generations are more often early adopters when it comes to technological innovations and increasingly turn to digital media, such as news websites, streaming services, or social network platforms. Though young people still watch conventional flow television and read printed newspapers, the proportion doing so is declining (Danish Ministry of Culture, 2017). Since these trends of media consumption are in line with those of other Western democracies, Denmark is a good case for studying the effects of generational differences of media usage.

Furthermore, adding to this advantage are a well-functioning democracy and a broad spectrum of participatory activities that citizens can engage in. With turnout rates at national elections constantly reaching more than 85 percent, the political consciousness of Danes is high. This is also true of the younger age brackets, with most young citizens turning out at their very first chance to cast their votes (Danmarks Statistik, 2015). The important role of elections and the strong, concomitant belief in a well-functioning political system make other types of political participation less pronounced, though a wide range of possibilities for political expression and activity exists.

Given that both political information in the media and ways to act politically are broadly available, opportunity structures for news exposure and political participation in Denmark are high. However, the relative unimportance of political participation, apart from voting, makes Denmark an interesting case for observing media effects on political involvement because the threshold for political information to spark engagement is rather high. The strong digital media environment is helpful to discover generational differences well before they become visible in countries with less digitalized 
media usage. This combination makes Denmark an especially interesting object of study.

\section{Design}

To study the relationship between exposure to political news and political involvement, we apply a comprehensive panel design. First, between November 2014 and November 2015, we conducted a five-wave online survey of a representative sample of the Danish population; three waves were conducted during non-election times and two around the 2015 Danish national election. ${ }^{1}$ To obtain a more precise estimate of the amount of political information the respondents were exposed to, survey measures of media exposure were linked with an automated content analysis at the media outlet level. In addition, a subsample of the panellists participated in a mobile media diary survey that was conducted on their smartphones, which aimed at tapping exposure to political information on social media. This dynamic, multi-methods research design helps make firmer causal interpretations of news selection and media effects by following changes in the key variables over time (Slater, 2007, 2015).

\section{Sample}

To tap citizens' exposure to political information in the media and their political involvement, we use original, national, online survey data. Since 96 percent of Danish households have access to the internet (World Bank, 2018), online surveys are an appropriate research strategy. Due to wellknown difficulties in ensuring decent numbers of respondents in survey research, a multiple-sample strategy was used. Figure 3.1 illustrates the different samples and their response and retention rates throughout the five online and the three mobile survey waves.

\section{Online survey sample}

Starting with the online panel survey, the upper part of Figure 3.1 shows that the respondents consist of a general population sample, a sample of elderly citizens (older than 61 years) and a youth sample (17-21 years). We collaborated with the Danish pollster company Epinion to conduct the surveys. The general and the elderly samples were recruited from Epinion's database, with representative characteristics of the Danish population. Since Epinion mainly conducts market research, their panellists are less likely to be biased towards politically interested citizens. Their database is invitation-only and is maintained using face-to-face, web, and telephone interviews. The sampling strategy used a light quota on age and gender. Email invitations and reminders were sent out in four batches during the first wave to adjust for potential biases in these quotas. A total of 10,315 people were invited for the general sample, and 3,059 people were invited for the elderly sample. 

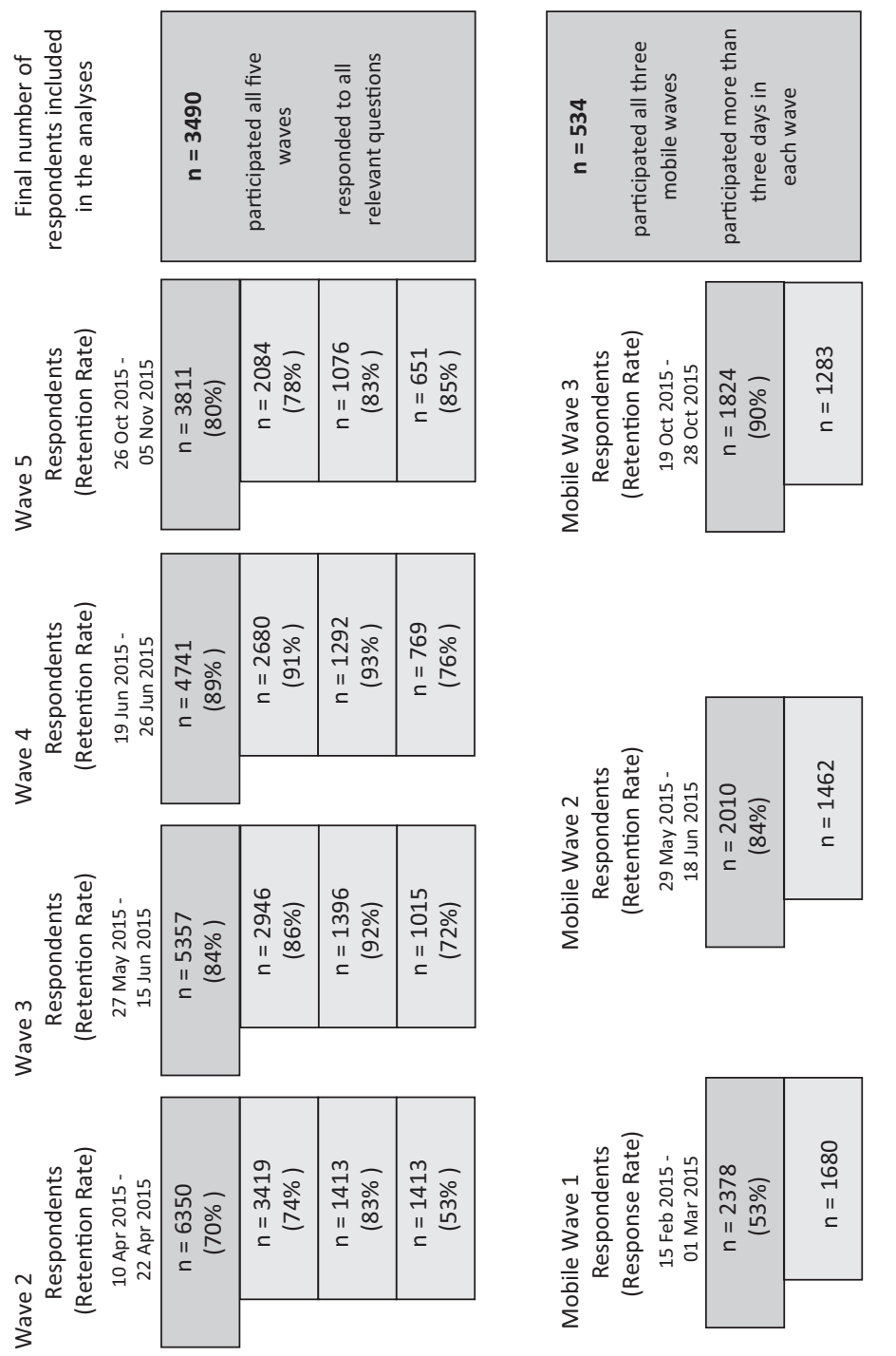

0
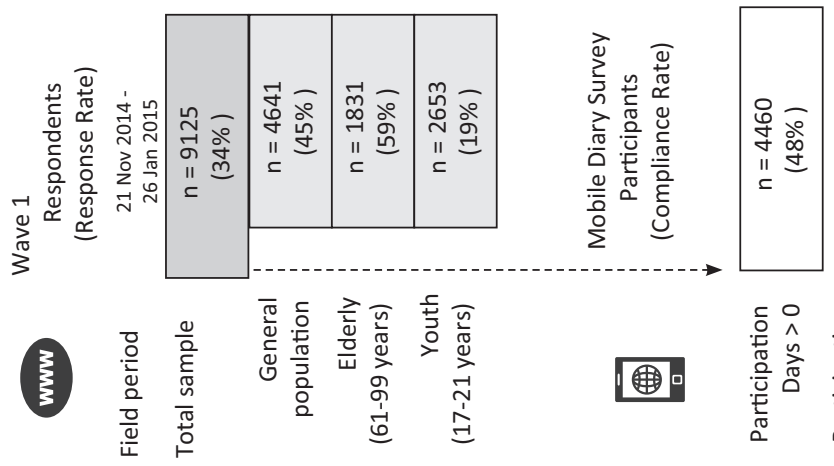

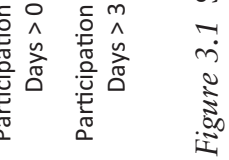




\section{A multi-methods research design}

To secure the inclusion of citizens from the youngest generations, a random sample of 9,000 citizens aged 17-21 years who were eligible to vote for the first time in the upcoming national elections were invited to participate in the survey. These young respondents were randomly sampled through the Danish Civil Registration (CPR) system, which is a complete register of all residents in Denmark. The representative sample of first-time voters was invited by letter to participate in the survey. The letters included a unique username and password as well as a link and QR code to access the online survey. Where possible, Epinion subsequently registered respondents' telephone numbers (approximately 70 percent). This part of the sample received reminders via telephone calls and text messages. The remaining part of the sample received reminders by letter.

In order to secure a broad and diverse starting sample for our data collection, the field period for the first wave started in late November 2014 and ran over a longer period, until the beginning of January 2015. A total of 9,125 respondents participated in this first wave, with response rates ranging from 19 percent among the youth sample to 45 percent in the general sample and 59 percent in the elderly sample. The second wave was conducted approximately four months later in mid-April 2015. In late May and at the start of June, wave 3 was conducted as a pre-election wave. This wave was fielded as the prime minister called the election to be held on June 18, 2015. National elections in Denmark can be called at any time with a minimal three-week notice. Starting right after election day, wave 4 was conducted as a post-election wave in late June. Lastly, wave 5 was conducted approximately four months after the election in late October to the start of November. Highest retention throughout the field period was achieved among elderly respondents (83 to 93 percent), followed by the general sample ( 74 to 91 percent) and the youth sample (53 to 85 percent).

The analytic approach applied in this book relies on the participation of respondents in all five survey waves. Therefore, the results presented throughout the book are based on a total number of 3,490 respondents. The average age of this sample is 55 years, with 52 percent of respondents being female. In regard to education, 41 percent had finished primary, vocational, or high school; 37 percent, a short-or medium-cycle higher education; and 21 percent a long-cycle higher education. Though the sample reflects general population data closely, retaining only a share of the respondents throughout the five panel waves leaves us with some bias in the sample's composition (see Tables A3.1 and A3.2 in the Appendix).

\section{Mobile survey sample}

Media exposure is subject to recall bias, especially when it comes to shorttime social media exposure (Slater, 2004; Ohme, Albæk, \& de Vreese, 2016). By including a mobile media diet study in our design, we were able to partly overcome this shortcoming when measuring exposure to political 
information on social media. We asked respondents on a total number of 35 days to report their political social media exposure in a smartphone-based media diary. The days were spread over three waves that were different from the online survey waves. To increase the number of potential respondents, the smartphone-based media diary was accessible to the respondents via an app or in their smartphone's mobile browser. The app was developed in close collaboration with the pollster so that design and layout of the mobile browser version and the app were almost identical. Respondents could choose which of the two platforms they wanted to use for the mobile diary survey and were contacted via text message or push message, respectively. On each day of the study, we sent out invitations at 9:45 p.m. The time was chosen based on a pre-test in which late send-outs resulted in higher response rates than early send-outs in the morning (Ohme, de Vreese, \& Albæk, 2017). To facilitate the ubiquitous mobile measurements-to be taken anywhere, anytime- the diary survey was designed for rapid completion by respondents, while they were on the go or had little time at home. Subsequently, the average response time was 1 minute and 33 seconds.

The sample characteristics for the mobile survey are reported in the lower part of Figure 3.1. Participants were recruited from our total online sample in wave 1 . About half of the respondents agreed to be invited to participate in the mobile media diary study. The field periods of the three mobile waves are different from the original online survey waves, as can be seen in Figure 3.1. In wave 1 of the mobile survey, which was conducted at the end of February 2015, more than half of the invited respondents participated at least once. In the subsequent waves, 84 to 90 percent of the respondents were retained. Wave two of the mobile survey was conducted in June 2015 during election time, and wave 3 in October 2015. To develop a solid measurement based on the daily survey answers, we decided to include only participants who responded to the mobile surveys on four or more days of each mobile wave. Furthermore, to have all data needed for our analysis at hand, only respondents who participated in all five waves of the general online survey and in mobile waves one, two, and three were included in the analyses. These restrictions leave us with a total number of 534 respondents, for which we have all the necessary information to analyze the predictors and effects of their political social media usage.

The subsample for the mobile survey consists of respondents with an average age of $50(\min =18, \max =80)$, with 48 percent of them being female. As for our main online sample, most respondents' highest educational achievement was a primary, vocational, or high school degree (44 percent), followed by 31 percent with a short-or medium-cycle higher education, and 25 percent with a long-cycle higher education. If we compare these main characteristics of our subsample with the main online sample characteristics, only slight differences are visible. Since the subsample relied on the use of smartphones, we tested further for differences in mobile internet use between the samples. In the main online sample, respondents reported that 25 percent 


\section{A multi-methods research design}

of their internet time was spent on their mobile phones. In our subsample, the number is 40 percent. Though the difference is not large, we have to keep this characteristic of the subsample in mind when interpreting the results.

Having described the sample in detail, the chapter proceeds with a description of the operationalization of the key variables: political news exposure, political social media exposure, political engagement, political participation, and the different generations. Descriptive statistics of all variables can be seen in Table A3.3 in the Appendix.

\section{Media consumption: assessing exposure to political information}

The ways in which citizens receive information about political affairs nowadays have changed significantly, as have the possibilities to assess and analyze media exposure (de Vreese \& Neijens, 2016; see Chapter 1). We try to address the challenges of measuring media consumption in a 'high-choice media environment' (Prior, 2007), in which a more diversified selection of media outlets results in more fragmented audiences (Bennett \& Iyengar, 2008). This book looks at two concepts of political media use. 'Political news exposure' describes the frequency of exposure to a list of media channels and outlets, weighted by the amount of political content present in the relevant time period of the investigation. 'Political social media exposure' specifies the relative exposure to political information on social media platforms during each of the three waves with smartphone-based media diaries.

\section{Political news exposure}

To capture an inclusive picture of people's news media usage, the frequency of exposure to a comprehensive list of 14 newspapers, websites, and television newscasts was measured (Andersen, Albæk, \& de Vreese, 2016; Dilliplane, Goldman, \& Mutz, 2013). More specifically, we asked about exposure to the three most read national broadsheet newspapers (Berlingske, Jyllands-Posten, and Politiken), the two most read national tabloids (BT and Ekstra Bladet), and the newscasts of the two national broadcasters (DR and TV 2) as well as their respective online appearances (bt.dk, berlingske.dk, dr.dk, ekstrabladet.dk, jp.dk, politiken.dk, tv2.dk). These survey measures were combined with an automated content analysis of the respective media outlets to create a measure of how much political information the respondents were exposed to in the news media. This procedure helps to ensure that we investigate effects of exposure to content with political relevance, rather than relying on 'empty exposure' measures. The connection of survey data with content analysis (also known as linkage analysis) is recommended and has been successfully applied in previous media effects research (de Vreese et al., 2017; Scharkow \& Bachl, 2016; but see Fazekas \& Larsen, 2016). This elaborate procedure is beneficial for this book's purpose since it allows comprehensive tapping of media exposure in a diverse 
media environment and ensures focusing on media effects that are specifically evoked by political content.

In order to capture the amount of political information, an automated content analysis based on keywords was conducted, which allows us to collect a large amount of data efficiently (de Graaf \& van der Vossen, 2013; Matthes \& Kohring, 2008). The automated content analysis was conducted using the online database Infomedia, which stores all Danish news items. Through three steps, the search string was specified by defining the concepts, identifying and specifying search words, and programming the rules, using a series of iterations to increase precision in the final search string (Matthes \& Kohring, 2008; Shah, Watts, Domke, \& Fan, 2002). Following Easton's (1953, p. 146) well-known definition of politics as dealing with the authoritative allocation of scarce goods, we understand politics as a situation in which actors (e.g., politicians or interest organizations) try to influence this allocation of goods in society. A list of keywords was identified based on readings of relevant books, journal articles, and several random news items to identify words signalizing politics (e.g., party names, political institutions and positions). The search string specified that at least one political keyword had to be present in the news items for political information to be present (see Figure A3.1 in the Appendix; see also Bjarnøe, de Vreese, \& Albæk, 2020).

To test the quality and reproducibility of the content analysis, an intercoder reliability test was conducted to secure that, within a tolerable margin of error, a human being would agree with the data provided by the search string. Two human coders manually coded 63 random news items for whether they contained political information. The sample was drawn on three random days between November 23, 2014 and December 27, 2015, in which three news items were randomly selected in each of three national broadsheet newspapers (Politiken, Berlingske, and Jyllands-Posten), two national tabloid newspapers (Ekstra Bladet and BT), and two national television news shows (DR at 6:30 p.m. and TV 2 at 7:00 p.m.). The results between the two human coders were highly satisfying, with a Krippendorff's alpha score of .90 , while it was acceptable, though lower, between one of the authors and the machine (the search string) with a score of .74, indicating satisfying data quality (De Swert, 2012; Krippendorff, 2003).

The amount of political information was calculated as the average amount of news items containing political information of the total number of news items in each news outlet in a specific period. ${ }^{2}$ In the surveys, the respondents reported their media usage during the last seven days. Our weight for political information was based on the seven days leading up to the first day that the survey was running and the following three days (ten days in total) since most respondents reported their media use during those days. The amount of political information in all news outlets is illustrated in Figure 3.2. Generally, the national broadsheet newspapers and television newscasts, both offline and online, have the highest amount of political information, followed by the national 


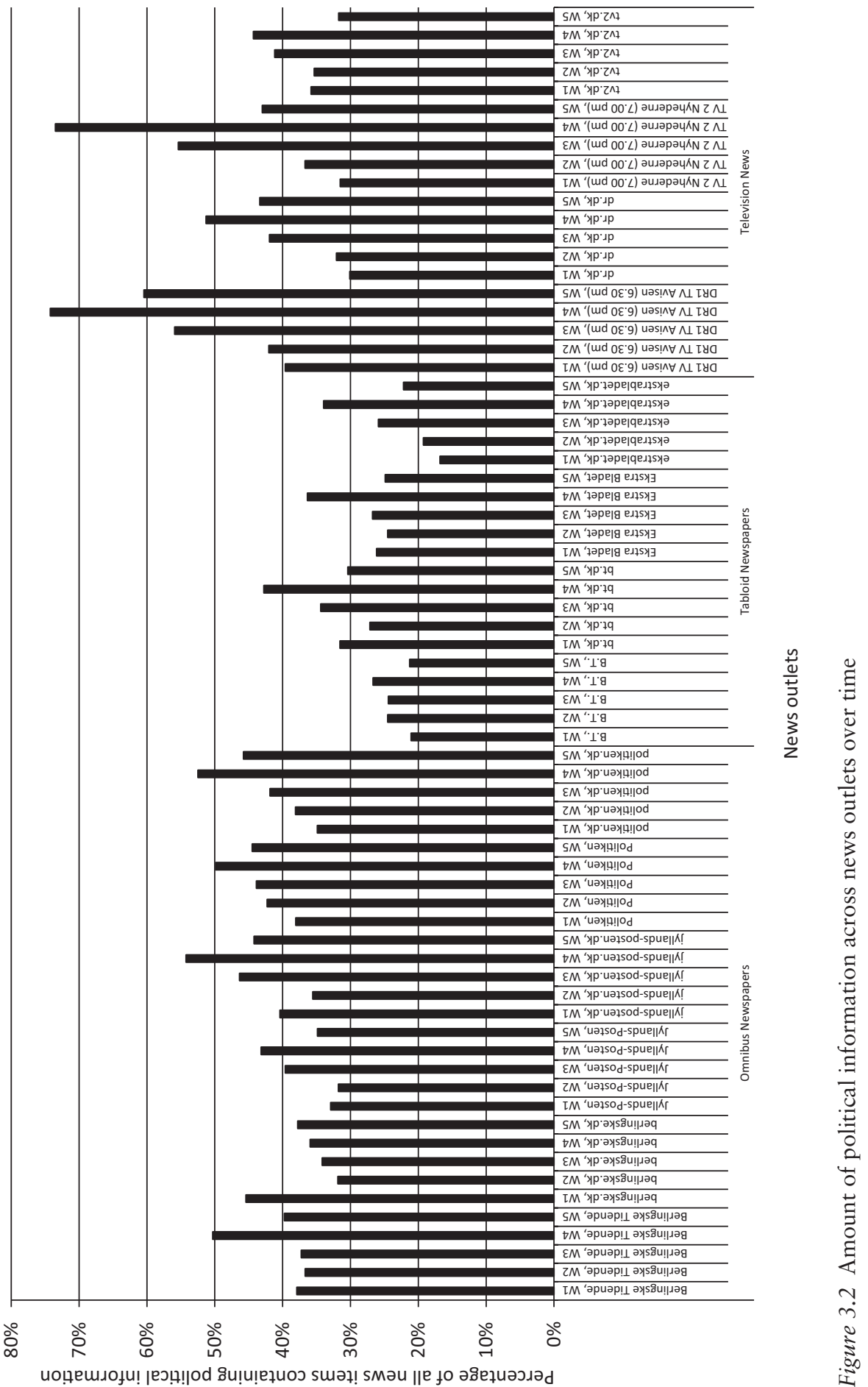


tabloid newspapers, both offline and online. However, in wave 4 (the postelection wave) and wave 5, the amount of political information in the two television newscasts was noticeably high. Taken together, our content analysis shows variation in the amount of political information both across outlets and over time. In other words, it matters for our respondents' level of exposure to political information which news media outlets they utilized.

The actual linkage of the survey and the content analysis was done by multiplying exposure to specific media outlets with the amount of political information in that media outlet. Afterwards, these weighted exposure measures were combined to an index with a theoretical range from zero to 100. However, since none of the news outlets contained 100 percent political information, the empirical range is lower and varies from wave to wave, dependent on the coverage.

\section{Political social media exposure}

In today's hybrid media system (Chadwick, 2013), particularly young people increasingly access media information via intermediaries like social network sites (Newman, Fletcher, Kalogeropoulos, \& Levy, 2017). Hence, it is important to assess social media news use in a detailed manner. However, this comes with a number of challenges: short-term exposure to content that respondents can hardly recall, a greater amount of available information sources than could ever be listed, and the difficulty of disentangling on which platform information has actually been received.

To obtain a reliable assessment of citizens' social media exposure to political information, respondents used a media diary with daily surveys on their smartphones. The daily questions were structured according to reception modes (listening, reading, watching) and helped extract the consumption of political information via links on social media from other media sources (Engel \& Best, 2012; Ohme et al., 2016). The full list of questions can be found in Figure A3.2 in the Appendix.

Each participant of the first survey wave was invited to take part in short surveys on his or her smartphone, in which questions about the participant's social media use on the respective day were asked. ${ }^{3}$ The respondents had the opportunity to take the diary surveys in an especially developed app or via their mobile browsers and were issued an invitation every night at 9:45 p.m. via push message or text message, respectively. Asking about political content rather than 'news' has been shown to be more reliable when investigating news media exposure on social media (Vraga, Bode, Smithson, \& Troller-Renfree, 2016). People were asked whether they had heard, read, or watched 'something about politics' on social media on the given day. To account for the varying days of participation, a relative exposure measure was calculated. ${ }^{4}$ The relative measure ranged from 0 to 1 , with 1 indicating exposure to political content on social media on all days that the respondent had participated. For a reliable estimation of political social media use, only respondents who 
participated four or more days were included in the analysis (see Figure 3.1). Due to the multiple political information sources citizens have at hand on social media, we refrained from conducting a subsequent content analysis. Instead, we applied an innovative questioning strategy that helped citizens determine if they had been exposed to political content via social media or not.

\section{Political engagement}

We concentrate on three dimensions of political engagement that have received high attention as antecedents and outcomes of political media consumption in previous research: political interest, political knowledge, and political efficacy (see also Chapter 2).

Political interest is a psychological state of mind referring to a person's curiosity about politics. It is understood as an intrinsic motivation and is expressed by personal self-rating (Shehata \& Amnå, 2017; see also Lazarsfeld, Berelson, \& Gaudet, 1948; van Deth, 1990). In each wave, we therefore asked respondents to rate their general political interest between not interested at all (0) and very interested (10), which is a standard measure in public opinion research (Shani, 2009).

Political knowledge in this book is defined as people's knowledge about recent happenings in politics and society (Barabas et al., 2014). This approach is appropriate when we study the process leading to changes in political engagement because it taps current political developments and ongoing learning acquired from the media (Barabas \& Jerit, 2009). In order to measure this concept, in each wave respondents were asked four questions that covered similar topic areas and had a comparable level of difficulty but asked for different content. With few exceptions, each question had four answer categories and a 'don't know' category, and participants had 20 seconds to respond. 'Don't know' responses and missing values were coded as incorrect answers. In total, 20 questions were asked across the five waves (see all questions in Table A3.4 in the Appendix).

Political efficacy is generally understood as the feeling a person has that his or her political activities have-or can have-an impact on the political system (Campbell, Gurin, \& Miller, 1954). Efficacy was measured in all waves by asking respondents how strongly they agreed or disagreed with a battery of five standard statements on a five-point scale. Subsequently, an additive index was formed and showed satisfying reliability (see full list of statements in Table A3.5 in the Appendix).

\section{Political participation}

To assess the relationship between media consumption and political behaviour, we are inspired by van Deth's (2014) distinction between four types of participation: namely, political participation that (1) takes place in the political sphere (PP I), (2) is targeted at the political sphere (PP II), (3) is targeted at 
community issues (PP III), and (4) is a non-political but politically motivated activity (PP IV). The latter two types have received significant attention and are often subsumed under terms like 'civic engagement' (Zukin et al., 2006) or 'unconventional participation' (Linssen, Schmeets, Scheeper, \& te Grotenhuis, 2014). In particular, young people find such forms of political participation attractive, and it is therefore important to apply a broad concept of participation to detect participation differences between generations.

To operationalize the framework suggested by Van Deth (2014) and its extension by Theocharis (2015), 23 items were assigned to four different types of political participation (see Table A3.6 in the Appendix). We included a similar number of digital and non-digital activities undertaken at both the local and the national levels of government. The activities were selected from previous studies and surveys (Ekström \& Östman, 2015; Ekström, Olsson, \& Shehata, 2014; GLES, 2013; Portney \& O'Leary, 2007; Stolle, Hooghe, \& Micheletti, 2005; Yndigegn \& Levinsen, 2015). Activities referring to participation within political institutions or stipulated as constitutional decision-making were identified as specimens of PP I (e.g., voting, being a party member). Activities are targeting the political sphere (PP II) if they refer directly to political institutions (e.g., visiting a politician, signing a petition) or happen in a state-guaranteed framework of protest (e.g., participating in a demonstration). Activities address issues at a community level (PP III) if they refer to a direct action with immediate outcomes on a local level (e.g., supporting a community's crowdfunding project, volunteering in a local organization). For non-political but politically motivated activities (PP IV), pertinent considerations and the political purpose need to be emphasized (e.g., boycotting products for political purposes, expressing an opinion on social media about a political issue). A confirmatory factor analysis was undertaken based on the data from the first survey wave and revealed a sufficient distinctiveness between the four types of political participation (Ohme, de Vreese, \& Albæk, 2018a; see Figure A3.3 in the Appendix for full model and factor loadings).

In addition to these four types of political participation, we also measure campaign participation during election time. We used two different operationalizations of campaign participation. In both operationalizations, we asked if the respondents planned or had conducted 12 political activities during the election. In the post-election wave 4 , we asked respondents to indicate if they had engaged in particular behaviours during the election on a dichotomous scale (No/Yes). The answers were then summarized in a campaign participation index indicating average amounts of the types of participation in which the respondents had been involved during the election. In wave 3 (pre-election), we asked the respondents to assess the probability of conducting a specific type of behaviour on a scale from 1 (not likely at all) to 11 (very likely). An overview of the items used and their frequencies is found in Table A3.7 in the Appendix. The answers were summarized in an index indicating the average probability of participating during an election. Due to the differences in scales before and during/after the election, both 
participation indexes were rescaled to a $0-1$ continuous variable, where 0 indicates the lowest level of (intended) participation and 1, the highest. We reconstructed the two indexes as a relative measure to make the two different operationalizations comparable.

\section{Age and generations}

Our analyses rely on a distinction between five different generations: Traditionalists (born between 1922-44), Baby Boomers (1945-64), Generation X (1965-79), Millennials (1980-94; also known as Generation Y), and the latest Generation Z (born 1995 and after). Defining exact cut-off points for the years of birth for each generation is a challenge; particularly for the younger generations, opinions differ as to when one generation ends and the next one begins. The Pew Centre recently described 1996 as the last year of birth for members of the Millennial cohort (Dimock, 2018). While it initially refrained from giving the youngest generation a name (Dimock, 2018), the term 'Generation Z' has recently established itself in the international literature (Dimock, 2019; Mangelsdorf, 2015), and we therefore also use it. Broad agreement is found for the existence of the four other generations: Traditionalists, Baby Boomers, Generation X, and Millennials (Dimock, 2018; Howe \& Strauss, 2007).

To determine which generation respondents belonged to, we asked for their year of birth and sorted the answers in the generation brackets (see Chapter 2). As mentioned in the sample description, we intentionally oversampled younger and older citizens in our study to secure a reliable age distribution on both ends of the generational spectrum. As seen in Table 3.1,

Table 3.1 Age span and number of respondents per generation

\begin{tabular}{lccccc}
\hline Generation & Born & $\begin{array}{l}\text { Age in } \\
2014\end{array}$ & $\begin{array}{l}\text { Percentages } \\
\text { (number) of } \\
\text { respondents in } \\
\text { wave 1 }\end{array}$ & $\begin{array}{l}\text { Percentages } \\
\text { (number) of } \\
\text { respondents in } \\
\text { wave 5 }\end{array}$ & $\begin{array}{l}\text { Number of } \\
\text { respondents } \\
\text { in relation } \\
\text { to number } \\
\text { of years in } \\
\text { age bracket }\end{array}$ \\
\hline Traditionalists & $1922-1944$ & $92-70$ & $14.2 \%(1,297)$ & $17.9 \%(626)$ & 27,2 \\
Baby Boomers & $1945-1964$ & $69-50$ & $33.8 \%(3,083)$ & $43.6 \%(1,520)$ & 76,0 \\
Generation X & $1965-1979$ & $49-35$ & $11.4 \%(1,039)$ & $19.4 \%(679)$ & 45,3 \\
Millennials & $1980-1994$ & $34-20$ & $19.7 \%(1,793)$ & $12.6 \%(440)$ & 29,3 \\
Generation Z & $1995-1997$ & $19-17$ & $20.1 \%(1,906)$ & $6.5 \%(225)$ & 75,0 \\
\hline
\end{tabular}

Notes: The number of respondents in relation to age brackets is calculated by dividing the total number of respondents included in the analysis of the book by the number of years that the age bracket spans over. The equation is as follows: $\frac{\text { Final number of respondents }}{\text { Number of years in age bracket }}$. In the case of Generation Z, our final $\mathrm{n}=225$ and the age bracket spans over three years. Therefore, we have 75.0 respondents per year in our sample 
this effort was successful when we look at the age distribution of our original sample in the first wave. When it comes to the numbers of respondents who participated in all five waves (the sample analyzed in this book), the age distributions shift. Due to panel attrition, we lose more participants from the two youngest generations, while the percentage of Traditionalists, Baby Boomers, and Generation X increases. However, the age span is different for each generation bracket. If we compare the number of participants from each generation to the number of years that the age brackets cover, (see the last column in Table 3.1.), sufficient numbers of participants are included in our analysis.

\section{Analytic approach}

Our comprehensive multi-methods design provides us with solid data to analyze cross-generational differences in the effects of media exposure to political information on political involvement and vice versa. In each of the following empirical chapters, we will explore these differences using roughly the same analytic structure. In general, we rely on respondents participating in all five online survey waves $(\mathrm{N}=3,490)$. For the analysis relying on the mobile survey, respondents were included only if they, in addition to the five online survey waves, had also participated in at least four mobile surveys $(\mathrm{N}=534)$.

In each chapter, we first examine how the average level of the main variable under consideration varies across generations and over time. In other words, we examine how levels of exposure to political information in the media, political engagement, and political participation differ across the five generations over the five online waves and the three mobile waves.

Second, we examine how the relationship under consideration differs across generations on a static and a dynamic level. In order to do so, we nest waves within each respondent and use OLS regressions to analyze how the relevant independent variables correlate across generations when controlling for other variables (static models) and how the relevant independent variables affect changes over time in the main dependent variable under consideration (dynamic models). Changes in the main variable are analyzed by including a lagged dependent variable. By doing so, we utilize the panel feature of our data to examine how differences in levels of the relevant independent variable explain changes in levels of the dependent variable (Finkel, 1995; Markus, 1979).

Lastly, in the chapters examining political participation, we utilize structural equation modelling with group comparison (Acock, 2013; van Spanje \& Azrout, 2019) to examine the potential indirect effects of exposure to political information in the media on political participation through political engagement. When doing so, we likewise nest time within individuals and explore both static and dynamic relationships, using a bootstrap resampling technique (Hayes, 2013).

From an analytical point of view, when analysing age effects on the basis of cross-sectional data or relatively short-time longitudinal data, as in our 


\section{A multi-methods research design}

case, it is difficult to distinguish between generation or life-cycle effects (see also Chapter 2). The problem arises because pre-adulthood socialization is known to affect people's political behaviour later in life. As such, any differences in media use or political involvement across generations at the time of measurement can be explained partly by preferences that meet the demands of people's current situation (life-cycle effects) or by opinions that were developed during people's formative youth (cohort effects) (Stubager \& Hansen, 2013; Walczak, Van Der Brug, \& de Vries, 2012). We will thus refrain from making any definitive conclusions on whether the differences in political behaviour between generations are due to generation or life-cycle effects. However, we discuss the likelihood of these two options more specifically when the results are presented in subsequent chapters.

\section{Summing up}

The analyses presented in the remaining part of the book rely on a multimethods design consisting of a five-wave online survey, a three-wave mobile survey, and an automated content analysis, all conducted in Denmark. The measurements of the key variables of interest are detailed, providing us with elaborate information on respondents' exposure to political information in the media and on their political involvement. Together, this sophisticated setup provides us with comprehensive data for analysing how these behaviours and the relationships between them vary across generations and over time.

\section{Notes}

1 Two additional waves conducted around the 2015 Danish European Union optout referendum and the 2017 Danish local elections were part of this project but are not included in the analyses in this book. A number of survey experiments were also part of the research project; the results of these experiments are likewise not discussed in this book.

2 The mathematical equation is as follows: The amount of political information, where the numbers refer $=\left(\frac{x_{1}}{n_{1}}+\frac{x_{2}}{n_{2}}+\frac{x_{3}}{n_{3}}+\frac{x_{4}}{n_{4}}+\frac{x_{5}}{n_{5}}+\frac{x_{6}}{n_{6}}+\frac{x_{7}}{n_{7}}+\frac{x_{8}}{n_{8}}+\frac{x_{9}}{n_{9}}+\frac{x_{10}}{n_{10}}\right) / 10$ to day 1 , day 2 , and so on; $\mathrm{n}$, to the total number of news items in a day; and $\mathrm{x}$, to the number of news items containing political information.

3 The daily surveys also asked about political information exposure on platforms other than social media. The analysis in this book, however, relies only on the social media-related exposure measures.

4 The equation is as follows: $\frac{\text { Days of exposure }}{\text { Daysof participation }}$ 


\section{Being exposed to political information in the media}

Being exposed to political information in the media is of key importance for getting involved in politics. In this chapter we show that the level of political information that citizens are exposed to in the news media and on social media varies over time, markedly increasing during election time. Furthermore, we show that exposure to political information is dependent on which generation citizens belong to and on their political engagement and participation. While older generations have a higher use of political news media, younger generations are more exposed to political information on social media platforms. Further, political engagement and participation have positive effects on political news media use but less so on political social media use.

Citizens in modern Western democracies live in a world saturated with information-both political and non-political. Given society's technological transformation during the past decades, the availability of news media outlets has proliferated. In addition, with the rise of social media sites, new opportunities for gaining information about politics have appeared. On Facebook, for example, citizens can choose to follow different groups and pages to obtain information about politics. Consequently, citizens in contemporary Western democracies are in a position where they can create their own personal media diets with varying degrees of political information corresponding to their individual preferences (Arceneaux \& Johnson, 2013; Prior, 2007). If people have a high preference for seeking out political information, they can easily do so; they can find political information in numerous television news shows or newspapers, they can access this information from news outlets' online websites, or they can get exposed to such information on social media sites. Citizens cope with increasing choice through different strategies. Some develop ways to find reliable sources that fit their needs, while others lack the skills to do so. For the latter, being overwhelmed by choice may make them stop seeking political information 
altogether (Edgerly, 2017). Especially among the youth, a major share report low levels of news use and are consequently termed 'news avoiders' (Edgerly, Vraga, Bode, Thorson, \& Thorson, 2018). In a high-choice environment, citizens having no preference for news can find alternative media content very easily. For example, they can watch series or movies on television channels devoted to such content, or they can subscribe to services such as Netflix or HBO, which provide endless amounts of entertainment. Alternatively, they can follow pages or be part of groups on Facebook or other social media sites devoted to precisely the type of content that they most like.

In this chapter we examine what determines whether people are exposed to political information in the news media and on social media. In order to do so, we address three questions. First, we examine how saturated the news media is with political information and whether the amount of political information varies over the time of the investigation. Second, we examine whether the amount of political information that citizens are exposed to in the news media and on social media differs across generations. Third, we examine how each generation's political involvement (i.e., their political engagement and participation) is related to their exposure to political information in the media.

\section{The amount of political information over time}

For people to be exposed to information about politics, the media first need to present them with news. In order to examine how much political information the news media contain, we conducted an automated content analysis of the 14 national Danish media outlets in parallel with our five panel survey waves (see Chapter 3 for methodological details). Figure 4.1 shows the general results of this content analysis by illustrating the percentage of political information in the news media across our five waves. We find that the amount of political information across different news media outlets lies within a range of 30-50 percent. We see an increase in the amount of political information in the survey waves surrounding the election (waves 3 and 4), with the highest amount of political information after election day (wave 4).

The increase in political information during the election campaign seems reasonable. Politics is a dynamic process, and the media's political news coverage fluctuates around important political events, such as national budget negotiations and parliamentary elections. As a consequence, these political events provide citizens with more opportunities for getting exposed to political information in the media. Elections, in particular, structure political work and the attention devoted to politics (Downs, 1972). As an election draws closer, political parties make a greater effort to obtain favourable media coverage, the news media pay more attention to politics, and the citizens-who are to cast votes on election day-likewise pay more attention to 


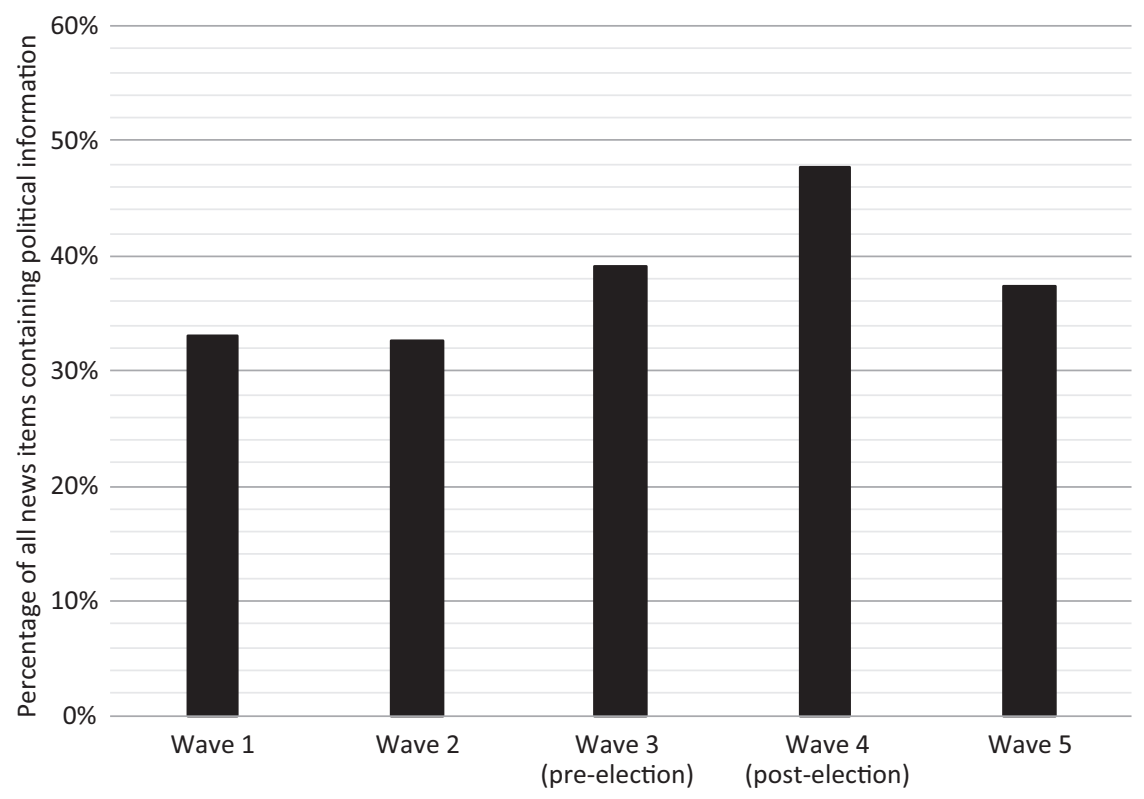

Figure 4.1 Political information in the news media over time

Notes. The amounts of political information were estimated by calculating the average of all news articles/features containing political information of the total number of news articles/ features in each news outlet in a specific period. For more details on the content analysis, see Chapter 3.

politics (Van Aelst \& De Swert, 2009). After election day, the media covers the election results and the formation of the new government. In Chapter 10, we will turn our attention the consequences of an increase in political information in the news during the election period.

\section{Exposure to political information in the media across generations}

Having seen how much political information the news media contains over time, we will now examine how much political information different generations are exposed to in the news media and on social media. To examine exposure to political information in the news media, we link our panel survey data to the content analysis. We thereby capture the amount of political information that each of our respondents is exposed to in the news media across time. To examine exposure to political information on social media, we rely on smartphone-based diary measures (see Chapter 3 for methodological details). Following the Engagement-Participation-InformationGeneration (EPIG) model, which we presented in Chapter 2, we expect 

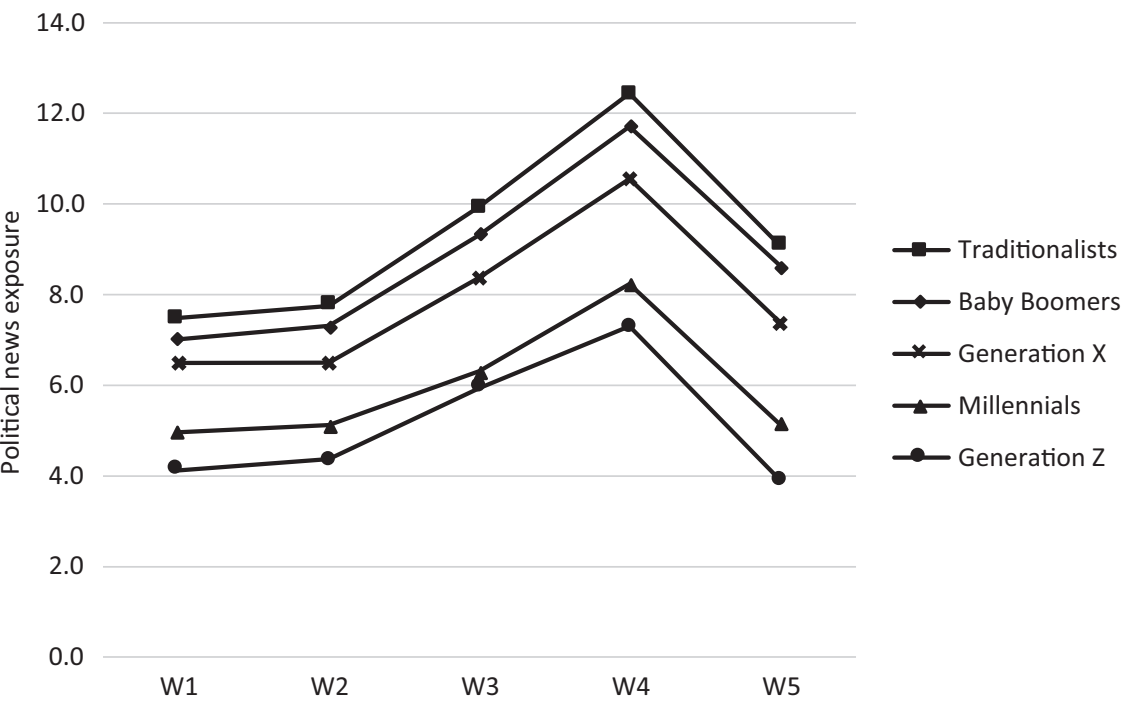

Figure 4.2 Average political news exposure over time across generations

Notes. Estimates are based on the mean exposure to political information in news media within each generation in each panel survey wave. Exposure to political information is estimated by linking the panel survey data to the content analysis (see Chapter 3 for methodological details).

higher political news use among the older generation and higher political social media use among the younger generation.

Figure 4.2 shows the average political news exposure over time across generations. As seen from the figure, there are clear differences in the amount of political information that each generation is exposed to in the news media. The Traditionalists are exposed to the highest amount of political information in the news media, followed by Baby Boomers. Generation $\mathrm{X}$ is exposed to the third highest amount of political information in the news media, followed by Millennials, while Generation $\mathrm{Z}$ is exposed to the lowest amount. These differences are maintained throughout the whole period of investigation.

Generally, across all generations, citizens get exposed to more political information as the election nears, while political news exposure drops after the election. By then, political information stabilizes to a level similar to the period before the election was called. This drop, however, appears to be largest for the younger generations. The pattern of exposure follows the amount of political information in the news media that we identified in our content analysis earlier (see Figure 4.1). This correspondence suggests that the amount of political information supplied by the news media conditions the level of information that citizens receive. Thus, news media seem to 


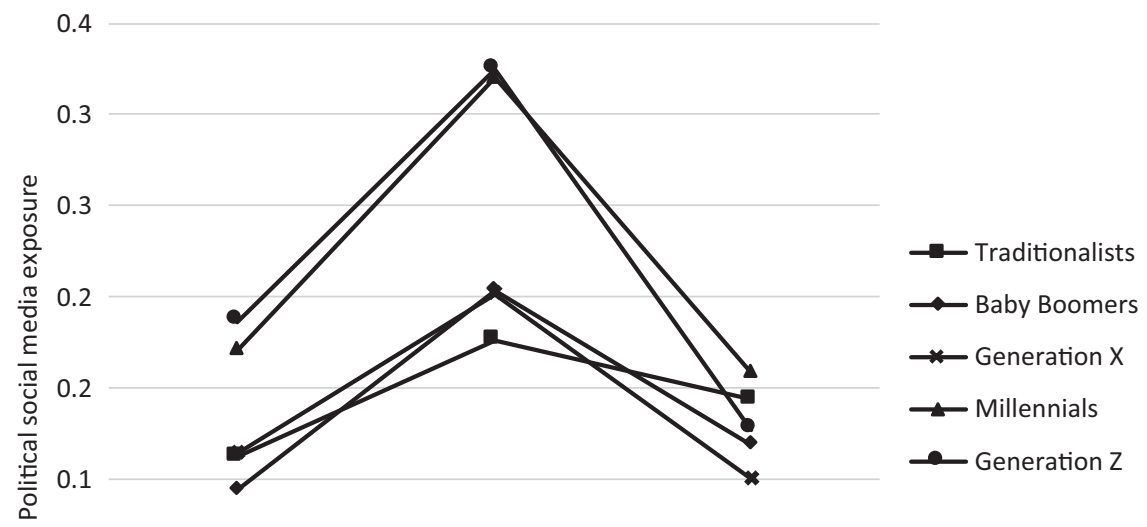

0.1

0.0

MW1 MW2 MW3

Figure 4.3 Average political social media exposure over time across generations

Notes. Estimates are based on the mean exposure to political information on social media within each generation in each mobile wave. The political social media exposure measure is based on the mobile media diary study (see Chapter 3), in which the respondents reported daily whether they had been exposed to political content on social media.

have an important role in determining the level of political information that citizens are exposed to.

As mentioned previously, citizens are exposed to political information not only in the news media; social media likewise offer ample opportunities for gaining political information. Figure 4.3 shows political social media exposure for each of the three mobile waves across the five generations. The amount of exposure is estimated from respondents' reports on how often they were exposed to political information on social media relative to the number of days they participated in the diary study. An amount of 20 percent, for example, means that respondents were exposed to political information on social media on 20 percent of the days for which they have reported their exposure in general (for more details see Chapter 3).

As seen from Figure 4.3, the youngest generations (Millennials and Generation Z) most often and almost equally reported being exposed to political information on social media sites, whereas the older generations are exposed to political information less often on such platforms. As was the case with political news exposure, we also see an increase in political social media exposure as the election nears. In particular, the younger generations experience a large increase in this type of exposure, while the other generations also experience an increase, albeit less noticeably. Once again, 
exposure after the election drops to approximately the same level as before the election.

According to the generational perspective, which we presented as part of the EPIG model in Chapter 2, these differences in levels of political news exposure can be understood in two ways. The result that older cohorts use more news media via traditional sources is in line with the life-cycle argument, posing that people, the older they get, turn more towards news in general. On top, a cohort effect might be present, since older generations became socialized with using traditional media sources for political information. In turn, the finding that younger generations turn more to social media to receive news can most likely be explained by a cohort effect. Social media platforms have only been around for a decade, hence all citizens had equal amount of time to start using them for news exposure. The finding that young people do so more is most likely caused by their socialization in a digital media environment.

Why is the post-election drop in exposure to political information most pronounced for the younger generations-Millennials and Generation Z? One reason may be that they engage heavily in personally relevant projects for a short period of time before turning their attention to other projects (Andersen, 2011; Dalton, 2017; Mangelsdorf, 2014; Milkman, 2017). Furthermore, since they are not as familiar with voting and not as certain who to vote for as are older generations, they may have a greater need to consult news media during an election campaign (Aalberg \& Jenssen, 2007; Colwell Quarles, 1979). Hence, generational differences in media exposure during election times compared to non-election times may be related to varying generational life cycles. Nevertheless, our results clearly show that both older and younger generations make use of the opportunities that are available to them to gain exposure to political information in the media. The next question is how the antecedents outlined in our EPIG model relate to this behaviour.

\section{Antecedents of exposure to political information in the media}

Though we can identify different patterns across generations, not everyone is equally likely to be exposed to political information in the news and on social media. Beyond the generational differences seen earlier, motivational and behavioural factors are likely to play an important role in determining exposure to political information. Gaining information about politics is a costly affair, and it takes time and energy. Consequently, more politically involved citizens are more likely to seek out and hence get exposed to political information in the media. Following the EPIG model (see Chapter 2), we therefore investigate whether political engagement and participation function as antecedents of political information exposure across each generation. By political engagement, we refer to political interest, knowledge, and efficacy. Political participation is divided into three types: participation 
targeted at the political sphere (PP II), participation targeted at the community (PP III), and politically motivated but non-political activities (PP IV). As argued in Chapter 2, we expect that both political engagement and participation are positively related to exposure to political information in the news media and on social media.

The following analysis shows how the different dimensions of political engagement and participation lead to exposure to political information in the news media and on social media within each generation. We look at each generation separately to show how the antecedents explain exposure to political information across the whole period of investigation. First, we investigate how political engagement relates to political news media use and to political social media use. Next, we look at how political participation relates to political news media use and to political social media use. The effects of each antecedent were estimated in separate models in which political news exposure and political social media exposure are predicted by an interaction between the antecedent under consideration and each generation. In addition, we added gender and education as controls in the models (full models can be seen in Tables A4.1-A4.4 in the Appendix).

The effects from both static and dynamic models are presented, which give us different insights into the nature of the relationship between political involvement and exposure to political information. As we discussed in Chapters 2 and 3, the relationships between political involvement and political media exposure are susceptible to endogeneity, which makes it difficult to estimate how the antecedents affect news use in the static models. We accommodate these issues by including a lagged dependent variable in the dynamic models, which controls for prior levels of political news exposure and political social media exposure.

\section{Political engagement and exposure to political information in the media}

According to the EPIG model, political interest, knowledge, and efficacy are all expected to be positively related with news media use. We first examine whether political interest functions as an antecedent to exposure to political information in the media for each of the five generations. We then turn to political knowledge and efficacy.

Political interest is an intrinsic motivation that gives people joy when engaging in politics. Political interest can thus be viewed as a factor that drives people to seize opportunities to seek out information about politics in the news media (Lecheler \& de Vreese, 2017; Strömbäck et al., 2013). Panels A and B in Figure 4.4 show the effect of the interaction between political interest and the generations on political news exposure. The figure shows the average marginal effects of political interest for each generation estimated in the static and dynamic models. Results from the static models show us that political interest is positively related to political news exposure 

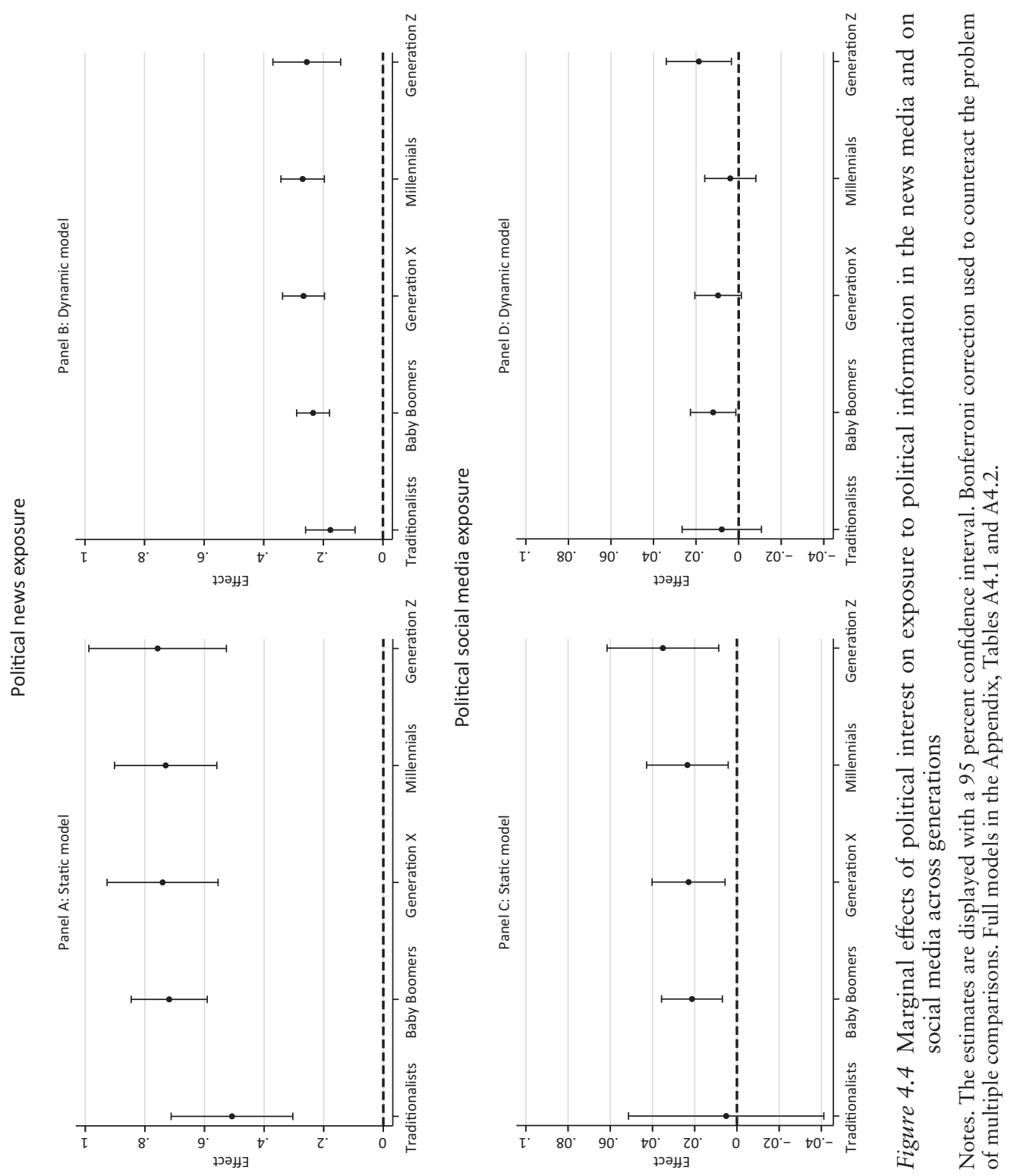
across all generations. The relationship is a bit weaker among Traditionalists but not to a large extent. The pattern repeats itself when we look at the dynamic model, where more political interest is associated with an increase in exposure to political news. Political interest is thus an important antecedent to political news exposure for all generations.

Turning to social media, Panels D and C in Figure 4.4 show the relationship between political interest and exposure to political information on social media for each generation. The results reveal that political interest is positively related to exposure to political information on social media for all generations, except the Traditionalists. Earlier in this chapter, we saw that the three oldest generations were exposed to roughly the same amount of politics on social media (see Figure 4.3); these levels of exposure, however, seem to be fostered by political interest only for Baby Boomers and Generation Z. When we look at the dynamic model, we can see that when Baby Boomers and Generation $\mathrm{Z}$ are more interested in politics, they also experience an increase in exposure to political content on social media. Interestingly, political interest does not foster more political social media exposure among the Millennials, though they belong to one of the generations that receive the most information on politics through this type of media.

We now turn to the relationship between political knowledge and exposure to political information in the media. In Chapter 2, we defined political knowledge as knowledge about recent events in politics and society. Political knowledge can be seen as an ability to seize opportunities for seeking out political information in the media, which is why we expect it to function as an antecedent of exposure to political news in the EPIG model. Panels A and B in Figure 4.5 show the relationship between political knowledge and exposure to political information in the news media for each generation. The results reveal a positive relationship in both the static and dynamic models. Individuals with higher political knowledge are likely to be more exposed to political information in the media. In addition, for Baby Boomers, Generation X, and Millennials, the more they know about politics, the greater the likelihood that their exposure to political information will increase over time.

In contrast to exposure to political information in the news media, political knowledge is not associated with more exposure to political information on social media, as seen in Panels C and D in Figure 4.5. The figure also reveals that more political knowledge does not lead to an increase in exposure to political information on social media for all generations. In other words, political knowledge cannot be considered an antecedent of exposure to political information on social media.

Next, we look at political efficacy, which we define as 'individuals' selfperceptions that they are capable of understanding politics and competent enough to participate in political acts' (Miller et al., 1979, p. 253). We understand political efficacy as both a motivation and an ability since believing in your own abilities to understand politics motivates you to seek out political information. The static model in Panel A of Figure 4.6 shows that people 


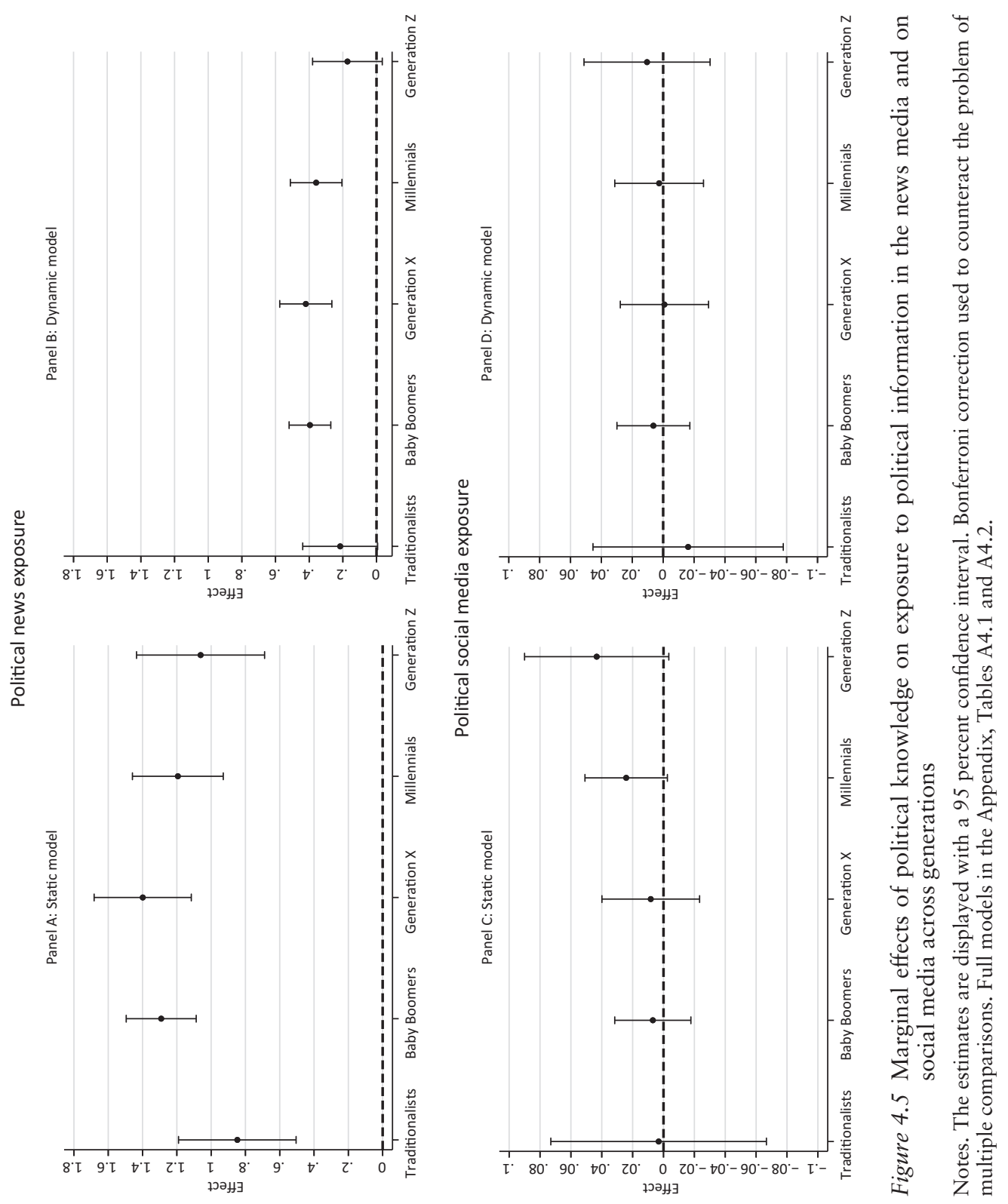



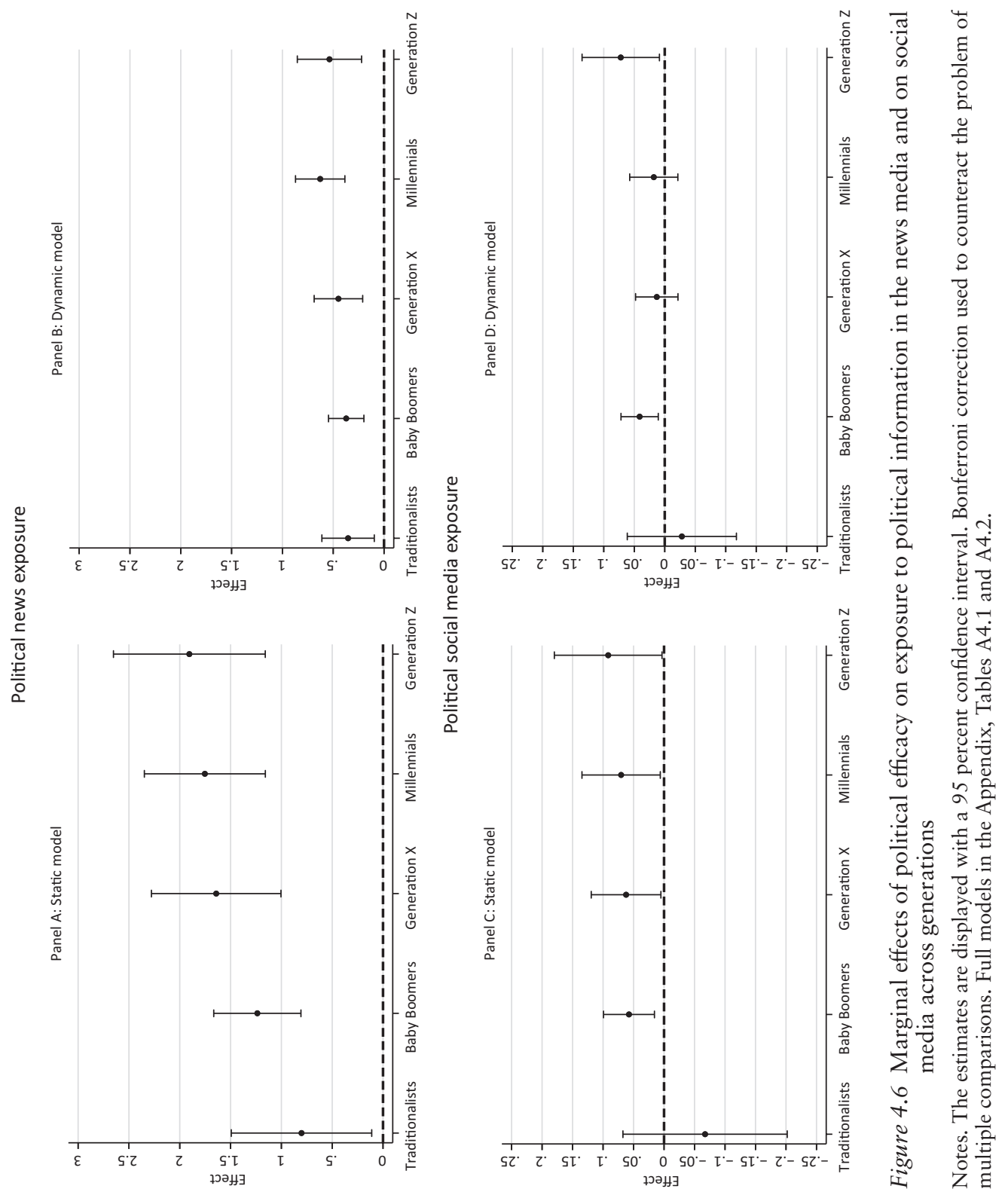
who feel more comfortable engaging in politics also have a higher exposure to political information in the news media. Next, the dynamic model in Panel B of Figure 4.6 shows that people who are more politically efficacious are more likely to increase their political news media use over time. Political efficacy is thus an important antecedent to political news exposure for all generations.

When it comes to political social media exposure, Panel C in Figure 4.6 reveals a positive relationship with political efficacy for all generations, except the Traditionalists. At the dynamic level, as illustrated in Panel D of Figure 4.6, we see that only for Baby Boomers and Generation Z does political social media exposure increase over time as they feel more efficacious. So, even if political efficacy is an antecedent associated with high political social media exposure, only for Baby Boomers and Generation $\mathrm{Z}$ does political efficacy lead to increased political information exposure on social media.

To sum up, our analysis shows that higher political interest, knowledge, and internal efficacy are associated with more exposure to political information in the news media for all generations. Political interest and efficacy predict more exposure for all generations, whereas political knowledge does so only for Baby Boomers, Generation X, and Millennials. Thus, in general, political engagement gives us the ability and motivation to seek out political information in the news media. A more mixed picture emerges when we look at exposure to political information on social media. While political interest and efficacy lead to higher political social media exposure only for Baby Boomers and Generation Z, political knowledge does not lead to higher political social media exposure for any generation.

\section{Political participation and exposure to political information in the media}

In this section we look at how each generation's political participation affects their political media use. Political participation is divided into three types of participation: PP II is targeted at the political system, PP III is targeted at the community, and PP IV is politically motivated but non-political. In the following analysis, we will look at each of these participation types separately. In Chapter 2, we argued that citizens who participate in different political activities are more likely to turn to the media to get information about politics and to seek out more information on the topics that they are engaged in or even to search for new issues to get involved with.

Panel A in Figure 4.7 shows how participation targeted at the political system is associated with political news media use. For all generations, except the Traditionalists, political participation targeted at the political system is positively related to political news use, with the relationship being strongest for Generation Z. The dynamic model, illustrated in Panel B of Figure 4.7, reveals that more political participation targeted at the political system leads to higher news media use for Baby Boomers and Generation Z. These results imply that whenever people from these two generations engage in political 

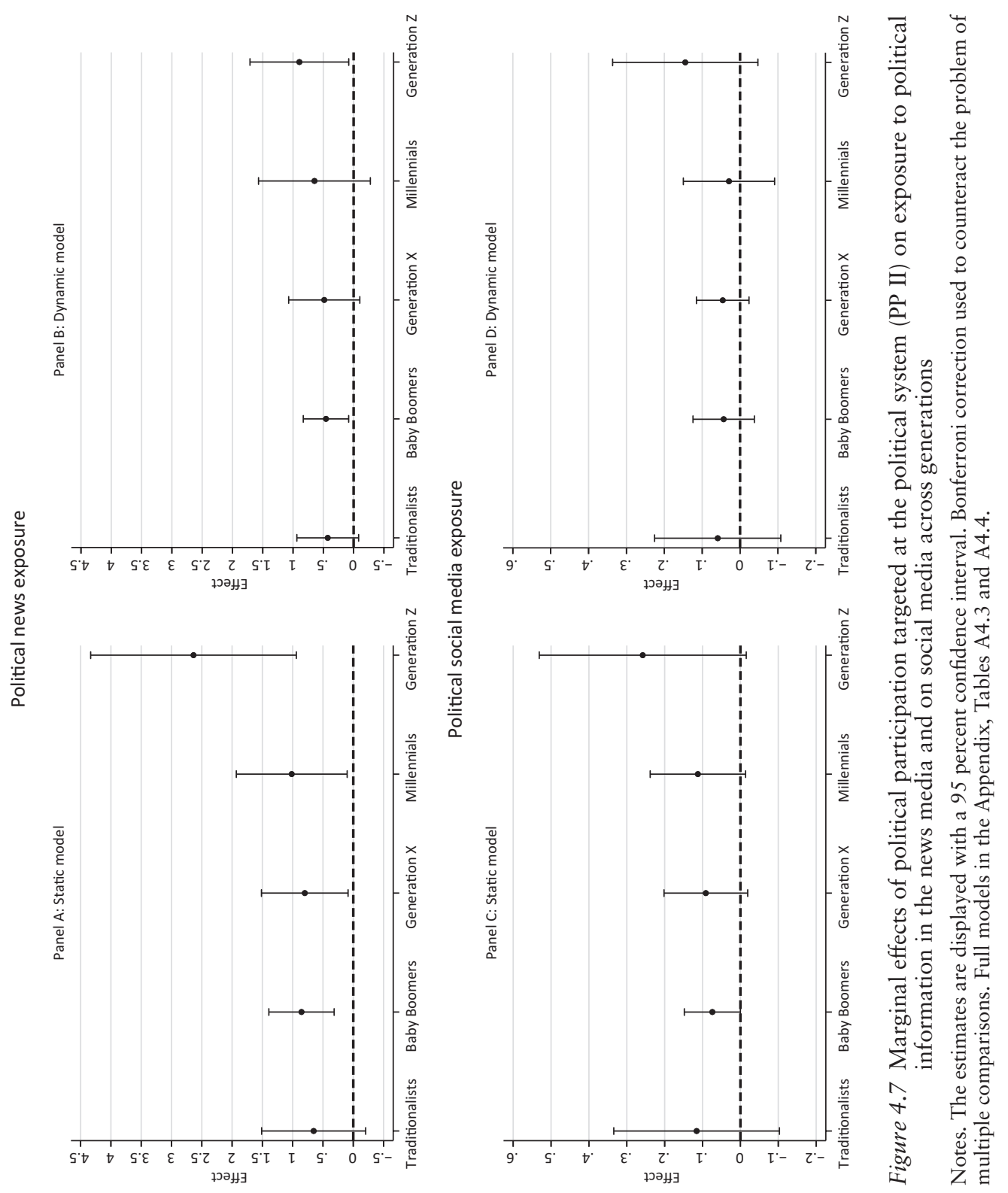
activities that aim at affecting the political system, they subsequently turn to the traditional news media to follow up on the most recent developments or to engage in new topics.

As seen from Panels C and D in Figure 4.7, political participation targeted at the political system is not positively related with political social media exposure for any generation. In other words, no matter which generation citizens belong too, chances are low that PP II activities drive them to expose themselves more often to political information on social media.

A different picture emerges when we look at political participation targeted at the local community. As seen from Panels A and B in Figure 4.8, both the static and dynamic models show that only Baby Boomers' political participation is positively related to-and leads to-higher political news exposure. These results are probably due to the nature of the news media outlets that we examine. These national media outlets cover local events only to a limited extent. Awareness of activities related to participation targeted at the local community is more likely to be picked up through direct, personal observation of the local area or through the local news. The different behaviour of Baby Boomers compared to other generations may be because Baby Boomers were the first to spend a good share of their spare time on political activities, mostly in a collective way (Mangelsdorf, 2014). Participating in local activities may therefore also lead them to keep a closer look on general political developments in the news media.

Panels C and D in Figure 4.8 reveal yet a different picture when it comes to the effect of participation targeted at the local community (PP III) and social media use. Again, participating in such activities is not related to political social media exposure, no matter what generation the participants come from. The high diversity of political information that people can encounter on social media platforms may explain this disconnectedness of participation and exposure. Though being active in one specific local activity could make people seek out more information about this project on social media, no general pattern can be observed that increased political participation at a local level results in more exposure to political information on social media.

Finally, we observe how non-political but politically motivated participation and news media exposure are related. Panel A in Figure 4.9 shows that this type of participation is positively related to political news media exposure for Baby Boomers, Generation X, Millennials, and Generation Z. The dynamic model presented in Panel B of Figure 4.9 further shows that more participation in non-political but politically motivated activities leads to more political news media exposure only for Baby Boomers and Generation Z. As with participation targeted at the political sphere (PP II), participating in non-political but politically motivated activities (PP IV) fosters more political news media use among Baby Boomers and Generation Z. The nature of the relationship between these two types of participation is likely to be different, however. People who participate in non-political but politically motivated activities (PP IV) cannot be expected to follow up on their 

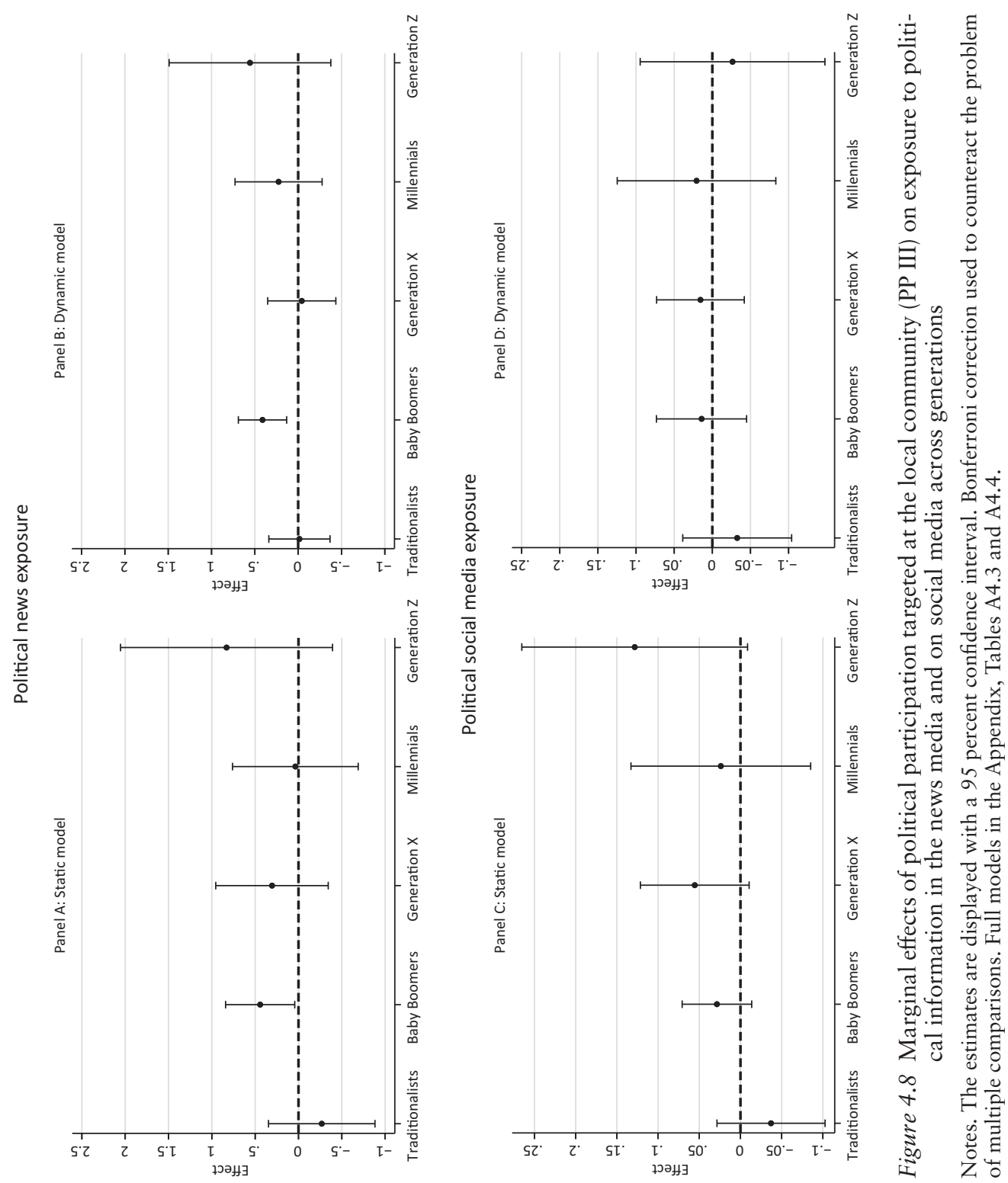


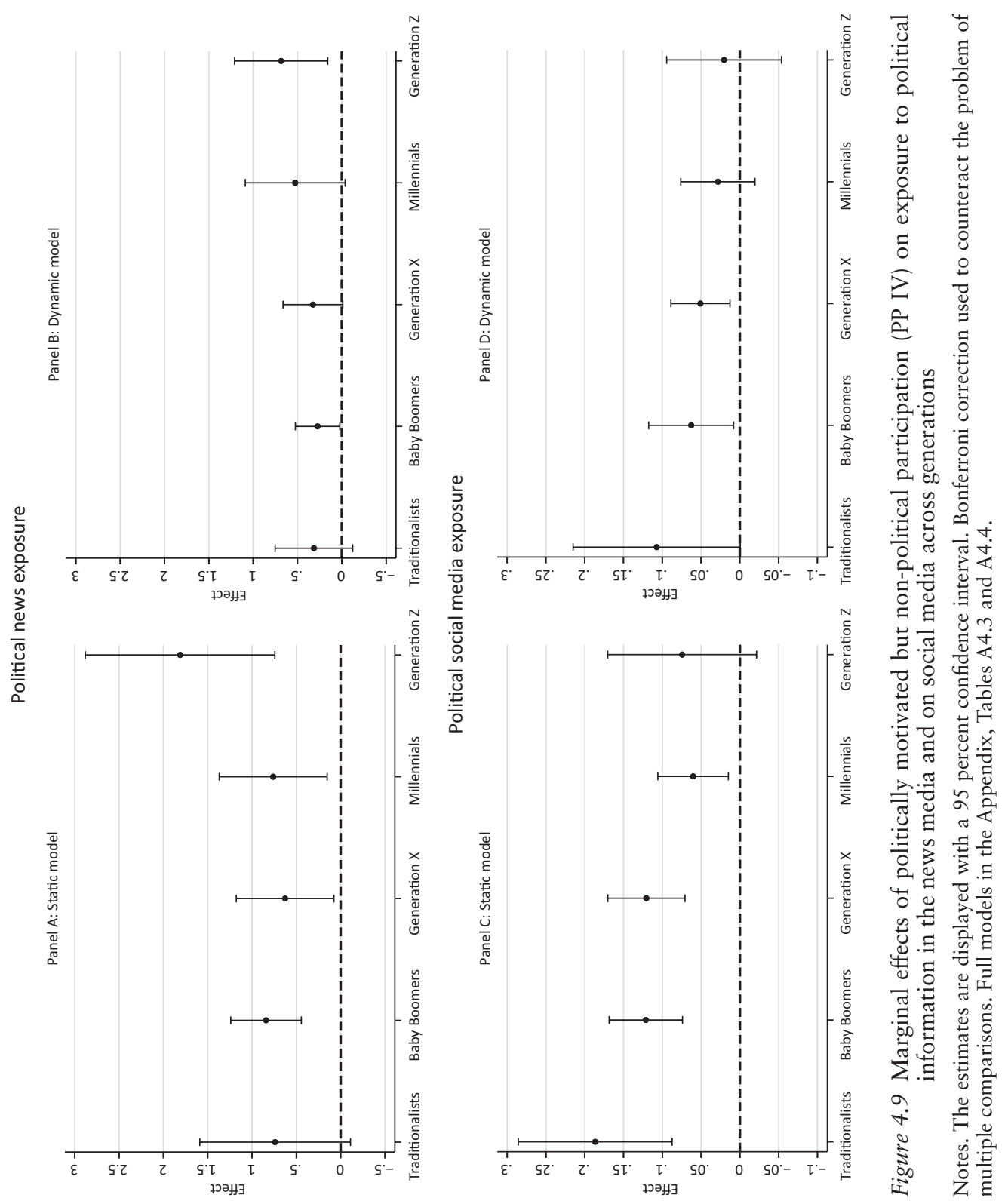


activities in the same way as those participating in activities targeted at the political sphere (PP II) since the former is inherently not targeted towards any political system and will hardly result in the media's coverage of politics. Because these actions are politically motivated, however, they might encourage people from these two generations to seek out more political information in the news media, fuelling future behaviour.

Panel C in Figure 4.9 reveals a positive relationship between political social media use and non-political but politically motivated participation (PP IV) for all but Generation Z. However, as seen in Panel D in Figure 4.9, only the non-political but politically motivated participation (PP IV) of Baby Boomers and Generation X leads to a higher political social media exposure. It is hence the older generations who follow up on political information on social media when they are actively participating in non-political but politically motivated activities. Possibly, information that is relevant to people participating in PP IV activities is more accessible on social media since users themselves define what is relevant and, in their eyes, 'political.' The fact that we do not see this relationship for Millennials and Generation $\mathrm{Z}$ may point to differences of social media use by these two generations, where they less often seek political information but are more often incidentally exposed to it.

Taken together, this part of our analysis has shown that political participation targeted at the political system (PP II) and politically motivated but non-political activities (PP IV) for most generations are associated with high political news consumption in the media. In addition, participating in these types of activities gives Baby Boomers and Generation $\mathrm{Z}$ experiences that engender the motivation and ability that are necessary to seek out political information in the news media. These findings suggest that the youngest generations' political participation creates a springboard for entering the positive spiral of political involvement and political news exposure, just like for their older and historically politically active Baby Boomer counterparts. We further uncovered that only Baby Boomers' political news exposure correlates with political activities targeted at the local community (PP III). This finding points towards a generational effect such that participation in community-based political activities (PP III) leads to higher political news exposure for Baby Boomers, whose political habits were formed in a period characterized by societal problems being addressed and solved by local, collectivistic, and social movements (Andersen, 2011). The grassroot approach to politics that dominated this generation's formative years is now reflected in our analysis, which shows that their political participation targeted at the community level (PP II) leads to more political news exposure.

Political social media exposure is less dependent on previous levels of political participation. It thus seems that social media exposure is a less demanding type of news consumption compared to political news exposure. But this result also shows that previous political participation leads people to seek additional political information on social media platforms less often. Politically motivated, non-political activities (PP IV) are the only 
political activities associated with higher exposure to political content on social media for all generations, except Generation Z. This type of political participation leads to more political social media use for older generations like Baby Boomers and Generation X and not, as one would expect, for the two younger generations.

\section{Summing up}

In this chapter we have examined the amount of political information in the news media over time, how exposure to political information in the media varies across generations, and how political involvement is related to this exposure. When elections draw close, the amount of political information in the media increases. Subsequently, during election time, citizens are more often exposed to political information in both types of media. Thus, the election serves as a political event when particularly the younger generations get more political media exposure, reducing the generational gap from nonelection times. We further see that the older generations receive more political information from news media, whereas this pattern is turned upside down for social media exposure: Millennials and Generation $\mathrm{Z}$ attend to news on social media more often than the three older generations.

We also examined how these different patterns of exposure to political information in the media are related to political involvement for each generation. Our results showed that political engagement, in general, is more strongly associated with exposure to political information in the news media than on social media across generations. Across generations we see that higher levels of political interest, knowledge, and efficacy make people turn to the news media for more political information. While higher levels of political interest and efficacy make some generations seek out more political information on social media (i.e., Baby Boomers and Generation Z), political knowledge is not a necessary antecedent of news consumption on social media platforms. In general, political participation is a less important precondition for political news consumption compared to political engagement. Previous political participation is more likely to increase peoples' political news exposure rather than their political social media exposure, with one exception: if older generations engage in politically motivated, non-political activities (PP IV), they will more likely seek out more political information on social media.

With the use of the EPIG model, we uncovered that even if the generations have different patterns of exposure to political information in the news media and on social media, they still utilize similar gateways and seize the opportunities that modern media provide. In other words, political engagement and participation facilitate political exposure to some extent but through different types of media. This chapter implies that the youth might not be that different from older generations since they follow the same road to the world of politics but just enter through a different door. 


\section{Getting interested in, learning about, and feeling capable of participating in politics}

Being interested in politics, having political knowledge, and feeling competent to participate politically are core dimensions of political engagement. In this chapter we show that older generations hold higher levels of political engagement-understood as political interest, knowledge, and efficacy-than younger generations. However, we also show that political news exposure has a positive effect on political engagement and is especially beneficial for engaging younger generations in politics. Thus, political news exposure can help bridge generational gaps in political engagement.

How does exposure to political information in the news media affect citizens' political interest, knowledge, and efficacy? In this chapter we examine this question with a focus on differences across generations. Political interest, knowledge, and efficacy are core dimensions of political engagement and are often seen as important forerunners to political participation (see Chapter 2). In an ideal world, citizens should have a high interest in politics and thus be motivated to engage in democracy (Prior, 2010). Likewise, they should base their political activities on knowledge about the political issues at stake (Delli Carpini \& Keeter, 1996). In addition, citizens should view themselves as capable of acting on their beliefs for participation to be meaningful (Finkel, 1985). If political news exposure has a positive effect on these engagement dimensions, then the news media play an important role for the health of democracy.

Exposure to political news may, however, influence political engagement differently across generations. While knowledge about current political affairs is likely to vary depending on the amount of political information that citizens are exposed to in the news media, it is unclear whether political interest and efficacy are open for changes throughout life (Jennings \& Markus, 1984) or at specific points in life, such as in earlier life stages (Krosnick \& Alwin, 1989; Neundorf, Smets, \& García-Albacete, 2013; Niemi \& 
Hepburn, 1995; Prior, 2010). We argue that political news exposure is likely to influence political engagement more among younger than older generations (see Chapter 2). Young citizens' political attitudes are still under development. Further, young citizens are typically more curious and are searching for ways to express or promote themselves. In contrast, older generations are more tied to routines and habits. Thus, political news exposure is more likely to influence engagement in younger citizens since they are likely to be more open and flexible. By the same token, young people are likely to be more susceptible to media effects.

In what follows, we examine how political interest, knowledge, and efficacy vary across generations and over time, including election and nonelection time. In addition, we examine how exposure to political information in the news media affects these different dimensions of political engagement.

\section{Getting interested in politics}

Political interest is an important dimension of political engagement. Citizens with a high interest in politics are more likely to use the news media (Prior, 2007; Strömbäck et al., 2013; see also Chapter 4) and to participate in political activities (Verba et al., 1995). As Van Deth and Elff (2004, p. 478) write: 'Without a minimum level of curiosity about politics, citizens would not even be aware of the political process or of opportunities to defend their well-being or contribute to collective decisions.' Thus, devoting some attention to the levels of political interest across generations and to the role of political news exposure in this regard is of vital importance for understanding the dynamics of political engagement in contemporary democracies. In the absence of a clear-cut definition of this central dimension of political engagement, "political interest can be considered an intrinsic motivation to pay attention to and engage in politics-not because of external pressures or as a means to achieve distinct outcomes, but for personal pleasure and the inherent satisfaction of doing so in itself' (Shehata \& Amnå, 2017, p. 3).

Though political interest has been found to be very stable at the individual level (Prior, 2010), studies have shown that news media use can have a positive influence on political interest. Thus, not only do more-interested citizens seek out news to a higher extent than less-interested citizens (see Chapter 4), but those who consume news may, in fact, also become more interested in politics (Kruikemeier \& Shehata, 2017; Lecheler \& de Vreese, 2017; Strömbäck \& Shehata, 2010, 2018). Political news exposure might foster political interest by capturing people's attention and presenting them with different perspectives and arguments on political issues. The news media thereby help citizens make sense of the political world. This effect may be especially likely among younger generations, who are new inhabitants of the political world and therefore hold less stable political attitudes than they will later in life (Shehata \& Amnå, 2017). 
8.0

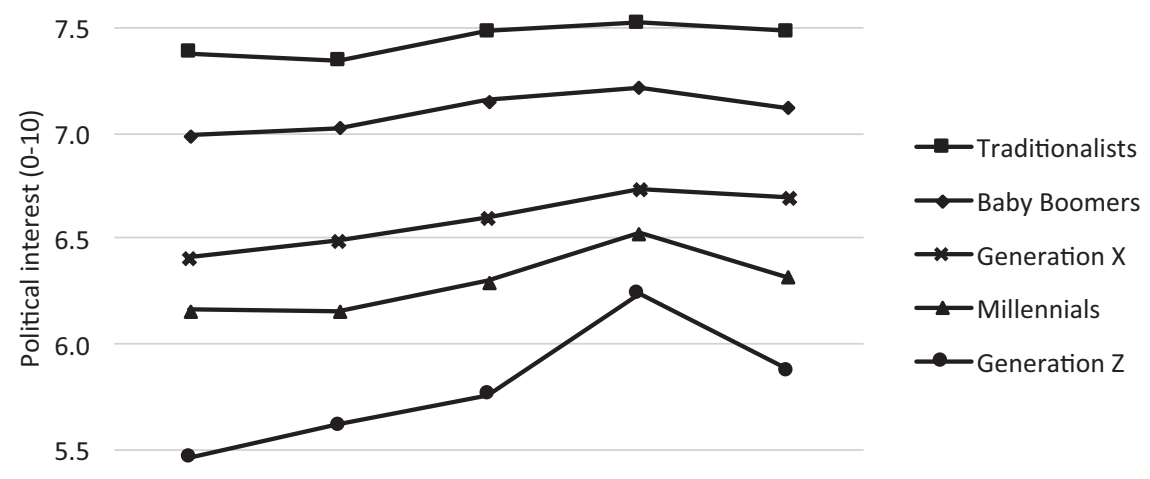

5.0

$\begin{array}{lllll}\text { W1 } & \text { W2 } & \text { W3 } & \text { W4 } & \text { W5 }\end{array}$

Figure 5.1 Average political interest over time across generations

Notes. Estimates are based on the mean of political interest within each generation for each online survey wave.

We begin by examining average levels of political interest over time and across generations, as illustrated in Figure 5.1. In general, we see that older generations hold a higher level of political interest than younger generations. In addition, we find that the levels of political interest fluctuate over time. This is particularly the case during election time (waves 3 and 4), when we find a slight increase in political interest. It may come as no surprise that citizens become more politically interested during election time-the highlight of democracy-as they likely consider and perhaps even choose to participate in politics by casting votes on election day. As expected, this tendency towards increased interest seems to be especially pronounced among younger generations. However, after election day, the levels of political interest drop and the generational gaps increase again.

How does exposure to political information in the news media affect citizens' political interest? Figure 5.2 shows the effect of exposure to political information in the news media on political interest across generations. The effects are shown at a static level, where we focus on correlational relationships and at a dynamic level, where we look at changes in the dependent variable-political interest-by including a lag on the dependent variable. The results show that exposure to political information is generally positively related to political interest. Importantly, our results from the dynamic models also show that political news exposure has a positive effect on political interest. Thus, citizens get more interested in politics when they are 


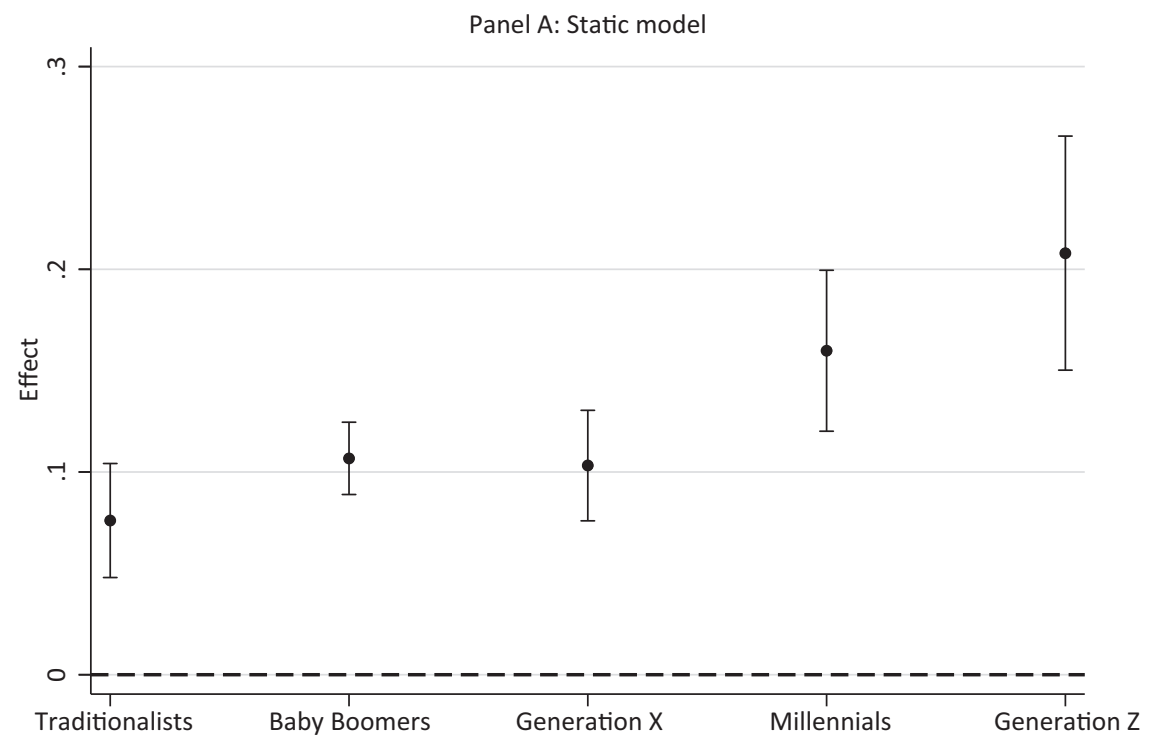

Panel B: Dynamic model

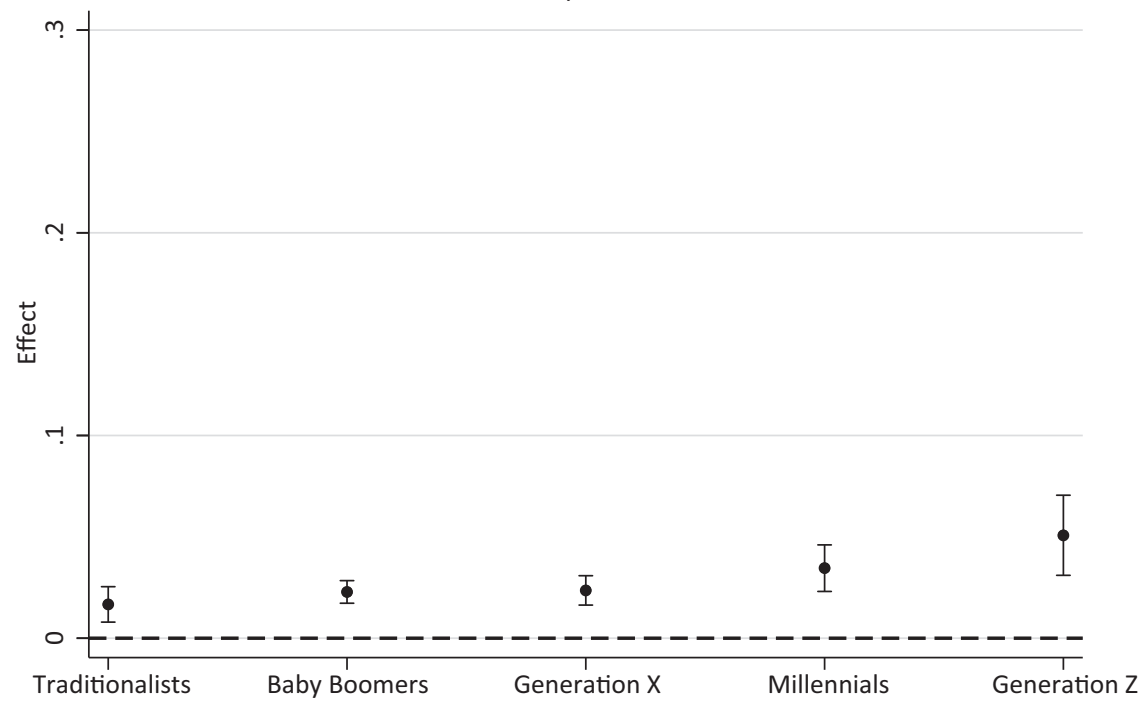

Figure 5.2 Marginal effects of exposure to political information in the news media on political interest across generations

Notes. The estimates are displayed with a 95 percent confidence interval. Bonferroni correction used to counteract the problem of multiple comparisons. Full models in the Appendix, Table A5.1. 
exposed to political news. Strikingly, this effect is especially positive among the younger generations.

Taken together, we find that political interest varies across generations, being higher for older generations-and that it varies over time-increasing during election campaigns, especially among younger generations. We also find that political interest is positively influenced by exposure to political information in the news media. The effects, however, vary across generations and are especially pronounced among the younger generations. These patterns follow our expectations. As the younger generations are still developing their political interest, they are more malleable and hence more susceptible to media effects. In other words, exposure to political news helps decrease gaps in political interest between older and younger generations.

\section{Learning about politics}

Politics is a complicated topic to follow. Every day, political actors present, discuss, implement, or dismiss many political problems and solutions. In today's mediated democracies, it is literally impossible for citizens to follow such political processes without relying on the news media to prioritize and segregate relevant from irrelevant information. Given the fact that most citizens primarily gain their political information from the news media (Strömbäck, 2008; Zaller, 2003), it becomes vital to understand how people learn from the information that they are exposed to.

It seems self-evident that we learn about politics when it is covered by the news media-for example, when we are informed about a newly appointed minister of social affairs, the outbreak of a war, or an immigration bill passed in parliament. Several studies have also empirically shown that citizens generally learn about politics from news media consumption (Aalberg \& Curran, 2013; Delli Carpini \& Keeter, 1996; Jerit, Barabas, \& Bolsen, 2006; Prior, 2007). This knowledge may subsequently be used when we act politically in a democracy by, for example, attending a protest against a newly passed labour market reform.

We will now focus on current affairs knowledge, defined as knowledge about recent happenings in politics and society that have been covered by the media (see Chapter 2). In each survey wave, political knowledge was measured as the number of correct answers to four new questions about current affairs that had been covered in the news between each of the individual survey waves-for instance, the appointment of a new minister (see Chapter 3). Thus, it was impossible for citizens to know the answers to these questions prior to being exposed to the relevant political information.

As seen from Figure 5.3, political knowledge varies across generations, with older generations knowing more about ongoing political happenings in society. The results also indicate that levels of political knowledge vary over time, with people learning more during election time. Nonetheless, careful interpretation of these results is needed since the questions we used to 
4.0

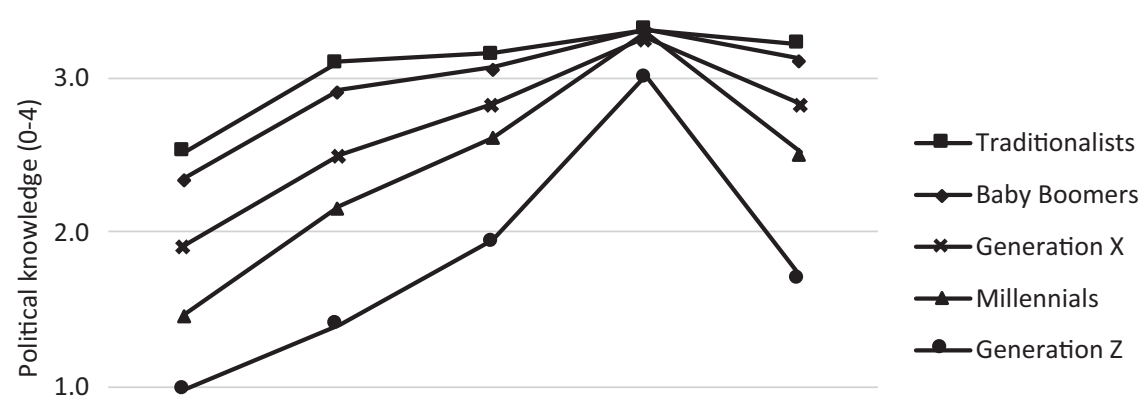

0.0

W1

W2

W3

W4

W5

Figure 5.3 Average political knowledge over time across generations

Notes. Estimates are based on the mean of political knowledge within each generation for each online survey wave.

tap political knowledge changed from survey to survey, though we strived to make them equally difficult. Based on prior studies showing that citizens become more attentive towards politics as they are about to cast votes on election day (Van Aelst \& De Swert, 2009), it makes sense that political knowledge increases during election campaigns. In addition, the results show that knowledge gaps between generations become smaller during election time, suggesting that the younger generations catch up with the older generations as the election day draws near. After election time, however, the generational gaps increase again.

Turning to the factors that influence the levels of knowledge about current affairs, Figure 5.4 illustrates the effects of political news exposure on current affairs knowledge across generations. Again, the effects are examined both in a static and in a dynamic model, where the latter tests changes in current affairs knowledge by including a lagged dependent variable in the model. As expected, we find that the effects of exposure to political information on current affairs knowledge is positive both on a static and a dynamic level across generations. Citizens simply learn from being exposed to political information. Again, this is especially true for younger generations. Thus, political news exposure can help bridge generational gaps in knowledge about current political affairs.

Summing up, we find a gap between what younger compared to older generations know about politics, with younger people generally being less 

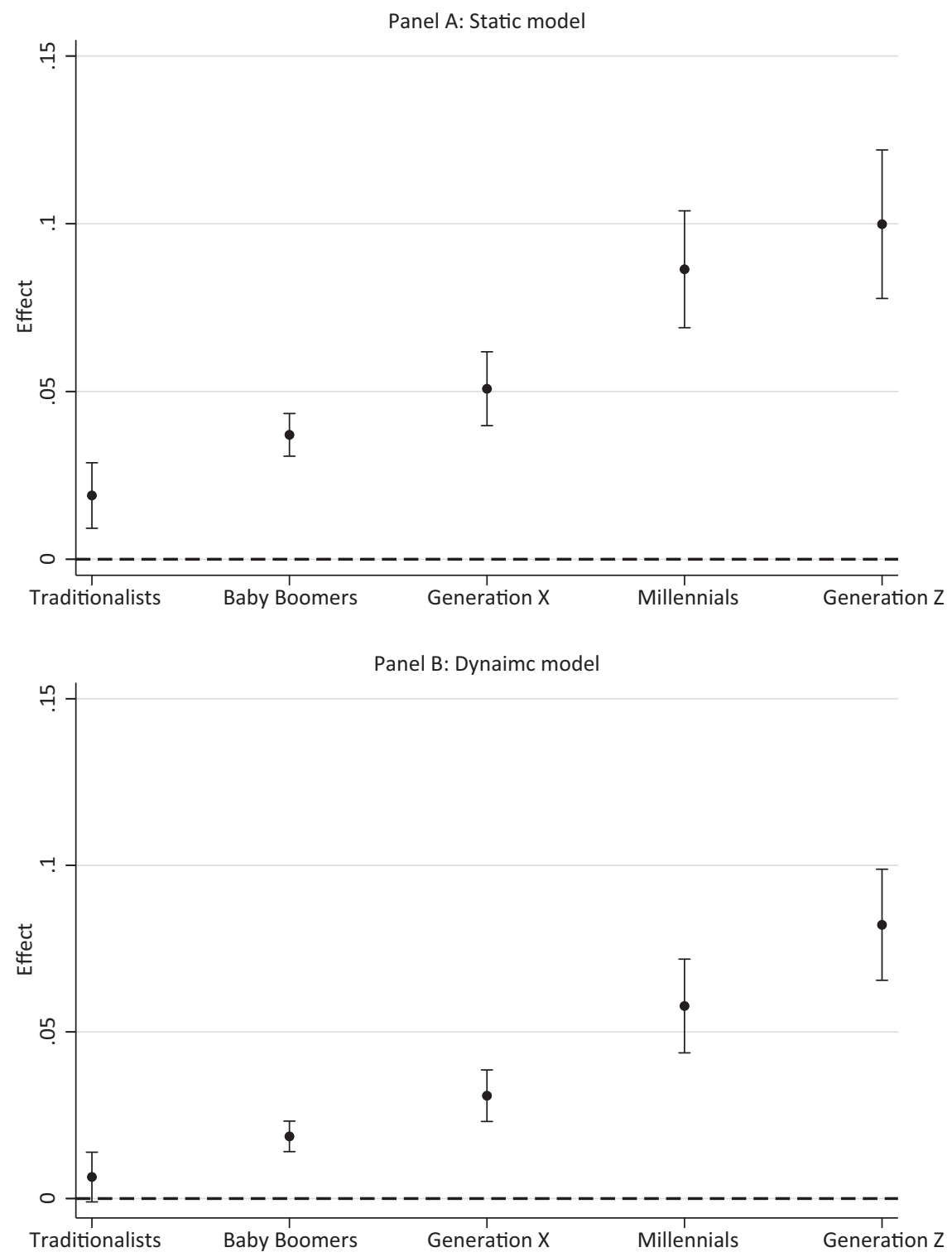

Figure 5.4 Marginal effects of exposure to political information in the news media on political knowledge across generations

Notes. The estimates are displayed with a 95 percent confidence interval. Bonferroni correction used to counteract the problem of multiple comparisons. Full models in the Appendix, Table A5.2. 
knowledgeable than older generations. The gap decreases during the election campaign, indicating that the younger generations keep up with the older generations, probably due to motivation associated with the fastapproaching election. Turning to the explanation of gained knowledge, we find that exposure to political information in the news media has a positive effect on political knowledge. The effect, however, varies across generations and is especially pronounced among the younger generations. As the younger generations are still forming their political engagement, they are likely to be more open-minded and curious, hence more susceptible, to media effects. As a consequence, the younger generations benefit more from exposure to political information in the news media, which thereby can help bridge generational gaps in political knowledge.

\section{Feeling capable of participating}

Next, we focus on the importance of feeling politically competent to engage in political activities. Political efficacy refers to 'individuals' self-perceptions that they are capable of understanding politics and competent enough to participate in political acts' (Miller et al., 1979, p. 253). Political efficacy thus captures the basic questions that citizens may ask themselves when facing options of political participation: do I feel that I understand politics? Am I competent to participate? We argue that these perceptions of oneself are important for citizens to move from engagement to actual participation in politics (see Chapter 2).

Though this link seems logical-that is, you act because you feel that you understand politics and possess the skills to participate-less scholarly attention has been devoted to political efficacy as a dimension of engagement compared to political interest and knowledge. However, we argue that political efficacy is likewise a key component of political engagement. If you feel that you do not understand what is happening in politics and are not competent to participate, why would you participate? The answer to this question determines whether you feel efficacious or not. We argue that exposure to political information in the news media is likely to have a positive effect on the feeling of being efficacious. The more political information you are exposed to in the news media, the more capable and competent you will feel.

Levels of political efficacy vary over time, with an increase during election time, as illustrated in Figure 5.5. Interestingly, as the election comes to an end, political efficacy stays at the same level. Compared to the patterns of political interest and knowledge, this trend indicates that the possibility of casting a vote may have a more lasting effect on the feeling of understanding and of being competent to act politically. We also find generational differences. Older generations have a higher degree of internal efficacy than the youngest generation, Generation Z. In other words, older citizens feel to a higher extent that they can make a difference in politics. One reason for this 
4.0
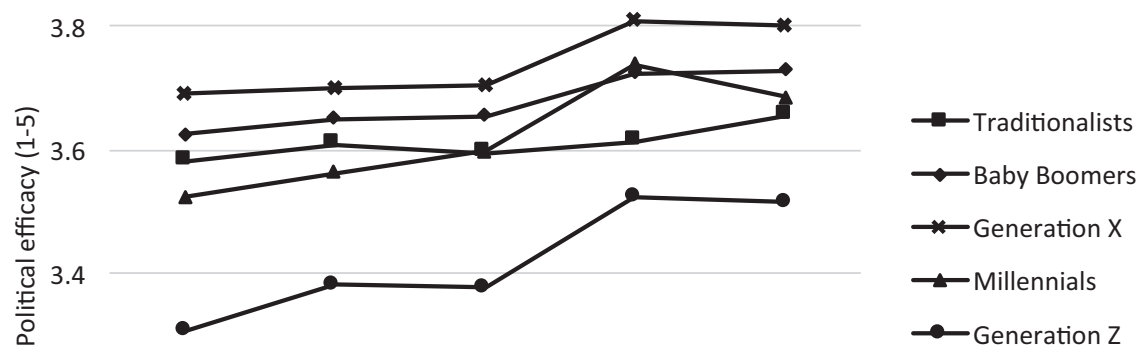

3.2

3.0

$\begin{array}{lllll}\text { W1 } & \text { W2 } & \text { W3 } & \text { W4 } & \text { W5 }\end{array}$

Figure 5.5 Average political efficacy over time across generations

Notes. Estimates are based on the mean of political efficacy within each generation for each online survey wave.

gap may be that during their lifespans, citizens build up a better understanding of what politics is all about and develop a skill box enabling them to deal with political matters, which makes them feel competent to act. At the least, they may have acted politically by casting votes at several elections, or they may have felt obliged to do so. Naturally, such generational gaps decrease over time as younger generations go through the process of becoming more experienced with politics and therefore catch up with the older generations.

Moving on to the factors that influence political efficacy, Figure 5.6 shows the effects of exposure to political news across generations. Again, the figure illustrates the effects for both a static and a dynamic model, where the latter model tests changes in political efficacy by including a lag on the dependent variable in the model. As for political interest and knowledge, we find a positive effect of exposure to political information in the news media, again particularly for the younger generations. In other words, exposure to political news has the largest effect on the younger generations. Thus, once again, political news exposure seems to have a bridging potential for narrowing generational gaps.

Taken together, we find that political efficacy varies over time and that it is especially high during election campaigns. Further, political efficacy is positively influenced by exposure to political information in the news media. This effect, however, varies across generations and is particularly 


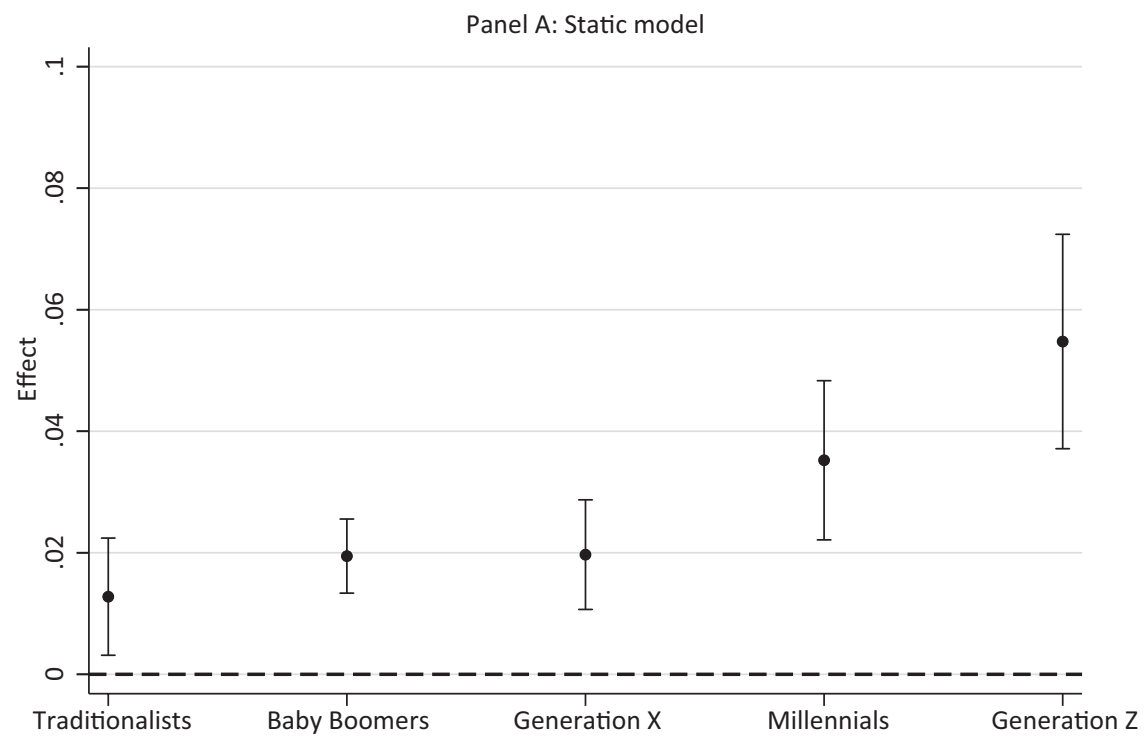

Panel B: Dynamic model

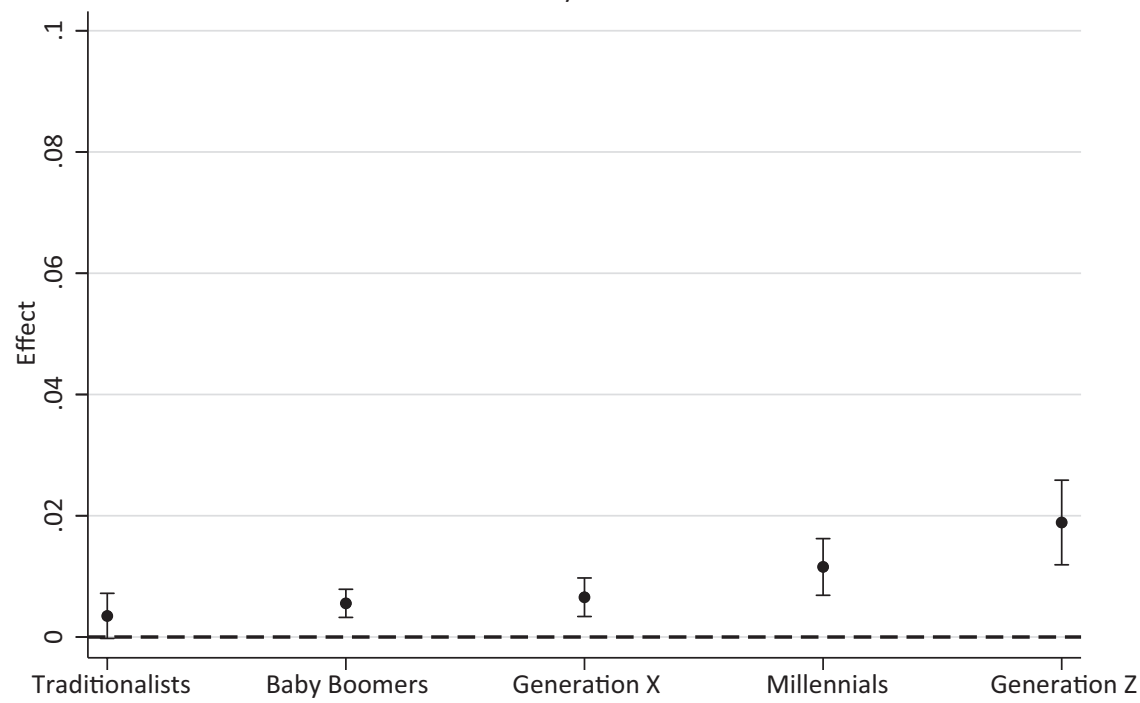

Figure 5.6 Marginal effects of exposure to political information in the news media on political efficacy across generations

Notes. The estimates are displayed with a 95 percent confidence interval. Bonferroni correction used to counteract the problem of multiple comparisons. Full models in the Appendix, Table A5.3. 
pronounced among the younger generations. Older generations may have already gained a more solid understanding of their self-perceptions, whereas the younger generations are still forming an understanding of themselves as democratic citizens. Thus, they are more susceptible to the information they receive, including political news. These young citizens are still in the formative phase of life and may therefore be more influenced by the amount of information they receive compared to older generations with more grounded self-perceptions. As a result, political news exposure has the potential to bridge generational gaps in internal efficacy when younger citizens are exposed to political news in the media.

\section{Summing up}

Political interest, knowledge, and efficacy are core dimensions of political engagement. Being interested in, being knowledgeable about, and feeling capable of participating in politics are all important components of fostering a healthy citizenship. In this chapter we have examined how each of these components of political engagement varies across generations and over time as well as how news media exposure affects them. We have shown how older generations, in general, hold higher levels of political interest, knowledge, and efficacy than younger generations. However, political interest, knowledge, and efficacy all increase during election time. This increase is especially pronounced for the youngest generations. Thus, elections can work as a kick-off into democracy for young citizens.

Most importantly, we have shown that exposure to political news increases political interest, knowledge, and efficacy. This effect is especially pronounced for the youngest generations. Thus, exposure to political information in the media helps younger citizens, in particular, to engage in politics. The news media play an important role in narrowing generational gaps in political engagement. As we showed in Chapter 4, however, younger generations are not exposed to political information in the news media to the same extent as older generations. They thus miss out on important currency for their democratic citizenship. Instead, younger generations are turning to social media. In Chapter 9, we explore whether exposure to political information on social media can foster political engagement. 


\section{Participation targeting the political system}

Participating in activities targeting the political system is a key dimension of citizens' political involvement. In this chapter we show that political participation targeting the political system is generally rather stable and low during non-election times, especially for Generation Z, the youngest generation. Political news exposure has a positive effect on this type of political participation, again especially for Generation $Z$. This influence seems to be the result of an indirect effect of political interest, knowledge, and internal efficacy, which all positively mediate the relationship between political news exposure and political participation targeting the political system.

A democratic political system is expected to address and be responsive to problems that the public formulates. Besides voting in elections, citizens provide input to politicians (Easton, 1953) through participatory actions targeted directly at the political system. Citizens may, for instance, contact politicians, sign petitions, and organize or join demonstrations. When addressed in this way, a well-functioning political system will take such input into accountfor example, in parliamentary debates, in administrative reviews, or through immediate or long-term legislative changes. This type of participation refers to Political Participation II in our taxonomy and can be described as participation directly targeted at the political system (Chapter 2). It comes close to what others have called institutionalized participation (McLeod et al., 1999) or elite-directed participation (Inglehart, 1990).

This chapter examines whether and how citizens' participation in activities targeting the political system varies across generations and over time. First, we map out how frequently citizens participate in these types of activities and whether this changes over time. Next, we examine how political news exposure affects this type of participation. Finally, we also examine whether the potential effect of political news exposure is mediated through political interest, knowledge, and efficacy. This chapter focuses on non-election time, whereas we examine political participation during election time in Chapter 10. 


\section{Targeting the political system}

Citizens engage in activities targeting the political system in various ways, such as signing petitions, making donations, contacting politicians, and attending or inviting others to demonstrations. Based on their age and political socialization, citizens may differ in how familiar they are with certain types of political actions and how natural it seems to engage in them. Most activities that directly address the political system existed before the digital age; yet, today many of them can be performed via online platforms (Gibson \& Cantijoch, 2013; Theocharis, 2015). For some types of participation, the threshold to engage in politics has been lowered in the new digital age. For example, it is no longer necessary to sign petitions only on paper since there are online platforms available. And you no longer need to write letters to politicians or meet them face to face; instead, you may reach them via emails and social network sites. Hence, in some respects, participation targeted at the political system has become more easily accessible, especially for competent digital media users.

Across the five generations, Figure 6.1 reports the frequency of participation in relevant activities targeted at the political system over the past

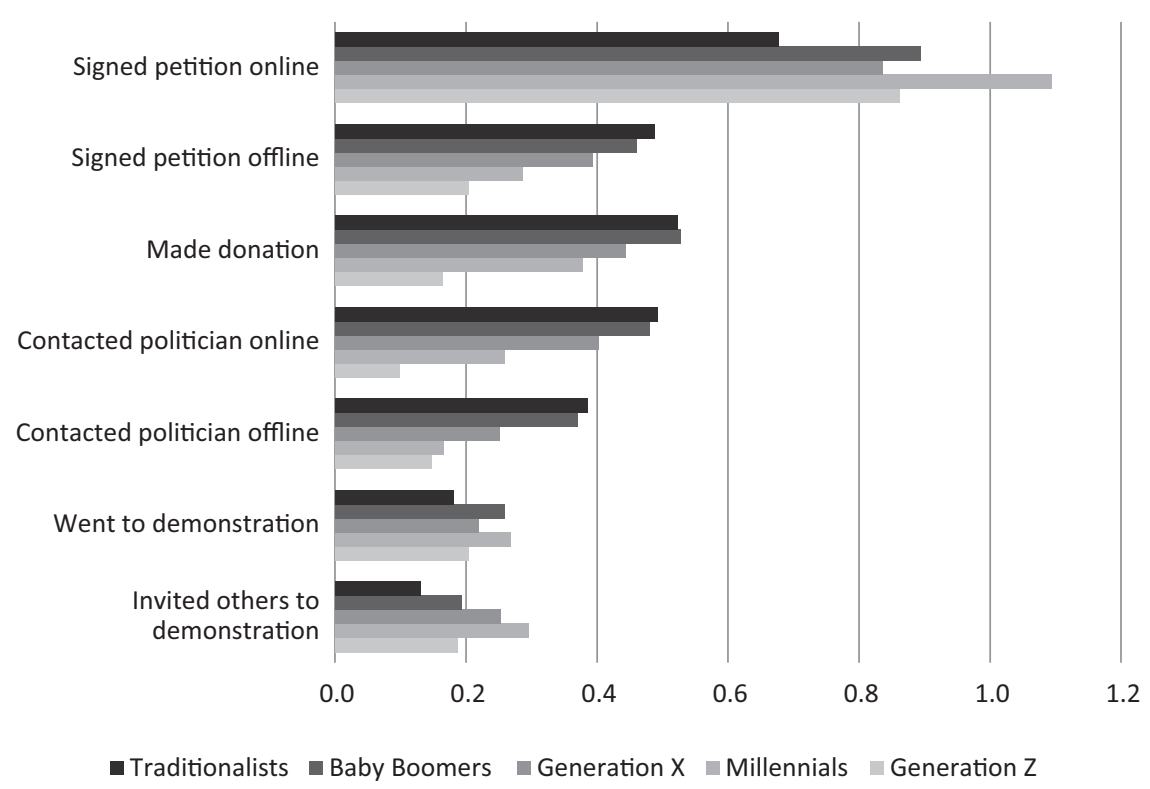

Figure 6.1 Frequency of participatory activities targeted at the political system (PP II) across generations

Notes. Measured in first online survey wave asking about participation during the past 12 months on a scale from 0 to 4 (or more) times. 
12 months as measured in the first survey wave. Frequencies range from 0 to 4 (or more) times. Signing petitions online is the most frequent type of participation, whereas signing petitions offline is less common. The second and third most frequent types of participation are donations and contacting politicians-again, with the online option being more popular. Citizens are least likely to participate in demonstrations or to invite others to join them. On average, citizens engaged in each of these activities one time or fewer during the past 12 months. Opportunity structures clearly matter for political participation: digital activities offer lower thresholds for participation and may therefore be more popular.

Though the patterns are similar across the five generations, we nevertheless see some variations. Millennials, for example, most often invite others to join demonstrations and to sign petitions online, whereas Traditionalists along with Baby Boomers most often sign petitions offline and contact politicians (both offline and online). These results suggest that the generations participate differently. An explanation from a generational perspective could be that different generations are raised under different societal circumstances, which may influence their preferred choice of activities. Growing up in times when direct contact with political actors was more common may explain why older generations still seek to get in touch with elected representatives. For younger generations, however, politicians appear more distant; connecting with other citizens to collect signatures may seem more effective (and convenient) to them.

Altogether, two things are clear. First, citizens' participation in activities targeted at the political system is generally low. During a period of 12 months (in non-election times), the political system only received a limited amount of participatory input from its citizens. Second, the different participatory activities are not equally popular across generations. In the following, we pay closer attention to whether the participatory levels for activities aimed at the political system are stable or differ over time.

Combining participatory activities targeted at the political system into an index, Figure 6.2 shows the average level of participation across generations over time. While we asked for frequency of participation in the past 12 months in the first survey wave, we asked about participation frequency in the past four months in the second and the fifth waves, which corresponds to the time periods between the waves. Naturally, the average frequency drops from the first wave to subsequent waves. Even so, we observe two interesting patterns.

First, older generations are more likely to participate in activities targeted at the political system than younger generations. Though the difference decreases over time, we still see indications that the difference is substantial, indicating that the youth participate less in this type of political activity. Second, if we focus on the second and fifth survey waves, which cover behaviour during the past four months, participation on average 


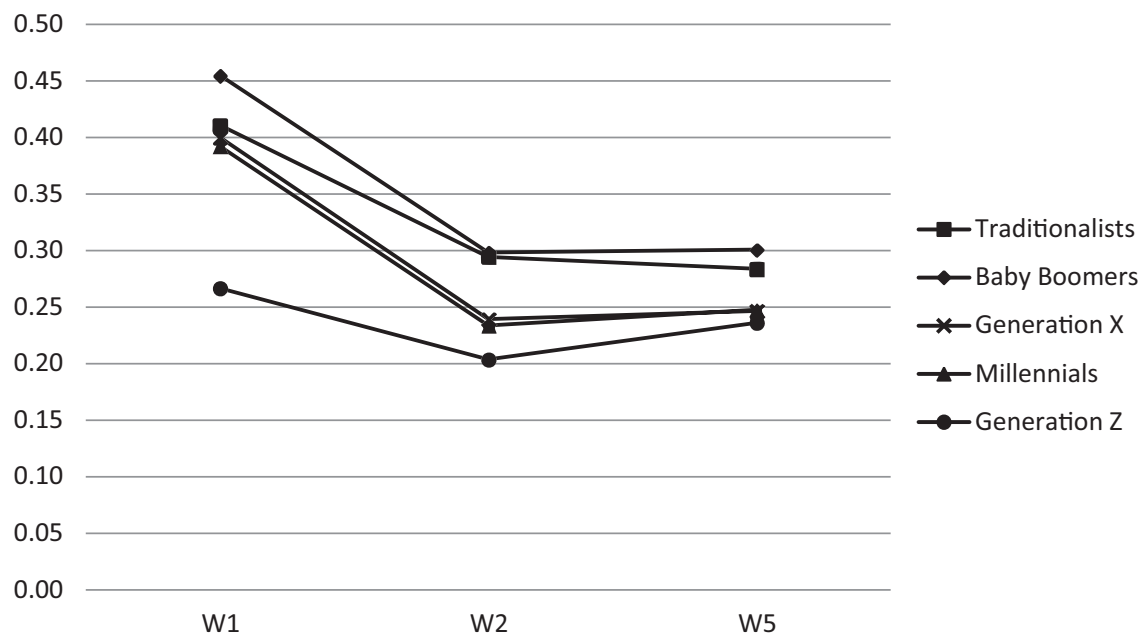

Figure 6.2 Average level of political participation targeted at the political system (PP II) over time across generations

Notes. Average levels of political participation II are higher in wave 1 since the reference period in the survey questions for this wave was the last 12 months, whereas for waves 2 and 5, it was the last four months.

seems quite stable. Despite the occurrence of an election between waves 2 and 5, we still find a high level of stability. Studies have suggested that political activity increases during an election campaign (Van Aelst \& De Swert, 2009), but the elections do not seem to influence activity in the months following, at least when it comes to activities targeting the political system. In Chapter 10, we turn more specifically to political participation during campaign time. An exception seems to be Generation Z, who show slightly more political activity targeting the political system in the postelection wave (wave 5). If we take this result into account together with similar patterns for political interest and efficacy that were examined in Chapter 5, we find an indication that elections may function as entry points into the political system for young citizens. It seems that Generation Z's level of participation approximates the levels of the two older generations, reducing the generation gap over time.

Taken together, these findings suggest that citizens rarely participate in activities targeted at the political system. During non-election times, the political system does not receive a great amount of participatory input from its citizens, no matter what participatory action we look at. This state of affairs may create disparities between those who make their voice heard and those who do not. 


\section{Participation targeting political system}

\section{The effect of political news exposure on activities targeting the political system}

One reason why citizens show different levels of activity when addressing the political system may be the political information they have gained in the news media. As argued in our Engagement-Participation-Information-Generation (EPIG) model (see Chapter 2), political information can function as a basis for political participation. We therefore explore whether receiving political information in the news media mobilizes citizens to participate politically, and we test for generational differences.

Overall, we find a positive influence of political news exposure on political participation targeted at the political system (see Table A6.1 in the Appendix). Figure 6.3 shows the marginal effects of exposure to political news on political participation targeting the political system. Both a static and a dynamic perspective are taken into account. In the static setting, we pool observations from the second and fifth survey waves and explore the correlation between political news exposure and participatory activities targeted at the political system while controlling for gender, education, and generation. In the dynamic setting, we utilize all three survey waves by including a lagged dependent variable in our models and thus examine changes in participation over time (for full models, see Appendix 6.1; for methodological details, see Chapter 3).

Overall, we find a positive effect of political news exposure in both the static and the dynamic models. The more often citizens are exposed to political news via news media, the more often they participate in activities targeted at the political system. However, not all generations benefit equally from their political news consumption. As seen in Figure 6.3, the relationship between political news exposure and political behaviours targeted at the political system is visible for all generations but the Traditionalists. Interestingly, in the more demanding dynamic models, we see that the four younger generations benefit positively from political news consumption. Even if we take their previous level of participation into account, following the news more closely makes them more likely to engage in political behaviours targeting the political system. Still, there are differences between the cohorts.

The positive effect of political news consumption is strongest for the youngest generation, Generation Z, and less so for the other four generations. This pattern holds for both the static and the dynamic models, being even more pronounced in the latter. This result suggests that exposure to political news has an especially strong effect on younger generations' behaviour. Furthermore, it shows that younger generations' use of political information from the news media can serve as an entry point into the political system despite changes in their news consumption patterns. For Traditionalists, political news consumption does not influence their level of political participation targeting the political system. Though they are the second 

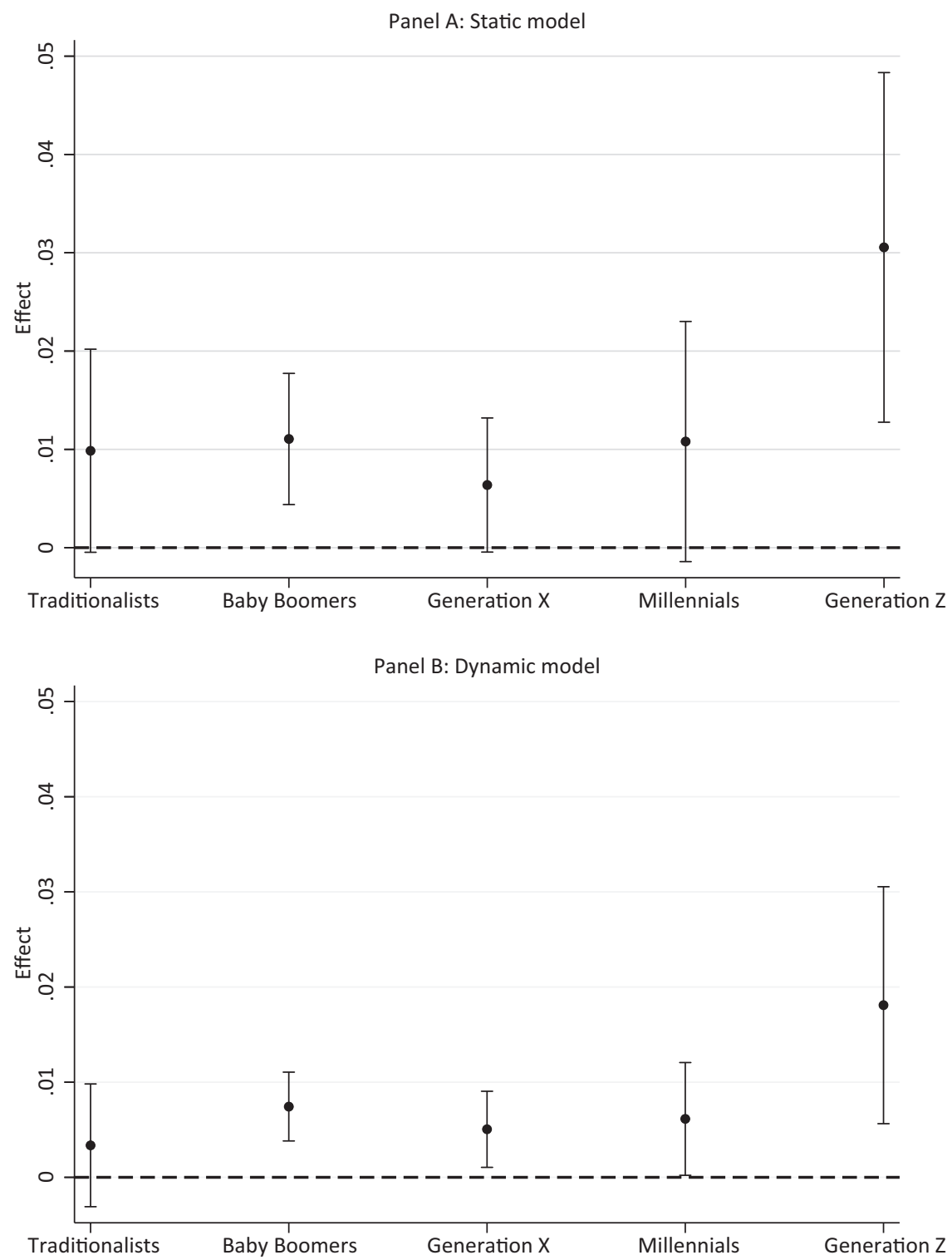

Figure 6.3 Marginal effects of exposure to political information in the news media on political participation targeted at the political system (PP II) across generations

Notes. The estimates are displayed with a 95 percent confidence interval. Bonferroni correction used to counteract the problem of multiple comparisons. Full models in the Appendix, Table A6.1. 
most active generation in this type of political participation, information from the news media does not seem to resonate with them (anymore). These results seem to reflect a life cycle, in which younger generations, still being in their formative years, are more open and curious and therefore more susceptible than older generations to political news affecting their political participation.

However, our data do not present a linear trend. Baby Boomers, for example, are the second-oldest generation and the generation most active in behaviours targeting the political system. A life-cycle perspective suggests that Baby Boomers' news consumption would affect their political participation only to a minor degree. However, the opposite is the case: Baby Boomers react strongly to political news, only outnumbered by Generation Z. This result may be due to a cohort effect, in which Baby Boomers, having grown up in times of political conflict and protest, even in later life stages hold the political system and its representatives accountable when receiving political information from the news media.

\section{Pathways to activities targeting the political system}

We now examine whether the positive impact of political news exposure on political behaviours targeting the political system, as suggested by the EPIG model (see Chapter 2), is mediated through the three dimensions of political engagement - that is, political interest, knowledge, and efficacy. In Chapter 5, we saw that exposure to political news does indeed have a positive effect on each of these three dimensions of political engagement, especially so for younger generations. The following examination will elucidate whether this effect translates into actual political behaviours targeting the political system.

In general, when we include political interest, knowledge, and efficacy into our models, the relationship between political news exposure and participatory activities targeted at the political system disappears (see Table A6.1, Models 6.4 and 6.8 in the Appendix). These findings give a first indication that political interest, knowledge, and efficacy mediate the effect of political news exposure on participatory activities targeting the political system and thereby support the suggested pathway of the EPIG model. We now take a closer look at this mediation. In order to examine the routes to participation more elaborately, we did a path model using multiple-group analysis for structural equation modelling. Again, we used both a static and a dynamic perspective. Table 6.1 lists the findings across generations for the three engagement measures: political interest, knowledge, and efficacy.

We first calculated the overall indirect effects across generations and found that indirect effects through political interest, knowledge, and efficacy were overall positive, in both the static and the dynamic models. This finding suggests that being exposed to political news makes citizens more politically interested, knowledgeable, and efficacious, which partly explains 
Table 6.1 Indirect effects of exposure to political information in the news media on political participation II

\begin{tabular}{|c|c|c|c|c|c|c|}
\hline & \multicolumn{3}{|l|}{ Static } & \multicolumn{3}{|l|}{ Dynamic } \\
\hline & Interest & Knowledge & Efficacy & Interest & Knowledge & Efficacy \\
\hline Overall & $\begin{array}{l}.009 * * * \\
(.000)\end{array}$ & $\begin{array}{l}.001 * * * \\
(.000)\end{array}$ & $\begin{array}{l}.004 * * * \\
(.000)\end{array}$ & $\begin{array}{l}.003 * * * \\
(.000)\end{array}$ & $\begin{array}{l}.001 * * * \\
(.000)\end{array}$ & $\begin{array}{l}.001 * * * \\
(.000)\end{array}$ \\
\hline Traditionalists & $\begin{array}{l}.007 * * * * \\
(.001)\end{array}$ & $\begin{array}{l}.001 \\
(.000)\end{array}$ & $\begin{array}{l}.003 * * * \\
(.001)\end{array}$ & $\begin{array}{l}.002 * * * \\
(.001)\end{array}$ & $\begin{array}{l}.001 \\
(.000)\end{array}$ & $\begin{array}{l}.001 * * \\
(.000)\end{array}$ \\
\hline Baby Boomers & $\begin{array}{l}.008 * * * \\
(.001)\end{array}$ & $\begin{array}{l}.001 \\
(.000)\end{array}$ & $\begin{array}{l}.004 * * * \\
(.000)\end{array}$ & $\begin{array}{l}.003 * * * \\
(.000)\end{array}$ & $\begin{array}{l}.001 * \\
(.000)\end{array}$ & $\begin{array}{l}.001 * * * \\
(.000)\end{array}$ \\
\hline Generation Y & $\begin{array}{l}.008 * * * \\
(.001)\end{array}$ & $\begin{array}{l}.002 * \\
(.000)\end{array}$ & $\begin{array}{l}.004 * * * \\
(.001)\end{array}$ & $\begin{array}{l}.003 * * * \\
(.001)\end{array}$ & $\begin{array}{l}.001 * \\
(.001)\end{array}$ & $\begin{array}{l}.001 * * \\
(.000)\end{array}$ \\
\hline Millennials & $\begin{array}{l}.013 * * * \\
(.001)\end{array}$ & $\begin{array}{l}.002 * \\
(.000)\end{array}$ & $\begin{array}{l}.008 * * * \\
(.001)\end{array}$ & $\begin{array}{l}.004 * * * \\
(.001)\end{array}$ & $\begin{array}{l}-.002 * \\
(.001)\end{array}$ & $\begin{array}{l}.003 * * * \\
(.001)\end{array}$ \\
\hline Generation Z & $\begin{array}{l}.012 * * * \\
(.002)\end{array}$ & $\begin{array}{l}.002 \\
(.000)\end{array}$ & $\begin{array}{l}.007 * * * \\
(.002)\end{array}$ & $\begin{array}{l}.005 * * \\
(.002)\end{array}$ & $\begin{array}{l}-.001 \\
(.001)\end{array}$ & $\begin{array}{l}.003 * \\
(.001)\end{array}$ \\
\hline
\end{tabular}

Notes. SEM without/with group comparison. Unstandardized coefficients. Standard errors in parentheses. Models include gender and education as controls. Dynamic models also include a lagged dependent variable.

$* \mathrm{p}<.05, * \mathrm{p}<.01, * * \mathrm{p}<.001 . \mathrm{N}_{\text {Static }}=3,490 / 10,470 . \mathrm{N}_{\text {Dynamic }}=3,490 / 6,980$.

why they engage in behaviours targeting the political system. In general, for the younger generations, the indirect effects were larger in the static perspective, suggesting that political information from news media transforms more often into interest and, subsequently, political action. While we find indications of a positive indirect effect of political interest and efficacy for all generations, increased political knowledge through political news consumption did not translate into political participation for all generations. When we control for previous levels of participation, Traditionalists' and Generation Z's political participation seems unaffected by an increase in political knowledge through news consumption. A slight positive indirect effect is found for Baby Boomers and Generation X, while Millennials become less politically active the more political-news consumption increases their political knowledge.

Taken together with a non-significant, negative indirect effect for Generation $\mathrm{Z}$, we may see a pattern where for younger generations, knowledge gained from political news does not automatically translate into higher political action. A life-cycle perspective would suggest that when the younger generations become older, they will learn how to channel knowledge into action. A cohort perspective suggests a future in which learning about general political issues from news consumption no longer makes 
citizens politically active. In sum, however, we do see that political interest and efficacy, in particular, have a pervasive indirect effect on participation that targets the political system directly. This finding provides us with a deeper understanding of how political news use contributes to a more active citizenship.

\section{Summing up}

In this chapter we explored how exposure to political information in the news media may mobilize citizens to participate in activities that target the political system. Since these activities are closely linked to the political system, this type of participation is especially important for a healthy democracy. If political actors and institutions are to be responsive, citizens must have the means to make their voices heard. Contacting politicians, signing petitions, or taking part in demonstrations are a means towards this end. This chapter uncovered that not every citizen makes use of these means but finds that the news media can play an important role in sparking political activity among the citizenry.

This finding supports the suggested route in our EPIG model (Chapter 2); the news media help citizens voice their opinions to the political system. This bridge between citizens and their political leaders, which was already discussed by scholars like Verba and Nie in the 1970s, still works. More importantly, we find that the younger generations, which are the least active in behaviours targeting the political system, are the ones benefitting the most (or at least as much as older generations) from exposure to political news media. Thus, exposure to political news can help narrow generational gaps in political behaviours targeting the political system.

However, two findings from the chapter blur this positive picture. First, given the low levels of political participation targeted at the political system, the participatory contribution of the news media is also minimal. Second, news media consumption contributes to participation by making citizens more politically interested and efficacious but barely by making them more knowledgeable. Though enthusiasm and the feeling of being capable to act politically are important prerequisites of participation, informed political decisions are a core element in a democracy (Downs, 1957). We find only a little evidence that news media increase political knowledge in a way that makes citizens participate more actively in behaviours targeted at the political system. 


\section{Participation targeting the local community}

Citizens' participation in their local communities is an important part of a healthy democracy. In this chapter we show that local community participation is highest among the older generations and lowest among the youngest. We also show that political news exposure has a positive effect on this type of political participation, especially so for the Baby Boomers, being mediated through political interest and efficacy.

In this chapter we turn our attention to participation in the local communityor van Deth's (2014) Political Participation III (PP III). Political citizens focus on matters directly connected to the political system, as described in Chapter 6. As social beings, however, citizens are part not only of a political sphere but also of the local community in which they live. Their quality of life depends on a number of matters related to their local environment, be it the sports club, the church, a women's organization of which they are members, the school their kids attend, or the help they can expect from their neighbours when needed. Decisions on such local community matters are often not made by distant political representatives; rather, they are dealt with by citizens themselves. When they participate in local community matters, people have the chance to actively shape their everyday surroundings and more quickly and directly see the effects of their actions.

From a democratic viewpoint, citizens' political activities in the local community may have positive effects on the political system. Taking part in their community can prepare citizens to participate in activities addressing the political system more directly. As described by John Stuart Mill (1861, p. 46), participation among equal citizens trains people to weigh interests that are not their own and to make decisions that are not purely driven by private partialities. Equal citizens are neighbours, fellow members of a citizens' initiative, or opponents on a local, political discussion board. Van Deth's (2014) decision rule for Political Participation III reflects this line of 
reasoning when stating that an 'activity [is] aimed at solving collective or community problems' (p. 358). By having to take into account other, different, or even conflicting arguments on a political matter, people experience the idea of a common public good much more closely and directly (Zakaras, 2007). Thus, political participation at the local community level—for instance, by volunteering in a local organization or attending and supporting meetings and projects in the local community (Zukin et al., 2006)—can be a breeding ground for a participatory democracy. Participation within a local community is more than just addressing the political system at the local level (Verba et al., 1995). Participation in such activities is important for the health of both the community and society more broadly since it fosters social capital (Putnam, 2000). As argued by Shah, Cho, Eveland, and Kwak (2005, p. 533), this type of participation 'plays a central role in the health and functioning of democratic societies by channelling collective action toward community building.'

This chapter examines whether and how citizens' participation in activities targeting the local community varies across generations and over time. First, we map out the frequency of citizens' political participation in the local community and whether this changes over time. Next, we examine how political news exposure affects this type of participation. Finally, we also examine whether the potential effect of political news exposure on local community participation is mediated through political interest, knowledge, and efficacy, as suggested by the Engagement-Participation-InformationGeneration (EPIG) model (see Chapter 2).

\section{Being involved with the local community}

Citizens are involved in their local communities in different ways. Some citizens participate in local organizations, such as an urban gardening community, or attend local meetings. Others prefer to engage online on social media sites, for example, by collecting community updates in a Facebook group. Common to these activities is their focus on the local community and thus on citizens' daily interactions with each other. People's motives to get involved may vary. Some settle in a community and involve themselves in an effort to shape it for the better, while for others, local involvement is a pastime activity or a way to get to know the neighbours better. Some citizens may even deliberately decide not to get involved-for instance, if they are living in the local community only temporarily. Such motivations may shift over a person's lifespan. Students, having moved from home to a new city, where they will stay for only a few years before taking up their first job in a different city, will have different motives for getting involved in local community matters than the young parents who have settled in a neighbourhood where they want their children to have a safe and rewarding upbringing. It therefore makes sense to investigate whether participation targeted at local community issues differs between the five generations we are looking at. 


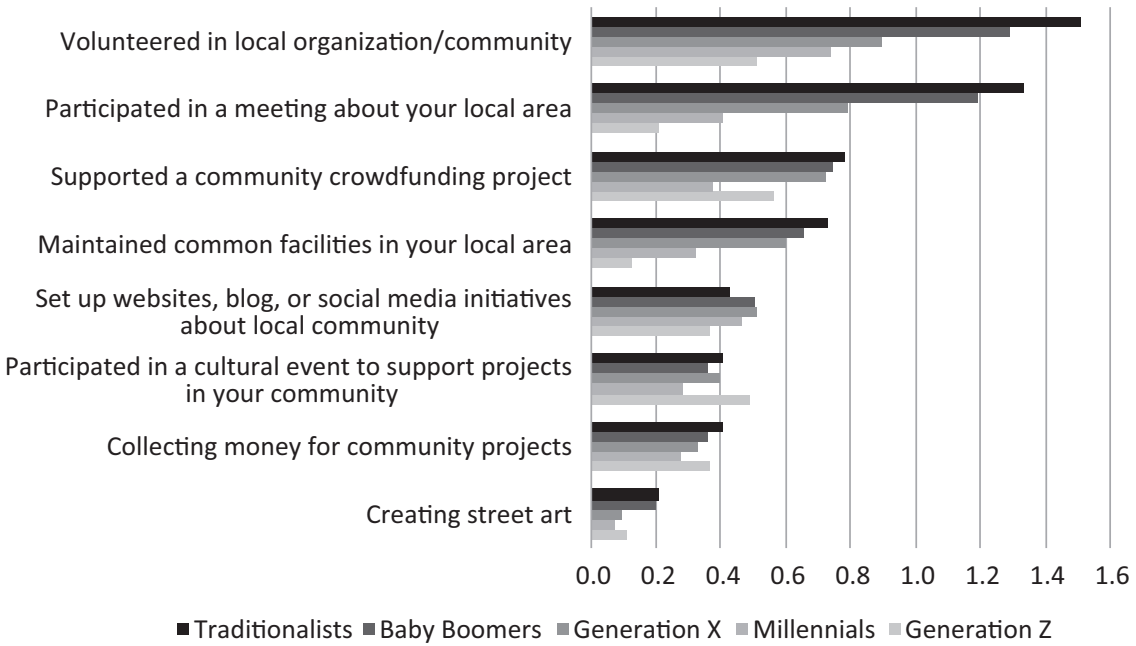

Figure 7.1 Frequency of participatory activities targeted at the local community (PP III) across generations

Notes. Measured in first survey wave asking about participation during the past 12 months on a scale from 0 to 4 (or more) times.

Across the five generations, Figure 7.1 reports the frequency of local community participation over the past 12 months as measured in the first survey wave. The frequency ranges from 0 to 4 (or more) times. Volunteering in a local organization is the most frequent way of participating in one's local community, followed by attending a meeting about the local area, supporting a community crowdfunding project, and maintaining common facilities in the local area. Common to these activities is that they are done mostly by the older generations. By contrast, activities such as setting up online initiatives about the local community, participating in cultural events to support a project in the local community, collecting money for a community project, and creating street art, do not entail the same generational differences. To assess age versus cohort differences, it is worth looking at participation frequencies among Millennials and Generation Z. Notable differences are visible when it comes to cultural and beneficiary activities.

Generation $\mathrm{Z}$ seems to be more motivated to support local crowdfunding and other fundraising and to participate in cultural events. These activities are often spontaneous and oriented towards a singular event. Millennials, in turn, participate slightly more in activities that point to a longer lasting engagement with the local community-for example, by setting up citizen initiatives online or maintaining local facilities. Though differences are minor, they point to higher levels of local community participation when 


\section{Participation targeting local community}

people are certain about their future location compared to a younger generation that is still being educated. The low level of local community participation among young people may also indicate that when people have a more permanent job and have had more experience with political participation, they also become more engaged in their local community.

In sum, two patterns stand out. First, as expected, the older generations participate more in political activities targeting the local community than the younger generations. But second, the older generations are much more active than the younger generations in only a few specific activities, which suggests that younger citizens engage nonetheless in local community affairs.

Across generations, Figure 7.2 shows the average level of a combined index of the participatory activities targeting the local community over time. While we asked for frequency of participation in the past 12 months in the first survey wave, we asked about participation frequency in the past four months in the second and the fifth waves, which corresponds to the time periods between the waves. Naturally, the average frequency drops from the first wave to subsequent waves. Even so, we observe how older generations are more likely than younger generations to participate in activities targeting the local community. These generational differences remain the same over time.

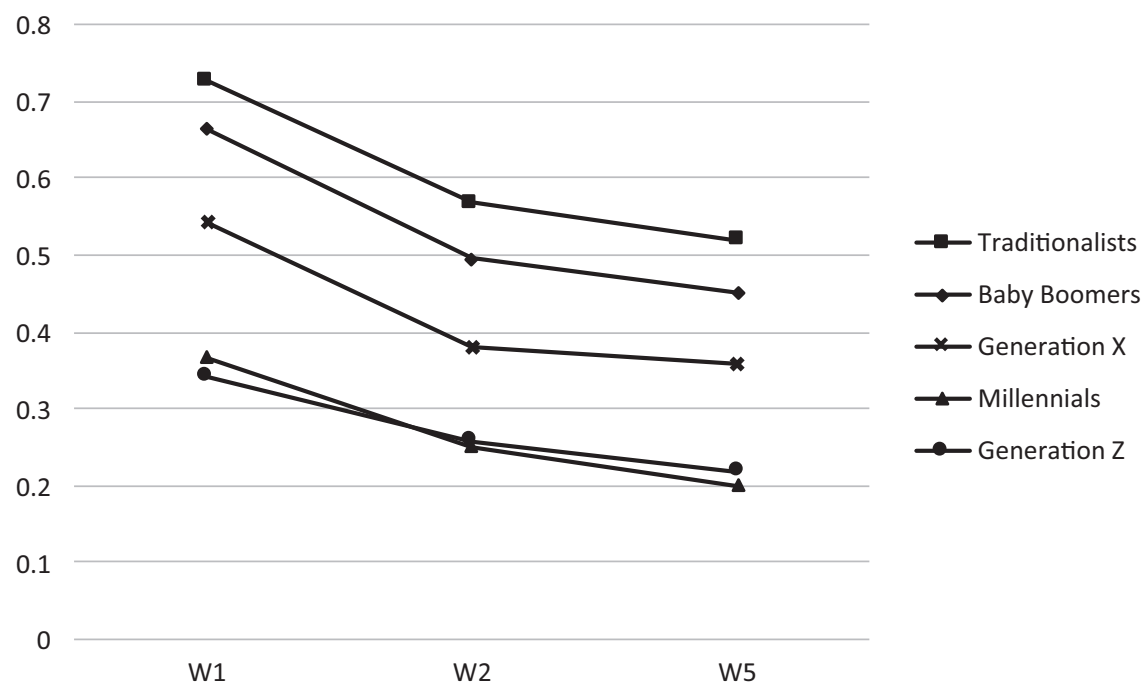

Figure 7.2 Average level of political participation targeted at the local community (PP III) over time across generations

Notes. Average levels of participation are higher in wave 1 since the reference period in the survey questions for this wave was the last 12 months, whereas for waves 2 and 5 , it was the last four months. 
Taken together, we see that citizens do participate in activities targeting the local community. However, older citizens participate in such activities to a higher extent than younger generations.

\section{The effect of political news exposure on local community participation}

As argued in our EPIG model (see Chapter 2), political information can function as a basis for political participation. It might also fulfil this function in regard to behaviours that target the local community. By using the news media, citizens obtain political information that may have positive consequences for their political involvement. Previous studies have confirmed that newspaper reading, local news viewing, and internet use for informational purposes are positively related to local community participation (McLeod et al., 1996, 1999; Shah et al., 2001). However, little is known about how these effects vary across generations. In the following, we explore whether receiving political information in the news media mobilizes citizens to participate in political activities targeted at the local community and test whether such effects differ between generations.

Overall, we find a positive influence of political news exposure on political participation targeted at the local community (see Table A7.1 in the Appendix). Figure 7.3 reports the marginal effects of exposure to political news on local community political participation. Both a static and a dynamic perspective are taken into account. In the static setting, we pool observations from the second and fifth survey waves and explore the correlation between political news exposure and local community participation while controlling for gender, education, and generation. In the dynamic setting, we utilize all three survey waves by including a lagged dependent variable in our models and thus examine changes in participation over time (see Table A7.1 in the Appendix for full models; for methodological details, see Chapter 3).

In general, we find a positive effect of political news exposure on local community participation targeting the local community in both the static and the dynamic modes. In other words, the more citizens are exposed to political information in the news media, the more likely they are to participate in political activities targeting the local community. Not all generations benefit equally from using the news media. As seen in Figure 7.3, the relationship between political news exposure and local community participation is strongest for Baby Boomers and less so for the other four generations. This pattern holds both for the static and the dynamic models. Baby Boomers grew up in politically fairly stable and economically prosperous times. That early period affects their societal engagement: they are the first generation to use their newly won spare time for voluntary societal engagement (Howe \& Strauss, 2007; Mangelsdorf, 2014). Based on our findings, their involvement is ongoing. They are still the ones who pick up information from the news media and act upon it voluntarily and politically. This result 


\section{Participation targeting local community}
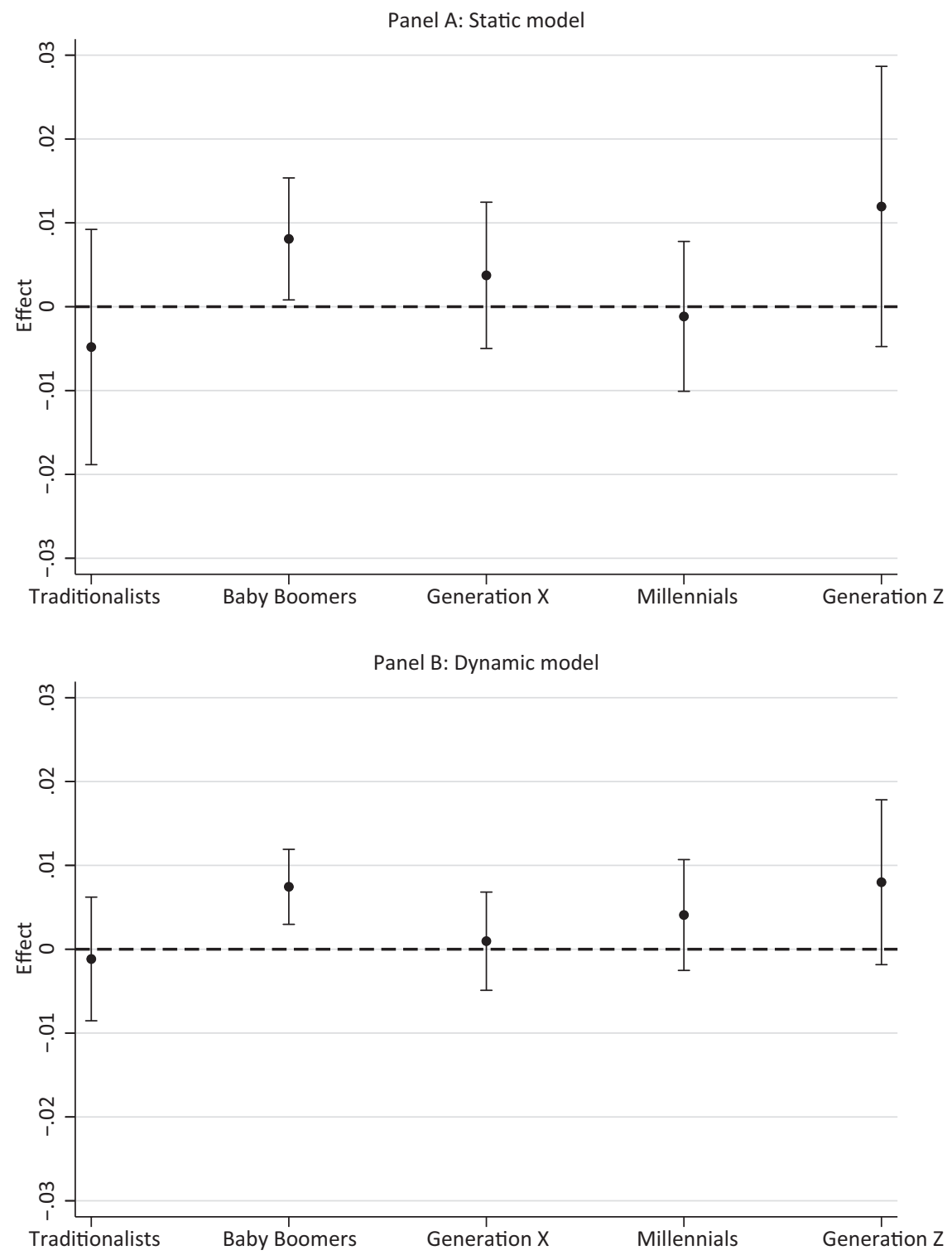

Figure 7.3 Marginal effects of exposure to political information in the news media on political participation targeted at the local community (PP III) across generations

Notes. The estimates are displayed with a 95 percent confidence interval. Bonferroni correction used to counteract the problem of multiple comparisons. Full models in the Appendix, Table A7.1. 
is in line with the results in Chapter 4, where we found that only for Baby Boomers is local community participation a predictor of political news use. Thus, for Baby Boomers, a functioning circle exits in which political news use affects their participation at the community level, which, in turn, leads to more political news consumption. In this case, the EPIG model provides a useful explanation for how political engagement, news media use, and political participation are related.

For all other generations, participation on a local level remains unaffected by their political news consumption. This result suggests a specific cohort effect, where Baby Boomers' upbringing may be the core determinant of their strong reaction to news media information when it comes to their local community participation. Growing up in the heyday of local newspaper subscriptions and strong, local citizen initiatives seems to have shaped the way Baby Boomers respond to new information about politics in the media even today.

Though our descriptive results do not indicate high local orientation for the youngest generation, Generation Z, and though they include statistical uncertainty, we should not neglect the comparatively strong relationship between news media consumption and local community participation for this generation. A potential reason may be that many still live in the community where they grew up, with Baby Boomers as parents, which, on the one hand, points towards a life-cycle effect. On the other hand, the results for local participation are similar to the results found in Chapter 5, where Baby Boomers and Generation $\mathrm{Z}$ were also the two generations whose participation targeted at the political system (PP II) was most clearly mobilized by news media consumption; this result points instead to a potential cohort effect.

\section{Pathways to political activities targeting the local community}

We now examine whether the positive impact of political news exposure on local community political participation-as suggested by the EPIG model (see Chapter 2)-is mediated through the three dimensions of political engagement: political interest, knowledge, and efficacy. In Chapter 5, we saw that exposure to political news does indeed have a positive effect on each of these three dimensions of political engagement. Thus, the following examination will provide us with insight into whether this effect translates into actual political behaviours targeting the local community.

In order to examine the pathways to local political participation, we did a path model using multiple-group analysis for structural equation modelling. Again, we did this both from a static and from a dynamic perspective. Table 7.1 lists the overall indirect effects and the findings across generations for the three engagement measures: political interest, knowledge, and efficacy. Overall, political interest generally acts as a positive significant mediator in a static setting and in a dynamic setting. Furthermore, an indirect effect of political knowledge and efficacy exists across generations, though smaller coefficients 
Table 7.1 Indirect effects of exposure to political information in the news media on political participation III

\begin{tabular}{|c|c|c|c|c|c|c|}
\hline & \multicolumn{3}{|l|}{ Static } & \multicolumn{3}{|l|}{ Dynamic } \\
\hline & Interest & Knowledge & Efficacy & Interest & Knowledge & Efficacy \\
\hline Overall & $\begin{array}{l}.006^{* * * *} \\
(.000)\end{array}$ & $\begin{array}{l}.000 * * * \\
(.000)\end{array}$ & $\begin{array}{l}.001 * * * \\
(.000)\end{array}$ & $\begin{array}{l}.002 * * * \\
(.000)\end{array}$ & $\begin{array}{l}.001 * \\
(.000)\end{array}$ & $\begin{array}{l}.000 * \\
(.000)\end{array}$ \\
\hline Traditionalists & $\begin{array}{l}.004 * * * \\
(.001)\end{array}$ & $\begin{array}{l}-.001 \\
(.001)\end{array}$ & $\begin{array}{l}.004 \\
(.000)\end{array}$ & $\begin{array}{l}.001 \\
(.001)\end{array}$ & $\begin{array}{l}.000 \\
(.001)\end{array}$ & $\begin{array}{l}-.000 \\
(.000)\end{array}$ \\
\hline Baby Boomers & $\begin{array}{l}.005^{* * * *} \\
(.001)\end{array}$ & $\begin{array}{l}-.001 * * \\
(.001)\end{array}$ & $\begin{array}{l}.001 * * * \\
(.000)\end{array}$ & $\begin{array}{l}.002 * * * * \\
(.001)\end{array}$ & $\begin{array}{l}.000 \\
(.000)\end{array}$ & $\begin{array}{l}.001 * \\
(.000)\end{array}$ \\
\hline Generation Y & $\begin{array}{l}.006^{* * * *} \\
(.001)\end{array}$ & $\begin{array}{l}-.001 \\
(.001)\end{array}$ & $\begin{array}{l}.002 * * * * \\
(.001)\end{array}$ & $\begin{array}{l}.003 * * \\
(.001)\end{array}$ & $\begin{array}{l}.000 \\
(.001)\end{array}$ & $\begin{array}{l}.001 * \\
(.000)\end{array}$ \\
\hline Millennials & $\begin{array}{l}.001 \\
(.001)\end{array}$ & $\begin{array}{l}-.002 \\
(.001)\end{array}$ & $\begin{array}{l}.002 * \\
(.001)\end{array}$ & $\begin{array}{l}.000 \\
(.001)\end{array}$ & $\begin{array}{l}.000 \\
(.001)\end{array}$ & $\begin{array}{l}.001 \\
(.001)\end{array}$ \\
\hline Generation Z & $\begin{array}{l}.005^{* * *} \\
(.002)\end{array}$ & $\begin{array}{l}-.003 \\
(.002)\end{array}$ & $\begin{array}{l}.002 \\
(.002)\end{array}$ & $\begin{array}{l}.001 \\
(.002)\end{array}$ & $\begin{array}{l}-.001 \\
(.002)\end{array}$ & $\begin{array}{l}.000 \\
(.002)\end{array}$ \\
\hline
\end{tabular}

Notes. SEM without/with group comparison. Unstandardized coefficients. Standard errors in parentheses. Models include gender and education as controls. Dynamic models also include a lagged dependent variable.

$* \mathrm{p}<.05, * * \mathrm{p}<.01, * * * \mathrm{p}<.001 . \mathrm{N}_{\text {Static }}=3,490 / 10,470 . \mathrm{N}_{\text {Dynamic }}=3,490 / 6,980$.

suggest this indirect relationship to be less pronounced than the mediation through political interest. Turning to differences between generations in the dynamic setting, we see that particularly the political interest of Baby Boomers and Generation $\mathrm{X}$ is positively affected by their political news consumption and therefore contributes to higher levels of local community political participation. No indirect effect, however, was found for political knowledge. This finding indicates that an increase in knowledge through political news consumption does not mobilize political participation at the local level.

Though the results are similar to those in Chapter 5, we have to keep in mind that we measure knowledge about current political affairs at a national and an international level, which may be of less relevance for participation in local activities. As was the case with political interest, it is once again the Baby Boomers and Generation X whose participation on a community level is strengthened because their political news consumption contributes to their feeling of being politically efficacious. The participation of Millennials and Generation $\mathrm{Z}$ in activities that address community issues, however, cannot be explained by an increase in political interest, knowledge, or efficacy through news media use.

Hence, though our results in Chapter 6 supported the idea suggested in the EPIG model of an indirect relationship between news media consumption 
and participation targeting the political system through political engagement, this indirect relationship is less pronounced for local community participation, especially among the younger generations.

\section{Summing up}

In this chapter we examined citizens' political participation in their local communities and the importance of exposure to political information in this regard. Local participation is valuable in itself since it determines the circumstances under which people live their lives on an everyday, practical level. Furthermore, this type of participation can prepare for other types of participation since it trains interaction with other citizens and strengthens political decision-making that is more public- than self-minded (Mill, 1861).

Our results show that participation in the local community is highest among the older generations and lowest among the youngest. This result may reflect that the generations are at different stages of their lives. Members of the younger generations may be about to fly-or have just flown-from the nest and thus have a lower interest in the local community, whereas older generations have settled and are thus more interested and motivated to involve themselves in the local community. News media consumption changes little in this pattern. While it has a positive effect on local community participation for Baby Boomers, all other generations are less affected. This finding speaks for a cohort rather than a life-cycle effect. A life-cycle effect would be visible if we were to find younger generations more affected by political news consumption, with older generations being less responsive. Only Baby Boomers are conspicuous, which suggests that they are a special cohort, indicating that political socialization in the formative years of a generation determines the relationship between political news consumption and participation, even at the local level.

We furthermore find an indirect effect through political interest and efficacy, both of which mediate the relationship between political news exposure and political participation targeting the local community. Thus, citizens' level of political interest and the feeling of being capable of participating are important determinants for local community participation. Knowledge does not mediate the relationship. However, this result may be due to the way knowledge is measured. We focus only on current affairs knowledge on a national level, while it may be that knowledge about current affairs on the local level mediates the relationship. Likewise, if we had measured local political news exposure, the relationship might have been even stronger.

All in all, the EPIG model is useful to understand local political participation. The model may have been even more useful had we measured news consumption and knowledge with a stronger relation to the local community itself. 


\section{Being politically motivated}

Citizens do not need to target the political system or their local community in order to act politically. They can also do so by participating in other types of politically motivated activities, such as boycotting specific products or expressing opinions on social media sites. In this chapter we show that participation in behaviours that are non-political but politically motivated is highest among the middle generations (Baby Boomers, Generation X, and Millennials) and lowest among the oldest generation (the Traditionalists) and the youngest generation (Generation Z). We show that political news exposure has a positive effect on this type of political participation, especially so for the Baby Boomers and Generation Z. This effect seems to be the result of an indirect effect mediated through political interest and efficacy.

We now turn our attention to non-political activities that are nonetheless politically motivated and therefore considered a specific type of political participation. These are the types of activities that van Deth (2014) labels Political Participation IV (PP IV). This somewhat unorthodox categorization emerged due to recent changes in the political landscape. Over the last two decades, citizens discovered new ways of expressing their political goals and viewpoints, believing that such expressions can result in real-world changes (Anduiza, Perea, Jensen, \& Jorba, 2012; Ekström \& Östman, 2015; Ratto \& Boler, 2014; Stolle et al., 2005; Xenos et al., 2014). The increase in buying or boycotting certain products is an example of this new trend of individual behaviour (i.e., one person boycotting one product), which in and of itself has little impact on the resolution of a political or societal problem, but when it becomes part of larger scale behaviour (i.e., a mass of people boycotting unethically produced products), it has the potential to alter real-world developments (Micheletti, Stolle, \& Follesdal, 2004).

The emergence of these new participatory actions was linked with new means of political expression, mostly — but not only-in the digital sphere, 
which are (1) low cost in terms of time and energy and (2) easily spread among interested citizens. To some extent, this development is related to the globalization of political participation: while previously citizens' own, national political systems or local communities were the targets of their political actions, new forms of participation are aimed at more-diffuse targets and entail more-uncertain political outcomes. Some scholars have coined such activities 'unconventional participation' (Linssen et al., 2014; see Pitti, 2018), distinguishing them from 'traditional' types of participation. Others have called them 'online participation' (e.g., Bakker \& de Vreese, 2011; Gil de Zúñiga et al., 2012), stressing the digital nature of many such activities. The latter has contributed to giving these new forms of participation a reputation of being slacktivist (i.e., feel-good activities involving little effort or commitment), mostly ineffective, and done for narcissistic reasons (Morozov, 2009). Nonetheless, such new forms of participation can be effective, are fuelled by various motivations, and though they can be conducted with the help of digital media, they need not be (Van Deth, 2014; Dennis, 2019; Theocharis \& Van Deth, 2016).

A common denominator of these new forms of participation is that they utilize behaviours that are per se non-political to express or pursue political goals—and as such these behaviours are politically motivated. They are mostly part of citizens' everyday lives, such as shopping, wearing clothes, or sharing information on social media but get a political twist if performed with political motivation. Hence, behaviours and practices are considered political participation if people are motivated by political or ethical considerations or wish to cause societal change 'either with or without relying on the political system' (Stolle et al., 2005, p. 255). Such non-political (i.e., not relying on the political system) but at the same time politically motivated behaviours include boycotting products, wearing clothes with political statements, and sharing information on social media sites.

This chapter examines whether and how citizens' participation in these non-political, politically motivated practices varies across generations and over time and how political news exposure affects this type of participation. First, we map out the frequency of citizens' non-political, politically motivated participation and whether this changes over time. Next, we examine how political news exposure affects this type of participation. Finally, we also examine whether the potential effect of political news exposure is mediated through political interest, knowledge, and efficacy.

\section{Non-political but politically motivated behaviours}

A range of participatory behaviours exists that are targeted neither directly at the political system nor the local community. Nevertheless, when someone wears a shirt bearing the words 'Nuclear power? No thanks!,' carries a tote bag stating 'This is NOT plastic,' or changes pictures on his or her social media profile to express support for a political cause, such behaviours 
Bought or boycotted products for political, ethical, or environmental reasons

Shared posts by others about a political or societal issue on Facebook or similar social media sites

Expressed your opinion in a post about a political or societal issue on Facebook or similar social media sites

Worn a badge, other accessories, or clothes with a political message

Initiated a political discussion or supported a political issue, e.g., by creating a group or donating money to a political project or event

Changed personal information or picture on your social media profile information because of a political or societal issue

- Traditionalists

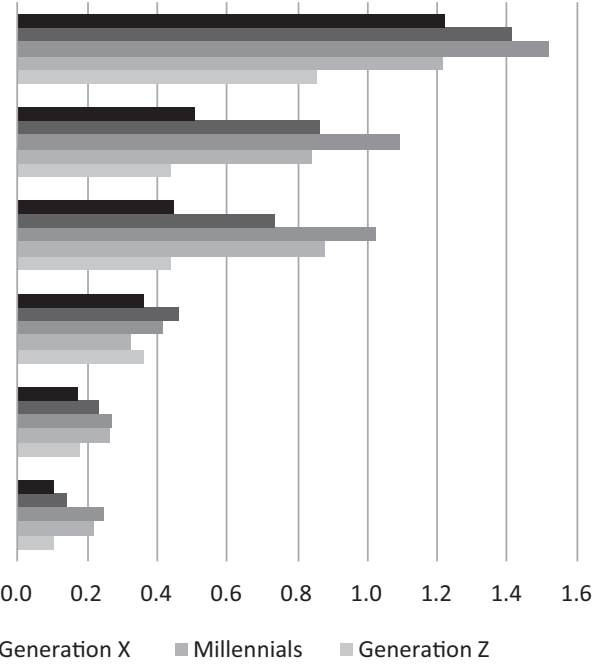

Figure 8.1 Frequency of participation in non-political but politically motivated behaviours (PP IV) across generations

Notes. Measured in first survey wave asking about participation during the past 12 months on a scale from 0 to 4 (or more) times

are politically motivated. They send a signal about a person's political stand. The question is, do these participatory practices vary across generations?

Across the five generations, Figure 8.1 shows the frequency of non-political but politically motivated participation over the past 12 months as measured in the first survey wave. The frequency ranges from 0 to 4 (or more) times. Buying or boycotting products for political, ethical, or environmental reasons is the most frequent behaviour. These actions are followed by expressing one's own opinion or sharing others' posts about a societal or political issue on a social media site. It is less common to wear badges, other accessories, or clothes with a political statement or, on social media sites, to initiate a discussion or change personal information or pictures because of a political or societal issue.

In general, Generation X most often engage in these types of practices, followed by Baby Boomers and Millennials. Across generations, Figure 8.2 reports the average level of a combined index of the non-political but politically motivated participatory practices over time. While we asked for participation frequency in the past 12 months in the first survey wave, we asked about participation frequency in the past 4 months in the second and the fifth waves, which corresponds to the time periods between the waves. Naturally, the average frequency drops from the first wave to subsequent waves. Even so, we see clear generational differences. Generation X, Baby Boomers, and Millennials are the most active, whereas the oldest generation, the 

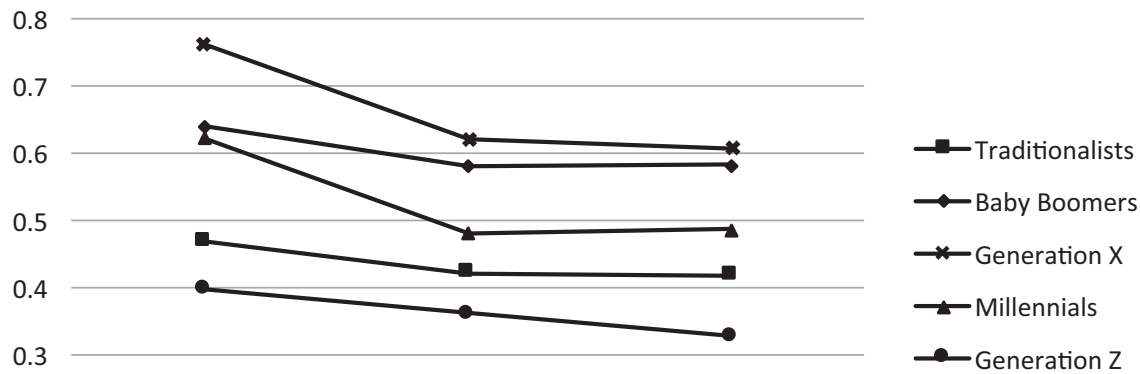

0.2

0.1

0
W1
W2
W5

Figure 8.2 Average level of participation in non-political but politically motivated behaviours (PP IV) over time across generations

Notes. Average levels of participation are higher in wave 1 since the reference period in the survey questions for this wave was the last 12 months, whereas for waves 2 and 5 , it was the last four months.

Traditionalists, and the youngest generation, Generation Z, are the least active. These generational differences remain the same over time.

Generation X have been characterized as independent and autonomous. They have less faith in promises made in politics or about the economy and are known as the first generation for whom political protest against existing power structures in society was regarded as an appropriate means of not only political but also personal self-expression (Mangelsdorf, 2014, see Chapter 2). Compared to earlier generations, Generation X grew up in a highly modern world with less stable social structures, in which the individual has to choose his or her own education, job, sexuality, family type, lifestyle, friends, and the like, with no clear path to follow (Giddens, 1991). This increased individualism seems to be reflected in their high level of nonpolitical, politically motivated practices. Only when it comes to wearing clothes or badges with political statements is Generation X slightly outnumbered by the Baby Boomers, who, as a generation, were introduced to this form of political practice already in the more collectivistic peace or antinuclear power movements.

All in all, citizens do engage in non-political, politically motivated practices, but generational differences exist. Interestingly-and in contrast to the assumption of an unpolitical, unengaged youth that only participates in non-binding, low-risk activities (Morozov, 2009)—-the youngest generations 


\section{Being politically motivated}

do not lead in these practices. In fact, Generation $\mathrm{Z}$ engages the least in non-political but politically motivated practices, followed by Traditionalists. Millennials, however, engage more frequently in these practices than in the political activities discussed in Chapters 6 and 7. Millennials grew up in times of affluence, social security, and higher levels of education, leading to a 'rise in post-material or self-expressive values among younger generations' (Dalton, 2017, p. 86; Inglehart, 1990). This trait is reflected in their higher level of participation when it comes to non-political, politically motivated activities. The level of involvement in these new forms of participation can more likely be attributed to the cohort that citizens belong to, rather than the life-cycle stage they are in.

\section{The effect of political news exposure on non-political but politically motivated participation}

As argued in our Engagement-Participation-Information-Generation (EPIG) model (Chapter 2), political information can function as a basis for political participation, including non-political but politically motivated participatory practices. Though rarely studied, there is clear indication that news consumption can positively affect participation in these new, often digital forms of participation (Dennis, 2019; Dimitrova, Shehata, Strömbäck, \& Nord, 2014; Xenos et al., 2014). Most previous studies have explicitly focused on the youth when examining the role that media can have in mobilizing this type of participation, but little is known about how these effects vary across generations. In the following, we therefore explore whether receiving political information in the news media mobilizes citizens to participate in nonpolitical but politically motivated practices and test whether such effects differ between generations.

Overall, we find a positive influence of political news exposure on nonpolitical but politically motivated activities (see Table A8.1 in the Appendix). Figure 8.3 reports the marginal effects of exposure to political news on this type of participation. Both a static and a dynamic perspective are considered. In the static setting, we pool observations from the second and fifth survey waves and explore the correlation between political news exposure and non-political but politically motivated participation while controlling for gender, education, and generation. In the dynamic setting, we utilize all three survey waves by including a lagged dependent variable in our models and thus examine changes in participation over time (see Table A8.1 in the Appendix for full models; for methodological details, see Chapter 3).

In general, we find a positive effect of political news exposure on nonpolitical but politically motivated participation in both the static and the dynamic models. In other words, the more citizens are exposed to political information in the news media, the more they engage in non-political but politically motivated practices. Not all generations benefit equally from using the news media. The relationship between political news exposure 

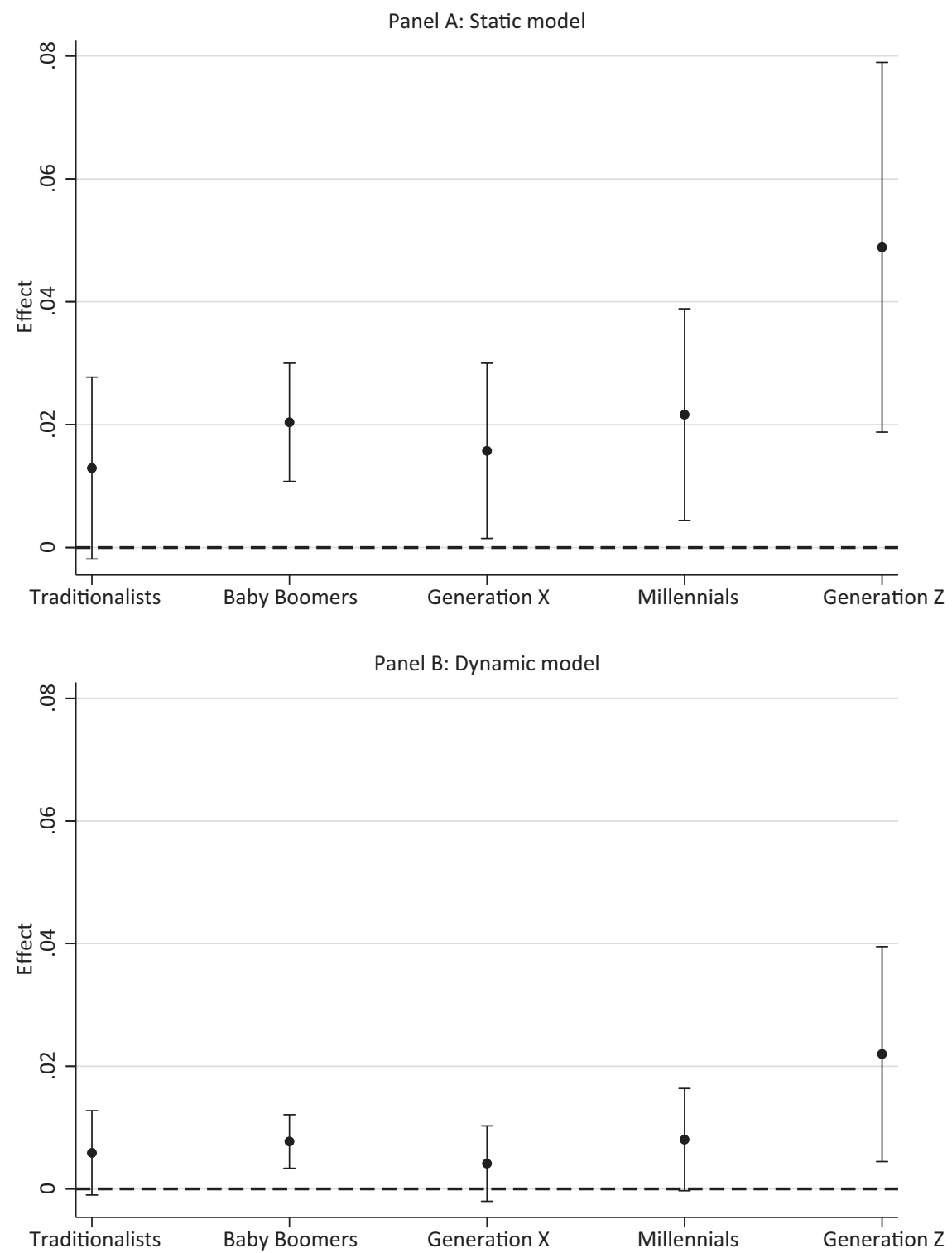

Figure 8.3 Marginal effects of exposure to political information in the news media on non-political but politically motivated participation (PP IV) across generations

Note. The estimates are displayed with a 95 percent confidence interval. Bonferroni correction used to counteract the problem of multiple comparisons. Full models in the Appendix, Table A8.1. 
and non-political but politically motivated participation is strongest for the youngest generation, Generation $\mathrm{Z}$. When looking at the dynamic model, the news media has a positive effect only for Generation Z and Baby Boomers. We found a similar pattern between Baby Boomers and Generation Z when we looked at the effect of political news consumption on participation targeted at the political system (PP II); that is, they were the two generations most affected. This raises the question whether their political socialization during their formative years can explain why they become mobilized more strongly than other generations. Interestingly, the generation that engages most often in non-political but politically motivated practices, Generation $\mathrm{X}$, benefits the least from political news media exposure. Receiving political information from traditional news information sources does not therefore seem to explain why they are so active in this type of political participation.

\section{Pathways to being politically motivated}

As suggested by the EPIG model (Chapter 2), we now examine whether the positive impact of political news exposure on non-political but politically motivated participation is mediated through the three dimensions of political engagement: political interest, knowledge, and efficacy. In Chapter 5, we saw that, sure enough, exposure to political news has a positive effect on each of these three dimensions of political engagement. Thus, the following examination will provide us with insight into whether this effect translates into non-political but politically motivated participation.

In order to examine the pathways to participating in non-political, politically motivated activities, we did a path model using multiple-group analysis for structural equation modelling. Again, we did this both from a static and from a dynamic perspective. Table 8.1 lists the findings across generations for the three engagement measures: political interest, knowledge, and efficacy. Overall, we find clear indication that a positive relationship exists between political news consumption and non-political, politically motivated participation since media consumption also contributes to higher levels of political interest, efficacy, and knowledge. If we compare the coefficients with indirect effects examined in previous chapters, it becomes clear that the mediation of the effect that political news media consumption has on non-political, politically motivated participation is stronger than for the two other types of political participation (PP II, PP III). Here again, we find an indication of generational differences, especially in the dynamic models: the stronger the indirect effect of political interest, the younger the generation.

In the case of Generation Z, which is most strongly affected, political news consumption contributes to their political interest and therefore strengthens the youngest generation's engagement in non-political, politically motived practices. The rather strong effect we find for Generation $\mathrm{Z}$ in the analysis displayed in Figure 8.3 partly stems from an indirect effect through political 
Table 8.1 Indirect effects of exposure to political information in the news media on political participation IV

\begin{tabular}{|c|c|c|c|c|c|c|}
\hline & \multicolumn{3}{|l|}{ Static } & \multicolumn{3}{|l|}{ Dynamic } \\
\hline & Interest & Knowledge & Efficacy & Interest & Knowledge & Efficacy \\
\hline Overall & $\begin{array}{l}.014 * * * \\
(.000)\end{array}$ & $\begin{array}{l}.072 * * \\
(.002)\end{array}$ & $\begin{array}{l}.007 * * * \\
(.000)\end{array}$ & $\begin{array}{l}.004 * * * \\
(.000)\end{array}$ & $\begin{array}{l}.002 * * * \\
(.000)\end{array}$ & $\begin{array}{l}.022 * * * \\
(.000)\end{array}$ \\
\hline Traditionalists & $\begin{array}{l}.008 * * * \\
(.001)\end{array}$ & $\begin{array}{l}.002 * \\
(.001)\end{array}$ & $\begin{array}{l}.004 * * * * \\
(.001)\end{array}$ & $\begin{array}{l}.003 * * * \\
(.001)\end{array}$ & $\begin{array}{l}.001 \\
(.000)\end{array}$ & $\begin{array}{l}.001 * * \\
(.000)\end{array}$ \\
\hline Baby Boomers & $\begin{array}{l}.011^{* * *} \\
(.001)\end{array}$ & $\begin{array}{l}.002 * * \\
(.001)\end{array}$ & $\begin{array}{l}.007 * * * \\
(.001)\end{array}$ & $\begin{array}{l}.004 * * * \\
(.001)\end{array}$ & $\begin{array}{l}.001 \\
(.000)\end{array}$ & $\begin{array}{l}.002 * * * \\
(.000)\end{array}$ \\
\hline Generation X & $\begin{array}{l}.017 * * * \\
(.002)\end{array}$ & $\begin{array}{l}.004 * * * \\
(.001)\end{array}$ & $\begin{array}{l}.009 * * * \\
(.001)\end{array}$ & $\begin{array}{l}.004 * * * \\
(.001)\end{array}$ & $\begin{array}{l}.002 * \\
(.001)\end{array}$ & $\begin{array}{l}.002 * * * * \\
(.001)\end{array}$ \\
\hline Millennials & $\begin{array}{l}.020 * * * \\
(.002)\end{array}$ & $\begin{array}{l}.005 * * \\
(.002)\end{array}$ & $\begin{array}{l}.012 * * * \\
(.002)\end{array}$ & $\begin{array}{l}.006 * * * \\
(.002)\end{array}$ & $\begin{array}{l}.003 * \\
(.001)\end{array}$ & $\begin{array}{l}.004 * * * \\
(.001)\end{array}$ \\
\hline Generation Z & $\begin{array}{l}.023 * * * \\
(.003)\end{array}$ & $\begin{array}{l}.007 * * * \\
(.002)\end{array}$ & $\begin{array}{l}.013 * * * \\
(.002)\end{array}$ & $\begin{array}{l}.008 * * \\
(.003)\end{array}$ & $\begin{array}{l}.003 \\
(.002)\end{array}$ & $\begin{array}{l}.002 \\
(.002)\end{array}$ \\
\hline
\end{tabular}

Notes. SEM without/with group comparison. Unstandardized coefficients. Standard errors in parentheses. Models include gender and education as controls. Dynamic models also include a lagged dependent variable.

$* \mathrm{p}<.05, * * \mathrm{p}<.01, * * * \mathrm{p}<.001 . \mathrm{N}_{\text {Static }}=3,490 / 10,470 . \mathrm{N}_{\text {Dynamic }}=3,490 / 6,980$.

interest. Only political interest, however, has an indirect effect for this generation, while no indication is found for mediation by political knowledge or interest. The non-political, politically motivated participation of Generation $\mathrm{X}$ and Millennials can most consistently be explained by an indirect effect of interest, knowledge, and efficacy. Interestingly, while we do not find a direct effect of political news consumption on these two generations' levels of participation, strong indirect effects exist. The political news consumption of Generation X and Millennials increases their levels of political interest, knowledge, and efficacy, which has a positive effect on their level of nonpolitical but politically motivated participation. This pathway, to a weaker extent, also exists for Traditionalists and Baby Boomers; the contribution of their political news consumption to political knowledge, however, is not a determining factor for their involvement in this type of participation.

\section{Summing up}

In this chapter we explored the effect of exposure to political information in the news media on citizens' engagement in non-political but politically motivated practices. When walking in the streets, we often see people carrying bags or wearing T-shirts and badges with political statements. And when scrolling through the news feed on social media, we often see that somebody 
has changed his or her profile picture to support a political cause. In other words, citizens do things that are not directly targeted at the political system but are nonetheless politically motivated. They want to express their stand on a current political matter but may do so in a subtler manner than by participating in a demonstration. Though the outcomes are harder to assess than, for example, voting in a referendum, engaging in such practices has become a core phenomenon of participation in the twenty-first century. Such actions have global clout since people can become inspired and express their political stance digitally across borders.

Our results show that citizens do indeed engage in these types of nonpolitical but politically motivated practices. This is especially true for the middle Generation X, who seem to have found 'their' type of participation in these highly expressive practices. However, the youngest and most digitally native generation, Generation $\mathrm{Z}$, does not engage in these types of practices to the same extent. These results indicate that the level of participation is more strongly connected to the cohort that people belong to rather than their current stage of life.

More importantly for the EPIG model (Chapter 2), we show that political news exposure has a positive effect on this type of political participation, especially so for Generation Z. This finding supports our life-cycle argument, according to which younger generations are more malleable and open to political information, reacting more strongly to it. However, Baby Boomers also react strongly to political news consumption with non-political, politically motivated participation. This finding speaks more for a cohort effect, since Baby Boomers stand out from their bordering generations. Moreover, the similar way in which Baby Boomers and Generation Z members respond to political news consumption fuels the idea that these cohorts share similarities regarding their political upbringing, which causes them to react with the same patterns of behaviour. We cannot tell from the results whether only one or both perspectives (i.e., life-cycle and cohort) apply, but taken together, the relationship between political media consumption and political participation is less likely to be driven solely by a life-cycle effect. The effects we find seem to be partly indirect through, in particular, political interest and efficacy, which both mediate the relationship between political news exposure and non-political but politically motivated participation. Thus, being interested in politics and feeling capable of changing political matters are important steps towards participating and engaging in politically motivated but non-political practices. 


\section{Social media, political engagement, and participation}

Compared to traditional media, social media possess the opportunity to deliver political content in a more relevant, diverse, and direct way, which constitutes an alternative route for the different generations to encounter political information. Some generations may find this gateway to political information more appealing, which may, in turn, affect their political engagement and participation differently. In this chapter we show how exposure to political content on social media has different effects on each generation's political involvement. We also uncover how political social media exposure has limited and diverse indirect effects on political participation through the different types of political engagement. This chapter shows how social media possess the potential for affecting political involvement in different ways for each of the different generations.

The use of digital media for consuming news and political information has added a new layer to the question of generational differences in the effects of news on political participation. Political social media exposure has a different modus operandi than general news exposure, and platforms like Facebook, YouTube, and Twitter are used to varying degrees by different generations. This chapter addresses the question: what effects does the use of political social media have on political involvement in different generational contexts? We focus on three different possibilities: first, social media use may be responsible for a shift of mobilization patterns in different age segments of the population; second, social media use may affect citizens' political engagement (i.e., political interest, knowledge, and efficacy) in different ways than do traditional media, resulting in distinct pathways to participation; third, political social media exposure may trigger some types of participation more while triggering other types less.

The chapter proceeds with the presentation of an argument for why we can expect social media to have distinct effects on different age brackets of the population. Afterwards, we explore the levels of political engagement 


\section{Social media, political engagement}

and political participation in society and how political social media exposure may be driving these key democratic variables. Lastly, we compare the indirect effects of political engagement that may be responsible for the effect of political social media use on participation among different generations.

\section{Why social media may be different}

In line with the model presented in Chapter 2, social media may alter the antecedents of political media exposure and the consequences for political involvement. Hence, different generations may turn to political information on social media to different extents compared to legacy media, and, in turn, political social media exposure may affect political involvement of these generations to varying degrees.

A first indication of potential differences in selecting political information on social media between generations can be found in Figures 4.4 to 4.9 in Chapter 4. While we see strong effects of political interest and knowledge predicting political news media use, political interest only modestly predicts political social media exposure. Furthermore, the frequency of exposure makes no difference to whether people are politically knowledgeable or not. This is in line with previous research that found low levels of political learning through social media use (Boukes, 2019; Cacciatore et al., 2018; Edgerly, Thorson, \& Wells, 2018; Shehata \& Strömbäck, 2018; Lee \& Xenos, 2019). Hence, the content of political information and the way in which it is presented on social media attract different groups of the population, most noticeably citizens belonging to Millennials and Generation Z, who have less political interest and knowledge than older news consumers. Previous research has furthermore shown how people who encounter political information on social media do not always actively seek it but encounter it inadvertently (Fletcher \& Nielsen, 2017; Gil de Zúñiga et al., 2017). These findings provide us with some evidence that political involvement as an antecedent of exposure to political information in social media plays a minor role compared to legacy media. But it is still an open question whether this shift in exposure results in different engagement and participation patterns.

How are social media actually different when comparing political information accessed on these platforms to more traditional media channels? While we expect the general pathways leading to participation to be less affected, our argument focuses on the differences in content that citizens receive on social media. We argue that the content people encounter on platforms like Facebook, Twitter, and Instagram is potentially more personally relevant, diverse, and directed compared to information that people, on average, receive outside social media. Hence, the consequences of political social media exposure will be explored.

To begin with, content consumed on social media is more relevant because it can be personalized: algorithms determine the selection of information displayed to a user, and information comes from the social and geographic 
proximity of users due to the platforms' network character (Messing \& Westwood, 2014; Klinger \& Svensson, 2015). The result is a curated news diet, tailored to the interests of users (Thorson \& Wells, 2016). Moreover, the content in a social media news diet comes from more diverse sources. A personalized media diet frees space to consume more information of actual interest (Beam \& Kosicki, 2014). Since basically every person, societal actor, organization, and institution can maintain profiles on social media, information from very different sources about any field of interest can be accessed in a single location (Messing \& Westwood, 2014). The likelihood of inadvertent exposure to content that a user did not seek may further increase the diversity of sources (Fletcher \& Nielsen, 2017; Valeriani \& Vaccari, 2016). Importantly, this diversity does not necessarily pertain to political leanings (potentially quite the opposite; see the 'filter bubble' discussion in Flaxman, Gael, \& Rao, 2016), but citizens may receive information from a greater number of sources in general. Lastly, content received via social media does not stand alone but is accompanied by different social cues, which makes it more directed than information without such cues. Posts in a news feed, for example, can have a commenting lead, a comment by the friend who recommended it, or a number of likes (or emoticons). Such cues attached to an informational item on social media can drive selection, serve as interpretation aids, and shape how information is processed, what citizens learn from it, and how they act upon it (Messing \& Westwood, 2014; Messing, Westwood, \& Lelkes, 2011; Ohme \& Mothes, 2020).

\section{Implication of social media use for political engagement and behaviour}

These different features of social media platforms can have important implications for political media exposure and its effects on engagement and participation. One can argue that the different nature of political information on social media is especially appealing to younger generations-who see politics as boring and restricted in terms of topics—and the legacy media as not being focused on younger generations (Briggs, 2017; Mindich, 2005; Moeller, Kühne, \& de Vreese, 2018). Added to the easy and ubiquitous access on social media, which connects them with each other, personal relevance, diversity, and directedness may explain the high uptake of social media platforms for political information use among the young.

Furthermore, we may see distinct effects of political social media exposure on citizens' political engagement and participation. Opportunity structures matter for citizens to act politically, and people have different capacities to participate fully in society (Leighley, 1995). Citizens need information to act upon, and media can be an important provider of information that mobilizes (Colwell Quarles, 1979). With high personal relevance, diversity, and directedness, information on social media can therefore be an important antecedent of political involvement. For example, the possibility to tailor messages 


\section{2}

on social media to the geographic proximity of users may help them become informed about topics that they can easily relate to and feel the need to act upon. At the same time, exposure to a greater diversity of political information sources increases the likelihood of topics or cases that citizens find worth supporting or becoming involved with. On social media, it is possible for users to stumble upon a niche topic, such as information about animal welfare, which they find relevant enough to want to pursue. Lastly, information that has an immediate connection to other users in the network-be it via recommendations, social cues, or direct calls for action-may be perceived to be of a higher order than information without any social utility (Chaffee $\&$ McLeod, 1973). Being addressed by one's social contacts is an important antecedent of political participation, as outlined in Verba et al.'s (1995) Civic Voluntarism Model, and the directedness of social media information may enforce the likelihood of acting on that information.

Though all generations, in theory, can select the same information on social media, we argue that variations in effects on political involvement can stem from the ability —or lack thereof—to use social media in a fruitful and effective way. Millennials and particularly members of Generation Z are better prepared to use social media in political information contexts and therefore benefit more from it than older generations (Prensky, 2001). Disparities of social media literacy among different generations may exist. By and large, the instinctive use of social media should be higher for members of the two youngest generations. If that is the case, we should find generational differences as part of a cohort effect as regards social media use and its relation to citizens' political behaviour and engagement.

In our analysis, we test how strongly the use of social media for political information exposure predicts both political engagement and political participation and if these effects occur indirectly through political interest, knowledge, and internal efficacy. We rely on the fifth wave of our panel study, in which a ten-day period of smartphone-based media diaries preceded the measurement of the mediating and dependent variables in the model. Therefore, only a subsample of our general sample is analyzed here (see Chapter 3 for details).

\section{Levels of political interest, knowledge, and internal efficacy}

At first, we take a look at the average levels of political engagement among our five different generations (Figure 9.1). As we have already seen in the main analysis of Chapter 5, the younger generations have a lower level of political interest. Similarly-but on a smaller scale-the level of knowledge about current political affairs decreases as the generations get younger. Only the level of internal political efficacy is rather stable across generations, with Generation X feeling efficacious most strongly. Interestingly, the feeling of being capable of understanding politics is not much lower among Millennials and members of Generation Z. In this regard, prerequisites for political participation do not differ strongly by generation. 


\section{Political Interest}

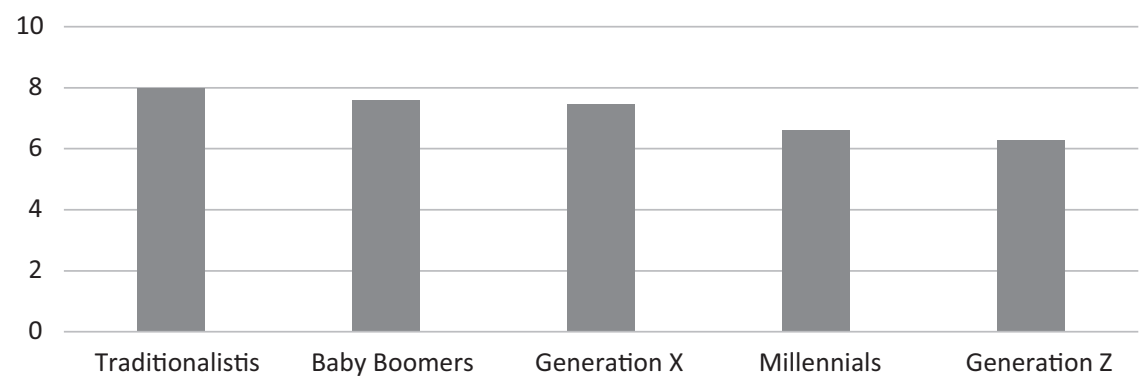

Political Knowledge

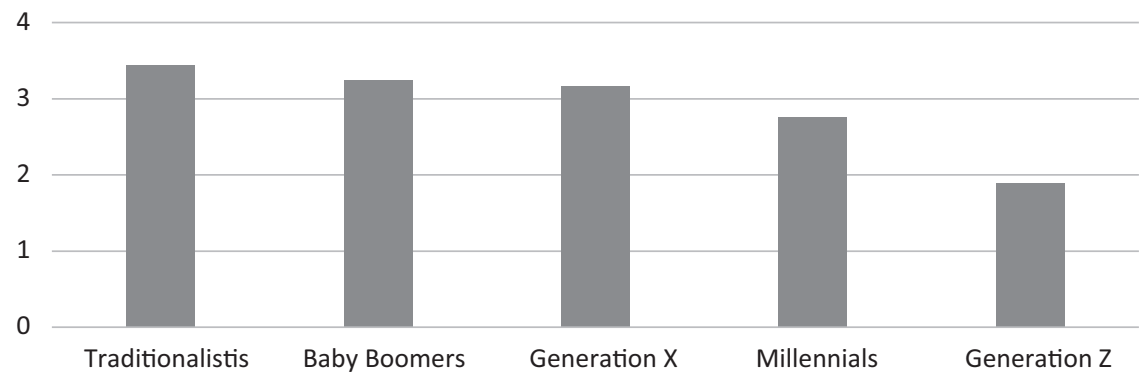

Political Efficacy

5

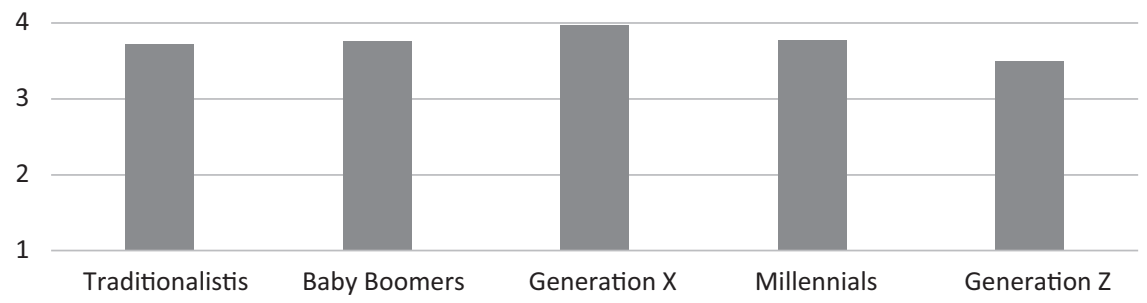

Figure 9.1 Average levels of political engagement across generations in mobile survey subsample

Notes. Levels of political engagement from the wave 5 of online panel survey among the mobile survey sample $(\mathrm{n}=534)$. Scale endpoints present minimum and maximum values.

We proceed by looking into the relationship between political social media exposure and the three types of political engagement (political interest, knowledge, and internal efficacy) shown in Figures 9.2 to 9.4. The effects are shown at a static and a dynamic level per type of political engagement across generations. We find a clear indication that the level of people's 


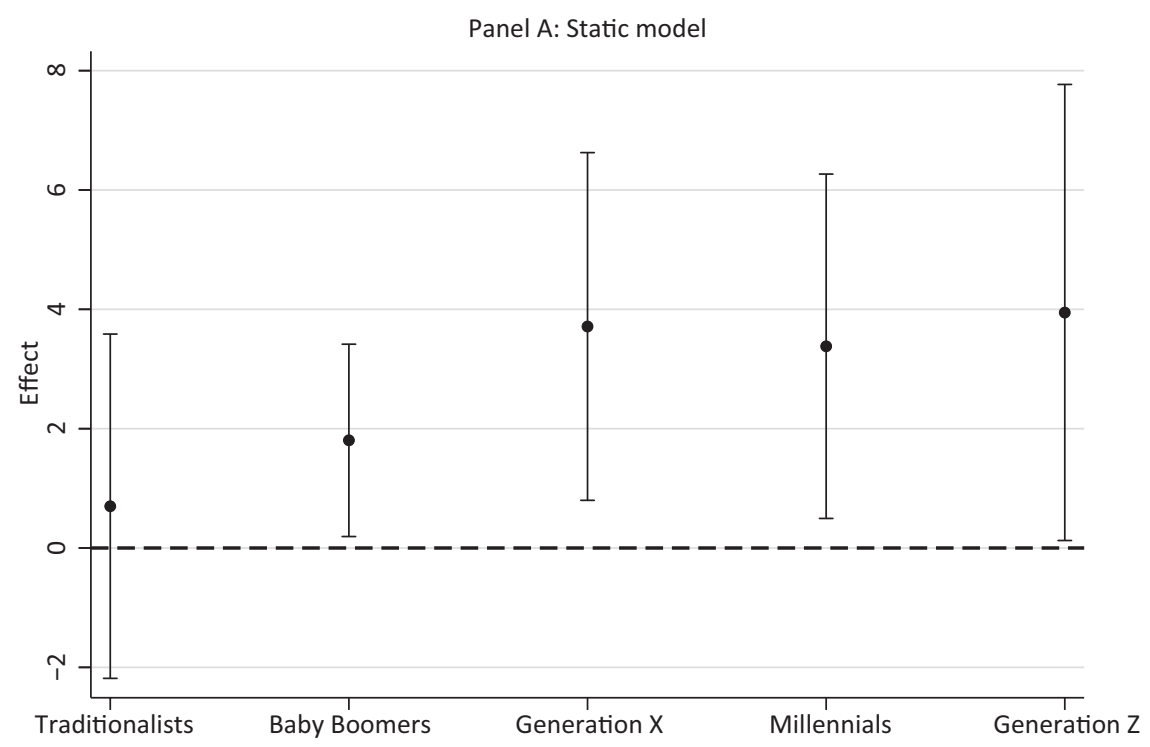

Panel B: Dynamic model

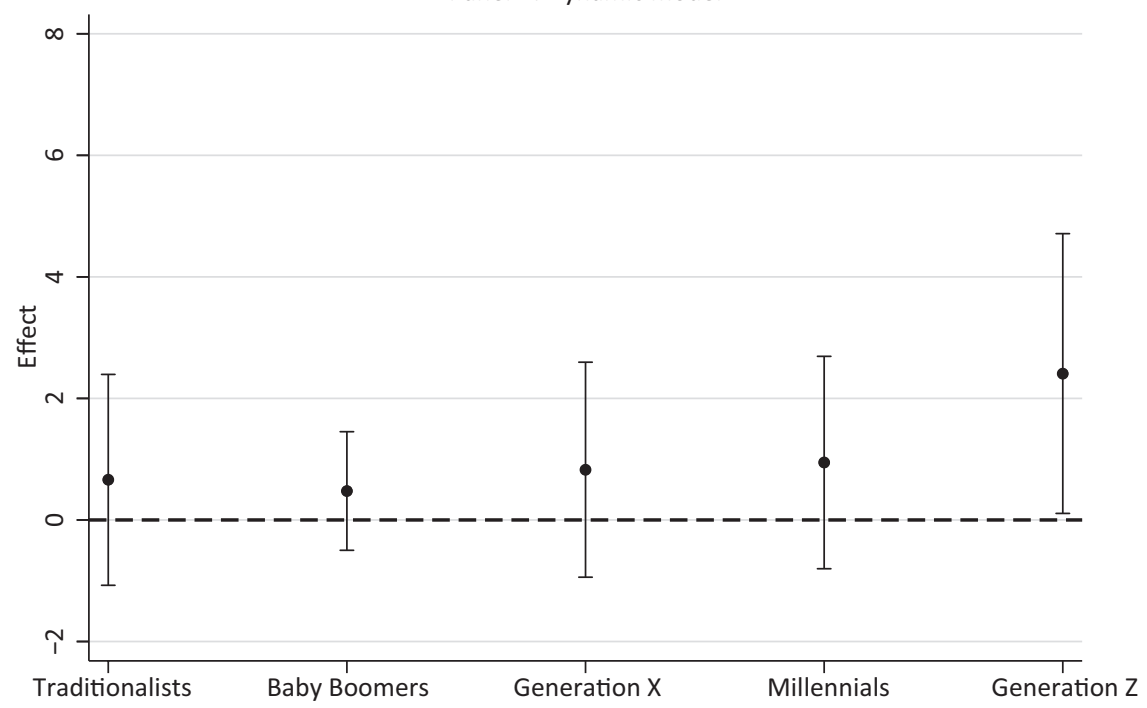

Figure 9.2 Marginal effects of exposure to political information on social media on political interest across generations

Notes. The estimates are displayed with a 95 percent confidence interval. Bonferroni correction used to counteract the problem of multiple comparisons. Full models in the Appendix, Table A9.1. 


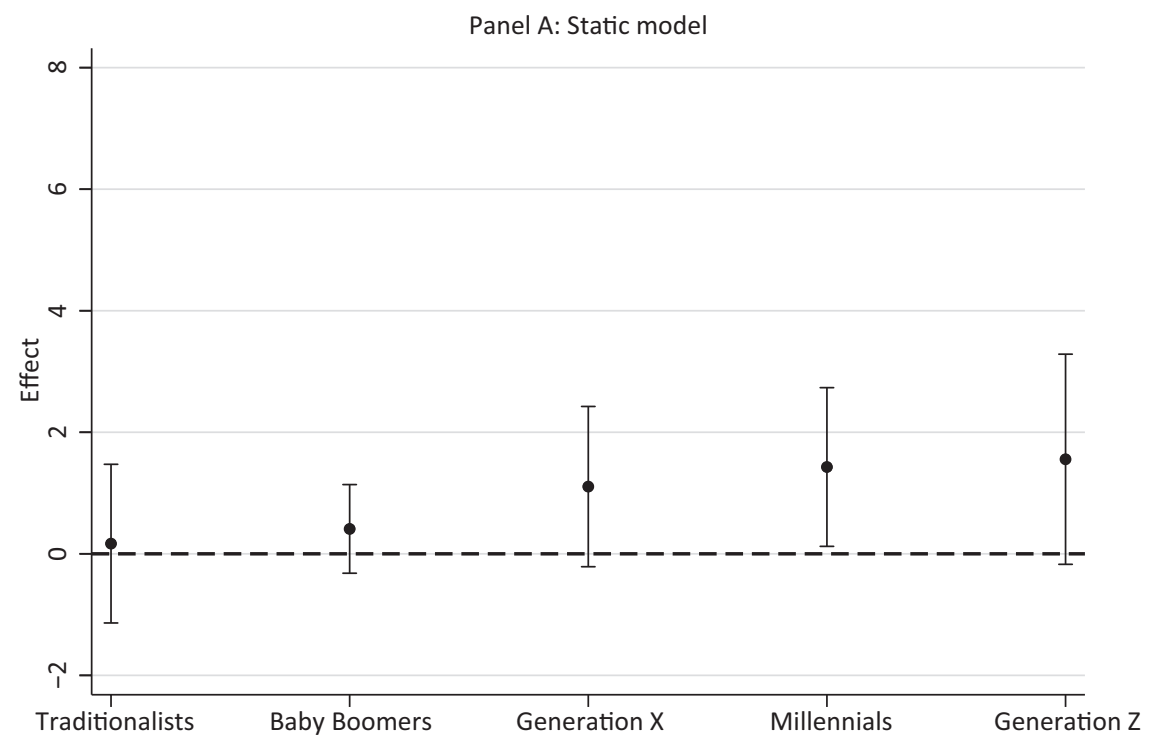

Panel B: Dynamic model

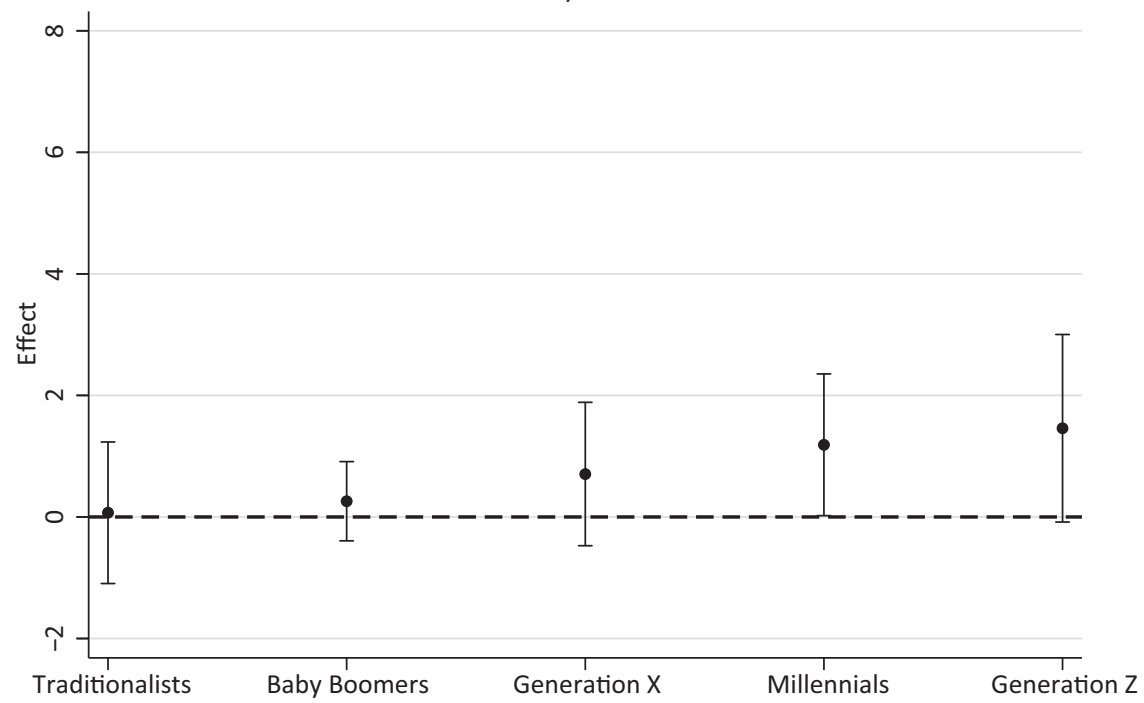

Figure 9.3 Marginal effects of exposure to political information on social media on political knowledge across generations

Notes. The estimates are displayed with a 95 percent confidence interval. Bonferroni correction used to counteract the problem of multiple comparisons. Full models in the Appendix, Table A9.2 


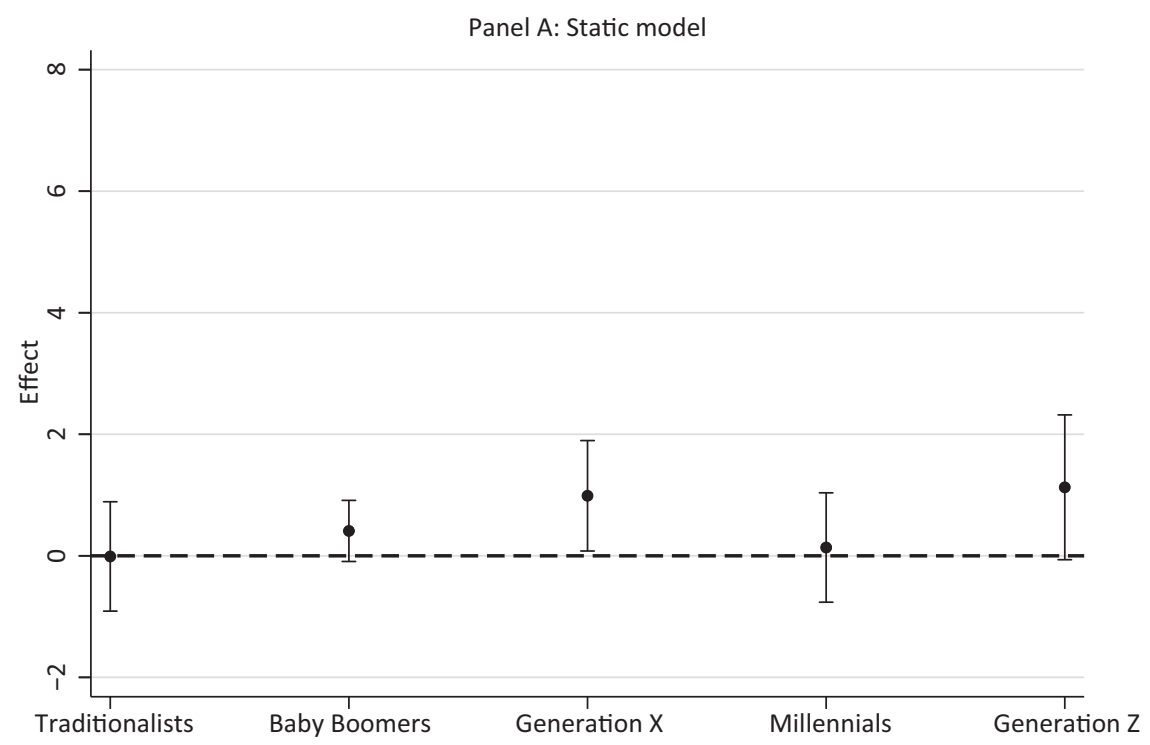

Panel B: Dynamic model

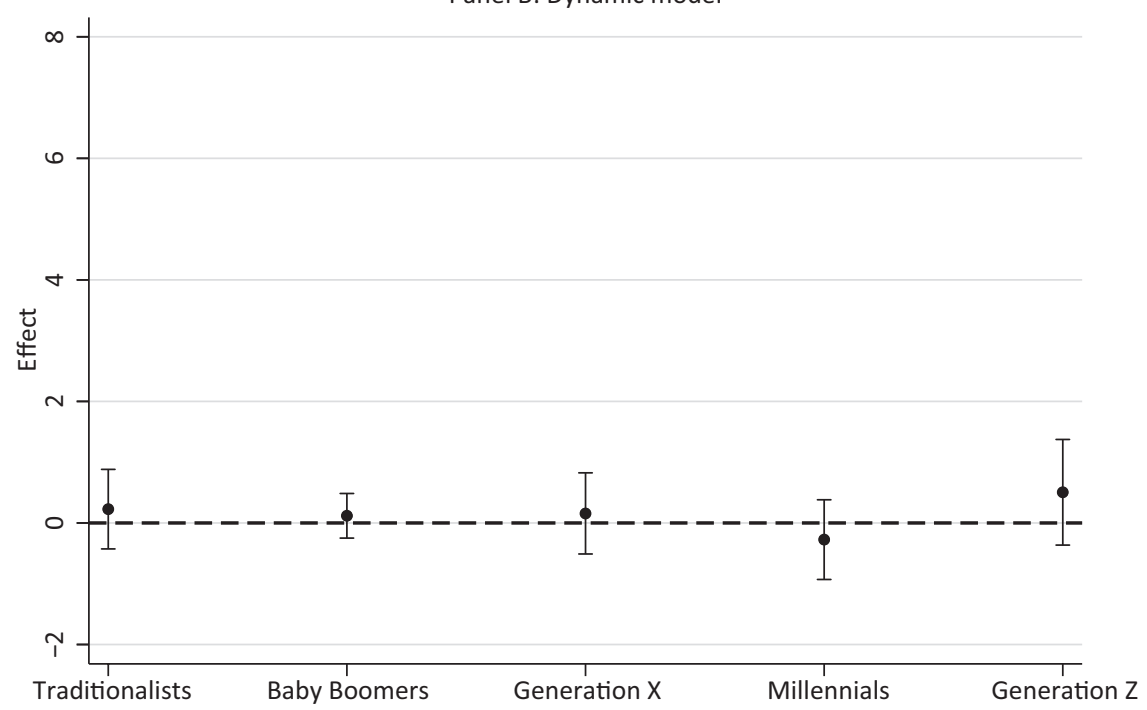

Figure 9.4 Marginal effects of exposure to political information on social media on political efficacy across generations

Notes. The estimates are displayed with a 95 percent confidence interval. Bonferroni correction used to counteract the problem of multiple comparisons. Full models in the Appendix, Table A9.3. 
political social media use is associated with their engagement with politics. Overall, in the static models, we find a positive relationship between political social media exposure and political interest, political knowledge, and political efficacy. In the dynamic models, political social media use predicts political interest and knowledge but not political efficacy (see Tables A9.1A9.3 in the Appendix). Hence, even when controlling for previous levels of engagement, a general effect of political social media exposure on two of the three political engagement variables becomes visible.

Nonetheless, we also find strong generational differences. The most prominent relationship is found for political interest: for all but Traditionalists, a high level of political social media use is positively related with political interest. Only for Generation Z, however, can we establish a positive effect of political social media exposure on political interest when controlling for previous levels of interest (Figure 9.2). Turning to political knowledge, we see that a positive relationship exists only for Millennials, and it remains significant in the dynamic analysis as well (Figure 9.3). For political efficacy, we see a positive relationship only for Generation X, but we cannot establish an effect of political social media use for any of the generations.

A comparison of the generations reveals an interesting pattern. The two ends of our generational spectrum react most coherently to receiving political information on social media. While Traditionalists' political interest, knowledge, and political efficacy do not change with an increasing level of political social media exposure, the opposite is the case for Generation Z. Here, we apparently see a traditional age gap. But interestingly, the political engagement of not only young citizens is contingent upon political social media exposure; so is the political engagement of Baby Boomers, Generation X, and Millennials. In general, the relationship between political social media exposure decreases slightly with increasing age, indicating a life-cycle effect rather than a cohort effect. However, since social media were not around when the older generations came of age, we do not know whether the higher effect of political social media exposure on political engagement will remain a distinctive feature of Millennials and Generation $\mathrm{Z}$ when they grow older.

In sum, levels of political engagement differ across generations. Though political social media exposure contributes to variations in political engagement across generations, such variations do not clearly follow a life-cycle pattern; in general, young citizens' political engagement is not more susceptible to political information from platforms like Facebook, YouTube, and Instagram than that of older generations.

\section{Differences in participation levels}

We now turn to the effects of political social media exposure on political participation. As a first step, we explore differences in participation levels across generations. As was the case in the analysis of the main sample, the participation patterns of the five generations differ (see Figure 9.5). Baby 


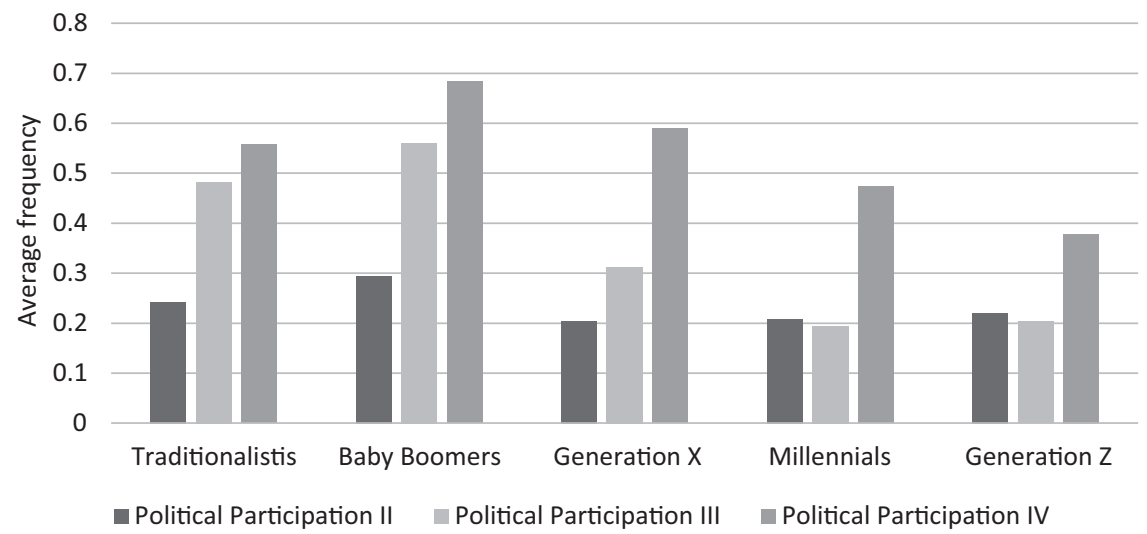

Figure 9.5 Average levels of political participation across generations in subsample Source: Notes. Levels of political participation (0-4) from wave 5 of the online panel survey among the mobile survey sample $(\mathrm{n}=534)$.

Boomers have the highest levels of participation across all three types of participation-PP II, III, and IV-followed by Traditionalists, with the youngest cohort, Generation Z, exhibiting the lowest levels. Participation directly addressing the political system (PP II) is rather stable across generations, with Traditionalists and Baby Boomers participating slightly more than the three younger cohorts. This pattern is even more pronounced for participation targeted at the local and community level (PP III): for Generation X, Millennials, and Generation Z, this type of participation is far less prominent than for Traditionalists and Baby Boomers. However, the very low levels of local participation among Millennials and Generation $\mathrm{Z}$ should not be overinterpreted since we know that local issues only increase in importance when a person has found a permanent place to live. All generations participate the most in nonpolitical but politically motivated activities. Contrary to the assumption that mostly younger generations undertake this type of participation, we see that the generations who, in general, participate politically the most are also the most active when it comes to non-political but politically motivated activities (PP IV). Therefore, it cannot be concluded that these new activities function as a substitution for other forms of political activity only for the young.

The degree to which the different generations participate in the three types of political activity is one thing. Another is the relative importance that the different generations ascribe to each type of participation. Figure 9.6 shows the share of each type of participation for each generation. In other words, it shows the participatory priorities of the different generations. The share of political activities targeted at the political system (PP II) is larger for younger than older citizens. As seen in Figure 9.5, the opposite is true for 


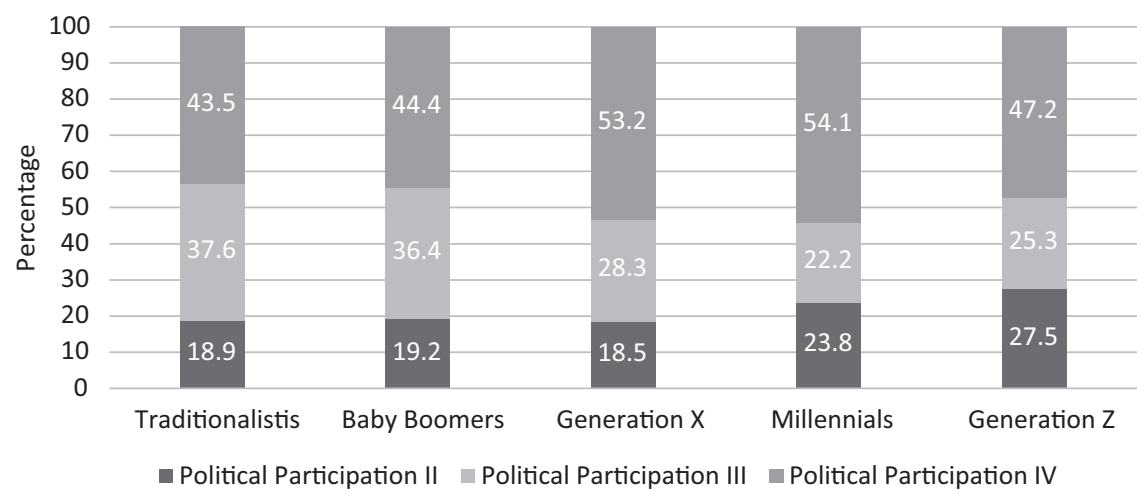

Figure 9.6 Share of participation types of total political participation across generations in subsample

Note. Levels of political participation from wave 5 of the online panel survey among the mobile survey sample $(\mathrm{n}=534)$.

political participation at the local level, which is of higher relative importance for the two oldest generations. Interestingly, even if younger generations participate less in non-political, politically motivated activities than do older generations, we find indications that this type of activity increases in relative importance the younger the generations get, with the exception of Generation Z, thus constituting a larger part of their overall participation compared to Traditionalists and Baby Boomers.

\section{Social media effects on political participation}

Next, we investigate to what extent political social media exposure explains variations in participation levels and if generational differences can be traced back to social media use.

Overall, we find a positive influence of political social media exposure on political participation (see Tables A9.4-A9.6 in the Appendix). The more often citizens are exposed to political news via social media, the more often they are active in political participation targeting the political system (PP II) and in non-political but politically motivated activities (PP IV). Only a weak relationship exists between political social media exposure and participation targeting the local community (PP III). Figures 9.7 to 9.9 show the unstandardized effects of political social media exposure on the three types of participation across the generations.

Almost equally for all generations but Traditionalists and Millennials, receiving political information on social media seems to be related to participation targeted directly at the political system (PP II; Figure 9.7). When taking previous levels of exposure into account, however, only Generation $\mathrm{Z}$ benefits 


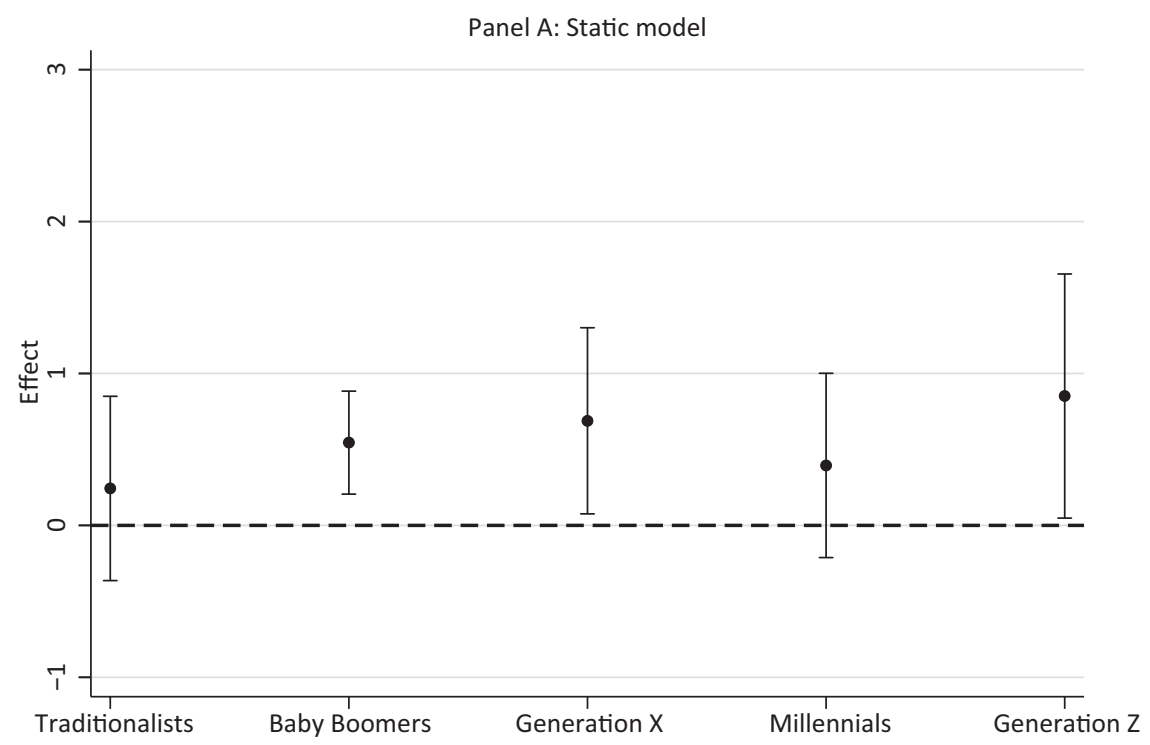

Panel B: Dynamic model

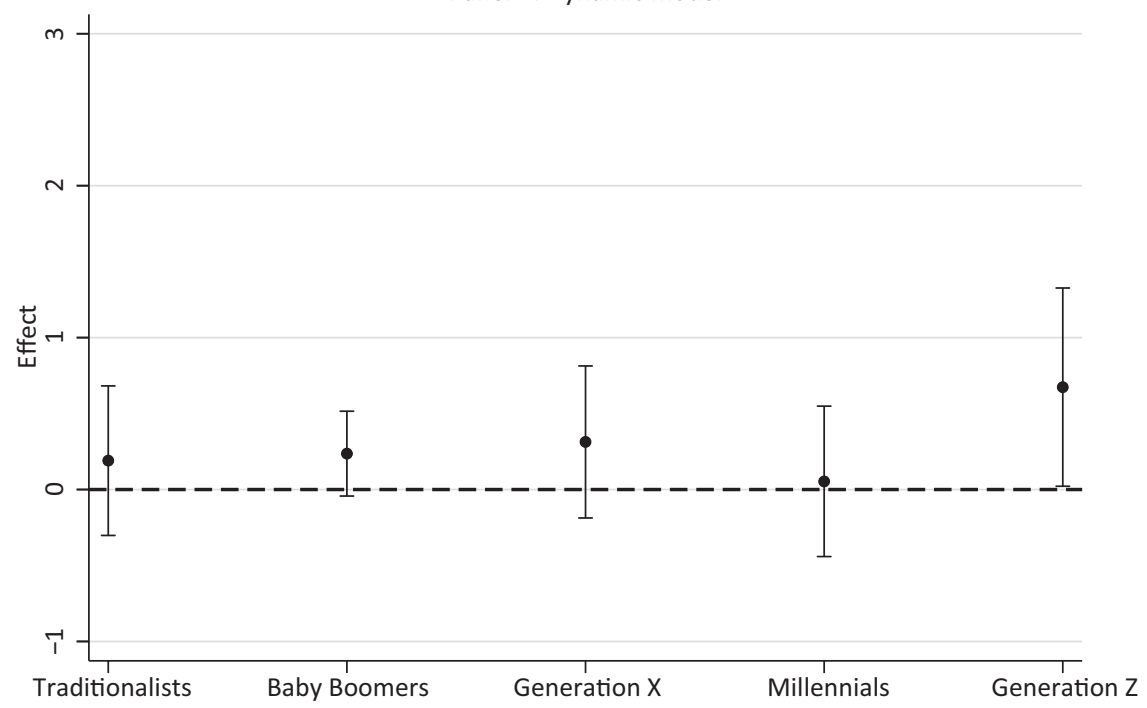

Figure 9.7 Marginal effects of exposure to political information on social media on political participation targeted at the political system (PP II) across generations

Notes. The estimates are displayed with a 95 percent confidence interval. Bonferroni correction used to counteract the problem of multiple comparisons. Full models in the Appendix, Table A9.4 
effectively from political social media exposure. Figure 9.8 indicates that for no generation does social media exposure contribute to participation in community-based activities (PP III). A different picture emerges for non-political but politically motivated participation (PP IV; Figure 9.9). Here, social media is a clear driver for the three oldest-but not for the younger-generations.

Is political social media use responsible for generational differences in political participation? Traditionalists become mobilized by political social media exposure only to a limited extent-in fact, solely when it comes to local, community-oriented activities (PP IV). By contrast, Baby Boomers are affected the most by social media exposure. This result is much in line with our expectation that Baby Boomers are currently the most politically active generation. In fact, the result indicates that political information on social media can very well translate into political action if a generation is susceptible to it. For Generation X, social media use is related to PP II and IV, but only weakly to PP III. Since Millennials grew up with social media and, compared to their younger fellow citizens, entered the political system some time ago, they may be expected to be affected the most by political social media exposure. However, the opposite is true. Millennials are the first cohort for whom participation in the new non-political but politically motivated activities by far outweighs other types of political participation; yet, Millennials are the least affected by their political social media use. Hence, their high levels of PP IV participation must be explained by factors other than political social media exposure. Lastly, the youngest cohort, Generation Z, participate politically the least, most likely due to their young age. Nevertheless, we find a positive effect of their social media exposure on political participation targeted at the political system but not on local-level participation. Unexpectedly, receiving political information on platforms like Facebook or Instagram does not contribute to their participation in non-political, politically motivated activities. Generation Z, who receive political information much more frequently from social than traditional news media, is the only generation for whom high levels of social media exposure are in sync with high levels of participation. So, though exposure to political news from legacy media had a strong effect on the political participation of this generation, they did not use legacy media content to a great extent; by contrast, we see that their exposure to political social media-the media source they use the most-actually contributes to some of their political participation.

In sum, we see a mixed picture when we look at the generational effects of political social media exposure on political participation. In some respects, the older generations, with higher levels of participation, benefit the most from political social media exposure. The younger generations are likewise affected by social media use but less so than expected. Millennials, in particular, benefit rather little from their high levels of political social media use. Hence, political social media exposure does not automatically translate into equally high levels of participation. 

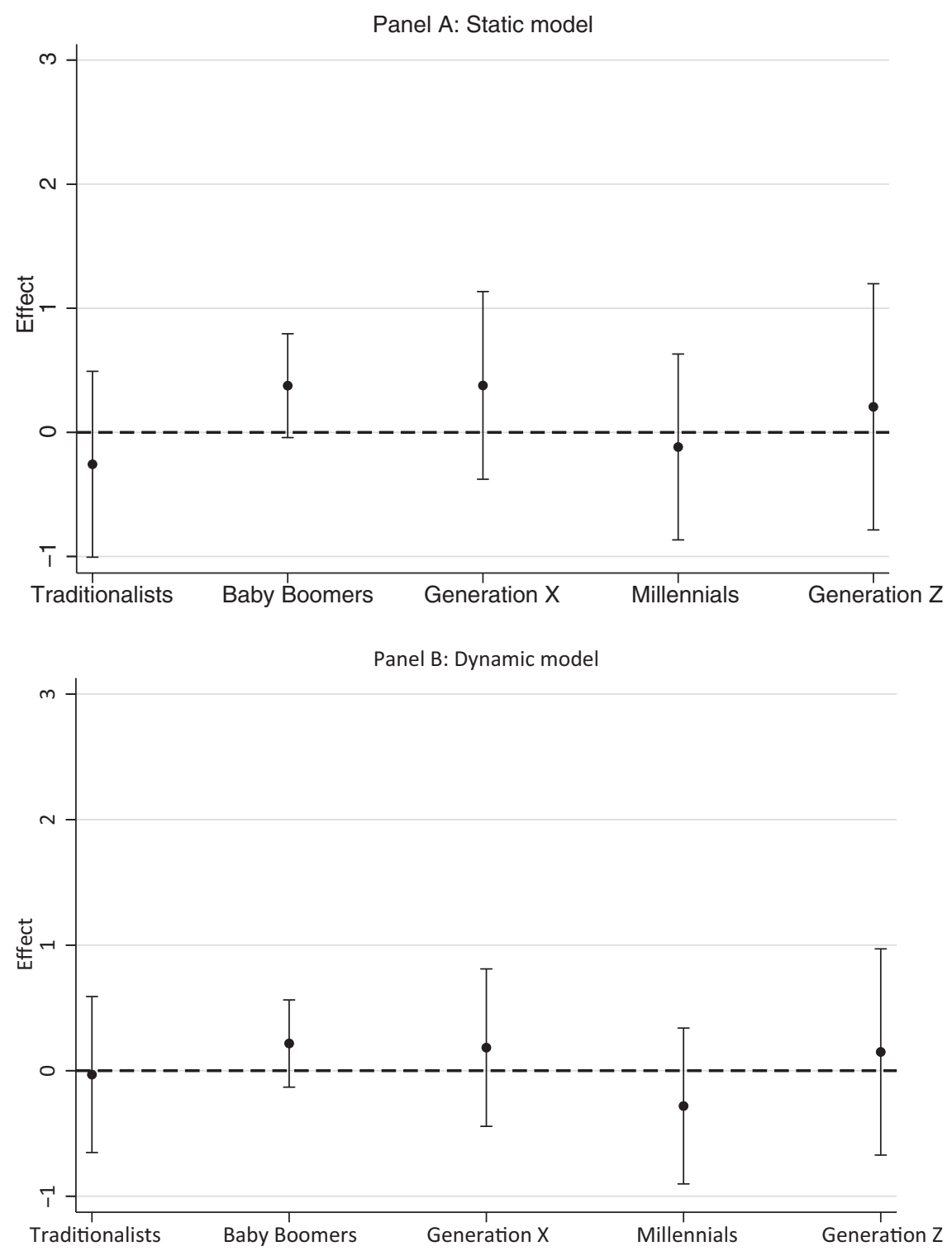

Figure 9.8 Marginal effects of exposure to political information on social media on political participation targeted at the local community (PP III) across generations

Notes. The estimates are displayed with a 95 percent confidence interval. Bonferroni correction used to counteract the problem of multiple comparisons. Full models in the Appendix, Table A9.5. 


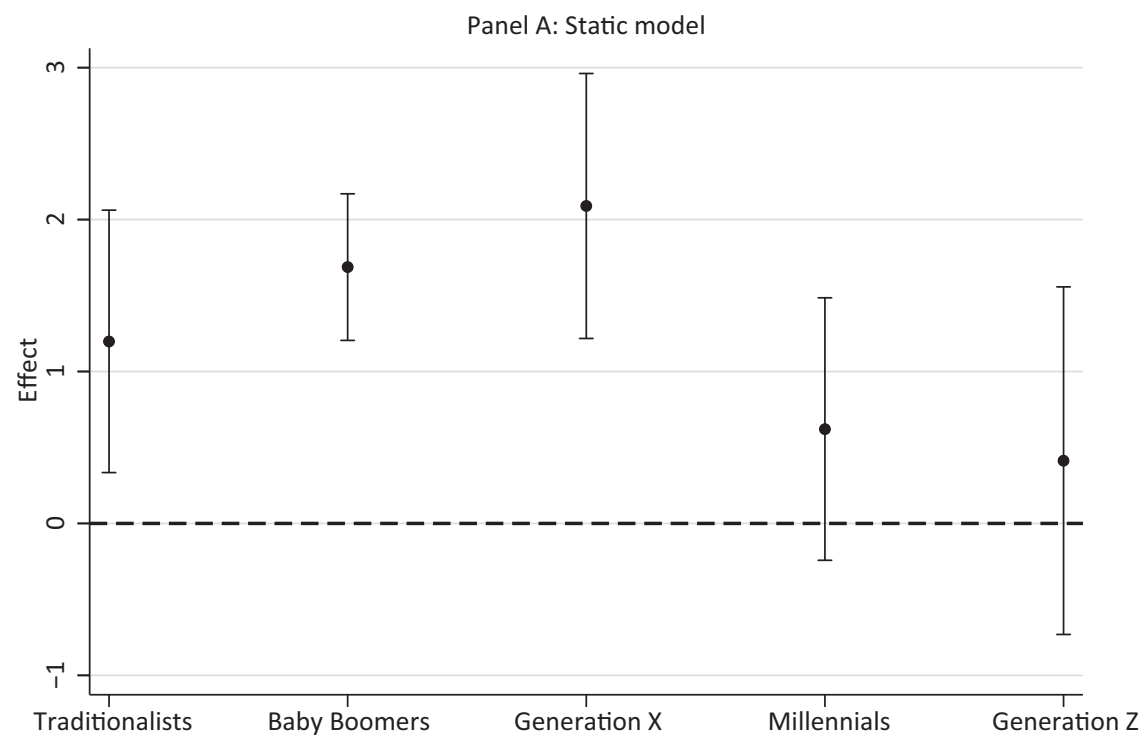

Panel B: Dynamic model

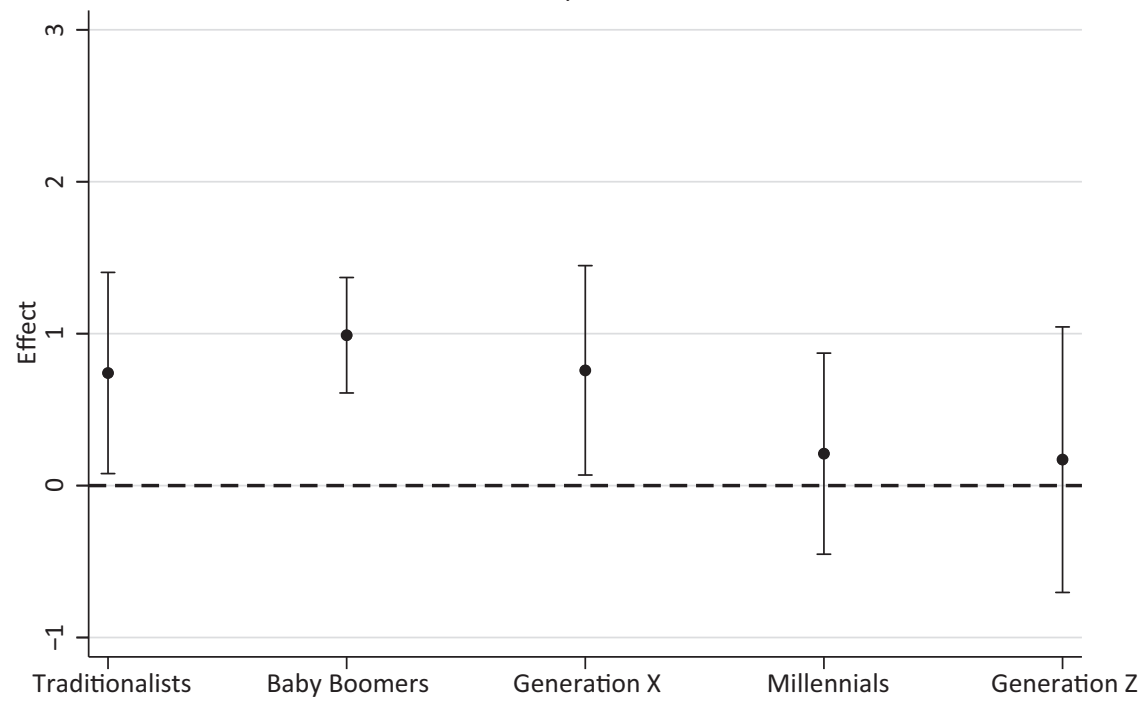

Figure 9.9 Marginal effects of exposure to political information on social media on non-political but politically motivated participation (PP IV) across generations

Notes. The estimates are displayed with a 95 percent confidence interval. Bonferroni correction used to counteract the problem of multiple comparisons. Full models in the Appendix, Table A9.6. 


\section{Social media, political engagement}

\section{Pathways to political participation}

How does social media exposure actually drive participation among citizens by affecting their political engagement-that is, their political interest, knowledge, and internal efficacy? Again, we focus on generational differences in the pathways to political participation by exploring potential mediation effects, using path model analysis.

For Baby Boomers and Millennials, political social media exposure contributes to their political interest and thereby strengthens their participation in activities targeted at the political system (PP II). For this type of participation, Baby Boomers and Generation X are subject to a weak mediation effect through an increase in political efficacy (Table 9.1). Effects on participation in non-political but politically motivated activities (PP IV) are mediated through an increase in political interest and internal efficacy (Table 9.3). However, no evidence is found that social media use drives PP II and PP IV through political knowledge. Nothing indicates that local participation (PP III) is affected by the effects of political social media exposure on political engagement (Table 9.2). This finding is no surprise since political social media use has limited power to mobilize this type of participation in the first place. Hence, exposure to political news on social media does

Table 9.1 Indirect effects of exposure to political information on social media on political participation II

\begin{tabular}{|c|c|c|c|c|c|c|}
\hline & \multicolumn{3}{|l|}{ Static } & \multicolumn{3}{|c|}{ Dynamic } \\
\hline & Interest & Knowledge & Efficacy & Interest & Knowledge & Efficacy \\
\hline Overall & $\begin{array}{l}.109 * * * \\
(.029)\end{array}$ & $\begin{array}{l}.033^{*} \\
(.016)\end{array}$ & $\begin{array}{l}.074 * * \\
(.026)\end{array}$ & $\begin{array}{l}.035^{*} \\
(.016)\end{array}$ & $\begin{array}{l}.024+ \\
(.014)\end{array}$ & $\begin{array}{l}.022 \\
(.019)\end{array}$ \\
\hline Traditionalists & $\begin{array}{l}.027 \\
(.045)\end{array}$ & $\begin{array}{c}-.016 \\
(.036)\end{array}$ & $\begin{array}{l}.000 \\
(.025)\end{array}$ & $\begin{array}{c}.017 \\
(.036)\end{array}$ & $\begin{array}{c}-.007 \\
(.022)\end{array}$ & $\begin{array}{l}.003 \\
(.024)\end{array}$ \\
\hline Baby Boomers & $\begin{array}{l}.107 * \\
(.045)\end{array}$ & $\begin{array}{l}.010 \\
(.018)\end{array}$ & $\begin{array}{l}.084 * \\
(.042)\end{array}$ & $\begin{array}{l}.031 \\
(.027)\end{array}$ & $\begin{array}{l}.002 \\
(.014)\end{array}$ & $\begin{array}{l}.041 \\
(.039)\end{array}$ \\
\hline Generation X & $\begin{array}{l}.146+ \\
(.087)\end{array}$ & $\begin{array}{l}.113 \\
(.073)\end{array}$ & $\begin{array}{l}.180 * \\
(.091)\end{array}$ & $\begin{array}{l}.021 \\
(.033)\end{array}$ & $\begin{array}{l}.083 \\
(.064)\end{array}$ & $\begin{array}{l}.012 \\
(.062)\end{array}$ \\
\hline Millennials & $\begin{array}{l}.188 * \\
(.084)\end{array}$ & $\begin{array}{l}.076 \\
(.056)\end{array}$ & $\begin{array}{l}.041 \\
(.067)\end{array}$ & $\begin{array}{l}.056 \\
(.047)\end{array}$ & $\begin{array}{l}.033 \\
(.046)\end{array}$ & $\begin{array}{c}-.075 \\
(.060)\end{array}$ \\
\hline Generation Z & $\begin{array}{l}.222 * \\
(.113)\end{array}$ & $\begin{array}{l}.132 \\
(.087)\end{array}$ & $\begin{array}{l}.075 \\
(.076)\end{array}$ & $\begin{array}{l}.056 \\
(.085)\end{array}$ & $\begin{array}{l}.086 \\
(.074)\end{array}$ & $\begin{array}{c}-.002 \\
(.034)\end{array}$ \\
\hline
\end{tabular}

Notes. SEM without/with group comparison. Unstandardized coefficients. Standard errors in parentheses. Models include gender and education as controls. Dynamic models also include a lagged dependent variable from wave 1 .

$+\mathrm{p}<.1, * \mathrm{p}<.05, * \mathrm{p}<.01, * * \mathrm{p}<.001 . \mathrm{N}=543$. 
Table 9.2 Indirect effects of exposure to political information on social media on political participation III

\begin{tabular}{|c|c|c|c|c|c|c|}
\hline & \multicolumn{3}{|l|}{ Static } & \multicolumn{3}{|c|}{ Dynamic } \\
\hline & Interest & Knowledge & Efficacy & Interest & Knowledge & Efficacy \\
\hline Overall & $\begin{array}{l}.084 * * \\
(.030)\end{array}$ & $\begin{array}{l}.039 * \\
(.020)\end{array}$ & $\begin{array}{l}.024 \\
(.017)\end{array}$ & $\begin{array}{l}.016 \\
(.015)\end{array}$ & $\begin{array}{l}.020 \\
(.015)\end{array}$ & $\begin{array}{c}.001 \\
(.006)\end{array}$ \\
\hline Traditionalists & $\begin{array}{c}.031 \\
(.058)\end{array}$ & $\begin{array}{c}-.028 \\
(.062)\end{array}$ & $\begin{array}{l}.000 \\
(.016)\end{array}$ & $\begin{array}{c}.045 \\
(.068)\end{array}$ & $\begin{array}{c}-.010 \\
(.031)\end{array}$ & $\begin{array}{c}-.043 \\
(.065)\end{array}$ \\
\hline Baby Boomers & $\begin{array}{c}.049 \\
(.042)\end{array}$ & $\begin{array}{l}.007 \\
(.024)\end{array}$ & $\begin{array}{c}.002 \\
(.030)\end{array}$ & $\begin{array}{c}.002 \\
(.017)\end{array}$ & $\begin{array}{c}-.004 \\
(.019)\end{array}$ & $\begin{array}{c}-.004 \\
(.015)\end{array}$ \\
\hline Generation X & $\begin{array}{l}.130 \\
(.089)\end{array}$ & $\begin{array}{l}.107 \\
(.074)\end{array}$ & $\begin{array}{l}.126 \\
(.081)\end{array}$ & $\begin{array}{c}.013 \\
(.026)\end{array}$ & $\begin{array}{l}.080 \\
(.064)\end{array}$ & $\begin{array}{l}.006 \\
(.033)\end{array}$ \\
\hline Millennials & $\begin{array}{c}.097 \\
(.059)\end{array}$ & $\begin{array}{l}-.002 \\
(.039)\end{array}$ & $\begin{array}{l}.021 \\
(.036)\end{array}$ & $\begin{array}{l}.035 \\
(.036)\end{array}$ & $\begin{array}{c}-.007 \\
(.038)\end{array}$ & $\begin{array}{c}-.041 \\
(.038)\end{array}$ \\
\hline Generation Z & $\begin{array}{l}.094 \\
(.122)\end{array}$ & $\begin{array}{l}.068 \\
(.082)\end{array}$ & $\begin{array}{l}.116 \\
(.098)\end{array}$ & $\begin{array}{c}-.013 \\
(.109)\end{array}$ & $\begin{array}{l}.041 \\
(.062)\end{array}$ & $\begin{array}{l}.010 \\
(.043)\end{array}$ \\
\hline
\end{tabular}

Notes. SEM without/with group comparison. Unstandardized coefficients. Standard errors in parentheses. Models include gender and education as controls. Dynamic models also include a lagged dependent variable from wave 1 .

$* \mathrm{p}<.05, * \mathrm{p}<.01 . \mathrm{N}=543$.

Table 9.3 Indirect effects of exposure to political information on social media on political participation IV

\begin{tabular}{|c|c|c|c|c|c|c|}
\hline & \multicolumn{3}{|l|}{ Static } & \multicolumn{3}{|c|}{ Dynamic } \\
\hline & Interest & Knowledge & Efficacy & Interest & Knowledge & Efficacy \\
\hline Overall & $\begin{array}{l}.176^{* * * *} \\
(.044)\end{array}$ & $\begin{array}{l}.070 * \\
(.028)\end{array}$ & $\begin{array}{l}.107^{* *} \\
(.038)\end{array}$ & $\begin{array}{l}.059 * \\
(.026)\end{array}$ & $\begin{array}{l}.046^{*} \\
(.023)\end{array}$ & $\begin{array}{l}.029 \\
(.025)\end{array}$ \\
\hline Traditionalists & $\begin{array}{l}.063 \\
(.103)\end{array}$ & $\begin{array}{c}-.013 \\
(.035)\end{array}$ & $\begin{array}{l}.000 \\
(.074)\end{array}$ & $\begin{array}{l}.066 \\
(.077)\end{array}$ & $\begin{array}{c}-.009 \\
(.030)\end{array}$ & $\begin{array}{l}.075 \\
(.098)\end{array}$ \\
\hline Baby Boomers & $\begin{array}{l}.177^{*} \\
(.069)\end{array}$ & $\begin{array}{l}.057 \\
(.039)\end{array}$ & $\begin{array}{l}.105^{*} \\
(.054)\end{array}$ & $\begin{array}{l}.063 \\
(.052)\end{array}$ & $\begin{array}{l}.039 \\
(.033)\end{array}$ & $\begin{array}{l}.041 \\
(.040)\end{array}$ \\
\hline Generation X & $\begin{array}{l}.275^{*} \\
(.137)\end{array}$ & $\begin{array}{l}.125 \\
(.097)\end{array}$ & $\begin{array}{l}.271 * \\
(.135)\end{array}$ & $\begin{array}{l}.033 \\
(.051)\end{array}$ & $\begin{array}{l}.111 \\
(.088)\end{array}$ & $\begin{array}{l}.015 \\
(.079)\end{array}$ \\
\hline Millennials & $\begin{array}{l}.248+ \\
(.135)\end{array}$ & $\begin{array}{l}.092 \\
(.094)\end{array}$ & $\begin{array}{l}.063 \\
(.104)\end{array}$ & $\begin{array}{l}.028 \\
(.066)\end{array}$ & $\begin{array}{l}.051 \\
(.086)\end{array}$ & $\begin{array}{l}-.067 \\
(.070)\end{array}$ \\
\hline Generation Z & $\begin{array}{l}.256 \\
(.162)\end{array}$ & $\begin{array}{l}.179 \\
(.127)\end{array}$ & $\begin{array}{l}.259+ \\
(.150)\end{array}$ & $\begin{array}{l}.052 \\
(.132)\end{array}$ & $\begin{array}{l}.075 \\
(.084)\end{array}$ & $\begin{array}{l}.119 \\
(.121)\end{array}$ \\
\hline
\end{tabular}

Notes. SEM without/with group comparison. Unstandardized coefficients. Standard errors in parentheses. Models include gender and education as controls. Dynamic models also include a lagged dependent variable from wave 1 .

$+\mathrm{p}<.1, * \mathrm{p}<.05, * \mathrm{p}<.01, * * \mathrm{p}<.001 . \mathrm{N}=543$. 
not make people more knowledgeable in a way that increases their political participation. However, the middle generations become more politically interested and efficacious when consuming political news on social media, and this seems to translate into an increase in their participation in certain types of political activity.

When it comes to generational differences, Baby Boomers are the generation whose political participation is most consistently affected by political social media exposure through political engagement. Their participation targeted at the political system (PP II) and in non-political but politically motivated activities (PP IV) is affected by political social media use through political interest and efficacy, as is-with some statistical uncertainties-the case with Generation X. Political social media exposure only affects Millennials' participation targeted at the political system (PP II) through political interest. So, even if political interest is mostly affected by social media exposure (see Figure 9.2), it is responsible for an increase in political participation only for Baby Boomers, Generation X, and Millennials.

Political participation among the youngest and oldest generations is not at all indirectly affected by political social media exposure. Hence, it may be worth exploring additional reasons for what drives political participation among these generations. Of particular relevance is the mobilizing effect that we find among Traditionalists in regard to PP IV; social media exposure increases this type of participation, but this increase seems not to be related to an increased political engagement.

\section{Are social media responsible for participation gaps?}

This chapter explored the potential of social media to spark political engagement and participation among different generations. Overall, gaps between types of participation are bigger than between generations. Nonetheless, political involvement does vary across generations, and the cohort in which citizens come of age also leads to notable differences in the levels of political engagement and behaviour.

Political social media exposure contributes to how strongly people are engaged in politics. Across generations, the strongest relation is found between political social media exposure and political interest, whereas political knowledge and internal political efficacy are less affected. But not all generations benefit equally: on average, the interest, knowledge, and efficacy of the youngest cohort, Generation Z, rises the most with increased political social media use. As for political participation, across generations there is indication that exposure to political information on platforms like Facebook or YouTube contributes to citizens' political behaviour. Not only is non-political, politically motivated participation (PP IV) affected by social media use-but so too is participation directly targeted at the political system (PP II). Hence, political social media exposure contributes to citizens' political participation in activities that are directly as well as only indirectly 
connected to the political system. The two youngest and the oldest generations, however, benefit only to a limited extent from their political social media use exposure.

Our analysis finds that a change in the media environment, such as the increasing social media platforms, may alter political behaviour. Such behavioural changes are not caused by technology itself. Instead, different media provide different opportunities to be informed about politics (Prior, 2007). It thus seems as if political social media content with high personal relevance, diversity, and directness has the potential to affect political behaviour. The easy, no-cost, and low-threshold access to political information from a variety of sources may increase opportunities to learn about political issues and become politically engaged. At the same time, algorithm-supported content curation and recommendations, as well as reactions or comments by other users, potentially minimize the need to be motivated as a prerequisite for processing political content and extracting relevant information.

Only weak support is given to our expectation that the upbringing of, in particular, Millennials and Generation $\mathrm{Z}$ in a digital media environment makes them the strongest beneficiaries of using social media platforms for political information. Their political social media exposure seems to result in higher levels of political participation in only a few cases. Interestingly, regarding political participation, the older generations' (Traditionalists, Baby Boomers, and Generation X) response to the availability of political information on social media platforms is also positive and includes new types of political participation. Thus, social media use does not seem to be responsible for generational gaps in political participation.

But from another perspective, our findings indicate that political social media use may contribute to participation disparities between different cohorts. Millennials and Generation $\mathrm{Z}$ are among the citizens most exposed to social media news; their exposure, however, translates into political participation only to a limited extent. Older generations are skilled in transforming political information-even when extracted from social media-into action. The two youngest generations never acquired such skills in an offline media environment, and our study indicates that they did not fully develop them in a digital media environment either. If so, the fact that they primarily expose themselves to political news on social media contributes to a generational participation gap.

Factors other than social media exposure may explain the participation patterns of younger generations. Millennials grew up in a in a time of great political uncertainty, which may make them question the meaningfulness of political participation, no matter how well informed they are about politics. If that is the case, we are dealing with a cohort effect. In addition, these generations, being at the early stages of their life cycles, are preoccupied by efforts to find their own positions in life and therefore may not have the individual resources, such as spare time and money, that are important preconditions for political participation (Verba et al., 1995). There is no 


\section{Social media, political engagement}

indication that Millennials tune out from political and current affairs in their news consumption, but though they inform themselves and participate online, in their stage of life it may be difficult to turn the possession of political information into everyday political action. This speaks for a life-cycle effect. Though we find similar patterns for Generation Z, it is too early to say whether the weak effects of social media exposure on participation remain once their formative years lie behind them.

We conclude that the capability of political information to spark political engagement and participation among Danish citizens is not endangered by a shift in news exposure from legacy to social media. Social media exposure contributes not only to a form of participation that that has been described as rather lightweight (Morozov, 2009) but also to more demanding ways of addressing the political system. Older generations seem to profit the most from the personally relevant, diverse, and directed content that they encounter on social media. On a more worrisome note, political information exposure on platforms like Facebook, YouTube, and Instagram does not seem to spark local political participation. It is important to explore further why social media's ability to mobilize is restricted in this respect. However, overall we find that political social media exposure, just like legacy media exposure, has the potential to mobilize political participation across generations. 


\section{Election times: special times?}

In previous chapters we found a rise in political participation and exposure to political information in traditional news media and on social media during an election. This chapter further explores the effects of media exposure on political participation during an election across different generations by also looking at the role of political engagement: interest, knowledge, and efficacy. Our analyses show that the political news consumption of Millennials and Generation $\mathrm{Z}$ contributes little to their high levels of campaign participation. In line with the findings in the previous chapter, mostly older generations benefit from political social media exposure as regards their campaign participation.

In this chapter we investigate whether elections are indeed special when it comes to media exposure and its mobilizing effects on political participation. As seen in previous chapters, media attention to political topics goes up during campaign time, and these reoccurring, politically heightened days seem to increase the political involvement of citizens. We now test the relationship between news media consumption and political participation in greater detail, applying the Engagement-Participation-Information-Generation (EPIG) model to the Danish election campaign period in 2015. Our focus lies on the effects of political news and political social media consumption as predictors of campaign participation. This allows us to compare not only the effects of news media and political social media consumption on campaign participation but also campaign to non-campaign times. We can thus determine if they differ, in particular, between our five generations.

\section{Political participation in election times}

Election times are important to democracy. To make a competitive model of democracy work, citizens are expected to be aware of political issues relevant for the election, to have knowledge about the track record of the 
incumbent government, and to be informed about the political alternatives (Strömbäck, 2005). The media can play an important role in helping citizens gather the relevant information that is needed to cast informed votes on election day (Colwell Quarles, 1979). Research has found that the media are especially relevant for younger voters since they have just entered the political system and are more uncertain than older generations about whom to vote for in their first elections (Aalberg \& Jenssen, 2007; Colwell Quarles, 1979; Gerber, Green, \& Shachar, 2003; Ha et al., 2013; Ohme, de Vreese, \& Albæk, 2018b; O'Keefe \& Liu, 1980). For the youngest generation in our sample, Generation $\mathrm{Z}$, the election under investigation was the very first national election they were eligible to vote in. They are also the first digital natives to enter the electorate (Moeller et al., 2014). It is therefore of special interest to investigate how they use digital media during the campaign and how it shapes their political behaviour.

Voting decisions are based on a number of different factors. For older citizens, the party orientation and political leanings they have developed over their lifetimes play an important role, though voter volatility is increasing also for older generations (Dalton \& Wattenberg, 2002; Fournier, Nadeau, Blais, Gidengil, \& Nevitte, 2004). Media exposure guides voters in high times of political competition - and not least the young, first-time voters (Aalberg \& Jenssen, 2007; Ha et al., 2013; O’Keefe \& Liu, 1980, Strömbäck, 2005). But so does active participation in the election campaign: it helps citizens make informed voting choices and decide which positions or candidates to support (Verba et al., 1995). This type of engagement with the campaign, beyond mere media use, may be especially important for younger citizens since it helps them get in touch with political candidates, find issues important to them, and identify spaces where they can connect with other voters. In short, active engagement with the campaign can help them cast informed, confident votes (Ohme et al., 2018b). We therefore investigate the relationship between political media exposure and active campaign participation as an additional type of political participation that comes closer to participation within the political system (PP I) but still differs from Van Deth's (2014) initial approach. We keep the proposed EPIG model in mind and look further into the indirect effects that different types of media use can have on campaign participation by increasing political engagement during an election campaign.

\section{Media exposure and campaign participation}

In Chapter 4, we already saw how exposure to political information increases considerably during election time. Hence, an upcoming election leads people to dedicate more attention to politics than they do in non-election times. While this pattern holds for all generations, we see generational differences between types of media consumption. The increase in political news exposure is almost equal for all generations (see Figure 4.2), which keeps the distance between generations stable: the older citizens are, the more they consume political news, also in election times. The spike that marks the growth of 
exposure also becomes visible for political social media exposure, though with an opposite generational pattern: the political social media exposure of Millennials and Generation $\mathrm{Z}$ increases almost by 15 percent in contrast to non-election times, whereas the three older generations show a more modest growth in their exposure to political content on social media. After the election, however, the level of social media use returns to its relatively low starting point. Political social media use may be more appealing to younger generations, also during election times, because this type of political news can be a by-product of other types of media exposure and is more easily digestible (Fletcher \& Nielsen, 2017; Brundidge, 2010). In addition, political actors, such as parties or candidates, increasingly use social media to directly reach citizens, thereby bypassing journalistic filters. This personalized style of communication (Kruikemeier, Sezgin, \& Boerman, 2016) may be especially appealing to younger generations and thus further contributes to their high level of political social media exposure during election times (Ohme, 2019).

Citizens participate in various activities related to the election campaign. At campaign events, they can get in touch with politicians and other voters, they can support a party or convince others to vote, or they may involve themselves in actions online, such as discussing political issues in social media groups or using a vote advice application. What these actions have in common is that they go beyond mere political information exposure and may thereby help citizens be more closely connected with the upcoming elections, thus helping them to cast more-informed votes.

Looking at overall participation patterns (Figure 10.1), the two younger generations more often participate in campaign-related activities than the three older generations. Hence, participation patterns are turned upside

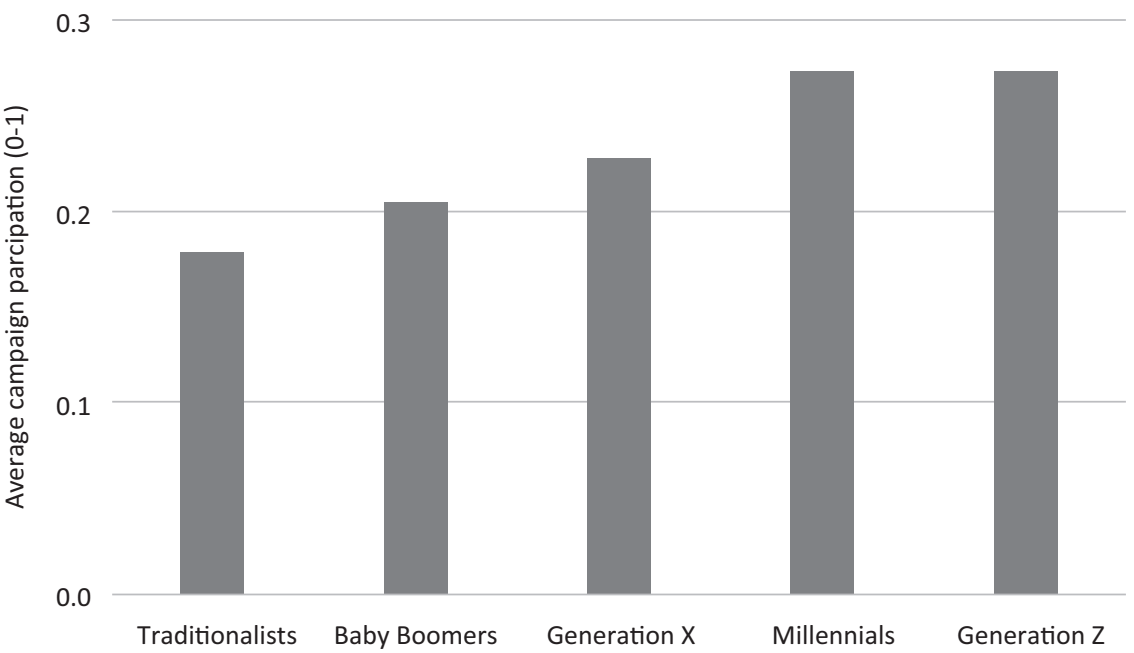

Figure 10.1 Levels of campaign participation across generations

Notes. Levels of campaign participation measured in wave 4 . 


\section{Election times}

down during an election campaign, compared to non-election times. While either Traditionalists, Baby Boomers, or Generation X exhibited the highest levels of activity in one of the three types of non-electoral participation in previous chapters, Millennials and Generation $\mathrm{Z}$ are leading, with equal levels of participation in election times. Thus, election campaigns have the power to especially engage and excite young citizens about politics.

However, a more differentiated picture emerges when we compare the different activities across generations (Figure 10.2). Millennials and Generation $\mathrm{Z}$ more often discuss election-related issues on social media, talk about the election, or take a vote advice application test. Traditionalists, Baby Boomers, and Generation X more often make others aware that they will vote, share information on social media about the election, or support a candidate with the help of social media. All generations score equally low when it comes to volunteering for a political party in an offline context. Though clear differences between generations exist, the fault line does not run between online and offline options of campaign participation. Rather, we see that Millennials and Generation $Z$ strongly engage in activities through which they receive additional input on the election, either through

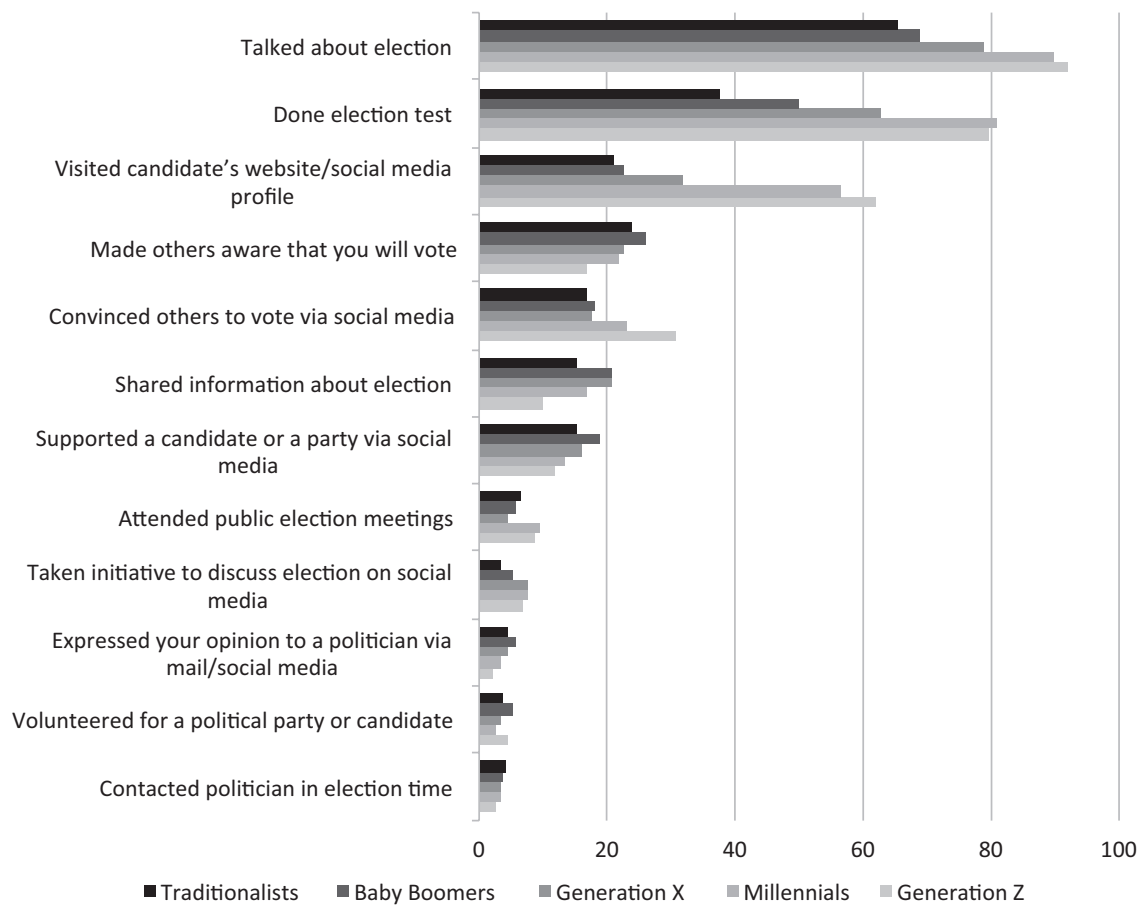

Figure 10.2 Frequency of campaign participation across generations

Notes. Measured in online survey wave 4. 
the use of dedicated websites or through discussions with others, whereas the three older generations are active in behaviours that are more directed towards making others aware about the election or issues related to it. This difference between young people informing themselves and older citizens informing others speaks for a life-cycle effect, resulting in less-experienced voters seeking information and more-experienced voters sharing information in various ways.

\section{Drivers of campaign participation}

How much are these differences in participation patterns related to political information exposure during the election campaign? We first look at a static model (Figure 10.3), which shows that political news consumption is more strongly related to campaign participation for the two youngest generations, followed by Baby Boomers. This pattern, however, changes when we look at the dynamic model. As explained in Chapter 3, our modelling strategy here differs from previous dynamic models, in which an actual lagged dependent variable was included. As a proxy for a lagged dependent variable, the dynamic models that enable us to predict campaign participation instead use the intention to participate that the respondents expressed at the beginning of the campaign. In the dynamic models, political news consumption positively changes the level of active campaign participation across campaign time only for Traditionalists, Baby Boomers, and Millennials. This pattern is similar to the one found in Chapter 6 for the mobilizing effects of political news consumption on participation directly targeted at the political system (PP II), though the effect on campaign participation is slightly weaker. The similarity in patterns may not be all that surprising given that campaign participation and PP II are both closely related to the political system. What is different is that political news consumption influences Millennials positively, whereas for Generation Z, higher levels of political news consumption during the election campaign do not lead to more activity in campaign participation, at least in a dynamic assessment.

With respect to political social media exposure, we find a different mobilization pattern. As estimated in the static model, being exposed to political information on social media during an election campaign is correlated with campaign participation for all generations (Figure 10.4). The relationship is stronger for the three older generations. Hence, though their use of social media during the election campaign is lower than for younger generations, it corresponds more with active campaign participation. In our dynamic models, this pattern is further solidified. Here, political social media use positively affects the campaign participation of only Traditionalists, Baby Boomers, and Generation X, while no significant influence is found for Millennials and Generation Z. The change between their intended participation and actual campaign participation over the campaign period cannot therefore be explained by the frequency of their political social media use. 

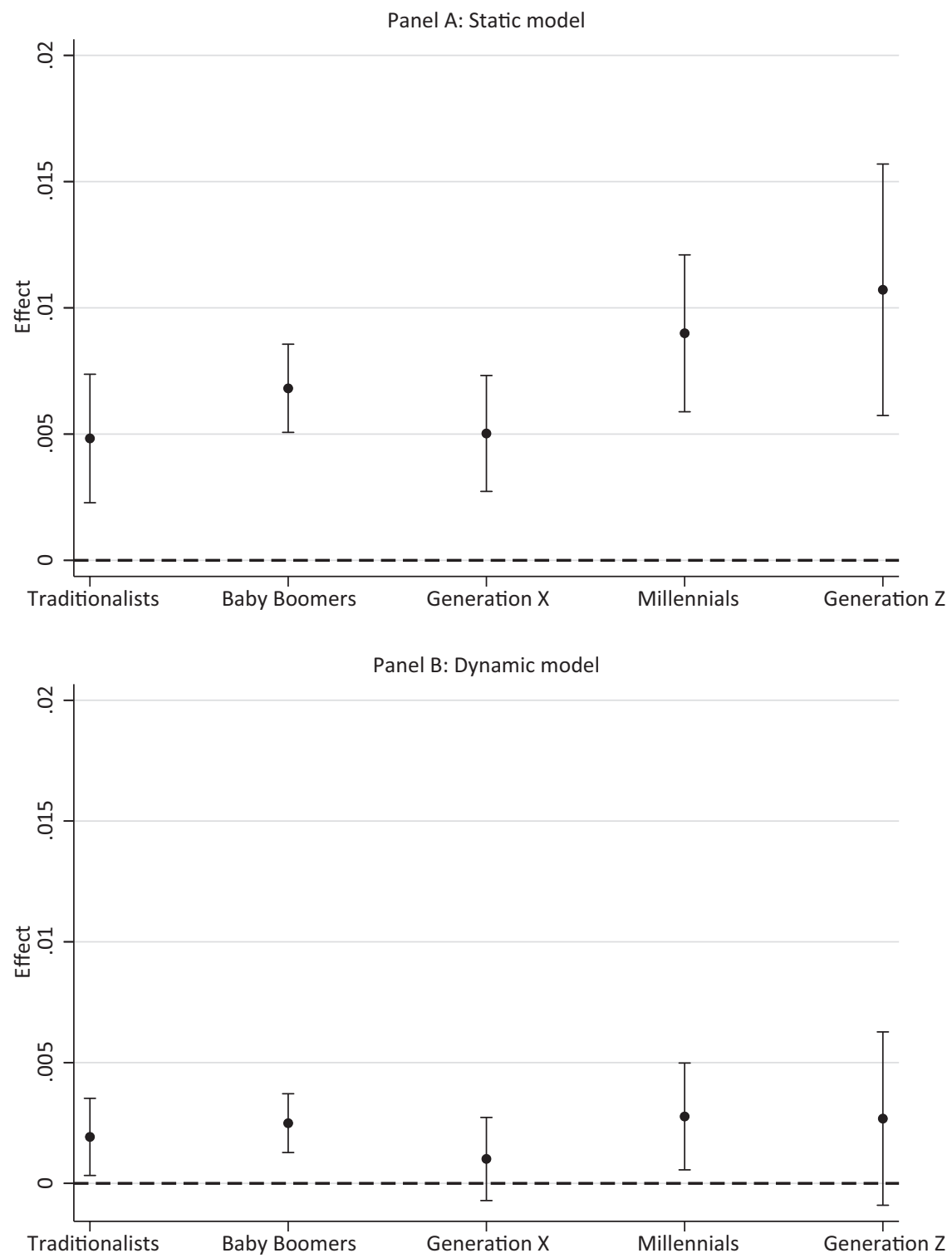

Figure 10.3 Marginal effects of exposure to political information in the news media on campaign participation

Notes. The estimates are displayed with a 95 percent confidence interval. Bonferroni correction used to counteract the problem of multiple comparisons. Full models in the Appendix, Table A10.1. 


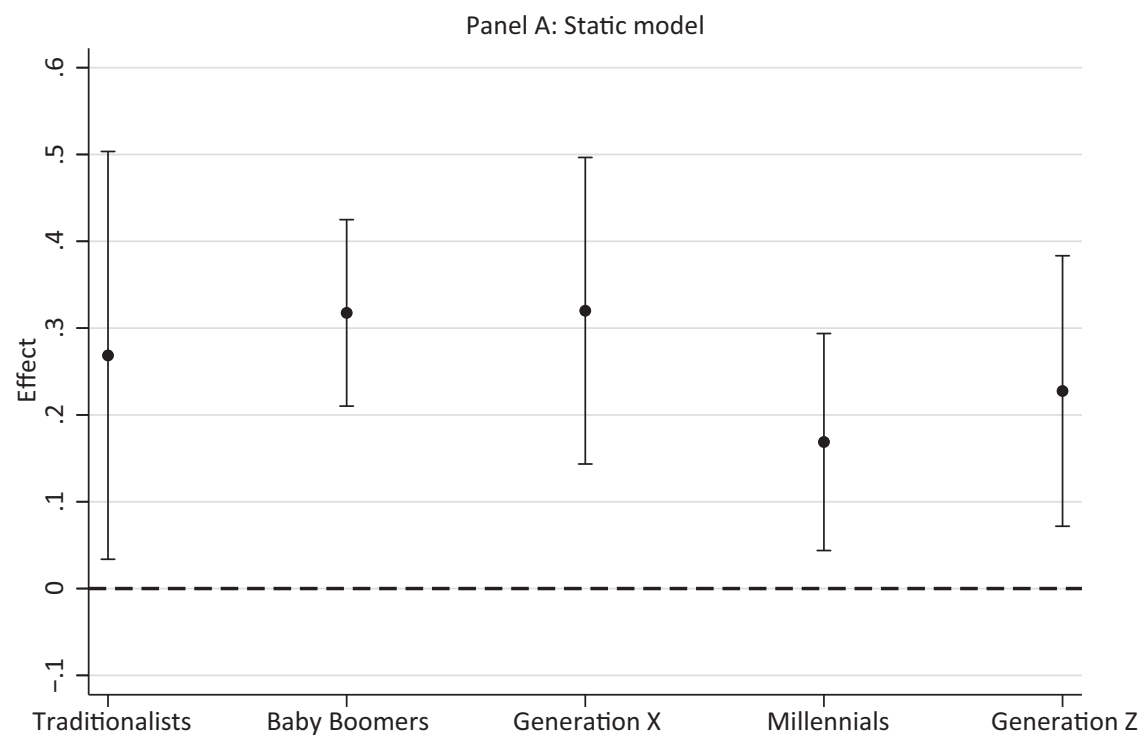

Panel B: Dynamic model

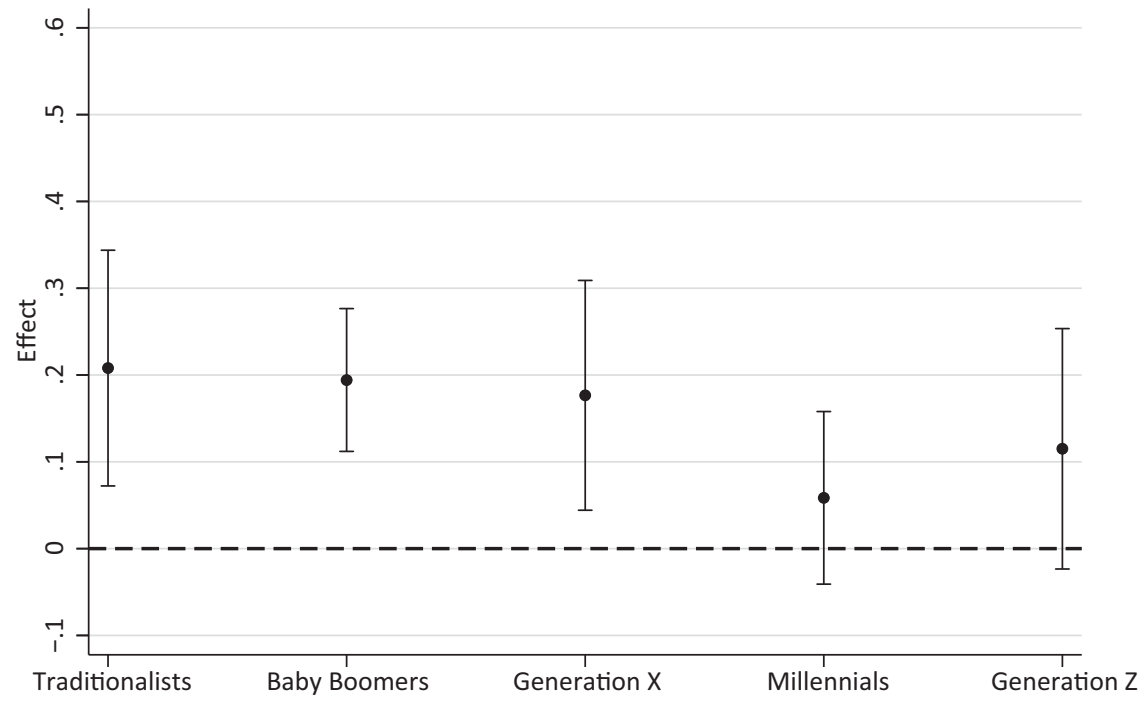

Figure 10.4 Marginal effects of exposure to political information on social media on campaign participation

Notes. The estimates are displayed with a 95 percent confidence interval. Bonferroni correction used to counteract the problem of multiple comparisons. Full models in the Appendix, Table A10.2. 


\section{Election times}

Though the results are contrary to our initial assumption that younger citizens benefit the most from political social media use (e.g., Holt, Shehata, Strömbäck, \& Ljungberg, 2013; Xenos et al., 2014), the pattern is strikingly similar to the mobilizing effect we found for political social media exposure in Chapter 9. Here, non-political but politically motivated activities (PP IV) were likewise affected by social media exposure for only the three older generations but not for Millennials and Generation Z. The similarities between the mobilization of campaign participation found in this chapter with the mobilization of, on the one hand, participation targeted at the political system (PP II; see Chapter 6) and, on the other hand, non-political but politically motivated activities (PP IV; see Chapter 9) indicate that we have found somewhat systematic patterns: political news consumption affects types of participation that are closely related to the political system, and political social media use affects older generations more than younger generations. In sum, we find support for the direct relationship between political media consumption and political participation as proposed in the EPIG model, in election as well as non-election contexts, and we also find generational differences in both contexts.

Furthermore, the EPIG model suggests that these effects are partly caused by a strengthening of political engagement. We therefore look at indirect effects of media exposure on campaign participation through increased political interest, knowledge, and efficacy (for direct effects, see Tables A10.1-A10.2 in the Appendix). In Table 10.1, we see substantial effects.

Table 10.1 Indirect effects of exposure to political information in the news media on campaign participation

\begin{tabular}{|c|c|c|c|c|c|c|}
\hline & \multicolumn{3}{|l|}{ Static } & \multicolumn{3}{|c|}{ Dynamic } \\
\hline & Interest & Knowledge & Efficacy & Interest & Knowledge & Efficacy \\
\hline Overall & $\begin{array}{l}.003 * * * \\
(.001)\end{array}$ & $\begin{array}{l}.000 * * * * \\
(.000)\end{array}$ & $\begin{array}{l}.001 * * * \\
(.000)\end{array}$ & $\begin{array}{l}.000 \\
(.000)\end{array}$ & $\begin{array}{l}.000 \\
(.000)\end{array}$ & $\begin{array}{l}.000 * * * \\
(.000)\end{array}$ \\
\hline Traditionalists & $\begin{array}{l}.001 * * * \\
(.000)\end{array}$ & $\begin{array}{l}.000 \\
(.000)\end{array}$ & $\begin{array}{l}.001 * \\
(.000)\end{array}$ & $\begin{array}{l}.000 \\
(.000)\end{array}$ & $\begin{array}{l}-.000 \\
(.000)\end{array}$ & $\begin{array}{l}.000 \\
(.000)\end{array}$ \\
\hline Baby Boomers & $\begin{array}{l}.003 * * * \\
(.000)\end{array}$ & $\begin{array}{l}.000 * \\
(.000)\end{array}$ & $\begin{array}{l}.001 * * * \\
(.000)\end{array}$ & $\begin{array}{l}.000 \\
(.000)\end{array}$ & $\begin{array}{l}.000 \\
(.000)\end{array}$ & $\begin{array}{l}.000 * * \\
(.000)\end{array}$ \\
\hline Generation X & $\begin{array}{l}.003 * * * \\
(.000)\end{array}$ & $\begin{array}{l}.001^{*} \\
(.006)\end{array}$ & $\begin{array}{l}.001 * * * * \\
(.000)\end{array}$ & $\begin{array}{l}.000 \\
(.000)\end{array}$ & $\begin{array}{l}-.000 \\
(.000)\end{array}$ & $\begin{array}{l}.000 \\
(.000)\end{array}$ \\
\hline Millennials & $\begin{array}{l}.004 * * * \\
(.001)\end{array}$ & $\begin{array}{l}.002 * * * \\
(.000)\end{array}$ & $\begin{array}{l}.002 * * * \\
(.001)\end{array}$ & $\begin{array}{l}.001 \\
(.000)\end{array}$ & $\begin{array}{l}.001 * \\
(.000)\end{array}$ & $\begin{array}{l}.001 * * \\
(.000)\end{array}$ \\
\hline Generation Z & $\begin{array}{l}.006^{* * *} \\
(.001)\end{array}$ & $\begin{array}{l}.002 * * \\
(.001)\end{array}$ & $\begin{array}{l}.003 * * * \\
(.001)\end{array}$ & $\begin{array}{l}.000 \\
(.001)\end{array}$ & $\begin{array}{l}.000 \\
(.000)\end{array}$ & $\begin{array}{l}.001 \\
(.001)\end{array}$ \\
\hline
\end{tabular}

Notes. SEM without/with group comparison. Unstandardized coefficients. Standard errors in parentheses. Models include gender and education as controls. Dynamic models also include a lagged dependent variable.

$* \mathrm{p}<.05, * \mathrm{p}<.01, * * \mathrm{p}<.001 . \mathrm{N}=3,490$. 
Overall, the static models indicate higher levels of campaign participation, apparently because the respondents' political news consumption increases their levels of political interest, knowledge, and efficacy. This effect is strongest for the two younger generations. However, in the dynamic models, there is little evidence that political media exposure affects campaign participation positively as a result of an increase in political engagement during campaign time. This is true for almost all generations. Millennials are the exception, with a mediation through political knowledge and efficacy.

Political engagement also mediates the relationship between political social media exposure and campaign participation. Here again, the static models indicate that high political engagement due to social media exposure increases the campaign participation of Millennials and Generation $\mathrm{Z}$ (see Table 10.2). In the dynamic models, we find a much weaker support for an indirect effect on campaign participation. While there are no indirect effects for Traditionalists, Baby Boomers, Millennials, and Generation Z, Table 10.2 indicates that the campaign participation of Generation $\mathrm{X}$ is affected positively by social media exposure due to the latter contributing to an increase in political interest and efficacy.

Table 10.2 Indirect effects of exposure to political information on social media on campaign participation

\begin{tabular}{|c|c|c|c|c|c|c|}
\hline & \multicolumn{3}{|l|}{ Static } & \multicolumn{3}{|l|}{ Dynamic } \\
\hline & Interest & Knowledge & Efficacy & Interest & Knowledge & Efficacy \\
\hline Overall & $\begin{array}{l}.030 * * * \\
(.007)\end{array}$ & $\begin{array}{l}.004 \\
(.003)\end{array}$ & $\begin{array}{l}.024 * * * \\
(.007)\end{array}$ & $\begin{array}{l}.005 \\
(.004)\end{array}$ & $\begin{array}{l}.001 \\
(.002)\end{array}$ & $\begin{array}{l}.009 * \\
(.004)\end{array}$ \\
\hline Traditionalists & $\begin{array}{l}.016 \\
(.022)\end{array}$ & $\begin{array}{r}.003 \\
(007)\end{array}$ & $\begin{array}{l}.004 \\
(.016)\end{array}$ & $\begin{array}{l}.004 \\
(.007)\end{array}$ & $\begin{array}{l}.006 \\
(.013)\end{array}$ & $\begin{array}{c}-.002 \\
(.008)\end{array}$ \\
\hline Baby Boomers & $\begin{array}{l}.036 * * \\
(.013)\end{array}$ & $\begin{array}{l}.001 \\
(.002)\end{array}$ & $\begin{array}{l}.020 * \\
(.009)\end{array}$ & $\begin{array}{l}.005 \\
(.006)\end{array}$ & $\begin{array}{l}.001 \\
(.002)\end{array}$ & $\begin{array}{l}.003 \\
(.005)\end{array}$ \\
\hline Generation X & $\begin{array}{l}.061 * \\
(.027)\end{array}$ & $\begin{array}{l}.013 \\
(.011)\end{array}$ & $\begin{array}{l}.064 * * \\
(.024)\end{array}$ & $\begin{array}{c}.034+ \\
(.018)\end{array}$ & $\begin{array}{l}.000 \\
(.008)\end{array}$ & $\begin{array}{l}.043 * \\
(.019)\end{array}$ \\
\hline Millennials & $\begin{array}{l}.037^{*} \\
(.018)\end{array}$ & $\begin{array}{l}.015 \\
(.013)\end{array}$ & $\begin{array}{l}.020 \\
(.017)\end{array}$ & $\begin{array}{l}-.005 \\
(.013)\end{array}$ & $\begin{array}{l}.008 \\
(.010)\end{array}$ & $\begin{array}{l}.008 \\
(.008)\end{array}$ \\
\hline Generation Z & $\begin{array}{l}.074 * \\
(.030)\end{array}$ & $\begin{array}{l}.035 \\
(.023)\end{array}$ & $\begin{array}{c}.039+ \\
(.022)\end{array}$ & $\begin{array}{l}.053 \\
(.034)\end{array}$ & $\begin{array}{l}.031 \\
(.022)\end{array}$ & $\begin{array}{l}.030 \\
(.019)\end{array}$ \\
\hline
\end{tabular}

Notes. SEM without/with group comparison. Unstandardized coefficients. Standard errors in parentheses. Models include gender and education as controls. Dynamic models also include a lagged dependent variable.

$+\mathrm{p}<.1,{ }^{*} \mathrm{p}<.05, * \mathrm{p}<.01, * * \mathrm{p}<.001 . \mathrm{N}=543$. 


\section{Election times}

\section{Importance of political campaigns for younger generations}

While most findings reflect the patterns between media use and participation that we found in previous chapters, two findings in the present chapter deserve special attention. First, the effects that media consumption has on Millennials stand out compared to other generations. Millennials exhibit high levels of campaign participation and are especially affected by political news exposure. Their political news consumption not only has a direct positive effect but also contributes to higher levels of knowledge and efficacy. Hence, when it comes to short-term engagement around a specific, high-profile political event, Millennials apparently can be mobilized by both types of political news consumption. For a generation that is otherwise considered lethargic and difficult to mobilize, an election campaign appears to be the right moment in time to activate them.

Second, Generation Z differs markedly from Millennials. Neither political news nor political social media consumption seems to mobilize their campaign participation, whether directly or through an indirect political engagement pathway. Research suggests that the media may play a greater role in affecting the turnout and vote choice of young, inexperienced voters compared to older voters (Holt et al., 2013; Ohme et al., 2018b); for Generation Z, however-who had their first chance to vote for parliament in the elections under investigation - the mobilizing potential that we found for political news exposure (Chapters 6 and 8) and for political social media exposure (Chapter 9) works more weakly, if at all, in a campaign context. Strikingly, however, this youngest generation exhibits relatively high levels of campaign participation, even on par with Millennials. So what mobilizes them to actively engage with the campaign, if not their political media consumption? One reason for this missing relationship may be that first-time voters still have to establish patterns of media use during election time, finding the right outlets and topics that interest them. Moreover, perhaps we do not find statistically significant effects of social media exposure on the campaign participation of Generation $\mathrm{Z}$ because we examine overall political media exposure instead of specific content types. Young citizens' electoral behaviour is strongly shaped by their social networks-that is, family, peers, and even teachers at school (Bhatti \& Hansen, 2012). With our focus on media effects, we did not dedicate attention to political interaction within peer networks, as done by other research (Lee, Shah, \& McLeod, 2012; Marquart, Ohme, \& Möller, 2020).

Nonetheless, election campaign participation among our youngest generations shows a positive pattern according to both a competitive and a participatory model of democracy. It remains to be seen if their activity level stabilizes or even increases when todays' first-time voters have established more stable patterns of campaign information-gathering through the use of (social) media. But we do see that an election campaign has the potential to mobilize citizens' political participation. 


\section{Are the kids alright?}

Saturday morning, 2025: the family is gathered at home. Father Peter and mother Sarah are still subscribers to the same newspaper, though they have skipped the print edition on weekdays and receive it only on weekends. The youngest kid, 18, still lives at home and, at the age of 15 , followed the older sibling in boycotting meat. Other than living a healthy and sustainable lifestyle, he doesn't show any great interest in politics and only occasionally sees news on social media or when his parents or friends send a news piece via messenger apps. When living at home, the middle kid, now 20, was a strong supporter of animal rights and a member of the Fridays for Future movement, travelling across Europe for demonstrations and boycotts. From those days, she still has a subscription to a left-wing news magazine and regularly informs herself about political developments, mostly via podcasts. Being busy with her studies, she rarely goes to protests anymore but holds an administrative position at her university's animal rights group. The oldest, now 24 , lives with her partner and their one-year old child. They moved to a bigger city for work and now struggle with a challenging housing market and affordable childcare. The little spare time they have after being at work and taking care of their daughter is not spent on following the news. The challenges faced by them have made them become increasingly cynical about a political system that, in their opinion, is unable to support young families. Though politics is still a frequently discussed topic when the oldest visits the family home, she tries to hold back with her political views and tends to air them in a personal messaging group, to which she was invited by a colleague.

Our book set out to explore, on the one hand, how political involvement can lead to different types of political media exposure and, on the other hand, how this media exposure can affect political engagement and participation. In this chapter we first summarize the findings from previous chapters 
to have an authoritative overview of the empirical sections. We then look across the different chapters through the lens of 'generational differences.' Finally, we revisit our Engagement-Participation-Information-Generation (EPIG) model and look ahead in this landscape of rapidly changing media and politics.

In Chapter 1, we outlined the parameters of the changing media landscape, the differences between generations in informing themselves, and the new opportunity structures in political participation. We also presented this book's key puzzle-namely, how different younger generations are compared to older generations in regard to media use and political participation. To provide a framework for this key puzzle, we developed and presented our EPIG model in Chapter 2. The model describes how political engagement and participation are both outcomes of using political information as well as potential antecedents of seeking out political information. We also laid out our generational perspective. A generational perspective enables us to explore differences in the levels of-and relationships between-exposure to political information in the media and political involvement and to assess how the future might look in regard to mobilizing citizens through the media to take part in democracy. We dubbed this the EngagementParticipation-Information-Generation (EPIG) model. In Chapter 3, we outlined the empirical backbone of our work: a five-wave online survey and a three-wave smartphone-based survey with a large national sample as well as an automated content analysis of the major news media.

In the empirical section of the book, we first, in Chapter 4, looked at generational differences in political news exposure. These differences are rather clear-cut. Political news exposure almost linearly increases from younger to the older generations. Social media are used much more by younger generations, with a clear demarcation between Millennials and Generation Z, compared to the three other generations. Election times change things, however. There is more political information in the news media during election time. On social media, the gap between older and younger generations increases during election times: the young use social media much more during election times. In other words, elections draw the attention of young citizens to political information on social media.

Turning to the influence of political engagement, this is in general positively related to citizens' exposure to political information in the media. For young citizens, higher political engagement is a more important precondition for news exposure on both traditional media and social media. This result speaks for a 'rich-get-richer' perspective, in which generations who had more time throughout their lives to develop political interest and efficacy more easily consume news-thereby creating a life-cycle difference. It also clearly indicates the higher threshold that news use still presents for younger citizens, regardless of platform. Social media seem to lower the levels of political engagement that are necessary for political exposure, but they do not diminish the differences between generations. Still, compared to 
older generations, young citizens need to be more interested or efficacious to turn to political information on social media in the first place.

Levels of participation in the three types of political activity addressed in this book are quite stable over time across generations. The prevalent pattern is that older generations are more politically active than the younger ones. All generations show the lowest levels of activity in political participation that directly targets the political system (PP II), with rather small generational gaps. These gaps become more pronounced for participation on a local level (PP III), where Generation Z and Millennials are clearly lagging behind Generation X, Baby Boomers, and Traditionalists. The only type of participation in which the younger-to-older pattern is broken is for nonpolitical but politically motivated participation (PP IV). Here, Generation $\mathrm{X}$ leads. But even though more activities that may be especially appealing to younger generations are subsumed under this last type, Millennials and Generation $Z$ are still the least active. As outlined in Chapter 2, the differences in participation levels speaks more strongly for a cohort effect, in which each generation finds 'their' way of participation, with the constraint that neither Millennials nor Generation Z have found such a way of frequently participating outside election times. This difference in participation patterns between the young and older generations also speaks against the common idea that young people participate most often in activities that are less connected to the political system. However, political activity seems to resonate in election times, when the two youngest generations are the most active in short-term, case-oriented, campaign activities. An election campaign seems to narrow gaps in political engagement, suggesting that election campaigns give impulse to youth engagement.

When it comes to mobilization through political information exposure, more clear-cut, generational differences become visible. We see a clear indication that the youngest generations benefit most from news exposure. News exposure leads to higher levels of participation targeted at the political system (PP II) for almost all generations, but it is strongest for Generation Z. Participation on a local level (PP III) is affected by news exposure only for Baby Boomers. Both Baby Boomers and Generation Z, however, become more active in non-political, politically motivated activities (PP IV) through news exposure; this finding suggests that more news exposure contributes to this type of participation, challenging the assumption that it is sparked only by social media use.

Exposure to political information on social media does indeed mobilize participation in non-political, politically motivated activities and also participation that is targeted at the political system. The youngest generation benefits most from social media use in regard to the latter. In particular, the more older generations are exposed to political information on social media, the more strongly they participate in activities least connected to the political system (i.e., PP IV). This finding speaks strongly against the great equalizer perspective (Xenos et al., 2014): political social media use seems 


\section{Are the kids alright?}

rather to increase inequality in participation between the generations. We find a similar mobilization pattern through social media exposure for campaign participation during election time. In both cases, older citizens benefit more from political social media use than younger generations. The only difference is that young generations are at their most active in campaign participation, which begs the question, what does actually activate them if not media exposure?

\section{Generational similarities and differences}

A number of our findings deserve closer attention and need to be put into perspective. First, we summarize the findings, per generation and per dimension of the EPIG model, looking at how political involvement affects media use (antecedents) and how media use affects political involvement (effects). Table 11.1 provides an overview of the main findings.

Traditionalists developed high levels of political engagement that helped embed political participation in their lives. High levels of involvement, however, are unrelated to their exposure to political information in the media, and this exposure does not shape their political involvement. Traditionalists can thus be described as the unchangeables, who no longer need strong external influences to be-and to remain-politically active. They have internalized political participation into their lives.

Baby Boomers are in a functioning circle between involvement and political information. Previous engagement sparks more news media use, which, in turn, increases levels of political engagement and participation. With this pattern, Baby Boomers clearly give credit to the label evergreen activists, and they seem to have adapted seamlessly to new opportunity structures in media exposure and participation.

Generation X's previous political participation draws them especially to more political social media exposure, which, in turn, increases their political participation. Despite being in their late 30s and 40s right now, they seem to be the real social media profiteers, though they use these platforms only to a modest extent.

The situation is different for Millennials, whose political media diet strongly relies on social media, but, in contrast to the generation that precedes them, their political involvement hardly profits from this exposure. This generation clearly benefits more from political news exposure but largely fails to put it to good use, creating a dilemma that makes Millennials, to some extent, a generation lost in transition.

Similar to their preceding generation, Generation $\mathrm{Z}$ is difficult to mobilize. Only if they have been politically involved do they turn to more political information, which they receive mostly through social media. In comparison to Millennials, Generation $\mathrm{Z}$ show signs of being mobilized by the new information opportunity structure. Nevertheless, political participation is not an integral part of their lives, making them the short-term activists in our generational ensemble. 


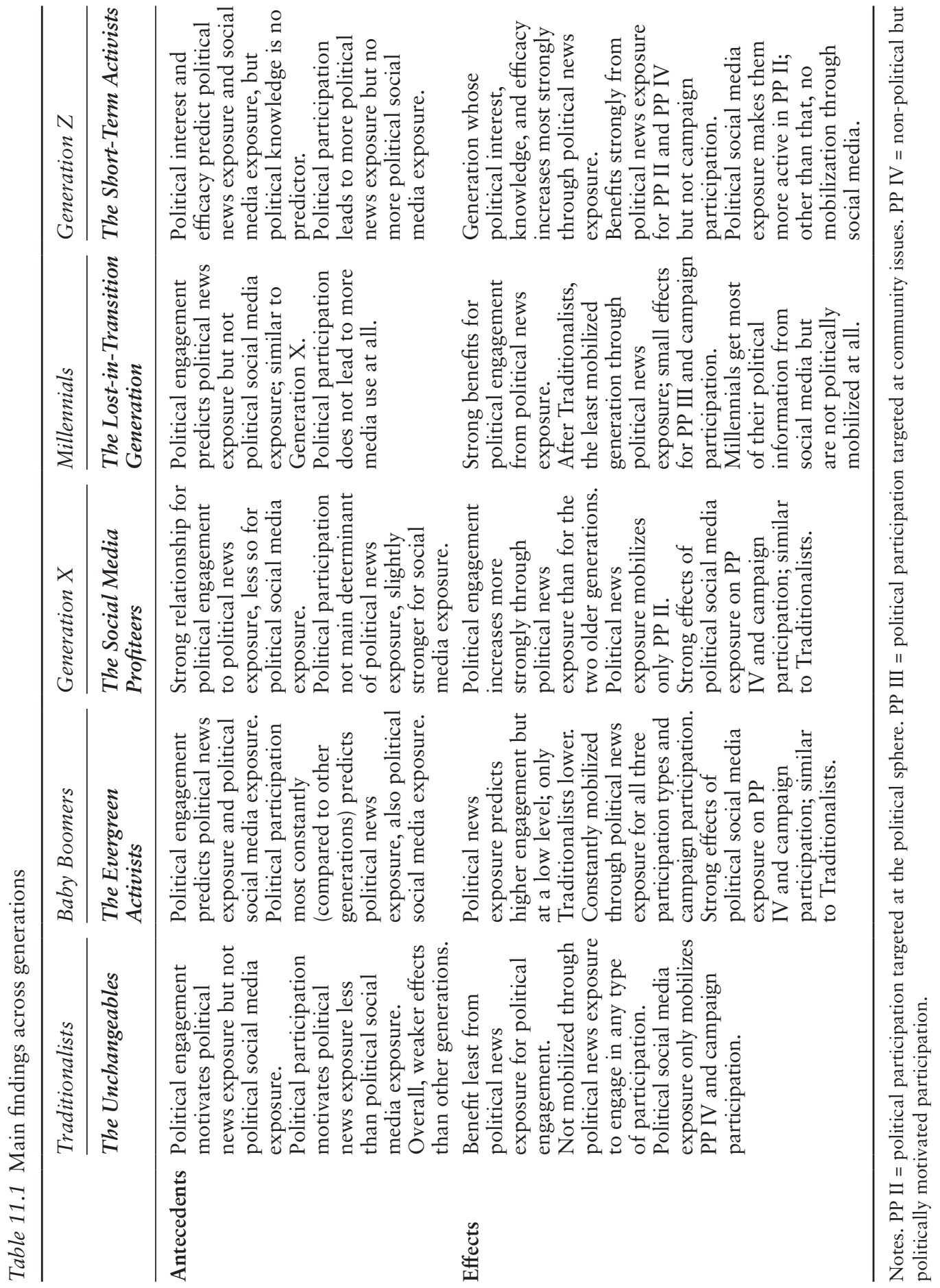




\section{Are the kids alright?}

Looking across the generations, it is a striking result that not one generation leads in all types of participation, but almost each generation leads in a specific type of participation. Traditionalists participate most often in political activities taking place in their local communities. Baby Boomers most often address the political system directly with their political activities, and Generation X is leading when it comes to participation in non-political but politically motivated activities. The two youngest generations, however, participate most often in campaign activities. This pattern makes sense if we consider that more case-oriented and short-term types of participation seem to be most appealing to Millennials and Generation Z. The results point in the direction of specific cohorts finding 'their' way of participating politically.

While it is clear for the three oldest generations which type of participation they prefer, it is more difficult to determine which type of participation, if any, the two younger cohorts are finding for themselves. Of all participation types, Millennials are most active when it comes to supporting political causes with non-political behaviour and may therefore follow Generation X in their high levels of activity in this participation type. For Generation Z, the question seems to be more open. Other than their high level of activity during campaign times, no clear pattern is visible. It is possible that they will not adopt one specific type of participation but rather adhere to supporting short-term causes with the means that they find the most appropriate or necessary. This way may prove more effective than persevering mainly with one specific type of participation; it bears the risk, however, that future generations will, for example, address the political system less often directly or will care less often about the communities that they are living in. Given that participation types are very much in flux, younger generations may possibly develop their own, new modes of participation that, at this point in time, we cannot foresee.

We find a number of generational differences (1) for political involvement that motivates news use and, even more prominently, (2) for how news media can contribute to political involvement. Our panel design is not fully suited to determine whether we are dealing with life-cycle or cohort effects. However, some pronounced patterns might help us attribute differences to either one of the possibilities. Whenever we find linearity in our resultsthat is, an increase or decrease in levels of effect sizes per generation-it is more likely that we are dealing with a life-cycle effect. The different political socialization paths described in Chapter 2 make clear that though different, it is unlikely that each cohort simply becomes less susceptible to news media or politically less active just because the members of each were born in a different time. With generations 'sticking out' of a linear pattern, what we therefore apparently see is an indication of a cohort effect.

The pattern of linearity becomes especially visible for the relationship between news media exposure and how strongly generations benefit in regards to their political interest, knowledge, and efficacy. Though less 
clear-cut, we also find an indication that, compared to older generations, younger generations' political interest and knowledge benefit more strongly from political social media exposure. These findings show that, in general, younger generations are more susceptible to political information, potentially due to its novelty and to their own curiosity, inexperience, ignorance, and lack of party identification and fixed political views. Perhaps lower levels of disillusionment with the political system also have a role to play. This finding also speaks for the argument (Shehata, 2016) that when it comes to news media's power to increase political engagement, we do not only experience a ceiling effect in terms of what our survey measures can achieve but also that the older citizens become, the less the news media moves their interest, knowledge, and efficacy—potentially because they have already achieved relative strength in these areas.

However, when it comes to news media exposure encouraging political participation in various areas, we find neither a linear pattern nor any other pattern that speaks for strong life-cycle effects. More than that, specific similarities between cohorts become visible. One striking similarity exists between Baby Boomers and Generation Z. These two generations become mobilized in equal ways, though differing in scale, by their news media use-in most instances, more strongly than other generations. This patterns also holds for certain (but not all) types of mobilization based on social media exposure.

The relevant question is whether the two generations have similarities in their upbringing and therefore exhibit similar patterns in mobilization by the news. One could consider that Baby Boomers and Generation Z, more than other generations, share the feeling that they not only need but also can act upon information that they receive in the political world. Baby Boomers grew up at a time when they wanted to differentiate themselves from their Traditionalist parents. A number of societal challenges gave them the opportunity to do so, be it demonstrations around Cold War developments or increasing environmental pollution as a result of new industrial developments and policies. Undoubtedly, the times in which Generation Z came of age were characterized by important upheavals, from climate change to the Arab Spring and a major economic crisis in the Western world. But unlike Millennials, who experienced $9 / 11$ and the rise of global terrorism as a shock to the old world order, Generation $\mathrm{Z}$ became socialized in a more enduring political-crisis mode that became a normality over time (see Mangelsdorf, 2015). Hence, they may not have the Millennials' sense of powerlessness or feeling of being overwhelmed when entering the political system. Growing up when they did may have made them more immune to-or decreased their respect for-the great challenges of our time, with the result that they act politically with less fear and resignation than do Millennials, who experienced bigger political shocks during their political socialization.

Furthermore, like Baby Boomers, Generation Z does not want to repeat the way their parents and older siblings dealt with political problems. They 


\section{Are the kids alright?}

appear to want to try something new, not least because they realize that the world will be a less liveable place, certainly when they have their own kids, if they do not act now. The conviction that acting half-heartedly like their parent's generation will not leave the world a better place is one that they share with Baby Boomers. The two generations therefore may be connected through a shared sense of urgency to act and a willingness to make a difference. Hence, when they receive political information-which often includes political turbulence and strife, as in the past-their political socialization makes them more susceptible to act on this information.

Lastly, collective actions were a formative experience in the political socialization of Baby Boomers; in a different sense, such actions are the same for Generation $\mathrm{Z}$ today, though one should speak rather of connective actions than collective actions (Bennett \& Segerberg, 2013). Generation Z is the first fully digital-native generation who do not have any reservations about using or working with digital technologies but rather see them as a normality. Contact with others may contribute to Generation $\mathrm{Z}$ acting on political information since their social online networks present them with the opportunity to make diverse connections and to reflect upon and discover important political topics.

Though more in-depth analysis (in particular, using qualitative methods) is necessary to confirm that the described similarities in socialization do, in fact, result in comparable patterns of mobilization through media use, the conspicuousness of these two generations compared to the others speaks more for a cohort effect than a life-cycle effect when it comes to the relationship between media exposure and political participation. How long will it take for a new generation to appear that is as politically active as Baby Boomers were and still are? This remains to be seen. We should not forget that Generation $\mathrm{Z}$ still shows the lowest level of participation of all. Notwithstanding, if their reaction to political information remains stable over the course of their lives, they may yet become a more politically active generation. A precondition of such a development, however, would be continuous and stable patterns of news use. But with the fast-changing media environment, such stability is rather unlikely.

\section{New research: what can be done better?}

We were in a privileged position to develop a research design that takes us a long way in addressing the core questions at stake. However, we want to emphasize a number of aspects that are open to further consideration and improvement.

First, the underlying model adapted in this book is essentially a 'national model,' in the sense that it focuses strongly on general political news use and does not look specifically at the use of local or regional media for political information. This approach might work for a country the size of Denmark and with its media landscape, but for other (often bigger) countries 
with more regional diversity and a greater media supply, a broadening of scope would be an important consideration. The weak connection between both our media use measures and political participation on a local level is a likely result of this selection. We acknowledge that this finding should not be generally understood as the impotency of media use to motivate participation on a local level; rather, it could possibly be just the opposite. However, if news media use is understood as a general mechanism that mostly includes information with relevance for the nation or beyond, the connection between news use and political participation on a local level appears weak. Future research should therefore focus more strongly on the role of local news media for participation and, specifically, the differences between more traditional ways of receiving local news (i.e., newspapers, radio, and television) and new digital and social ways. The role of hyperlocal news media-such as blogs and Facebook groups-is largely understudied, while these very specific and personalized information offerings may potentially lead to a closer connection between citizens and the community that they are living in.

Second, we note that the effect sizes, generally speaking—and, in particular, in our dynamic models that explain change-are modest to small. On the one hand, we simply note this observation and also acknowledge that it is not exceptional in rather fully specified models. On the other hand, we also use this fact to offer a few thoughts on this phenomenon. The standard model specifications in the field, including ours, have implicit assumptions about growth and increases. That makes sense given the core interest in the (reciprocal) relationship between involvement and media use. All the same, for many citizens it is probably unrealistic to expect a continuous growth in both. For most people, both media use and political involvement probably have some level of equilibrium. When that state occurs, it might be useful to consider changes as modest and mostly temporary. In that sense, we should perhaps rethink the 'effect size issue' and consider the contribution of individual involvement and of media use to maintain levels of both. A spiral of maintenance-where media use is a repeated antecedent for sustaining a certain level of political involvement-is a substantively important dynamic and probably not one that should be discarded on statistical grounds by modest effect sizes or limited variation and change in the dependent variables.

Third, our design is very much 'state of the art.' We use panel surveys, mobile data collection, and automated content analysis. Even within these different study components, challenges emerge-such as using different measures when looking at regular news media versus social media, which inhibits direct comparisons. However, more broadly, we also emphasize that current developments in digital technologies raise questions about the inclusiveness of such an approach. Digital technologies, algorithms, and artificial intelligence further expand the opportunities for a ubiquitous information supply. They are reshaping the communication and news industry, forcing 
us to rethink how we study communication effects on science and society. For that, we need new, additional methods to assess effects and collect data.

Fourth, and finally, we have been open about the difficulty in assessing cohort versus life-cycle effects. Essentially, we can never fully disentangle whether youth are exhibiting a unique type of behaviour (e.g., in terms of involvement) or whether they merely show this pattern before transitioning and socializing into the habits of older generations. This challenge has led us to exert caution throughout the book. Of course, on some accounts, we know that the youth are behaving differently than previous generations, simply because some media supply opportunities, and political involvement opportunities were unavailable in the past. In the future, even more extended studies that gather data over a longer period of time can help us to better pinpoint these differences (see for example Shehata, 2016). This book is an example of how applying a generational perspective can help pinpoint gaps in democratic behaviour that otherwise remain unseen. This suggests that future research can benefit from cross-generational studies of the levels and relationships between media use and behaviour.

\section{Moving on}

In the closing part of our book, we return to our starting point and reflect on the empirical findings in the light of our theoretical model and the changing nature of both the media landscape and citizens' political participation patterns. At the very end, we even engage in hyperbole and discuss how some of the core themes addressed here may develop in the future, in an age of datafication, artificial intelligence, misinformation, and threats to liberal democracies.

But first a broader perspective on our findings: the results in this book provide strong evidence for pathways from political involvement to media exposure and from news consumption from various sources to political engagement and participation, as described in our EPIG model. However, though our book shows that media effects apply across a number of different types of engagement and participation, they are highly dependent on the generation that citizens belong to. The generational differences suggest that the $G$ in our EPIG model must be seriously considered when looking at media effects in a population.

Our results draw a picture according to which older generations consume news through traditional news channels to a higher extent, whereas the younger generations, specifically Millennials and Generation $Z$, receive political information increasingly through social media channels, in which information from news media, political actors, and friends and followers blend to create a unique political information diet. While we do not find general differences in the gateways to news consumption between traditional media and social media, the younger generations find their way to political information in the news media less often. Though young citizens, 
in particular, benefit from political news exposure in regard to political interest, knowledge, and efficacy, increasingly these positive effects fail to materialize with the change in news consumption. News exposure through traditional channels alone will therefore not address the lower levels of engagement and participation.

Our results imply a virtuous cycle, though we do not explicitly test for it. News media use contributes to political involvement, which, in turn, leads to more news media exposure. Based on the results, one may wish to establish how to draw more young people into this virtuous cycle, which is still effective for the few who use it. One hoped-for solution is that social media initiate a virtuous cycle for younger generations. Our findings show little support for such optimism, though social media in some instances have the power to motivate even the youngest citizens to become more active in their political systems. Time and again, we see that social media make the 'politically rich' older generations even richer by mobilizing them, especially in activities with little connection to the political system. A virtuous circle 2.0 therefore seems rather out of sight.

One could also ponder whether a virtuous cycle could be a twentiethcentury solution to a twenty-first-century problem. Though participation levels in our study are generally low, we find that in certain political areas or at certain times, younger generations are politically active and generational gaps in political engagement close. Looking at differences only in general levels of participation may mask activities that are specific to young citizens; participation in these activities may intensify over time as these citizens grow older. In non-election times, Millennials are leading when it comes to participating in demonstrations and initiating political discussions on social media. No other generation participates more often in fundraising-in particular, for the communities in which they live-than Generation Z. And during election times, compared to citizens from older generations, the two younger generations are most active overall. Hence, these generations are far from politically inactive. But closer examination of their participation patterns reveals a strong case-orientation, as in fundraising and demonstrations, as well as more spontaneous and short-term activities, as in election campaigns.

Our results show a much lower continuous connection between young citizens' political involvement and their media use patterns. This result may be interpreted in the light of the new participation patterns (i.e., short-term, spontaneous, case-oriented). Hence, engaging spontaneously for a specific cause may go along with more erratic consumption of news about the cause in question. Rather than a continuous circle, the relation between news use and participation may look like the trace of a heart on a hospital monitor, where spikes of different amplitude alternate with rest periods. Though these breaks where nothing happens may be shorter or longer, the spikes are evidence that participatory democracy is still alive. During the heartbeats of a participatory democracy, media use and political activity will, more than ever, be strongly connected and intertwined. 
It is likely that social media will be playing an increasingly important role in this process. While we see a general positive relationship between news media and political participation, the relationship is more apparent for social media. Social media usage is positively related to more global types of participation. It might foster online expression more than it encourages, for example, interpersonal interaction. Social media could therefore contribute more to individualistic participation, whereas mainstream media are more conducive to collective participation. Specific social media affordances contribute to this situation. The specificity of information is important in such a scenario. But platforms like Facebook or Instagram will not necessarily be the main players in the future. More likely, the characteristics of today's social media platforms will prevail such that all news media will eventually turn into social media: fragmented information environments with high levels of personalization, which are determined by algorithmic selection, which, in turn, is strongly driven by users' previous interests and social networks. Such specific information delivery already characterizes social media. The weak connection that we see in our study between social media use and political involvement may be indicating a time when the general connection between news use and political participation is diminishing. This period of change makes future measurements of this connection challenging. The weak relationship between social media use and participation that we have found in our study, despite using a state-of-the-art method, may indicate that already our measures cannot keep up with the way that political information is sparking political behaviour nowadays.

We would also like to reflect on the use of Denmark as the case for our study. As argued in Chapter 3, Denmark presented a good context for our study-a context that offers variation in the supply side of political information and variation in the opportunities to engage and participate in politics. Danish political media consumption is comparable to that of other Western democracies. Furthermore, it is a well-functioning democracy with a broad spectrum of participatory activities that citizens can engage in. The relatively modest importance of political participation-besides turning out to vote-makes Denmark an interesting case in which to observe media effects on political involvement because the threshold for political information to spark engagement is rather high. This is a methodological point. There is also a substantive consideration. Citizen engagement does not stand out. Is Denmark therefore a kind of Western 'hibernation democracy'-a wellfunctioning state with high electoral turnout but with modest levels of citizen engagement? And if so, is that necessarily bad? Is the hibernation a sign of citizen satisfaction? A modestly participating citizenry that does turn out in great numbers at elections is perhaps adequate and sufficient for a wellfunctioning state. Indeed, not all models of democracy advocate for maximum participation-except at elections (Strömbäck, 2005). In our case, the media contribute to both more knowledge and a reduction of the generation gap during election campaigns. Maybe this kind of 'peak and go' is 
sufficient. In such a democracy, citizens might rely on the news media to find them in times of need, serving as a kind of alarm clock (Zaller, 2003). News alerts will find you when needed, but mostly, such action is not required. A fundamental discussion of both the news media's role and citizens' expectations will determine if the current level of participation is a blessing or a cause for concern.

\section{Outlook}

If we step back even further from our book, we may address the broader context in which the often intricate and detailed questions about media use and citizens' political involvement arise and are answered. In the book, we look at this relationship from a perspective of Western liberal democracies. Many of the questions or answers would look different if asked from a perspective of authoritarian regimes or transitioning societies. But even within liberal democracies, fundamental questions should be asked. Levitsky and Ziblatt (2018) provocatively warn against the gradual breaking down of liberal democracies in their book How Democracies Die. They argue that the built-in respect, tolerance, and acceptance of the legitimacy of virtually all political voices and forces-a cornerstone in liberal democracies-can destroy a democracy from within (see also Rijpkema, 2018). In both the United States and in different European countries, political movements have gained traction that openly criticize not only existing political elites but also core institutions of liberal democracies such as an independent judiciary and media system. These developments put the relationship between media use and participation in a different light. How are media used by power holders and political elites? Are media free to voice different viewpoints? Do some media encourage some types of participation? It is clear that political developments in Western democracies in the past decade have changed our ways of thinking about some of these questions and have revived interest in fundamental questions about a free and independent press and media system.

Parallel to the turn of events in politics, developments in the media landscape also continue. While this book has been concerned with the role of both traditional legacy media and social media for political information, the book in its entirety implicitly assumes that politics and political information are part of open, transparent public spheres. As social media platforms evolve, serious questions arise about the spaces and configurations in which the exchange of political information occurs. Social media platforms like Twitter and Facebook have quasi-open configurations allowing some level of scrutiny. Other platforms like WhatsApp and Snapchat are much more ephemeral and closed in nature. What will these developments mean for the relationship between (social) media use and political engagement? Will more closed, private platforms be conducive to participation? Will social media emphasize homogenous spaces for political interactions? 
Will they encourage polarization? Will politics be driven to the margins of social media platforms? Will social media be an instrument to those attacking or defending core institutions in liberal democracies? Will social media use lead to new generational gaps? These bigger, contextual questions will need to be considered by following studies on media and political engagement.

Related to this possible migration of the space that is occupied by political information is the ongoing debate about the 'health' of the information ecology. From the supply side, the political information environment has never been more accessible and omnipresent (Van Aelst et al., 2017), but for users, the nature of available information is also changing. Debates around elections from 2016 onwards have focused on the deliberate spread of disinformation. This development is important to consider in the context of not only changing platforms (see earlier) but also the information-participation nexus. Our findings concerning the positive impact of exposure to political information on engagement implicitly presuppose this information to be genuine, factually correct, and sincere. What if a portion of the information ecology is in fact polluted by ill-intentioned, factually incorrect information that is disseminated in bad faith? It is reasonable to assume that such information might also lead to different forms of political engagement. If so, the disinformation debate takes on an additional layer of complexity since disinformation would essentially lead to participation based on a false understanding of what is at stake. In these circumstances, the generally positive relationship between information use and participation would need to be revisited. Moreover, it would need to be established whether some generations are more prone to such pitfalls than others.

Taking it one step further, imagine the following: an incorrect news story about a political scandal (disinformation with bad intent) is shared purposely in a closed, encrypted communication network, then gets spread on public social media sites, which leads to a demonstration resulting in a riot and the imprisonment of counter-demonstrators. Can such a chain of events be caused by computer systems augmented by artificial intelligence? Arguably, the creation of the inaccurate story can be automated. So can dissemination, targeted at a closed network. Same for the wider spread in the broader information ecology. The call for demonstrations and counter-demonstrations can also be largely automated and orchestrated. In this context can automated processes plus artificial intelligence ultimately ignite unrest? And would older or younger citizens be more likely or less likely to be victims in such a dynamic? Such questions seem very distant from this book's central questions, but the core relationships in the changing media landscape, the differences between generations in how they inform themselves, and new opportunity structures in political participation remain the same, regardless of the nature of the information ecology. Our key assumption that political engagement and participation 
are both outcomes and potential antecedents of using political information remains. But the premise-namely, the quality of that information, its dissemination, and the different generational likelihood of finding, sharing, and responding to it-is different. Before going dystopian, however, it is perhaps more conducive-going forward-to ask what mechanisms and safeguards can be built into a system to ensure that, across generations, the basic relationship between political information exposure and participation is a positive one. 


\section{Appendix}

Table A3.1 Comparison of gender, age, and region for general population sample $(18+)$ and population (pct.)

\begin{tabular}{|c|c|c|c|c|c|c|c|c|c|}
\hline & & $\begin{array}{l}\text { Popu- } \\
\text { lation }\end{array}$ & W1 & W2 & W3 & W4 & W5 & $\begin{array}{l}\text { Diff. } \\
\text { Pop.- } \\
\text { W1 }\end{array}$ & $\begin{array}{l}\text { Diff. } \\
\text { Pop.- } \\
\text { W5 }\end{array}$ \\
\hline $\mathrm{N}$ & & & 4.641 & 3.419 & 2.946 & 2.68 & 2.084 & & \\
\hline \multirow[t]{2}{*}{ Gender } & Males & 49.24 & 49.17 & 49.14 & 49.42 & 49.7 & 50.48 & -0.07 & 1.24 \\
\hline & Females & 50.76 & 50.83 & 50.86 & 50.58 & 50.3 & 49.52 & 0.07 & -1.24 \\
\hline \multirow[t]{7}{*}{ Age } & $18-29$ & 19.33 & 15.15 & 12.31 & 11.17 & 10.67 & 8.64 & -4.18 & -10.69 \\
\hline & $30-39$ & 15.19 & 14.59 & 13.37 & 12.49 & 12.46 & 11.52 & -0.6 & -3.67 \\
\hline & $40-49$ & 17.97 & 15.28 & 15.06 & 14.36 & 14.25 & 13.58 & -2.69 & -4.39 \\
\hline & $50-59$ & 16.67 & 25.08 & 26.06 & 26.58 & 26.23 & 26.92 & 8.41 & 10.25 \\
\hline & $60-69$ & 15.4 & 22.43 & 24.77 & 26.65 & 27.5 & 29.22 & 7.03 & 13.82 \\
\hline & $70+$ & 15.46 & 7.41 & 8.42 & 8.76 & 8.88 & 10.12 & -8.05 & -5.34 \\
\hline & Mean & 48.83 & 49.11 & 50.7 & 51.56 & 51.84 & 53.15 & 0.28 & 4.77 \\
\hline \multirow{3}{*}{$\begin{array}{l}\text { Age } \\
\text { (Epinion) }\end{array}$} & $18-34$ & 26 & 26 & & & & & 0 & \\
\hline & $35-54$ & 35 & 36 & & & & & 1 & \\
\hline & $55+$ & 39 & 37 & & & & & 2 & \\
\hline \multirow[t]{5}{*}{$\begin{array}{l}\text { Region } \\
\text { (Epinion) }\end{array}$} & $\begin{array}{l}\text { Capital } \\
\text { Region of } \\
\text { DK }\end{array}$ & 31 & 33 & & & & & 2 & \\
\hline & $\begin{array}{l}\text { Central } \\
\text { DK Region }\end{array}$ & 22 & 23 & & & & & 1 & \\
\hline & $\begin{array}{l}\text { North DK } \\
\text { Region }\end{array}$ & 10 & 10 & & & & & 0 & \\
\hline & $\begin{array}{l}\text { Region } \\
\text { Zealand }\end{array}$ & 15 & 14 & & & & & 1 & \\
\hline & $\begin{array}{l}\text { Region of } \\
\text { Southern } \\
\text { DK }\end{array}$ & 21 & 21 & & & & & 0 & \\
\hline
\end{tabular}

Notes. Population numbers on November 1, 2014, from Danmarks Statistik (www. statistikbanken.dk), except 'Age (Epinion)' and 'Region (Epinion),' for which Epinion provided both population and sample numbers. 


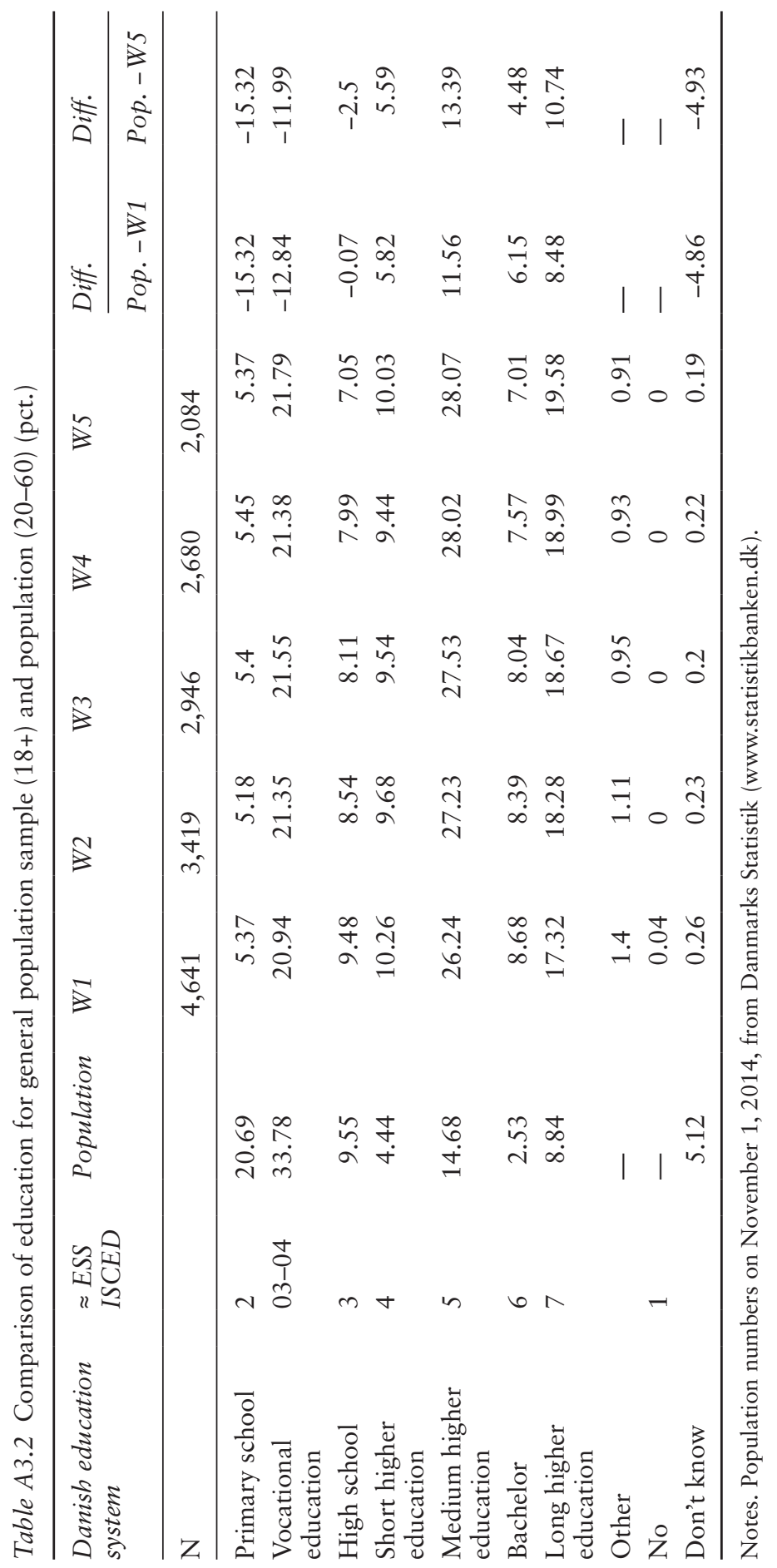




\section{Appendix}

Table A3.3 Descriptive statistics

\begin{tabular}{|c|c|c|c|c|c|}
\hline & Mean & $S D$ & Min & $\operatorname{Max}$ & Alpha \\
\hline Gender $($ female $=1)$ & .52 & .50 & 0 & 1 & \\
\hline Education & 4.08 & 1.97 & 0 & 7 & \\
\hline \multicolumn{6}{|c|}{$\begin{array}{l}\text { Exposure to political information } \\
\text { in the news media }\end{array}$} \\
\hline Wave 1 & 6.55 & 4.73 & 0 & 32.64 & .69 \\
\hline Wave 2 & 6.76 & 4.70 & 0 & 31.75 & .67 \\
\hline Wave 3 & 8.65 & 5.88 & 0 & 37.45 & .68 \\
\hline Wave 4 & 10.89 & 7.34 & 0 & 46.26 & .67 \\
\hline Wave 5 & 7.72 & 5.40 & 0 & 37.43 & .65 \\
\hline \multicolumn{6}{|c|}{$\begin{array}{l}\text { Exposure to political information } \\
\text { on social media }\end{array}$} \\
\hline Mobile wave 1 & .12 & .19 & 0 & 1 & .90 \\
\hline Mobile wave 2 & .24 & .29 & 0 & 1 & .92 \\
\hline Mobile wave 3 & .13 & .21 & 0 & 1 & .88 \\
\hline \multicolumn{6}{|l|}{ Political interest } \\
\hline Wave 1 & 6.75 & 2.44 & 0 & 10 & \\
\hline Wave 2 & 6.78 & 2.39 & 0 & 10 & \\
\hline Wave 3 & 6.91 & 2.25 & 0 & 10 & \\
\hline Wave 4 & 7.03 & 2.23 & 0 & 10 & \\
\hline Wave 5 & 6.92 & 2.30 & 0 & 10 & \\
\hline \multicolumn{6}{|l|}{ Political knowledge } \\
\hline Wave 1 & 2.10 & 1.25 & 0 & 4 & $.60 *$ \\
\hline Wave 2 & 2.68 & 1.21 & 0 & 4 & $.58 *$ \\
\hline Wave 3 & 2.91 & 1.13 & 0 & 4 & $.58 *$ \\
\hline Wave 4 & 3.28 & .82 & 0 & 4 & $.33 *$ \\
\hline Wave 5 & 2.92 & 1.04 & 0 & 4 & $.54 *$ \\
\hline \multicolumn{6}{|l|}{ Political efficacy } \\
\hline Wave 1 & 3.60 & .74 & 1 & 5 & .75 \\
\hline Wave 2 & 3.62 & .71 & 1 & 5 & .74 \\
\hline Wave 3 & 3.63 & .75 & 1 & 5 & .77 \\
\hline Wave 4 & 3.71 & .76 & 1 & 5 & .80 \\
\hline Wave 5 & 3.71 & .73 & 1 & 5 & .77 \\
\hline \multicolumn{6}{|c|}{ Political participation II } \\
\hline Wave 1 & .42 & .60 & 0 & 4 & .73 \\
\hline Wave 2 & .27 & .48 & 0 & 4 & .71 \\
\hline Wave 5 & .28 & .46 & 0 & 4 & .70 \\
\hline \multicolumn{6}{|c|}{ Political participation III } \\
\hline Wave 1 & .59 & .68 & 0 & 4 & .72 \\
\hline Wave 2 & .44 & .63 & 0 & 4 & .76 \\
\hline Wave 5 & .40 & .59 & 0 & 4 & .74 \\
\hline
\end{tabular}




\begin{tabular}{lccccc}
\hline & Mean & SD & Min & Max & Alpha \\
\hline Political participation IV & & & & & \\
Wave 1 & .62 & .79 & 0 & 4 & .70 \\
Wave 2 & .53 & .72 & 0 & 4 & .68 \\
Wave 5 & .53 & .72 & 0 & 4 & .68 \\
Campaign participation & & & & & \\
Wave 3 & .27 & .19 & 0 & 1 & .88 \\
Wave 4 & .22 & .17 & 0 & 1 & .73 \\
\hline
\end{tabular}

Notes. 'Exposure to political information on social media' was measured in the mobile survey. All other variables were measured in the online survey. $\mathrm{N}_{\text {online survey }}=3,490 . \mathrm{N}_{\text {mobile survey }}=534$. $*$ KR-20. 
("Enhedslisten' OR "Socialistisk Folkeparti”" OR "SF” OR "SFs" OR "SFer" OR "SFeren" OR "SFerens" OR "SFerne" OR "SFernes" OR 'socialdemokrat' OR "Radikale*" OR "Alternativet"” OR 'Nationalpartiet' OR 'Kristendemokrat' OR "Konservative*" OR "Venstre*" OR "Dansk Folkeparti"” OR "DF" OR "DFs" OR "DFer" OR "DFeren" OR "DFerens" OR "DFerne" OR "DFernes" OR "Liberal Alliance " " OR “ politik" OR " $\sim$ politiken*” OR " p politiker" " OR " politisk" " OR 'folketing' OR 'regionsråd' OR 'byråd' OR "EU" OR "EUs" OR "NATO" OR "NATOs" OR "FN" OR "FNs" OR 'borgmester' OR 'rådmand' OR “ "minister"” OR 'partiformand' OR 'partileder' OR 'regering' OR 'opposition' OR “ blå blok*” OR " $\sim$ rød blok"” OR 'venstrefløj' OR 'højrefløj' OR 'folkeafstemning' OR “ *valgkamp"” OR 'interesseorganisation' OR 'fagbevægelse' OR "Dansk Industri"” OR "Kommunernes Landsforening"” OR "KL" OR "KLs" OR "Dansk Erhverv"” OR "LO" OR "LOs" OR "3F" OR "3Fs" OR "Forbrugerrådet" " OR "Danske Regioner" " OR "FOA" OR "FOAs" OR "Danmarks Lærerforening"” OR "Landbrug \& Fødevarer"” OR "Landbrug og Fødevarer" " OR "Arbejderbevægelsens Erhvervsråd" " OR "Dansk Arbejdsgiverforening*" OR "DA" OR "DAs" OR "Dansk Byggeri" " OR "Finansrådet"”)

Figure A3.1 Search string for political information in the news media

Source: Bjarnøe et al. (2020)

Notes. The search string was applied using the search engine Infomedia. The following signs were used in the search string: 'refers to a phase search covering all versions of a phase'; refers to the exact wording of a word or an expression; refers to the first letter of a word should be spelled with either capital or small letters; * allows for deviation in the beginning or the ending of a word. The words used to identify political content were party names (and their abbreviations), general political words (e.g., politics, politicians, political), selected political institutions and positions (e.g., council, major, minister, left-wing, right-wing, red bloc, blue bloc, government, opposition, party leader), supranational political bodies (EU, NATO, UN), elections (e.g., referendum, election campaign), and interest organisations. Besides using the words 'interest organisations' and 'trade unions,' the names of the 15 most prominent interest organisations in the news media were included in the search string (identified using interarena. dk ['orglist']; see also Binderkrantz \& Christiansen, 2014). 


\section{Audio}

(3)

Where have you heard information about politics today?

On the radio offline

On the radio online

From friends, family or colleagues

Others (please specify)

I haven't heard anything about politics today

Page

Where have you read information about politics

E today?

In a printed newspaper

On a website of a newspaper

On other websites of media outlets (e.g. DR, TV2)

On other websites, (e.g. blogs)

On social media platforms like Facebook or

Twitter

Others

I haven't read anything about politics today

How much of the information you've read online about politics today did you reach following links from social media?

Most of it

Some of it

None of it

I don't remember

What did you read on social media platforms

E about politics today?

Posts, comments, tweets or links...

....by parties, politicians, political organizations or political actors

....by news media

....by other pages or blogs

....by friends and followers

Paid ads from parties, politicians, political

organizations or political actors

Others

Were the posts or tweets by friends or followers E mostly from...

... people you know personally and have a close relationship with (e.g. good friends, family)?

... people you know personally without having a close relationship (e.g. mutual friends)?

... people you don't know personally?
Stream

Where have you watched information about politics today?

On TV offline

On broadcasters' websites (on demand or streamed live)

On other websites (e.g. news pages or video platforms, e.g.YouTube)

On social media platforms like Facebook

Others (please specify)

I haven't watched information about politics today

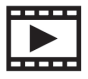

How much of the information you've watched

online about politics did you reach following links from social media?

Most of it

Some of it

None of it

I don't remember

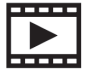

What did you watch on a social media platform about politics today?

Political ads (e.g. suggestions, commercials)

Videos posted by parties, political organizations or candidates

Videos posted by TV or radio stations or newspapers

Videos posted by other pages or profiles (e.g. news pages or blogs)

Videos posted or shared by friends and followers

Others

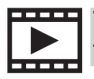

Were the videos posted or shared by friends or followers mostly from...

... people you know personally and have a close relationship with (e.g. good friends, family)? ... people you know personally without having a close relationship (e.g. mutual friends)? ... people you don't know personally?

\section{Figure A3.2 Questionnaire of Audio-Page-Stream measurement}




\section{Appendix}

Table A3.4 Political knowledge questions

Wave 1 1) Which post has Margrethe Vestager been appointed to in the European Commission? (Commissioner for Competition)

2) In what country is there currently war against IS (Islamic State)? (Iraq)

3) Who is the Conservative People's Party's spokesperson on politics? (Mai Mercado)

4) Who is Minister of Employment in Denmark? (Henrik Dam Kristensen)

Wave 2 1) Which party was Klaus Riskær Pedersen recently excluded from? (The Alternative)

2) Which country is currently experiencing fierce fighting after a rebel group overthrew the president? (Yemen)

3) What did a majority in the parliament recently decide that the Danes must hold a referendum about? (The EU legal reservation)

4) Who is Minister of the Environment in Denmark? (Kirsten Brosbøl)

Wave 3 1) Which party is Søren Gade running for at the upcoming national election? (Venstre-The Liberal Party of Denmark)

2) Who was recently elected as Prime Minister in Great Britain? (David Cameron)

3) Which politician from the Red-Green Alliance is not running again in the national election? (Frank Aaen)

4) Which minister was recently criticized for his/her role in the sale of Dong? (Bjarne Corydon)

Wave 4 1) Which party did not run for the national election? (The National Party)

2) Which country has started negotiations on its future relationship with the EU? (Great Britain)

3) What was also celebrated on Constitution Day on June 5 this year? (100 years of women's suffrage)

4) Which party got the most mandates at the national election? (The Social Democrats)

Wave 5 1) Who is chairman of the Danish parliament? (Pia Kjærsgaard)

2) Which country recently started air-strikes in Syria? (Russia)

3) Which of the following parties suggest voting 'no' in the referendum about the Danish justice opt-out in EU? (Danish People's Party and The Red-Green Alliance)

4) Who is the Danish minister of defence? (Peter Christensen)

Notes. Correct answers in parentheses. 
Table A3.5 Political efficacy statements

1. Sometimes politics is so complicated that a person like me cannot really understand what is going on

2. Generally speaking, I do not find it difficult to take a stand on political issues (reversed)

3. When politicians debate economic policy, I only understand a small part of what they are talking about

4. Citizens like me are qualified to participate in political discussions (reversed)

5. Citizens like me have opinions on politics that are worth listening to (reversed)

Table A3.6 Frequencies of political participation activities

\begin{tabular}{|c|c|c|c|}
\hline & $\begin{array}{l}\text { Wave } 1 \\
M(S D)\end{array}$ & $\begin{array}{l}\text { Wave } 2 \\
M(S D)\end{array}$ & $\begin{array}{l}\text { Wave } 5 \\
M(S D)\end{array}$ \\
\hline \multicolumn{4}{|l|}{$\begin{array}{l}\text { Political Participation II } \\
\text { (Targeted at political system) }\end{array}$} \\
\hline $\begin{array}{l}\text { Contacted a politician via e-mail or social } \\
\text { media to express your opinion }\end{array}$ & $.41(1.01)$ & $.29(0.84)$ & $.26(0.79)$ \\
\hline Contacted or visited a politician in person & $.30(0.90)$ & $.20(0.72)$ & $.16(0.61)$ \\
\hline $\begin{array}{l}\text { Participated in demonstrations, strikes, or } \\
\text { other political happenings }\end{array}$ & $.23(0.74)$ & $.14(0.59)$ & $.14(0.55)$ \\
\hline $\begin{array}{l}\text { Signed a written petition (on paper) about a } \\
\text { political or social issue }\end{array}$ & $.41(0.90)$ & $.23(0.73)$ & $.20(0.65)$ \\
\hline $\begin{array}{l}\text { Donated money to a political party, other } \\
\text { political organization, or NGO }\end{array}$ & $.46(1.10)$ & $.31(0.89)$ & $.37(0.95)$ \\
\hline $\begin{array}{l}\text { Encouraged or invited people to participate } \\
\text { in demonstrations, strikes, or other political } \\
\text { events }\end{array}$ & $.20(0.75)$ & $.15(0.63)$ & $.16(0.61)$ \\
\hline Signed an online petition & $.86(1.27)$ & $.56(1.08)$ & $.62(1.08)$ \\
\hline \multicolumn{4}{|l|}{$\begin{array}{l}\text { Political Participation III } \\
\text { (Targeted at community level) }\end{array}$} \\
\hline $\begin{array}{l}\text { Maintained common facilities in your local } \\
\text { area (e.g., kindergarten, waterworks, plants, } \\
\text { roads) }\end{array}$ & $.58(1.17)$ & $.40(1.01)$ & $.40(1.00)$ \\
\hline $\begin{array}{l}\text { Participated in a meeting about your local } \\
\text { area }\end{array}$ & $.97(1.35)$ & $.77(1.26)$ & $.65(1.15)$ \\
\hline $\begin{array}{l}\text { Participated in collecting money to support } \\
\text { projects in your community (e.g., by } \\
\text { organising or volunteering in a cultural } \\
\text { event) }\end{array}$ & $.35(0.89)$ & $.24(0.78)$ & $.20(0.07)$ \\
\hline $\begin{array}{l}\text { Supported a crowdfunding project taking } \\
\text { care of your community }\end{array}$ & $.68(1.16)$ & $.46(0.99)$ & $.41(0.92)$ \\
\hline $\begin{array}{l}\text { Participated in a cultural event to support } \\
\text { projects in your community (e.g., a concert) }\end{array}$ & .37 (0.91) & $.24(0.76)$ & $.22(0.72)$ \\
\hline
\end{tabular}




\section{Appendix}

Table A3.6 (Continued)

\begin{tabular}{|c|c|c|c|}
\hline & $\begin{array}{l}\text { Wave } 1 \\
M(S D)\end{array}$ & $\begin{array}{l}\text { Wave } 2 \\
M(S D)\end{array}$ & $\begin{array}{l}\text { Wave } 5 \\
M(S D)\end{array}$ \\
\hline $\begin{array}{l}\text { Created street art in your own community } \\
\text { (any use of creativity visible in the streets) }\end{array}$ & $.15(0.66)$ & $.11(0.58)$ & $.10(0.53)$ \\
\hline $\begin{array}{l}\text { Volunteered in an organization or a group in } \\
\text { your local area (e.g., a residents' association, } \\
\text { museum association, food club, or common } \\
\text { vegetable garden) }\end{array}$ & $1.13(1.67)$ & $.88(1.53)$ & $.86(1.5)$ \\
\hline $\begin{array}{l}\text { Set up private websites, blogs, or social } \\
\text { media initiatives about what is happening in } \\
\text { your community }\end{array}$ & $.47(1.17)$ & $.38(1.02)$ & $-.33(0.96)$ \\
\hline \multicolumn{4}{|l|}{$\begin{array}{l}\text { Political Participation IV } \\
\text { (Non-political, politically motivated) }\end{array}$} \\
\hline $\begin{array}{l}\text { Initiated a political discussion or supported } \\
\text { a political issue (e.g., by creating a group } \\
\text { or donating money to a political project or } \\
\text { event) }\end{array}$ & $.22(0.79)$ & $.19(0.73)$ & $.18(0.68)$ \\
\hline $\begin{array}{l}\text { Shared posts by others on Facebook or } \\
\text { similar social media sites about a political or } \\
\text { societal issue }\end{array}$ & $.99(1.54)$ & $.94(1.49)$ & $.99(1.51)$ \\
\hline $\begin{array}{l}\text { Changed personal information or picture } \\
\text { on your social media profile information } \\
\text { because of a political or societal issue }\end{array}$ & $.20(0.73)$ & $.17(0.66)$ & $.16(0.65)$ \\
\hline $\begin{array}{l}\text { Expressed your opinion in a post on } \\
\text { Facebook or similar social media sites about } \\
\text { a political or societal issue }\end{array}$ & $.90(1.48)$ & $.78(1.4)$ & $.83(1.43)$ \\
\hline $\begin{array}{l}\text { Bought or boycotted products for political, } \\
\text { ethical, or environmental reasons }\end{array}$ & $1.33(1.72)$ & $1.13(1.65)$ & 1.03 (1.6) \\
\hline $\begin{array}{l}\text { Wore clothes or other visible objects with a } \\
\text { political message (e.g., a badge or a bag) }\end{array}$ & $.41(1.08)$ & $.27(0.89)$ & $.29(0.93)$ \\
\hline
\end{tabular}

Notes. $\mathrm{N}=3,490$. 

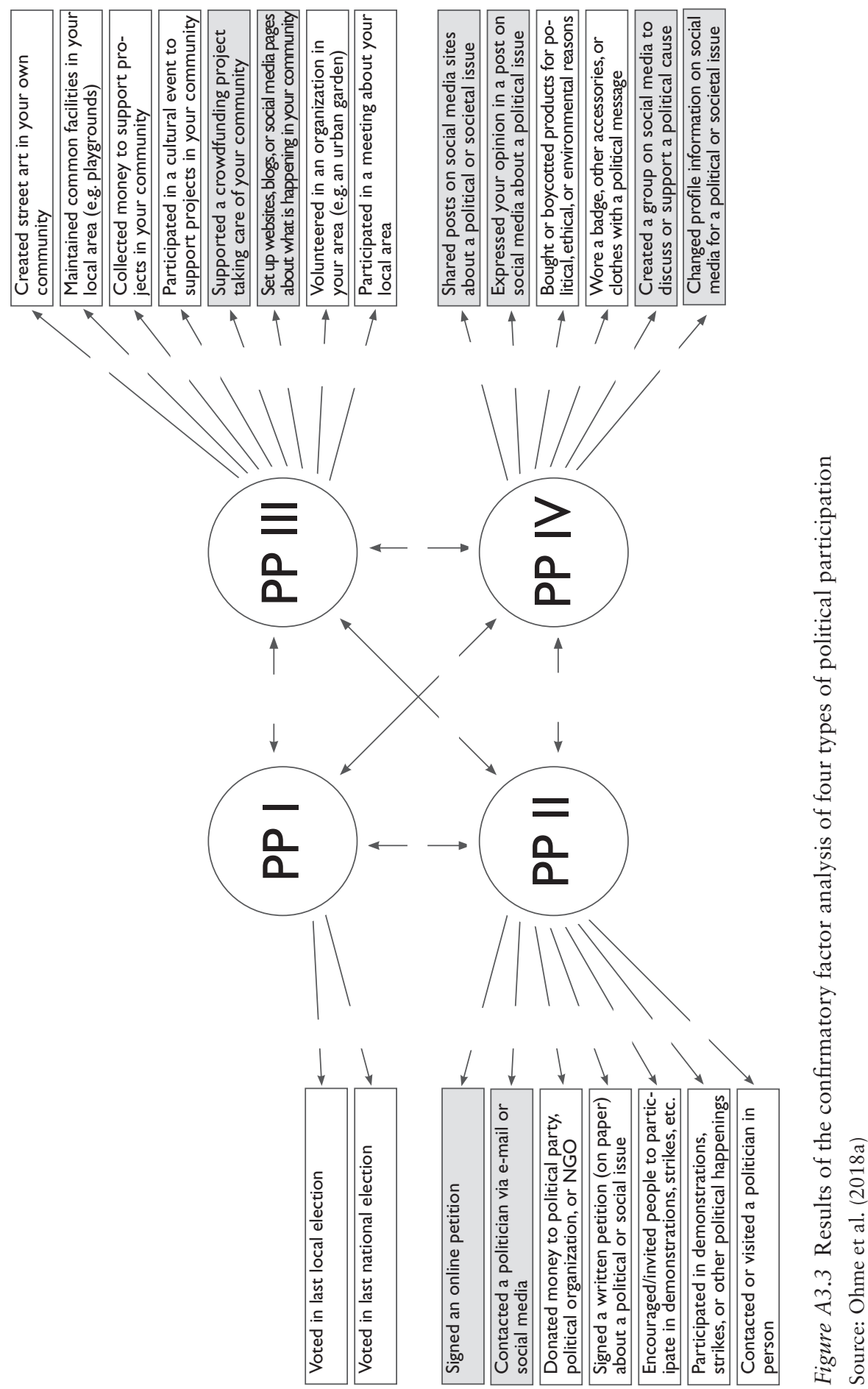


\section{Appendix}

Table A3.7 Frequencies of (intended) campaign participation activities

\begin{tabular}{lll}
\hline & $\begin{array}{l}\text { Intended } \\
\text { campaign } \\
\text { participation } \\
\text { (wave 3) }\end{array}$ & $\begin{array}{l}\text { Campaign } \\
\text { participation } \\
\text { (wave 4) }\end{array}$ \\
\hline Talked about election & $8.00(3.03)$ & $0.74(0.43)$ \\
Convinced others to vote via social media & $3.88(3.25)$ & $0.19(0.39)$ \\
Volunteered for a political party or candidate & $1.88(2.23)$ & $0.04(0.2)$ \\
Attended public election meetings & $3.03(2.75)$ & $0.06(0.24)$ \\
Contacted politician in election time & $2.10(2.22)$ & $0.03(0.18)$ \\
Visited candidates' website/social media profile & $5.07(3.64)$ & $0.30(0.46)$ \\
Taken initiative to discuss election on social & $1.82(1.89)$ & $0.05(0.23)$ \\
media & $2.15(2.28)$ & $0.04(0.21)$ \\
$\begin{array}{l}\text { Expressed your opinion to a politician via mail/ } \\
\text { social media }\end{array}$ & $6.21(3.89)$ & $0.56(0.49)$ \\
$\begin{array}{l}\text { Done election test } \\
\text { Supported a candidate or a party via social }\end{array}$ & $3.03(3.11)$ & $0.16(0.36)$ \\
media & $3.60(3.33)$ & $0.18(0.38)$ \\
Shared information about election & $4.29(3.80)$ & $0.23(0.42)$ \\
Made others aware that you will vote & &
\end{tabular}

Notes. Intended campaign participation was measured at wave 3 on a scale from 1 (Not likely at all) to 11 (Very likely). Campaign participation at wave 4 was measured dichotomously $(0=$ No, 1 = Yes). $\mathrm{N}=3,490$. 


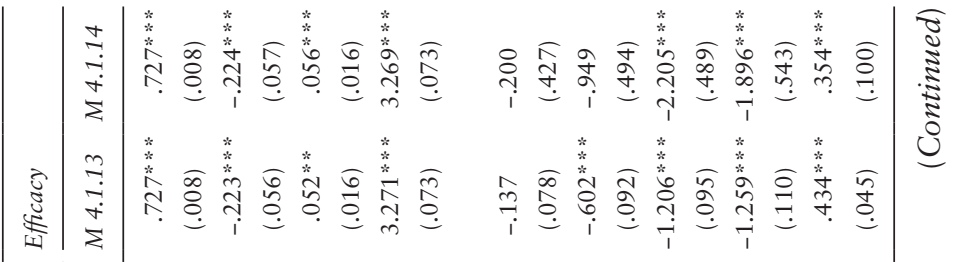

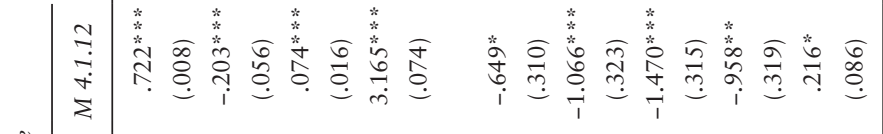

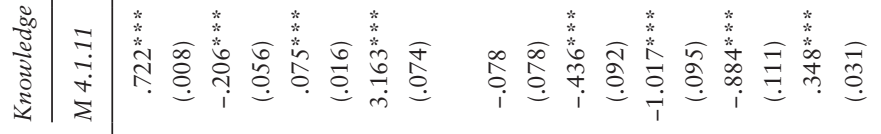

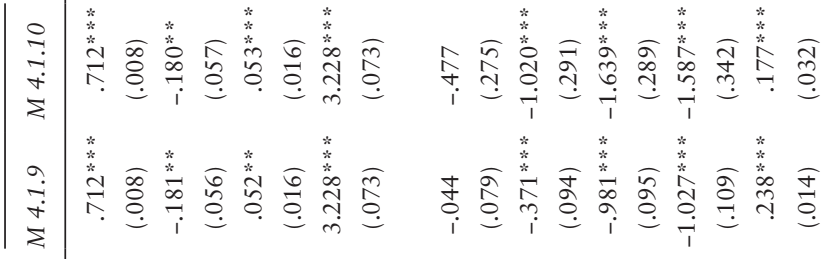

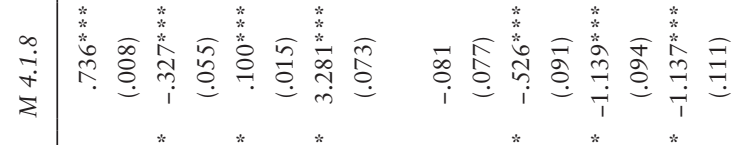

:

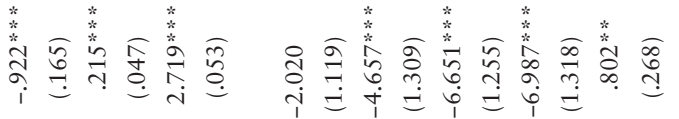

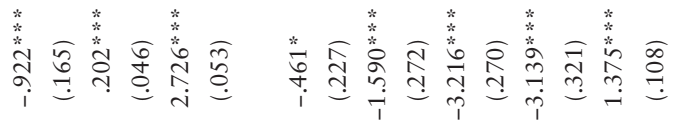

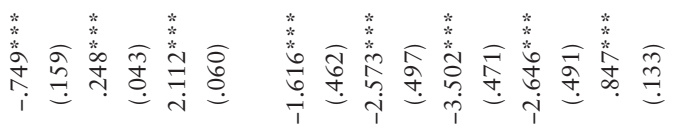

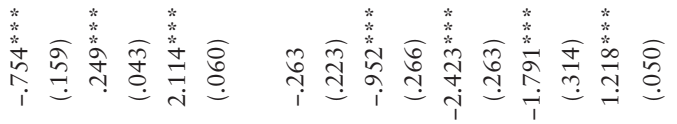

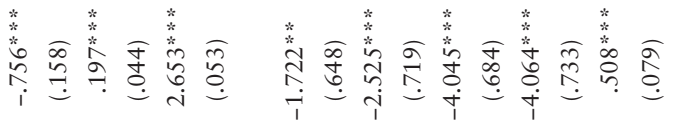

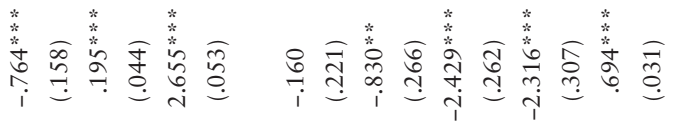

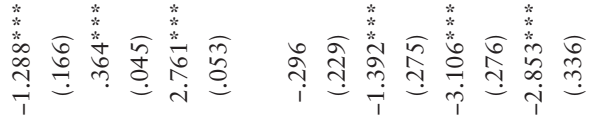

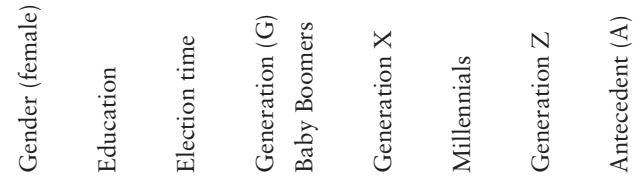




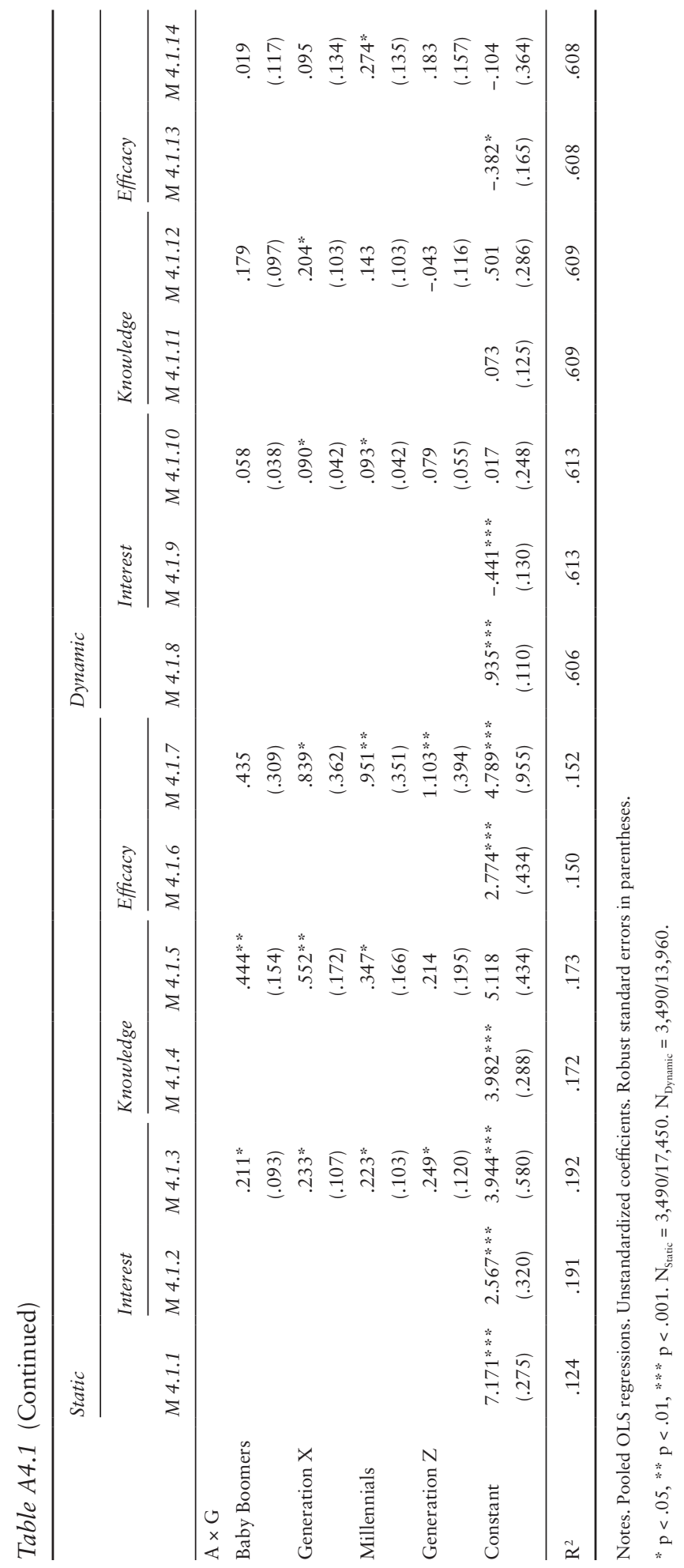




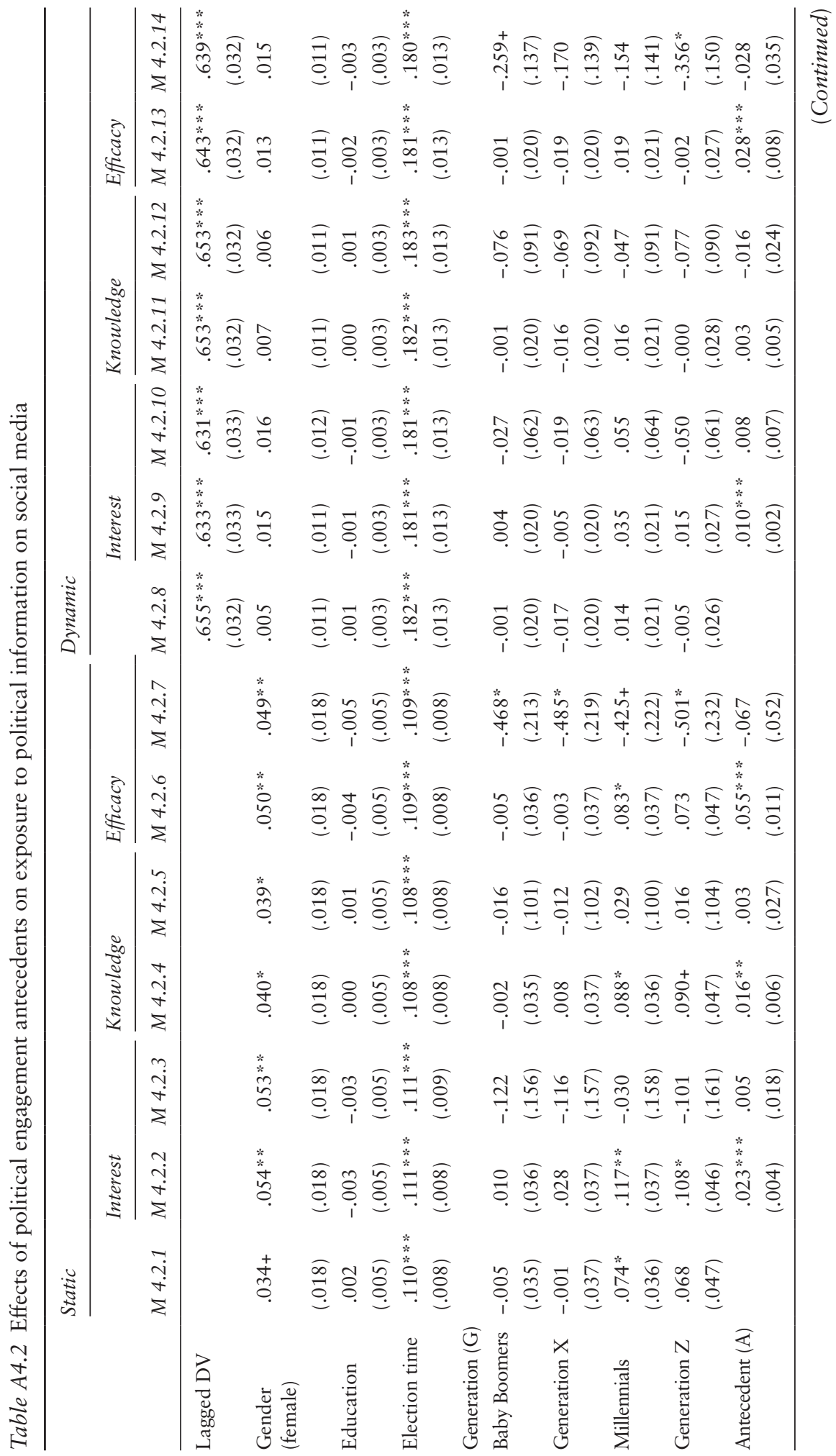




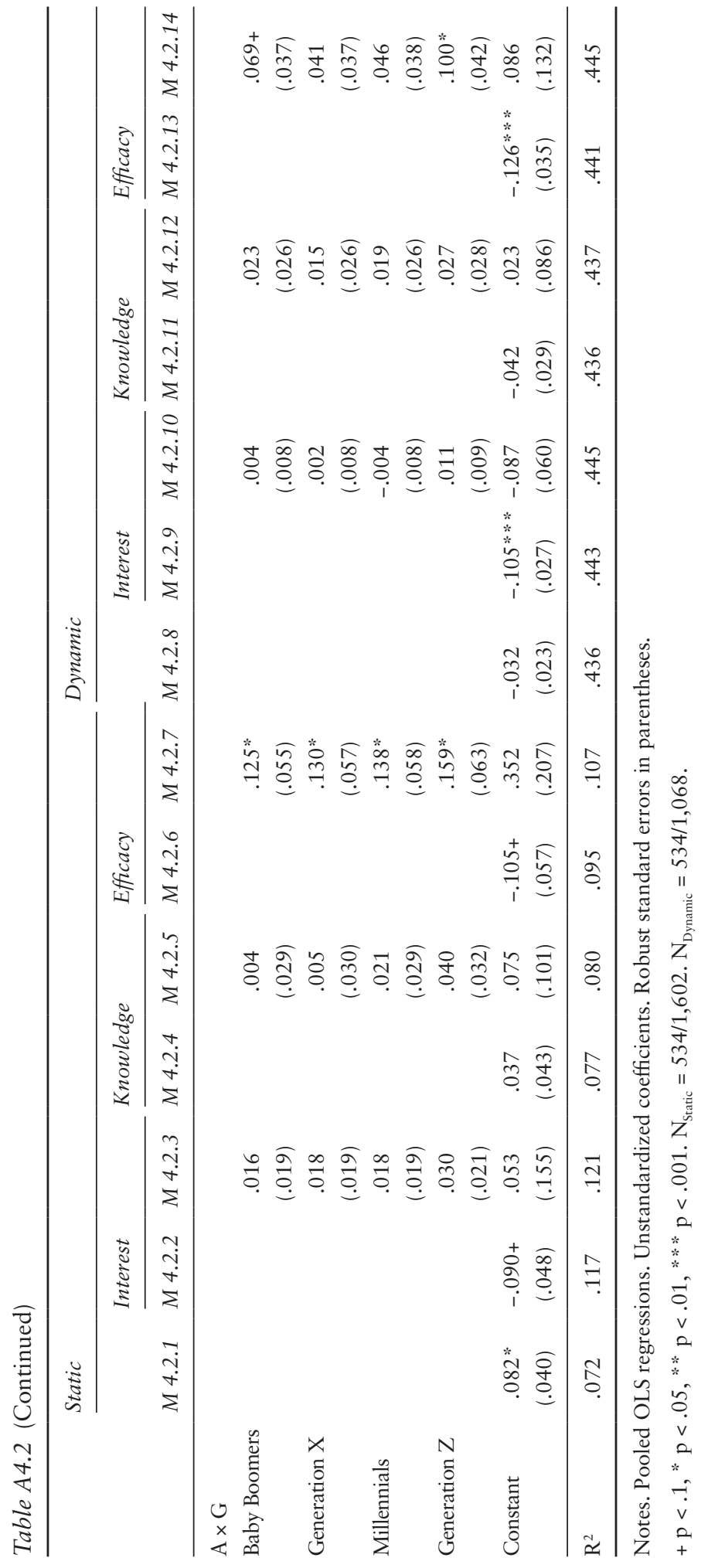




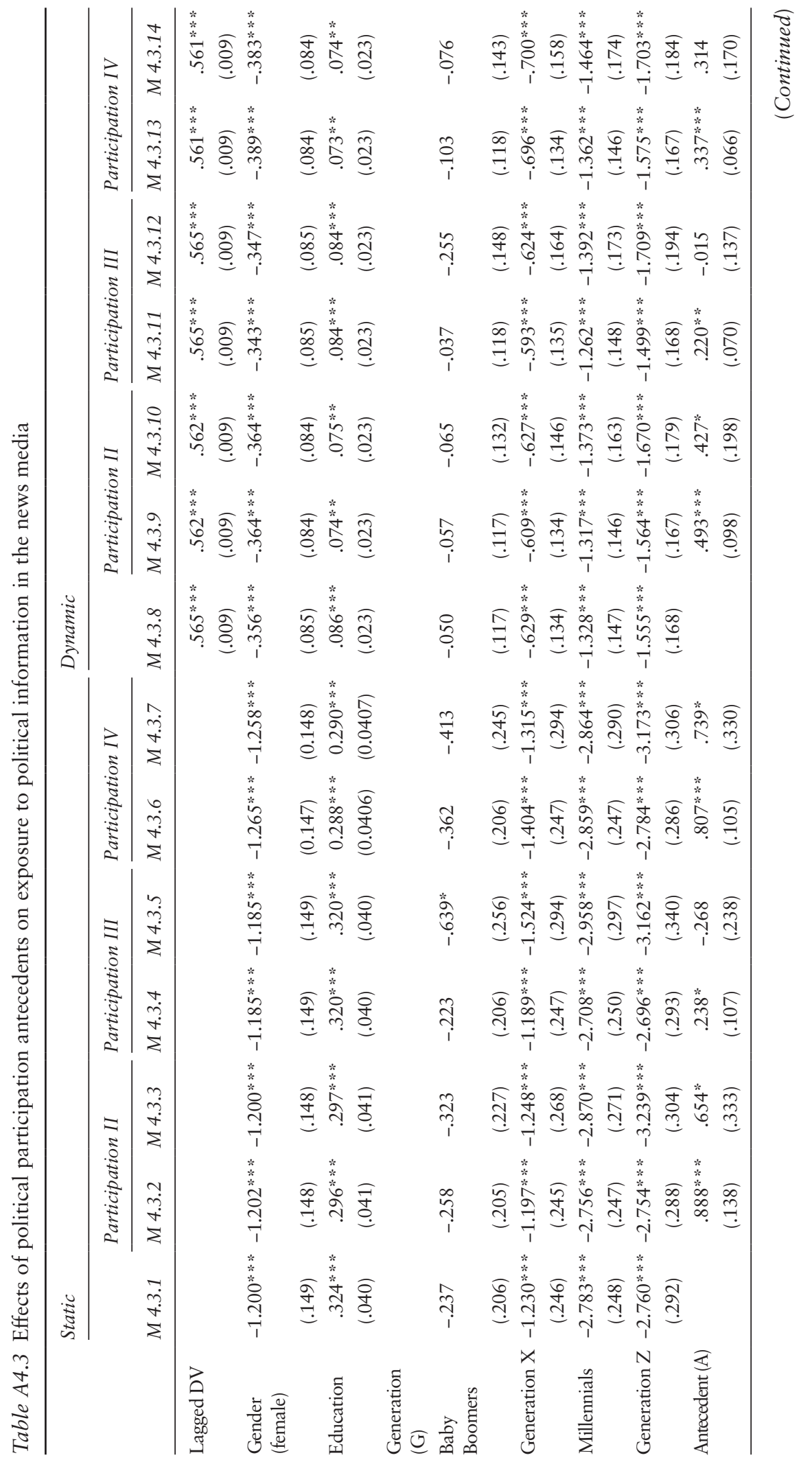




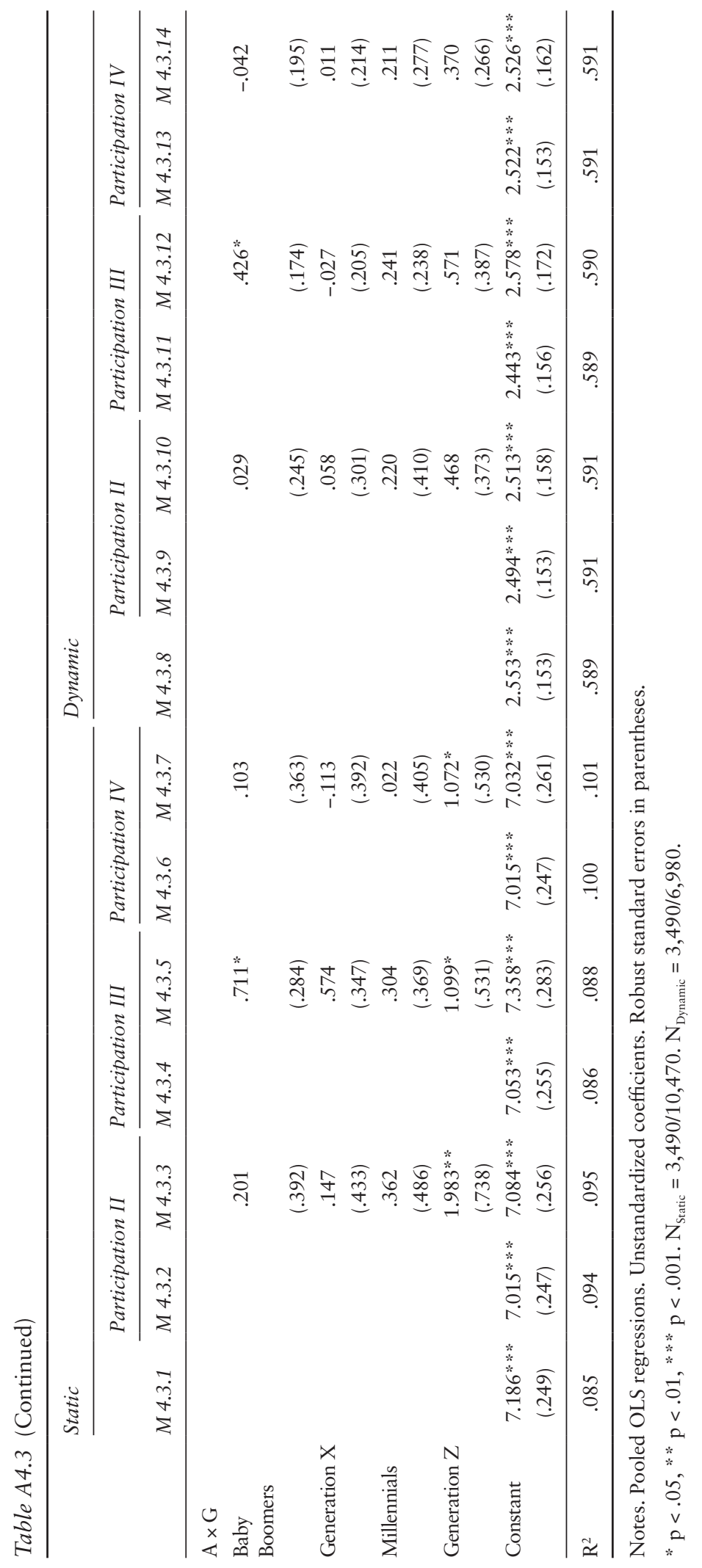




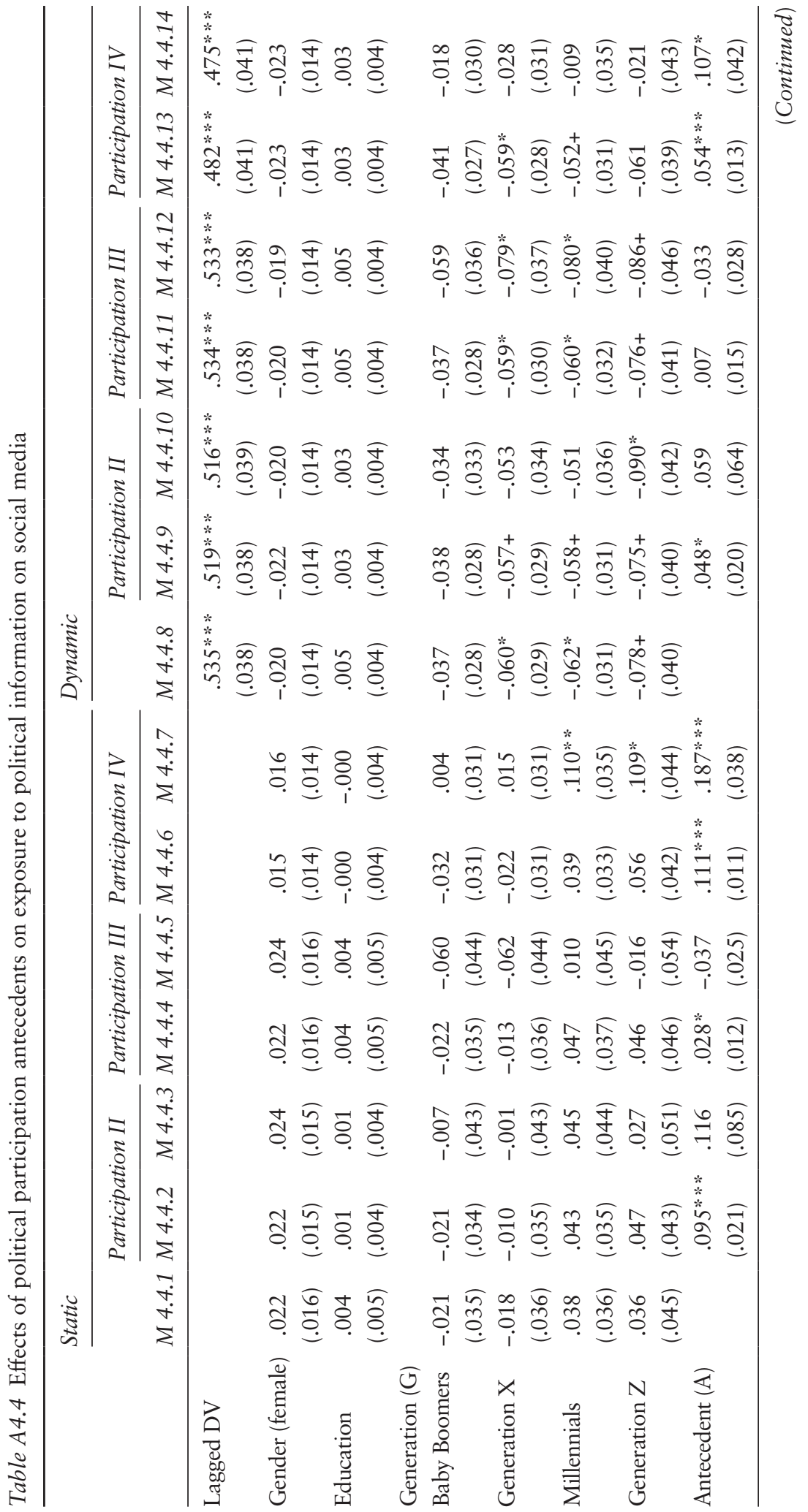




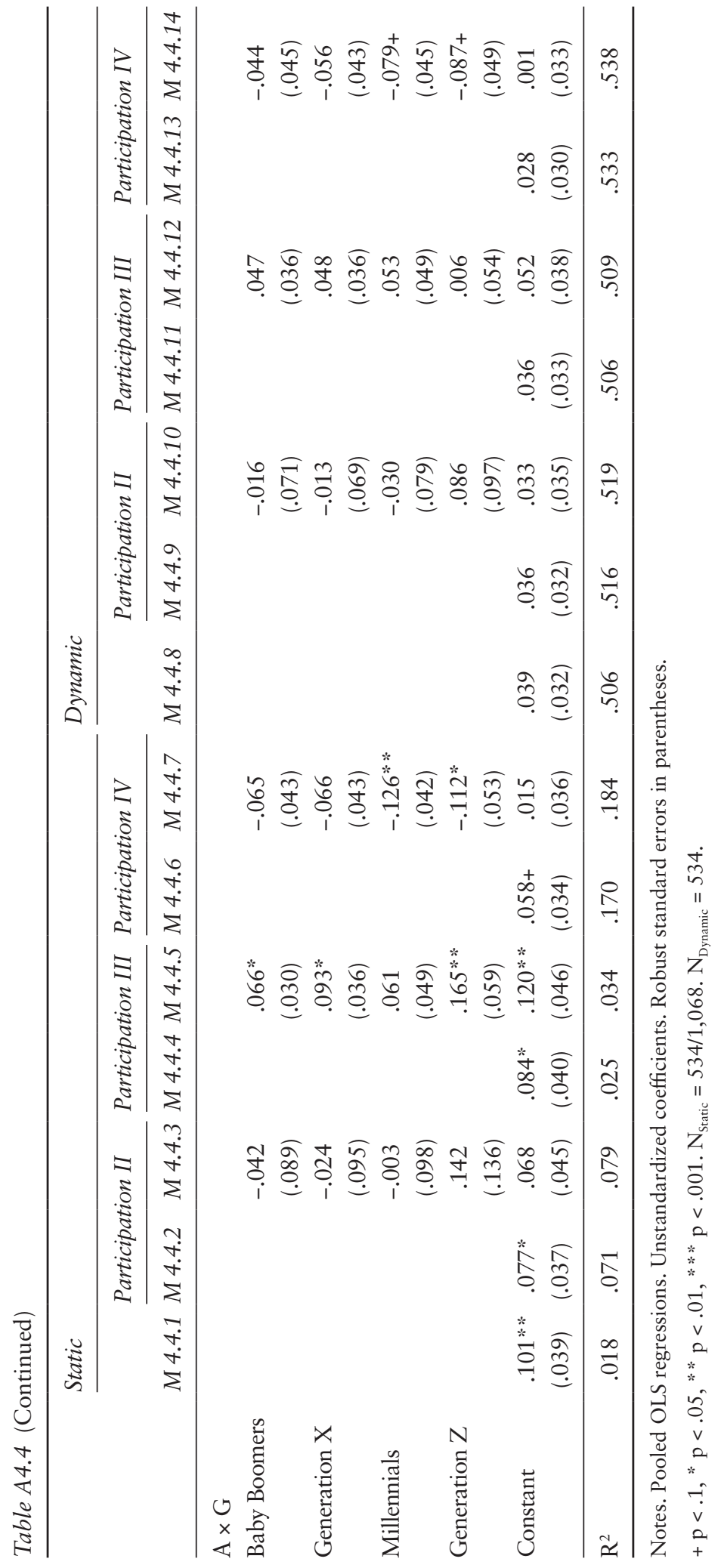


Table A5.1 Effects of exposure to political information in the news media on political interest

\begin{tabular}{|c|c|c|c|c|c|c|}
\hline & \multicolumn{3}{|l|}{ Static } & \multicolumn{3}{|l|}{ Dynamic } \\
\hline & $\begin{array}{l}\text { Model } \\
5.1 .1\end{array}$ & $\begin{array}{l}\text { Model } \\
5.1 .2\end{array}$ & $\begin{array}{l}\text { Model } \\
5.1 .3\end{array}$ & $\begin{array}{l}\text { Model } \\
5.1 .4\end{array}$ & $\begin{array}{l}\text { Model } \\
5.1 .5\end{array}$ & $\begin{array}{l}\text { Model } \\
5.1 .6\end{array}$ \\
\hline Lagged DV & & & & $\begin{array}{l}.820 * * * \\
(.005)\end{array}$ & $\begin{array}{l}.803 * * * \\
(.006)\end{array}$ & $\begin{array}{l}.802 * * * \\
(.006)\end{array}$ \\
\hline Gender (female) & $\begin{array}{l}-.756 * * * \\
(.069)\end{array}$ & $\begin{array}{l}-.614 * * * \\
(.066)\end{array}$ & $\begin{array}{l}-.613 * * * \\
(.066)\end{array}$ & $\begin{array}{l}-.105 * * * \\
(.017)\end{array}$ & $\begin{array}{l}-.087 * * \\
(.017)\end{array}$ & $\begin{array}{l}-.088 * * * \\
(.017)\end{array}$ \\
\hline Education & $\begin{array}{l}.244 * * * \\
(.019)\end{array}$ & $\begin{array}{l}.204 * * * \\
(.018)\end{array}$ & $\begin{array}{l}.202 * * * \\
(.018)\end{array}$ & $\begin{array}{l}.042 * * * \\
(.005)\end{array}$ & $\begin{array}{l}.037 * * * \\
(.005)\end{array}$ & $\begin{array}{l}.037 * * * \\
(.005)\end{array}$ \\
\hline Election time & $\begin{array}{l}.153 * * * \\
(.016)\end{array}$ & $\begin{array}{l}-.151 * * * \\
(.022)\end{array}$ & $\begin{array}{l}-.154 * * * \\
(.022)\end{array}$ & $\begin{array}{l}155 * * * \\
(.023)\end{array}$ & $\begin{array}{l}.093 * * * \\
(.023)\end{array}$ & $\begin{array}{l}.092 * * * \\
(.023)\end{array}$ \\
\hline \multicolumn{7}{|l|}{ Generation $(\mathrm{G})$} \\
\hline Baby Boomers & $\begin{array}{l}-.196 * \\
(.091)\end{array}$ & $\begin{array}{c}-.163 \\
(.088)\end{array}$ & $\begin{array}{l}-.451 * * \\
(.161)\end{array}$ & $\begin{array}{c}-.032 \\
(.022)\end{array}$ & $\begin{array}{l}-.027 \\
(.022)\end{array}$ & $\begin{array}{l}-.089 \\
(.050)\end{array}$ \\
\hline Generation X & $\begin{array}{l}-.810 * * * \\
(.111)\end{array}$ & $\begin{array}{l}-.656 * * * \\
(.107)\end{array}$ & $\begin{array}{l}-.920 * * * \\
(.186)\end{array}$ & $\begin{array}{l}-.106 * * * \\
(.026)\end{array}$ & $\begin{array}{l}-.083 * * \\
(.026)\end{array}$ & $\begin{array}{l}-.153 * * \\
(.054)\end{array}$ \\
\hline Millennials & $\begin{array}{l}-.974 * * * \\
(.132)\end{array}$ & $\begin{array}{l}-.632 * * * \\
(.125)\end{array}$ & $\begin{array}{l}-1.246 * * * \\
(.207)\end{array}$ & $\begin{array}{l}-.166 * * * \\
(.030)\end{array}$ & $\begin{array}{l}-.102 * * \\
(.030)\end{array}$ & $\begin{array}{l}-.241 * * * \\
(.059)\end{array}$ \\
\hline Generation Z & $\begin{array}{l}-.774 * * * \\
(.172)\end{array}$ & $\begin{array}{l}-.460 * * \\
(.160)\end{array}$ & $\begin{array}{l}-1.284 * * * \\
(.237)\end{array}$ & $\begin{array}{l}-.076 \\
(.040)\end{array}$ & $\begin{array}{l}-.016 \\
(.040)\end{array}$ & $\begin{array}{l}-.235 * * \\
(.070)\end{array}$ \\
\hline $\begin{array}{l}\text { Exposure to } \\
\text { pol. info. in the } \\
\text { news media } \\
\text { (NM) }\end{array}$ & & $\begin{array}{l}.110 * * * \\
(.005)\end{array}$ & $\begin{array}{l}.076 * * * \\
(.011)\end{array}$ & & $\begin{array}{l}.024 * * * \\
(.002)\end{array}$ & $\begin{array}{l}.017 * * * \\
(.003)\end{array}$ \\
\hline \multicolumn{7}{|l|}{$\mathrm{NM} \times \mathrm{G}$} \\
\hline Baby Boomers & & & $\begin{array}{l}.031 * \\
(.013)\end{array}$ & & & $\begin{array}{l}.006 \\
(.004)\end{array}$ \\
\hline Generation X & & & $\begin{array}{l}.027 \\
(.015)\end{array}$ & & & $\begin{array}{c}.007 \\
(.004)\end{array}$ \\
\hline Millennials & & & $\begin{array}{l}.084 * * * \\
(.019)\end{array}$ & & & $\begin{array}{l}.018 * * \\
(.006)\end{array}$ \\
\hline Generation Z & & & $\begin{array}{l}.132 * * * \\
(.025)\end{array}$ & & & $\begin{array}{l}.034 * * * \\
(.008)\end{array}$ \\
\hline Constant & $\begin{array}{l}6.631 * * * \\
(.116)\end{array}$ & $\begin{array}{l}5.841 * * * \\
(.117)\end{array}$ & $\begin{array}{l}6.166 * * * \\
(.158)\end{array}$ & $\begin{array}{l}1.146 * * * \\
(.050)\end{array}$ & $\begin{array}{l}1.079 * * * \\
(.050)\end{array}$ & $\begin{array}{l}1.165 * * * \\
(.063)\end{array}$ \\
\hline $\mathrm{R}^{2}$ & .104 & .172 & .178 & .723 & .727 & .727 \\
\hline
\end{tabular}

Notes. Pooled OLS regressions. Unstandardized coefficients. Robust standard errors in parentheses.

$* \mathrm{p}<.05, * * \mathrm{p}<.01, * * \mathrm{p}<.001 . \mathrm{N}_{\text {Static }}=3,490 / 17,450 . \mathrm{N}_{\text {Dynamic }}=3,490 / 13,960$. 


\section{Appendix}

Table A5.2 Effects of exposure to political information in the news media on political knowledge

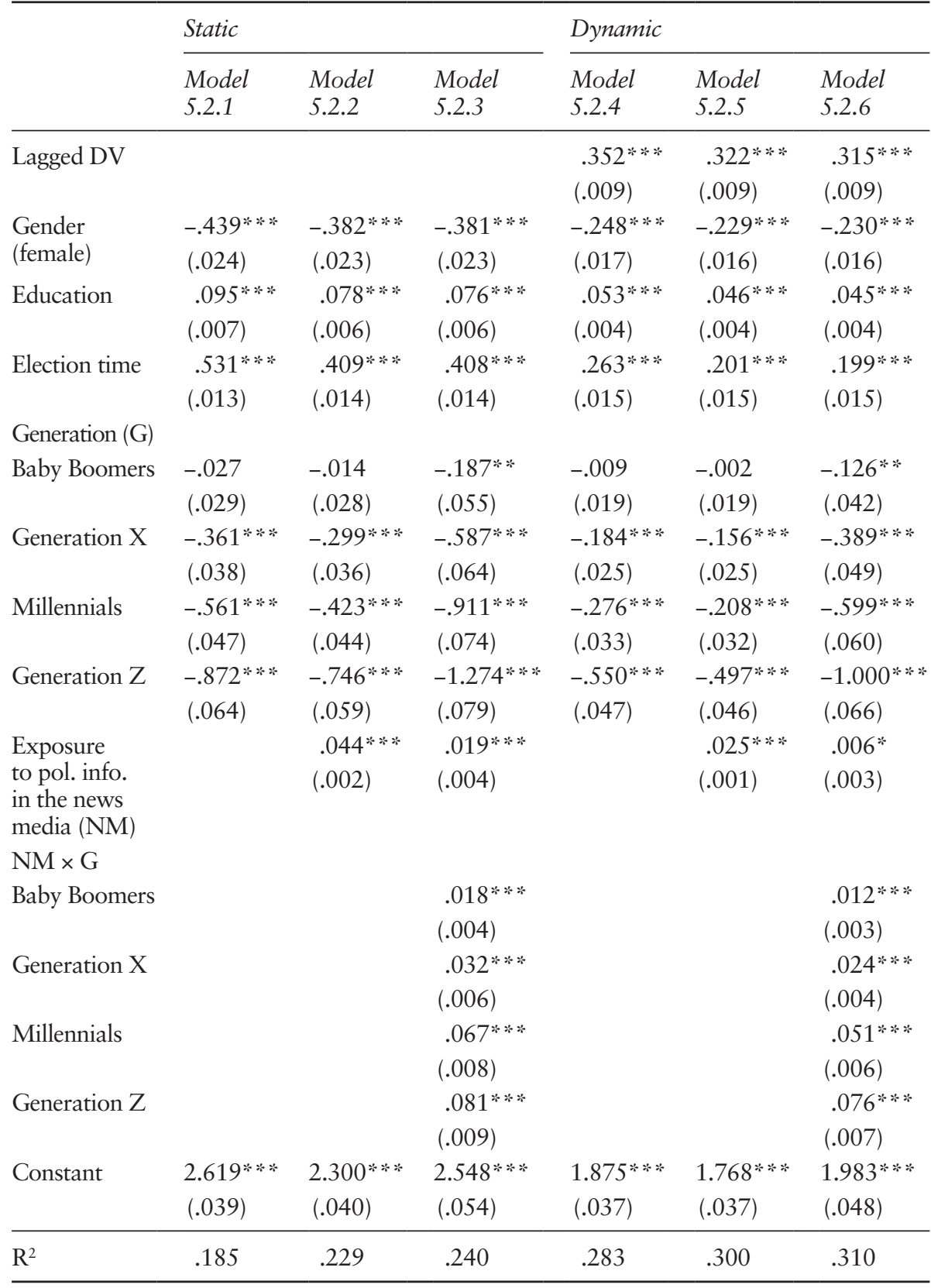

Notes. Pooled OLS regressions. Unstandardized coefficients. Robust standard errors in parentheses.

$* \mathrm{p}<.05, * \mathrm{p}<.01, * * * \mathrm{p}<.001 . \mathrm{N}_{\text {Static }}=3,490 / 17,450 . \mathrm{N}_{\text {Dynamic }}=3,490 / 13,960$. 
Table A5.3 Effects of exposure to political information in the news media on political efficacy

\begin{tabular}{|c|c|c|c|c|c|c|}
\hline & \multicolumn{3}{|l|}{ Static } & \multicolumn{3}{|l|}{ Dynamic } \\
\hline & $\begin{array}{l}\text { Model } \\
\text { 5.3.1 }\end{array}$ & $\begin{array}{l}\text { Model } \\
5.3 .2\end{array}$ & $\begin{array}{l}\text { Model } \\
5.3 .3\end{array}$ & $\begin{array}{l}\text { Model } \\
5.3 .4\end{array}$ & $\begin{array}{l}\text { Model } \\
5.3 .5\end{array}$ & $\begin{array}{l}\text { Model } \\
\text { 5.3.6 }\end{array}$ \\
\hline Lagged DV & & & & $\begin{array}{l}.758 * * * \\
(.006)\end{array}$ & $\begin{array}{l}.749 * * * \\
(.006)\end{array}$ & $\begin{array}{l}.747 * * * \\
(.006)\end{array}$ \\
\hline $\begin{array}{l}\text { Gender } \\
\text { (female) }\end{array}$ & $\begin{array}{l}-.267 * * * \\
(.021)\end{array}$ & $\begin{array}{l}-.239 * * * \\
(.021)\end{array}$ & $\begin{array}{l}-.239 * * * \\
(.021)\end{array}$ & $\begin{array}{l}-.058 * * * \\
(.007)\end{array}$ & $\begin{array}{l}-.052 * * * \\
(.007)\end{array}$ & $\begin{array}{l}-.053 * * \\
(.007)\end{array}$ \\
\hline Education & $\begin{array}{l}.118 * * * \\
(.006)\end{array}$ & $\begin{array}{l}.110 * * * \\
(.006)\end{array}$ & $\begin{array}{l}.109 * * * \\
(.006)\end{array}$ & $\begin{array}{l}.029 * * * \\
(.002)\end{array}$ & $\begin{array}{l}.028 * * * \\
(.002)\end{array}$ & $\begin{array}{l}.028 * * * \\
(.002)\end{array}$ \\
\hline Election time & $\begin{array}{l}.026 * * * \\
(.005)\end{array}$ & $\begin{array}{l}-.033 * * * \\
(.007)\end{array}$ & $\begin{array}{l}-.034 * * * \\
(.007)\end{array}$ & $\begin{array}{l}.023 * * \\
(.008)\end{array}$ & $\begin{array}{c}.006 \\
(.008)\end{array}$ & $\begin{array}{c}.006 \\
(.008)\end{array}$ \\
\hline Generation $(\mathrm{G})$ & & & & & & \\
\hline Baby Boomers & $\begin{array}{l}.120 * * * \\
(.027)\end{array}$ & $\begin{array}{l}.126 * * * \\
(.027)\end{array}$ & $\begin{array}{c}.063 \\
(.048)\end{array}$ & $\begin{array}{l}035 * * * \\
(.009)\end{array}$ & $\begin{array}{l}.038 * * * \\
(.009)\end{array}$ & $\begin{array}{c}.017 \\
(.019)\end{array}$ \\
\hline Generation X & $\begin{array}{l}.144 * * * \\
(.033)\end{array}$ & $\begin{array}{l}.174 * * * \\
(.033)\end{array}$ & $\begin{array}{c}.107 \\
(.055)\end{array}$ & $\begin{array}{l}.042 * * * \\
(.010)\end{array}$ & $\begin{array}{l}.054 * * * \\
(.011)\end{array}$ & $\begin{array}{c}.024 \\
(.021)\end{array}$ \\
\hline Millennials & $\begin{array}{l}.080 * \\
(.040)\end{array}$ & $\begin{array}{l}.147^{* * *} \\
(.039)\end{array}$ & $\begin{array}{c}-.016 \\
(.060)\end{array}$ & $\begin{array}{l}.039 * * \\
(.012)\end{array}$ & $\begin{array}{l}.062 * * * \\
(.012)\end{array}$ & $\begin{array}{c}.001 \\
(.022)\end{array}$ \\
\hline Generation Z & $\begin{array}{l}.208 * * * \\
(.052)\end{array}$ & $\begin{array}{l}.269 * * * \\
(.050)\end{array}$ & $\begin{array}{c}.017 \\
(.070)\end{array}$ & $\begin{array}{l}.082^{* * * *} \\
(.017)\end{array}$ & $\begin{array}{l}.104 * * * \\
(.017)\end{array}$ & $\begin{array}{c}.007 \\
(.027)\end{array}$ \\
\hline $\begin{array}{l}\text { Exposure to } \\
\text { pol. info. in the } \\
\text { news media } \\
\text { (NM) }\end{array}$ & & $\begin{array}{l}.021 * * * \\
(.002)\end{array}$ & $\begin{array}{l}.013 * * \\
(.004)\end{array}$ & & $\begin{array}{l}.007 * * * \\
(.001)\end{array}$ & $\begin{array}{l}.003 * \\
(.001)\end{array}$ \\
\hline $\mathrm{NM} \times \mathrm{G}$ & & & & & & \\
\hline Baby Boomers & & & $\begin{array}{c}.007 \\
(.004)\end{array}$ & & & $\begin{array}{c}.002 \\
(.002)\end{array}$ \\
\hline Generation X & & & $\begin{array}{c}.007 \\
(.005)\end{array}$ & & & $\begin{array}{c}.003 \\
(.002)\end{array}$ \\
\hline Millennials & & & $\begin{array}{l}.022 * * * \\
(.006)\end{array}$ & & & $\begin{array}{l}.008 * * * \\
(.002)\end{array}$ \\
\hline Generation Z & & & $\begin{array}{l}.042 * * * \\
(.008)\end{array}$ & & & $\begin{array}{l}.015 * * * \\
(.003)\end{array}$ \\
\hline Constant & $\begin{array}{l}3.199 * * * \\
(.034)\end{array}$ & $\begin{array}{l}3.046 * * \\
(.036)\end{array}$ & $\begin{array}{l}3.128 * * * \\
(.047)\end{array}$ & $\begin{array}{l}.775 * * * \\
(.023)\end{array}$ & $\begin{array}{l}.754 * * * \\
(.023)\end{array}$ & $\begin{array}{l}.791 * * * \\
(.027)\end{array}$ \\
\hline $\mathrm{R}^{2}$ & .128 & .154 & .159 & .630 & .632 & .633 \\
\hline
\end{tabular}

Notes. Pooled OLS regressions. Unstandardized coefficients. Robust standard errors in parentheses.

$* \mathrm{p}<.05, * * \mathrm{p}<.01, * * * \mathrm{p}<.001 . \mathrm{N}_{\text {Static }}=3,490 / 17,450 . \mathrm{N}_{\text {Dynamic }}=3,490 / 13,960$. 


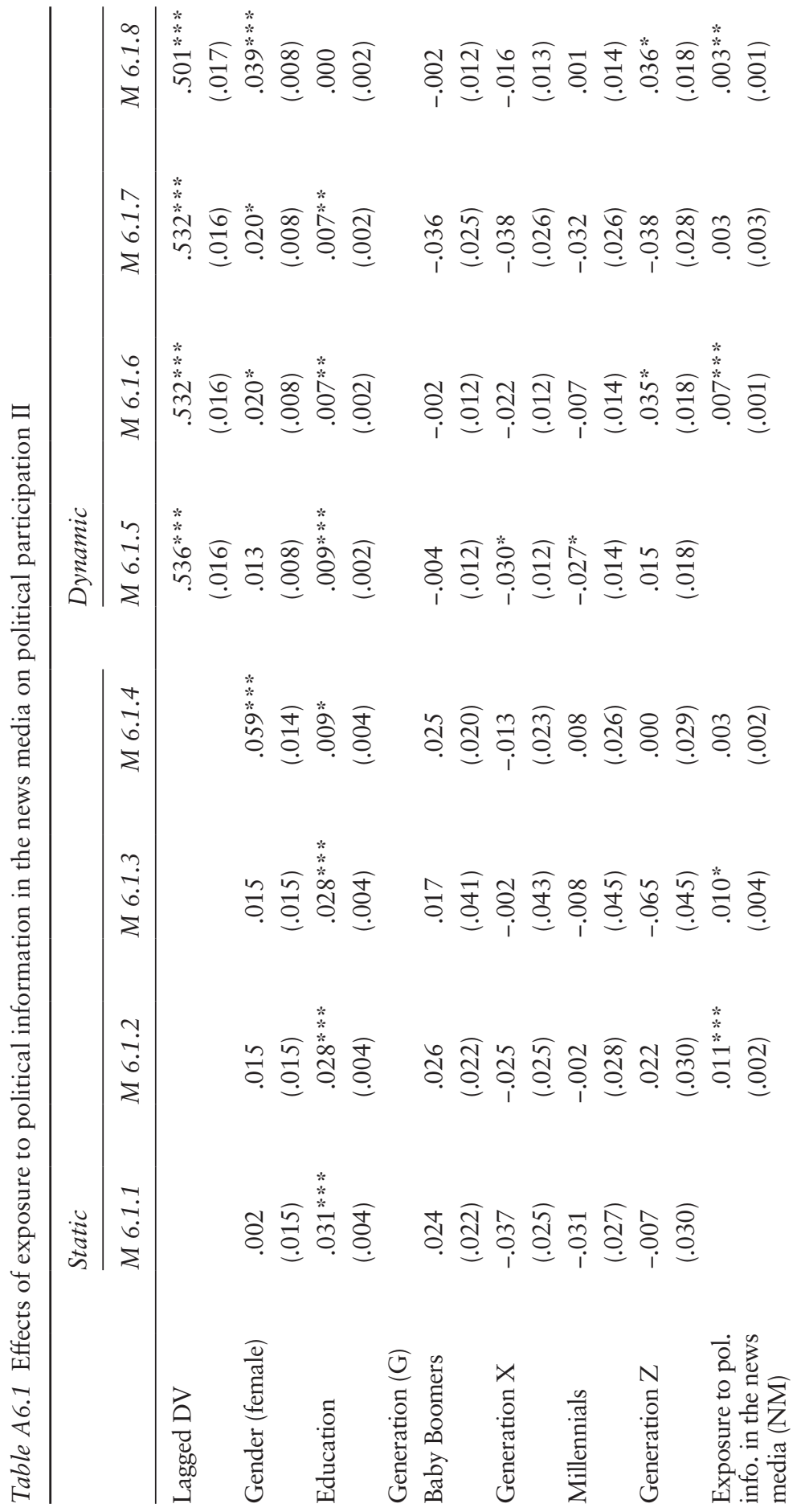




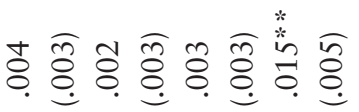

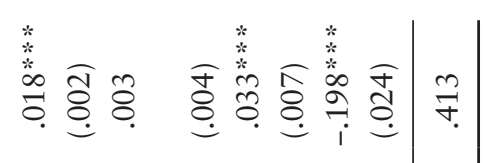

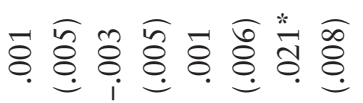

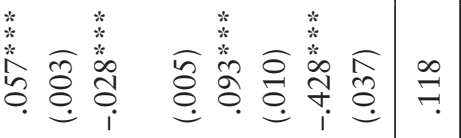

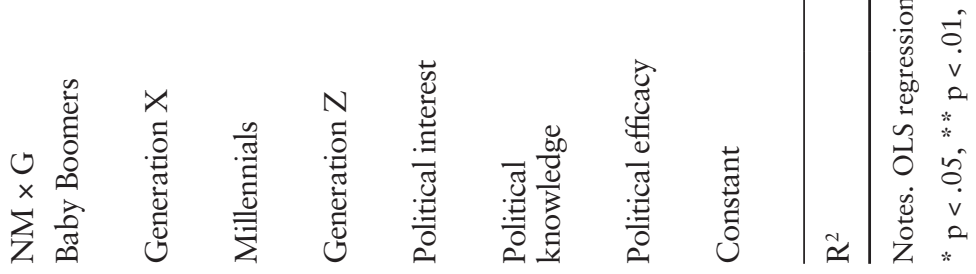




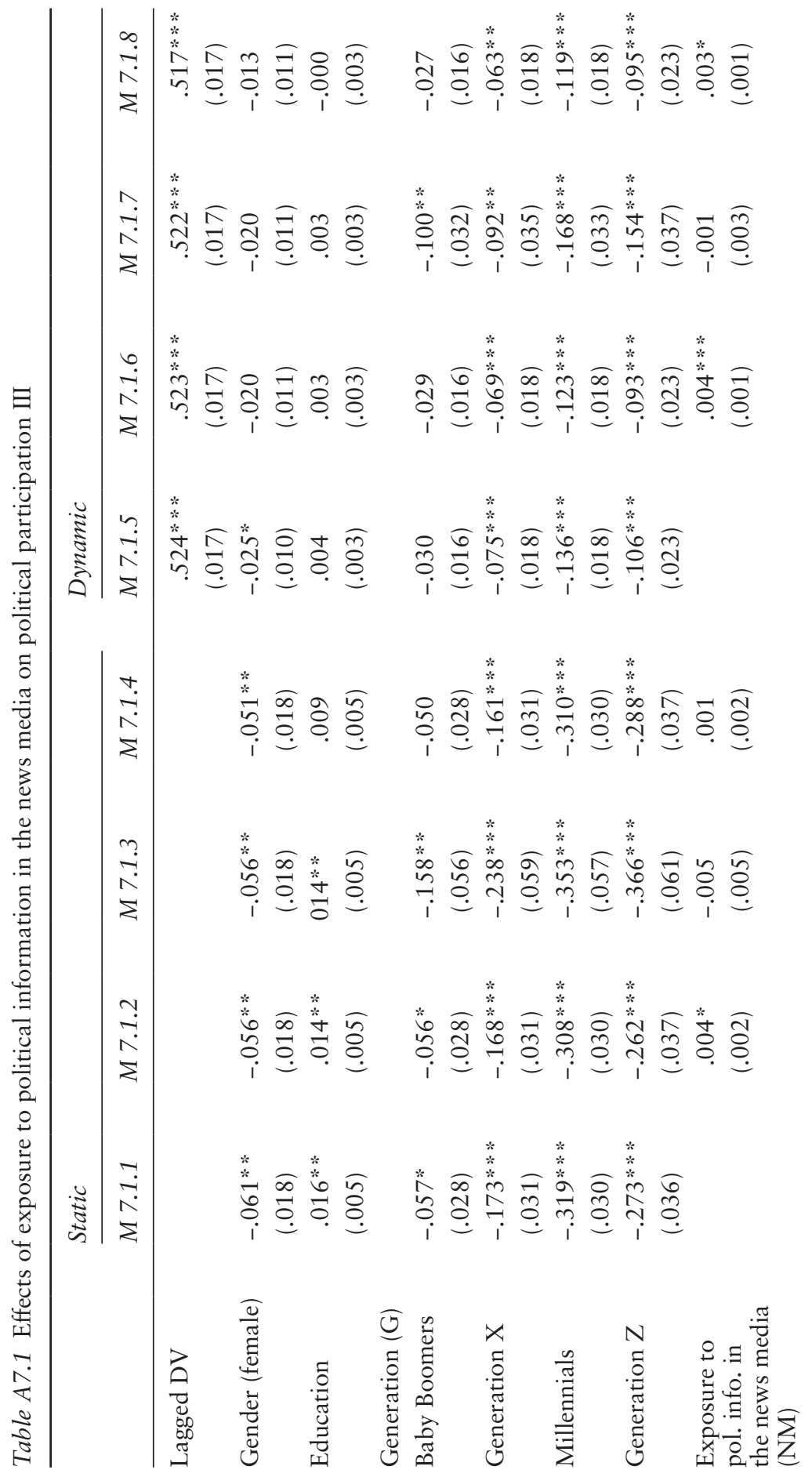


Appendix 169

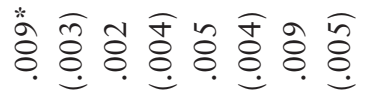

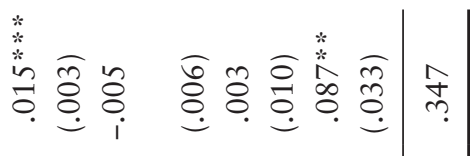

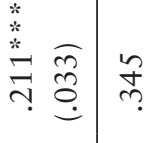

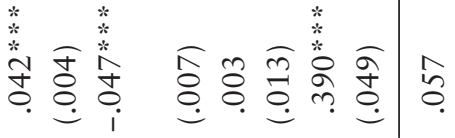

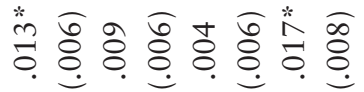

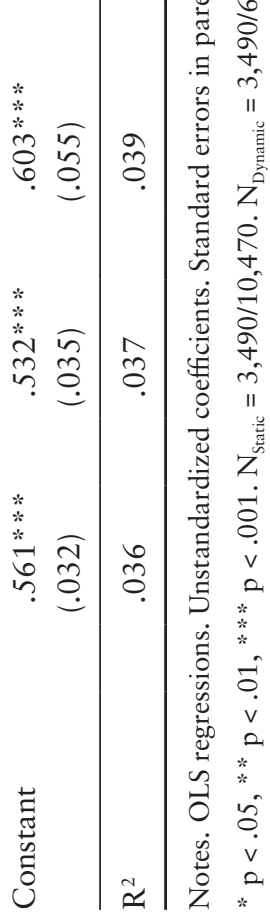

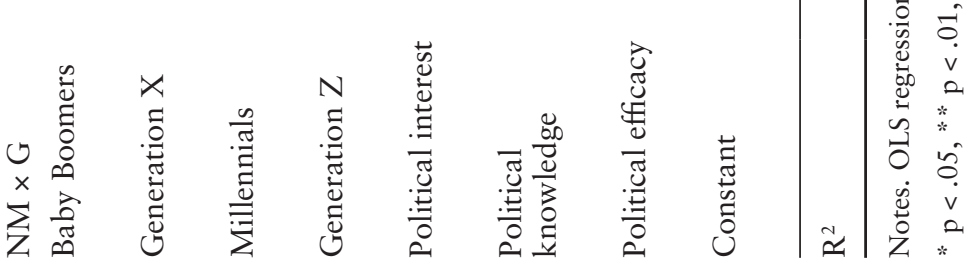


170 Appendix

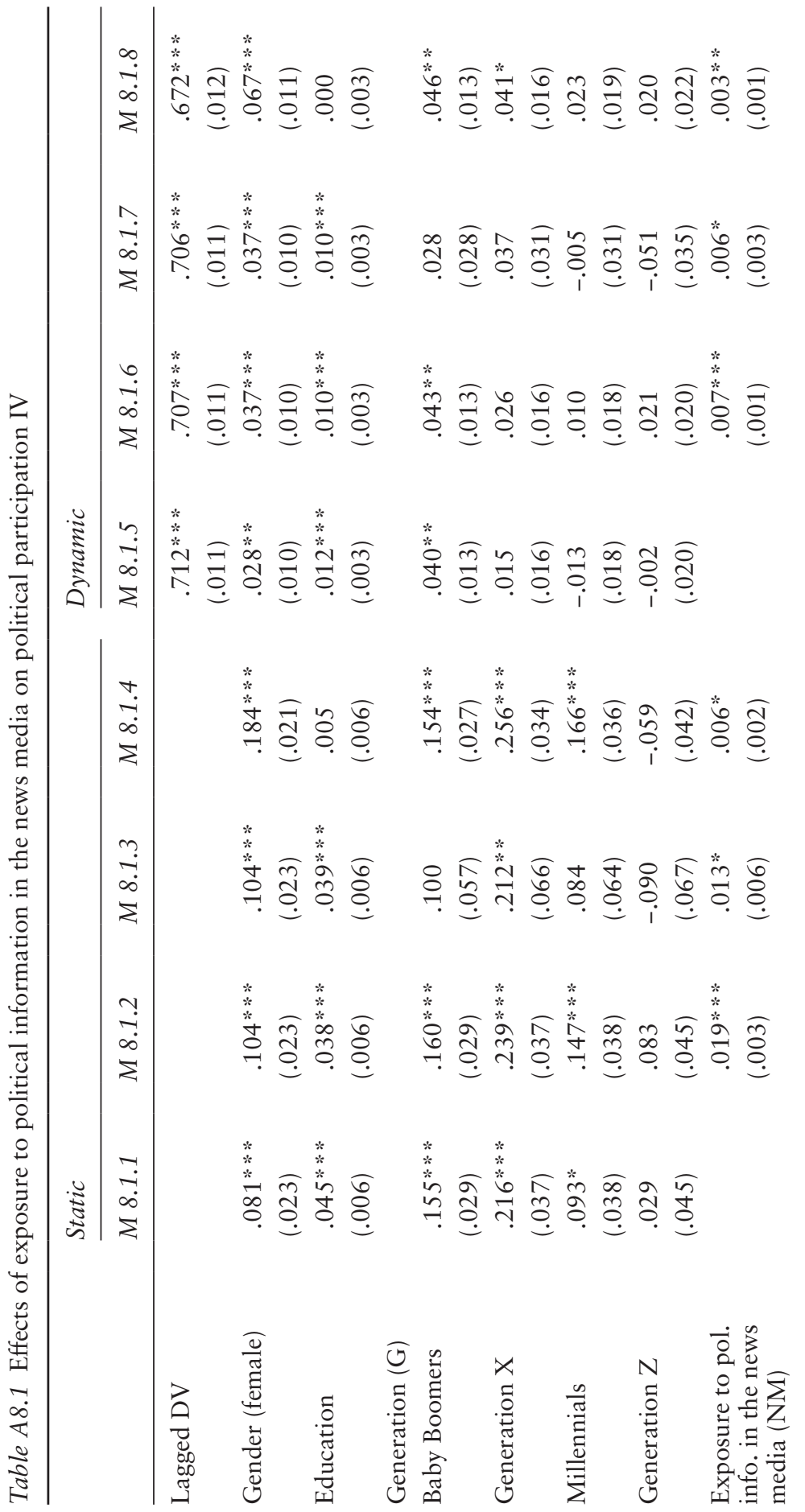


Appendix 171

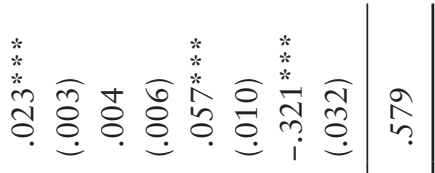

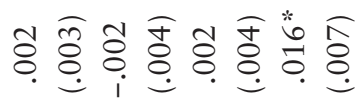

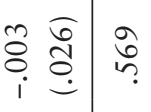

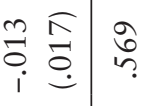

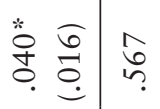

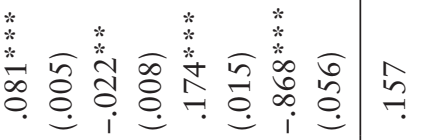

$$
\begin{aligned}
& \text { ڤิ }
\end{aligned}
$$

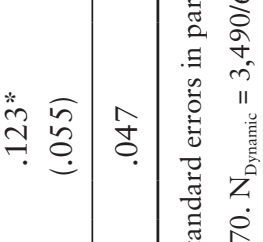

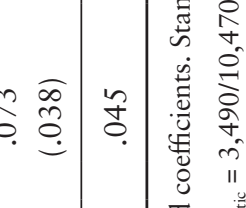

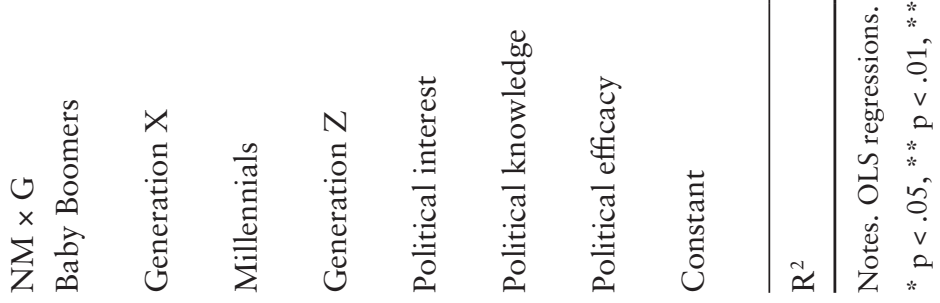




\section{Appendix}

Table A9.1 Effects of exposure to political information on social media on political interest

\begin{tabular}{|c|c|c|c|c|c|c|}
\hline & \multicolumn{3}{|l|}{ Static } & \multicolumn{3}{|l|}{ Dynamic } \\
\hline & $\begin{array}{l}\text { Model } \\
9.1 .1\end{array}$ & $\begin{array}{l}\text { Model } \\
9.1 .2\end{array}$ & $\begin{array}{l}\text { Model } \\
9.1 .3\end{array}$ & $\begin{array}{l}\text { Model } \\
9.1 .4\end{array}$ & $\begin{array}{l}\text { Model } \\
9.1 .5\end{array}$ & $\begin{array}{l}\text { Model } \\
9.1 .6\end{array}$ \\
\hline Lagged DV & & & & $\begin{array}{l}.761 * * * \\
(.024)\end{array}$ & $\begin{array}{l}.747 * * * \\
(.024)\end{array}$ & $\begin{array}{l}.746 * * * \\
(.025)\end{array}$ \\
\hline Gender (female) & $\begin{array}{l}-.764 * * * \\
(.190)\end{array}$ & $\begin{array}{l}-.790 * * * \\
(.185)\end{array}$ & $\begin{array}{l}-.786 * * * \\
(.185)\end{array}$ & $\begin{array}{c}-.092 \\
(.114)\end{array}$ & $\begin{array}{r}-.113 \\
(.113)\end{array}$ & $\begin{array}{c}-.106 \\
(.114)\end{array}$ \\
\hline Education & $\begin{array}{l}.239 * * * \\
(.051)\end{array}$ & $\begin{array}{l}.230 * * * \\
(.050)\end{array}$ & $\begin{array}{l}.224 * * * \\
(.050)\end{array}$ & $\begin{array}{c}.048 \\
(.031)\end{array}$ & $\begin{array}{c}.048 \\
(.031)\end{array}$ & $\begin{array}{c}.045 \\
(.031)\end{array}$ \\
\hline \multicolumn{7}{|l|}{ Generation $(\mathrm{G})$} \\
\hline Baby Boomers & $\begin{array}{l}-.415 \\
(.337)\end{array}$ & $\begin{array}{c}-.361 \\
(.328)\end{array}$ & $\begin{array}{l}-.535 \\
(.372)\end{array}$ & $\begin{array}{c}.272 \\
(.200)\end{array}$ & $\begin{array}{c}.277 \\
(.198)\end{array}$ & $\begin{array}{c}.294 \\
(.226)\end{array}$ \\
\hline Generation X & $\begin{array}{l}-.979 * * \\
(.368)\end{array}$ & $\begin{array}{l}-.881^{*} \\
(.359)\end{array}$ & $\begin{array}{c}-1.253^{* *} \\
(.408)\end{array}$ & $\begin{array}{c}.046 \\
(.219)\end{array}$ & $\begin{array}{c}.060 \\
(.217)\end{array}$ & $\begin{array}{c}.038 \\
(.249)\end{array}$ \\
\hline Millennials & $\begin{array}{c}-1.581 * * * \\
(.369)\end{array}$ & $\begin{array}{c}-1.619 * * * \\
(.360)\end{array}$ & $\begin{array}{c}-2.021 * * * \\
(.431)\end{array}$ & $\begin{array}{c}-.060 \\
(.223)\end{array}$ & $\begin{array}{r}-.101 \\
(.221)\end{array}$ & $\begin{array}{c}-.147 \\
(.267)\end{array}$ \\
\hline Generation Z & $\begin{array}{c}-1.381 * * \\
(.455)\end{array}$ & $\begin{array}{c}-1.366^{* *} \\
(.444)\end{array}$ & $\begin{array}{c}-1.826^{* * * *} \\
(.512)\end{array}$ & $\begin{array}{c}-.049 \\
(.271)\end{array}$ & $\begin{array}{l}-.069 \\
(.269)\end{array}$ & $\begin{array}{c}-.308 \\
(.312)\end{array}$ \\
\hline $\begin{array}{l}\text { Social media } \\
\text { exposure to pol. } \\
\text { info. (SMEPI) }\end{array}$ & & $\begin{array}{l}2.332 * * * \\
(.430)\end{array}$ & $\begin{array}{c}.700 \\
(1.116)\end{array}$ & & $\begin{array}{l}.785^{* *} \\
(.263)\end{array}$ & $\begin{array}{c}.660 \\
(.671)\end{array}$ \\
\hline \multicolumn{7}{|l|}{ SMEPI × G } \\
\hline Baby Boomers & & & $\begin{array}{c}1.103 \\
(1.279)\end{array}$ & & & $\begin{array}{c}-.183 \\
(.770)\end{array}$ \\
\hline Generation X & & & $\begin{array}{c}3.012+ \\
(1.584)\end{array}$ & & & $\begin{array}{c}.167 \\
(.957)\end{array}$ \\
\hline Millennials & & & $\begin{array}{c}2.680+ \\
(1.578)\end{array}$ & & & $\begin{array}{c}.285 \\
(.952)\end{array}$ \\
\hline Generation Z & & & $\begin{array}{c}3.247+ \\
(1.854)\end{array}$ & & & $\begin{array}{l}1.750 \\
(1.116)\end{array}$ \\
\hline Constant & $\begin{array}{l}7.314 * * * \\
(.392)\end{array}$ & $\begin{array}{l}7.034 \% * \% \\
(.385)\end{array}$ & $\begin{array}{l}7.295 * * * \\
(.413)\end{array}$ & $\begin{array}{l}1.618 * * * \\
(.293)\end{array}$ & $\begin{array}{l}1.629 * * * \\
(.291)\end{array}$ & $\begin{array}{l}1.666^{* * *} \\
(.310)\end{array}$ \\
\hline $\mathrm{R}^{2}$ & .129 & .173 & .177 & .698 & .702 & .702 \\
\hline
\end{tabular}

Notes. OLS regressions. Unstandardized coefficients. Standard errors in parentheses.

$+\mathrm{p}<.1, * \mathrm{p}<.05, * \mathrm{p}<.01, * * \mathrm{p}<.001 . \mathrm{N}=534$. 
Table A9.2 Effects of exposure to political information on social media on political knowledge

\begin{tabular}{|c|c|c|c|c|c|c|}
\hline & \multicolumn{3}{|l|}{ Static } & \multicolumn{3}{|l|}{ Dynamic } \\
\hline & $\begin{array}{l}\text { Model } \\
9.2 .1\end{array}$ & $\begin{array}{l}\text { Model } \\
9.2 .2\end{array}$ & $\begin{array}{l}\text { Model } \\
9.2 .3\end{array}$ & $\begin{array}{l}\text { Model } \\
9.2 .4\end{array}$ & $\begin{array}{l}\text { Model } \\
9.2 .5\end{array}$ & $\begin{array}{l}\text { Model } \\
9.2 .6\end{array}$ \\
\hline Lagged DV & & & & $\begin{array}{l}.405 * * * \\
(.034)\end{array}$ & $\begin{array}{l}.395 * * * \\
(.034)\end{array}$ & $\begin{array}{l}.394 * * * \\
(.034)\end{array}$ \\
\hline Gender (female) & $\begin{array}{l}-.364 * * * \\
(.085)\end{array}$ & $\begin{array}{l}-.372 * * * \\
(.084)\end{array}$ & $\begin{array}{l}-.370 * * * \\
(.084)\end{array}$ & $\begin{array}{c}-.174 * \\
(.077)\end{array}$ & $\begin{array}{c}-.185 * \\
(.077)\end{array}$ & $\begin{array}{c}-.181 * \\
(.077)\end{array}$ \\
\hline Education & $\begin{array}{l}.073 * * \\
(.023)\end{array}$ & $\begin{array}{l}.070 * * \\
(.023)\end{array}$ & $\begin{array}{l}.066^{* *} \\
(.023)\end{array}$ & $\begin{array}{c}.017 \\
(.021)\end{array}$ & $\begin{array}{c}.016 \\
(.021)\end{array}$ & $\begin{array}{c}.012 \\
(.021)\end{array}$ \\
\hline \multicolumn{7}{|l|}{ Generation $(\mathrm{G})$} \\
\hline Baby Boomers & $\begin{array}{l}-.111 \\
(.150)\end{array}$ & $\begin{array}{l}-.095 \\
(.149)\end{array}$ & $\begin{array}{l}-.138 \\
(.168)\end{array}$ & $\begin{array}{c}-.031 \\
(.134)\end{array}$ & $\begin{array}{r}-.020 \\
(.133)\end{array}$ & $\begin{array}{l}-.056 \\
(.150)\end{array}$ \\
\hline Generation X & $\begin{array}{c}-.421 \% \\
(.164)\end{array}$ & $\begin{array}{c}-.391 * \\
(.162)\end{array}$ & $\begin{array}{l}-.508 * * \\
(.184)\end{array}$ & $\begin{array}{c}-.150 \\
(.148)\end{array}$ & $\begin{array}{c}-.134 \\
(.147)\end{array}$ & $\begin{array}{l}-.218 \\
(.166)\end{array}$ \\
\hline Millennials & $\begin{array}{l}-.715 * * * \\
(.165)\end{array}$ & $\begin{array}{l}-.727 * * * \\
(.163)\end{array}$ & $\begin{array}{l}-.919 * * * \\
(.195)\end{array}$ & $\begin{array}{c}-.247 \\
(.152)\end{array}$ & $\begin{array}{c}-.267+ \\
(.151)\end{array}$ & $\begin{array}{c}-.440 * \\
(.179)\end{array}$ \\
\hline Generation Z & $\begin{array}{c}-1.354 * * * \\
(.203)\end{array}$ & $\begin{array}{c}-1.350 * * * \\
(.201)\end{array}$ & $\begin{array}{c}-1.547 * * * \\
(.232)\end{array}$ & $\begin{array}{l}-.774 * * * \\
(.187)\end{array}$ & $\begin{array}{l}-.785 * * * \\
(.186)\end{array}$ & $\begin{array}{l}-.984 * * * \\
(.212)\end{array}$ \\
\hline $\begin{array}{l}\text { Social media } \\
\text { exposure to pol. } \\
\text { info. (SMEPI) }\end{array}$ & & $\begin{array}{l}.723 * * * \\
(.195)\end{array}$ & $\begin{array}{l}.168 \\
(.505)\end{array}$ & & $\begin{array}{l}.534 * * \\
(.175)\end{array}$ & $\begin{array}{c}.069 \\
(.451)\end{array}$ \\
\hline SMEPI $\times \mathrm{G}$ & & & & & & \\
\hline Baby Boomers & & & $\begin{array}{c}.242 \\
(.578)\end{array}$ & & & $\begin{array}{c}.190 \\
(.516)\end{array}$ \\
\hline Generation X & & & $\begin{array}{c}.939 \\
(.717)\end{array}$ & & & $\begin{array}{c}.637 \\
(.640)\end{array}$ \\
\hline Millennials & & & $\begin{array}{c}1.261+ \\
(.714)\end{array}$ & & & $\begin{array}{c}1.119+ \\
(.637)\end{array}$ \\
\hline Generation Z & & & $\begin{array}{c}1.389+ \\
(.839)\end{array}$ & & & $\begin{array}{c}1.390+ \\
(.749)\end{array}$ \\
\hline Constant & $\begin{array}{l}3.259 * * * \\
(.175)\end{array}$ & $\begin{array}{l}3.172 * * * \\
(.174)\end{array}$ & $\begin{array}{l}3.268 * * * \\
(.187)\end{array}$ & $\begin{array}{l}2.282 * * * \\
(.176)\end{array}$ & $\begin{array}{l}2.241 * * * \\
(.175)\end{array}$ & $\begin{array}{l}2.327 * * * \\
(.186)\end{array}$ \\
\hline $\mathrm{R}^{2}$ & .212 & .231 & .234 & .377 & .387 & .390 \\
\hline
\end{tabular}

Notes. OLS regressions. Unstandardized coefficients. Standard errors in parentheses.

$+\mathrm{p}<.1, * \mathrm{p}<.05, * * \mathrm{p}<.01, * * \mathrm{p}<.001 . \mathrm{N}=534$. 
Table A9.3 Effects of exposure to political information on social media on political efficacy $(1-5)$

\begin{tabular}{|c|c|c|c|c|c|c|}
\hline & \multicolumn{3}{|l|}{ Static } & \multicolumn{3}{|l|}{ Dynamic } \\
\hline & $\begin{array}{l}\text { Model } \\
9.3 .1\end{array}$ & $\begin{array}{l}\text { Model } \\
9.3 .2\end{array}$ & $\begin{array}{l}\text { Model } \\
9.3 .3\end{array}$ & $\begin{array}{l}\text { Model } \\
9.3 .4\end{array}$ & $\begin{array}{l}\text { Model } \\
9.3 .5\end{array}$ & $\begin{array}{l}\text { Model } \\
9.3 .6\end{array}$ \\
\hline Lagged DV & & & & $\begin{array}{l}.674 * * * \\
(.030)\end{array}$ & $\begin{array}{l}.668 * * * \\
(.031)\end{array}$ & $\begin{array}{l}.669 * * \\
(.031)\end{array}$ \\
\hline Gender (female) & $\begin{array}{l}-.328 * * * \\
(.058)\end{array}$ & $\begin{array}{l}-.333 * * * \\
(.058)\end{array}$ & $\begin{array}{l}-.330 * * * \\
(.058)\end{array}$ & $\begin{array}{c}-.119 * * \\
(.043)\end{array}$ & $\begin{array}{l}-.122 * * \\
(.043)\end{array}$ & $\begin{array}{c}-.119 * * \\
(.043)\end{array}$ \\
\hline Education & $\begin{array}{l}.107 * * * \\
(.016)\end{array}$ & $\begin{array}{l}.106 * * * \\
(.016)\end{array}$ & $\begin{array}{l}.105 * * * \\
(.016)\end{array}$ & $\begin{array}{l}.035 * * \\
(.012)\end{array}$ & $\begin{array}{l}.036 * * \\
(.012)\end{array}$ & $\begin{array}{l}.036 * * \\
(.012)\end{array}$ \\
\hline \multicolumn{7}{|l|}{ Generation $(\mathrm{G})$} \\
\hline Baby Boomers & $\begin{array}{c}.078 \\
(.103)\end{array}$ & $\begin{array}{c}.089 \\
(.102)\end{array}$ & $\begin{array}{c}.027 \\
(.116)\end{array}$ & $\begin{array}{c}.079 \\
(.074)\end{array}$ & $\begin{array}{c}.082 \\
(.074)\end{array}$ & $\begin{array}{c}.098 \\
(.084)\end{array}$ \\
\hline Generation X & $\begin{array}{c}.126 \\
(.113)\end{array}$ & $\begin{array}{l}.145 \\
(.112)\end{array}$ & $\begin{array}{c}.025 \\
(.127)\end{array}$ & $\begin{array}{c}.093 \\
(.081)\end{array}$ & $\begin{array}{c}.098 \\
(.081)\end{array}$ & $\begin{array}{c}.110 \\
(.092)\end{array}$ \\
\hline Millennials & $\begin{array}{c}.005 \\
(.113)\end{array}$ & $\begin{array}{r}-.002 \\
(.112)\end{array}$ & $\begin{array}{c}-.019 \\
(.135)\end{array}$ & $\begin{array}{c}.111 \\
(.081)\end{array}$ & $\begin{array}{c}.108 \\
(.081)\end{array}$ & $\begin{array}{c}.186+ \\
(.098)\end{array}$ \\
\hline Generation Z & $\begin{array}{c}.031 \\
(.140)\end{array}$ & $\begin{array}{c}.034 \\
(.138)\end{array}$ & $\begin{array}{c}-.120 \\
(.160)\end{array}$ & $\begin{array}{c}.098 \\
(.100)\end{array}$ & $\begin{array}{c}.099 \\
(.100)\end{array}$ & $\begin{array}{c}.066 \\
(.116)\end{array}$ \\
\hline $\begin{array}{l}\text { Social media } \\
\text { exposure to pol. } \\
\text { info. (SMEPI) }\end{array}$ & & $\begin{array}{l}.452 * * * \\
(.134)\end{array}$ & $\begin{array}{c}-.010 \\
(.348)\end{array}$ & & $\begin{array}{c}.115 \\
(.099)\end{array}$ & $\begin{array}{c}.227 \\
(.253)\end{array}$ \\
\hline SMEPI $\times \mathrm{G}$ & & & & & & \\
\hline Baby Boomers & & & $\begin{array}{c}.420 \\
(.399)\end{array}$ & & & $\begin{array}{c}-.109 \\
(.291)\end{array}$ \\
\hline Generation X & & & $\begin{array}{l}.998 * \\
(.494)\end{array}$ & & & $\begin{array}{c}-.070 \\
(.362)\end{array}$ \\
\hline Millennials & & & $\begin{array}{c}.147 \\
(.492)\end{array}$ & & & $\begin{array}{r}-.502 \\
(.359)\end{array}$ \\
\hline Generation Z & & & $\begin{array}{c}1.138 \% \\
(.578)\end{array}$ & & & $\begin{array}{c}.278 \\
(.422)\end{array}$ \\
\hline Constant & $\begin{array}{l}3.419 * * * \\
(.120)\end{array}$ & $\begin{array}{l}3.365^{* * *} \\
(.120)\end{array}$ & $\begin{array}{l}3.430 * * * \\
(.129)\end{array}$ & $\begin{array}{l}1.159 * * * \\
(.133)\end{array}$ & $\begin{array}{l}1.164 * * * \\
(.133)\end{array}$ & $\begin{array}{l}1.143 * \\
(.141)\end{array}$ \\
\hline $\mathrm{R}^{2}$ & .151 & .167 & .172 & .562 & .563 & .563 \\
\hline
\end{tabular}

Notes. OLS regressions. Unstandardized coefficients. Standard errors in parentheses.

$+\mathrm{p}<.1, * \mathrm{p}<.05, * \mathrm{p}<.01, * * \mathrm{p}<.001 . \mathrm{N}=534$. 


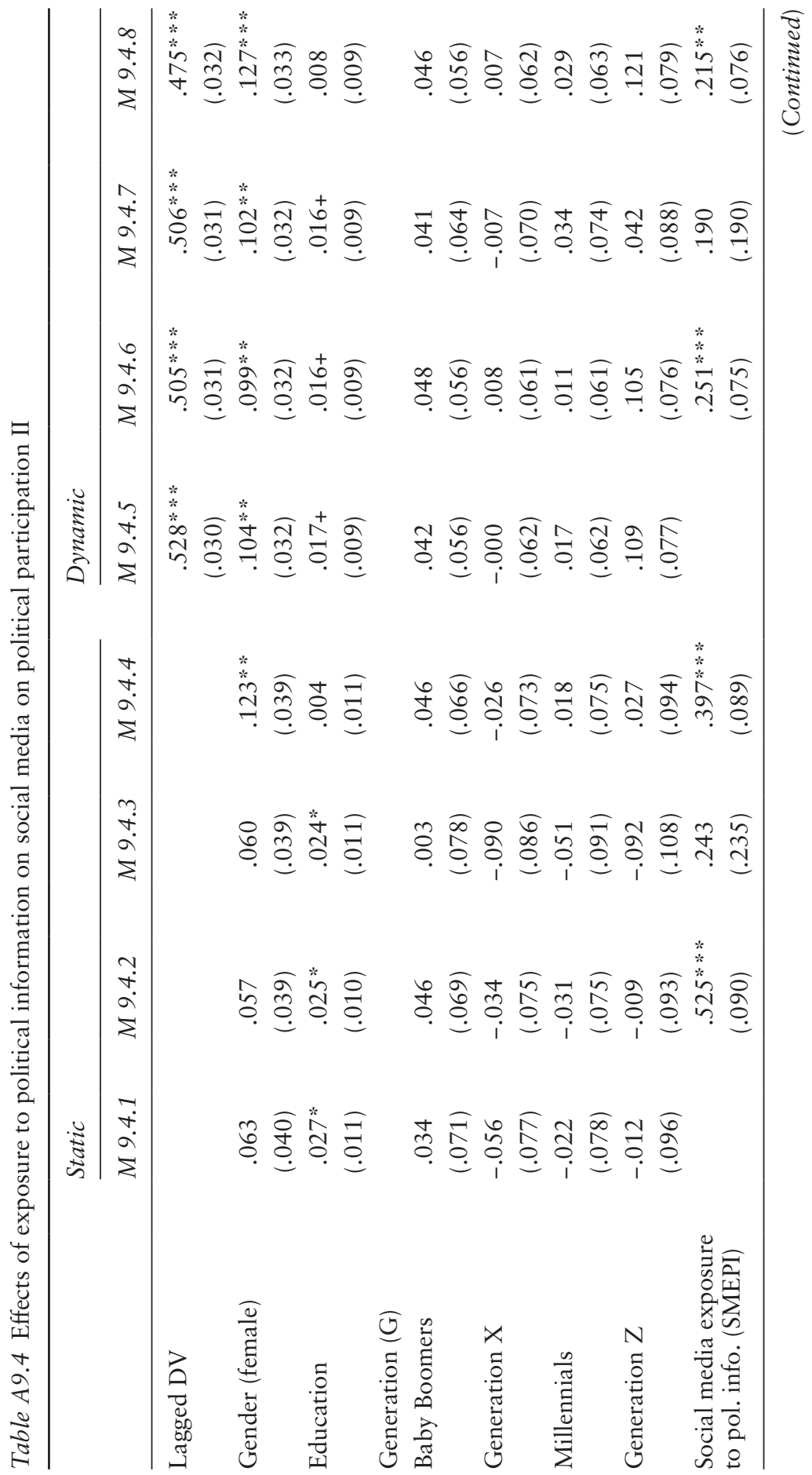


176 Appendix

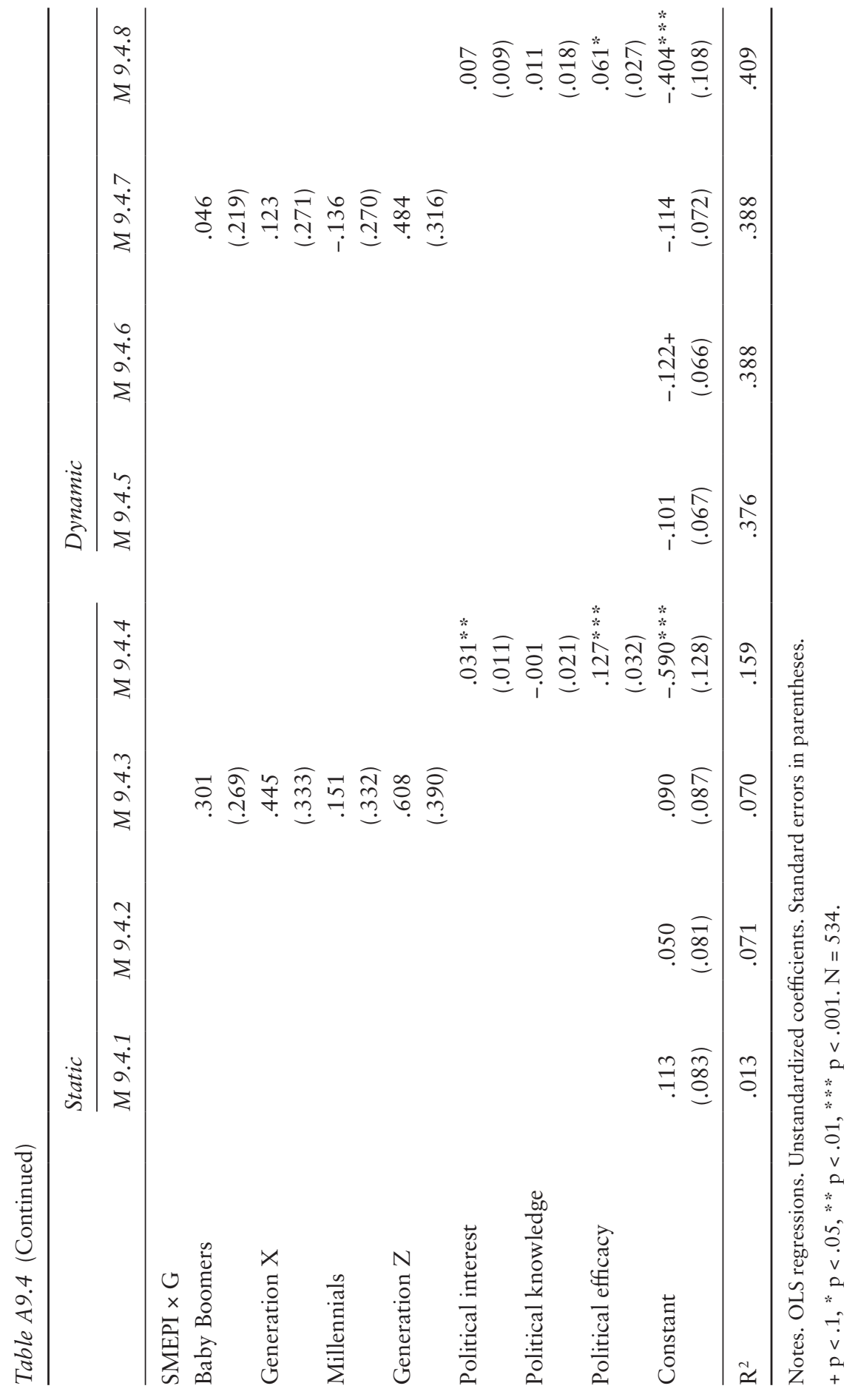




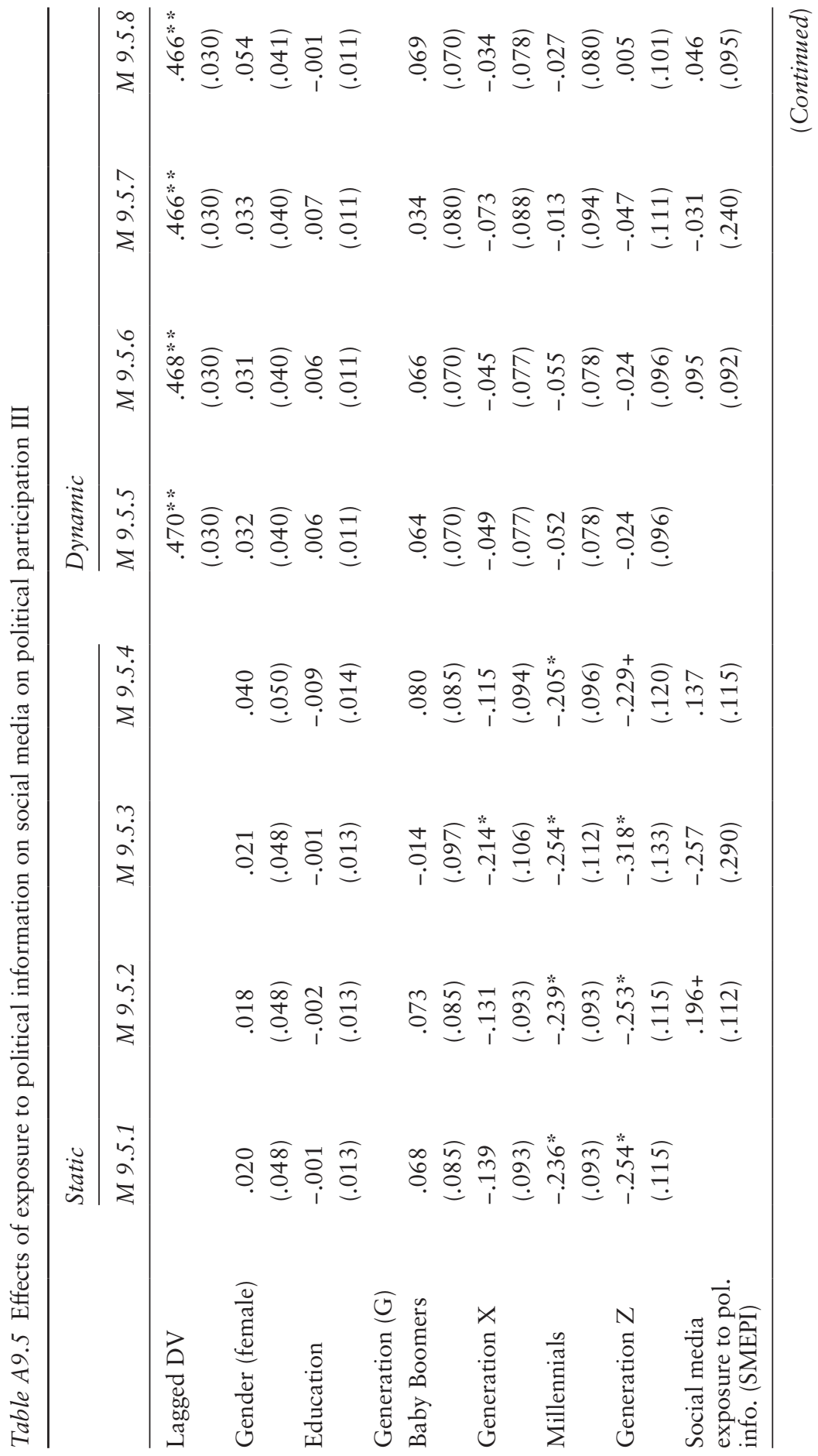


178 Appendix

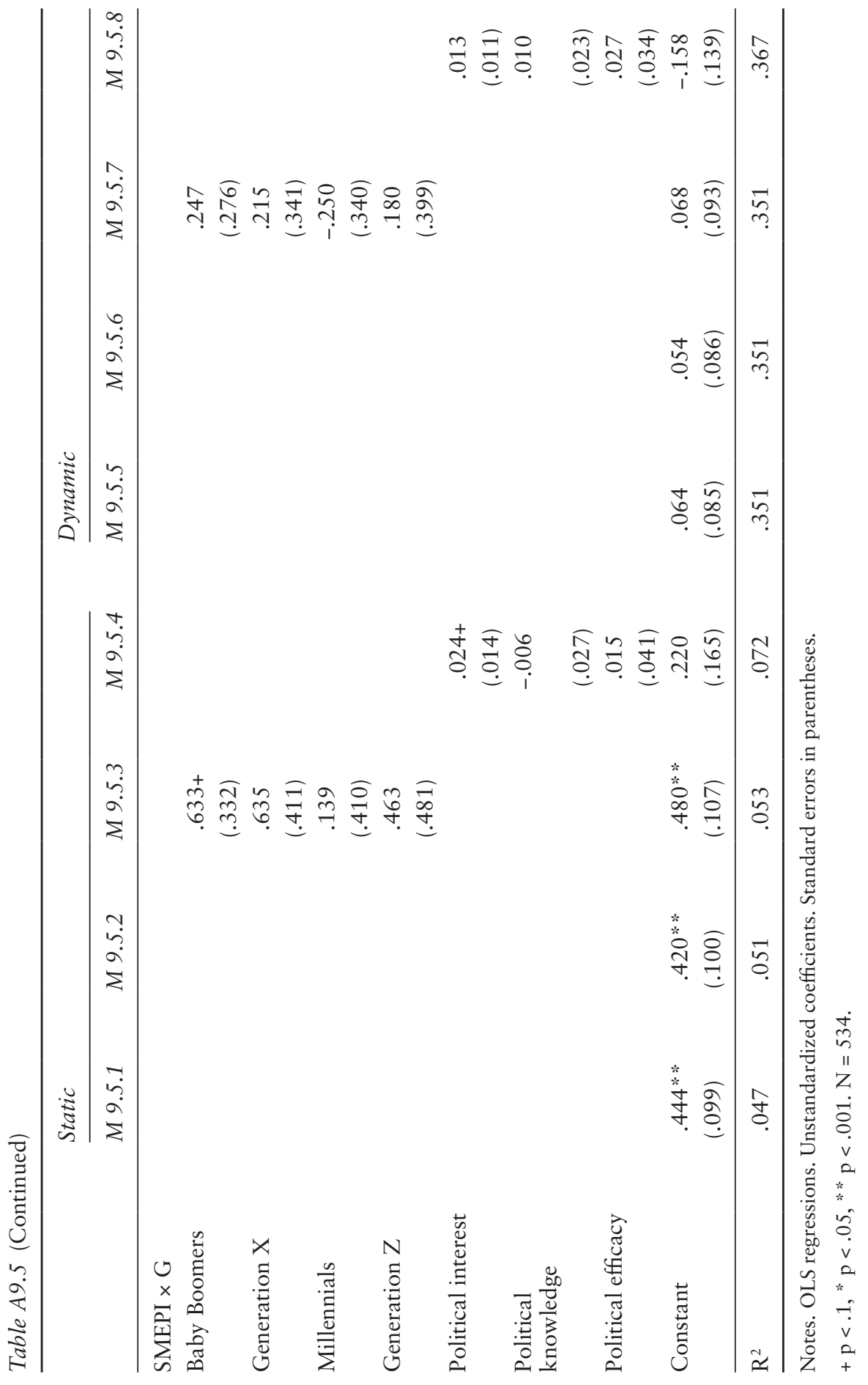




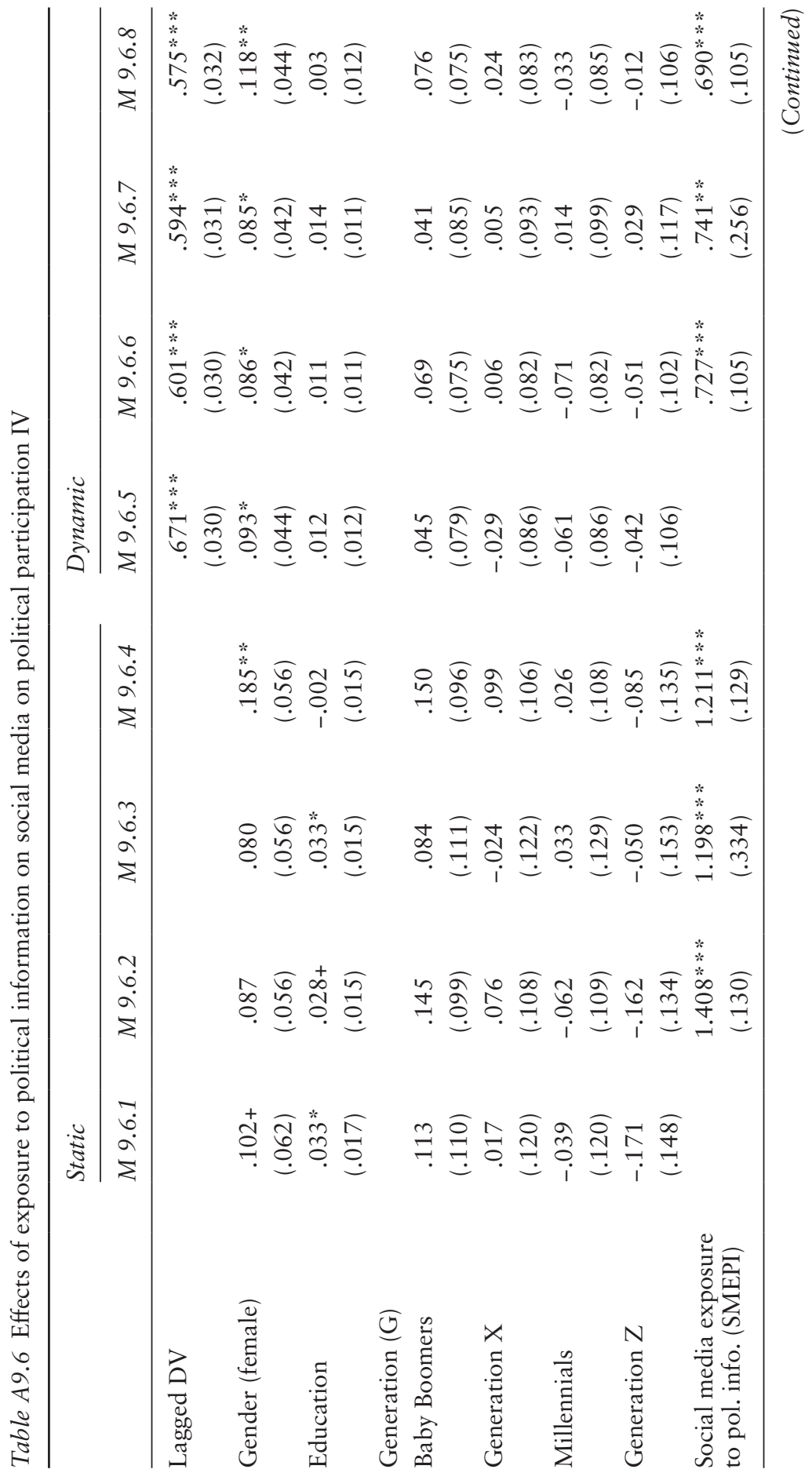


180 Appendix

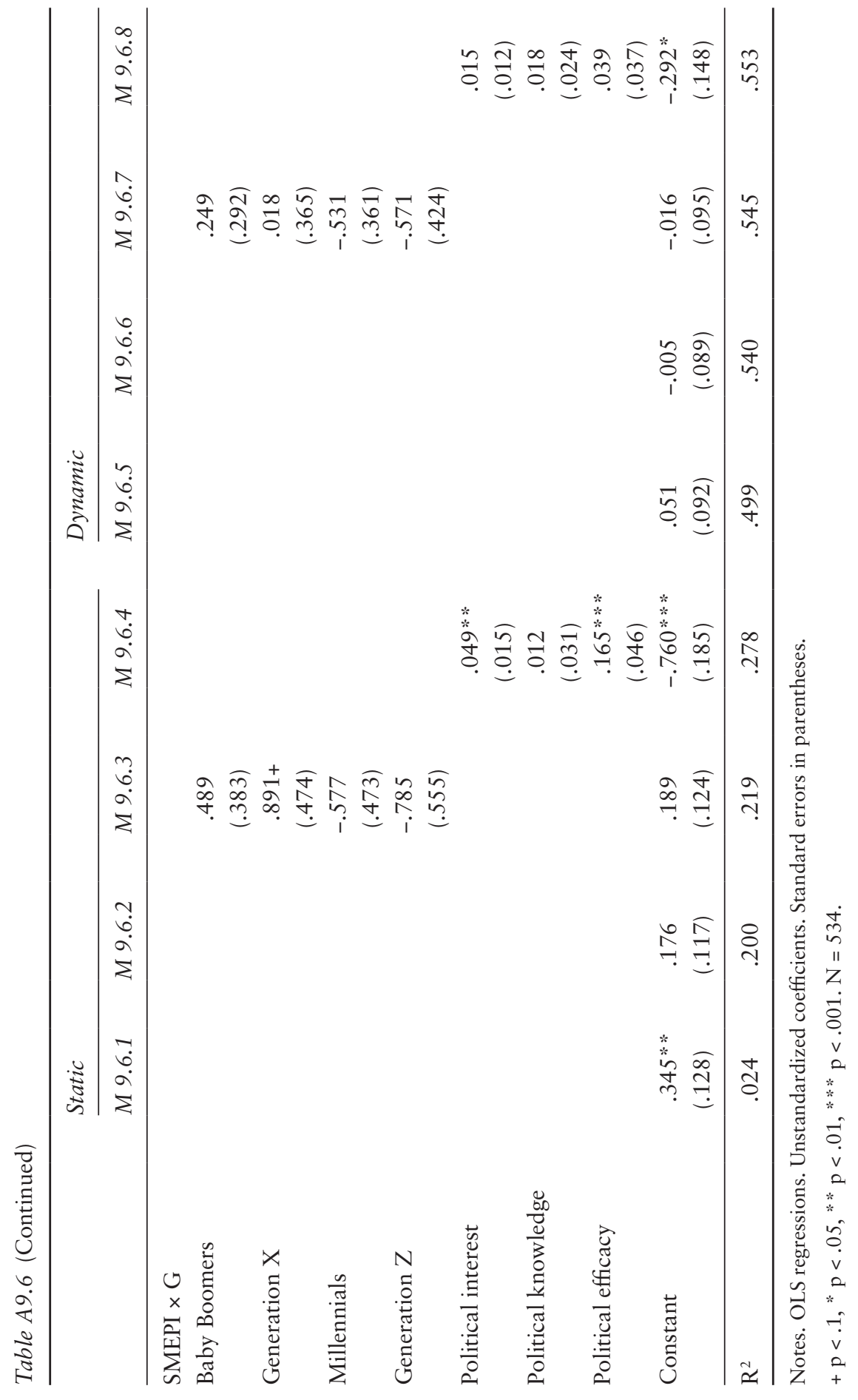


182 Appendix

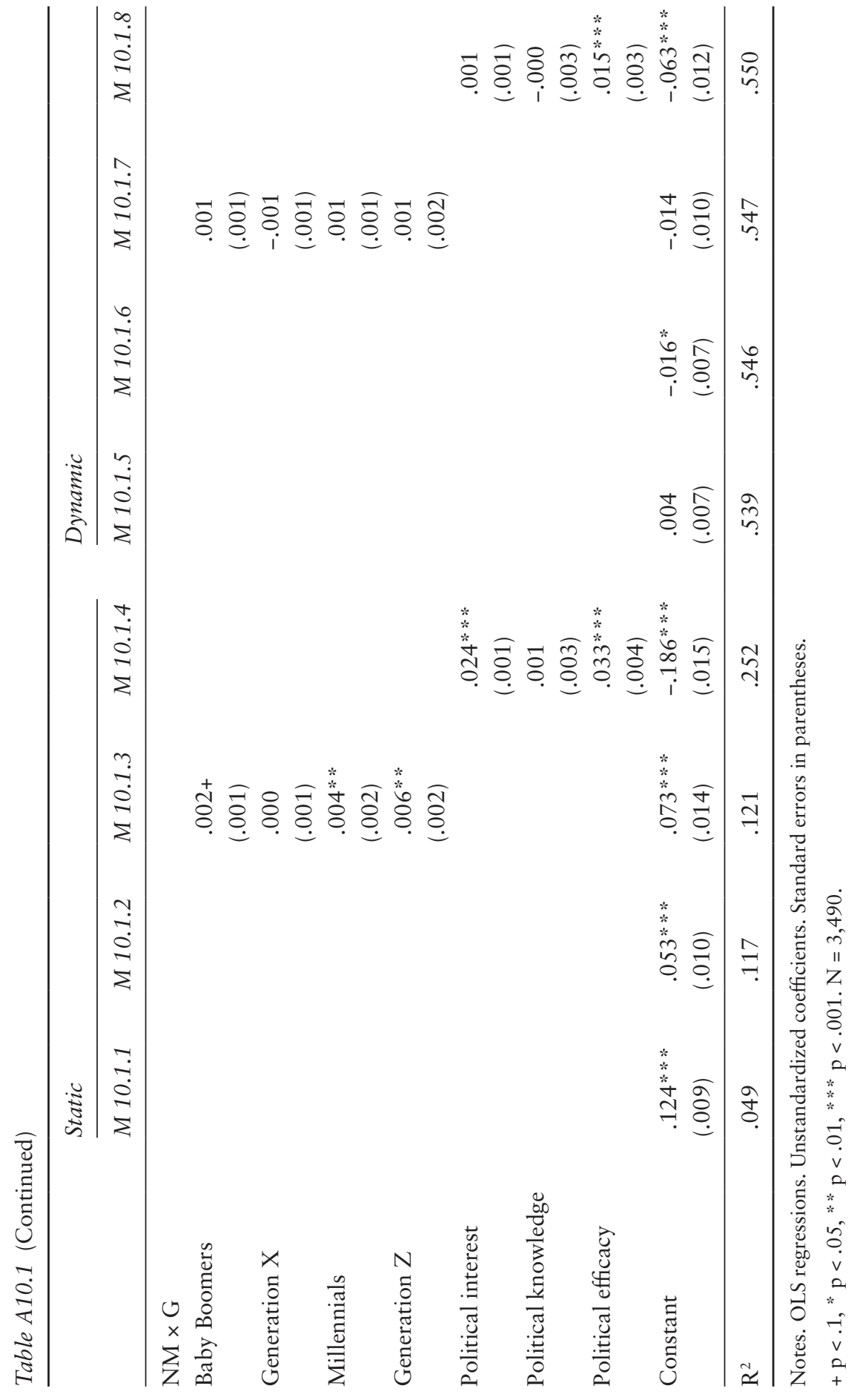


184 Appendix

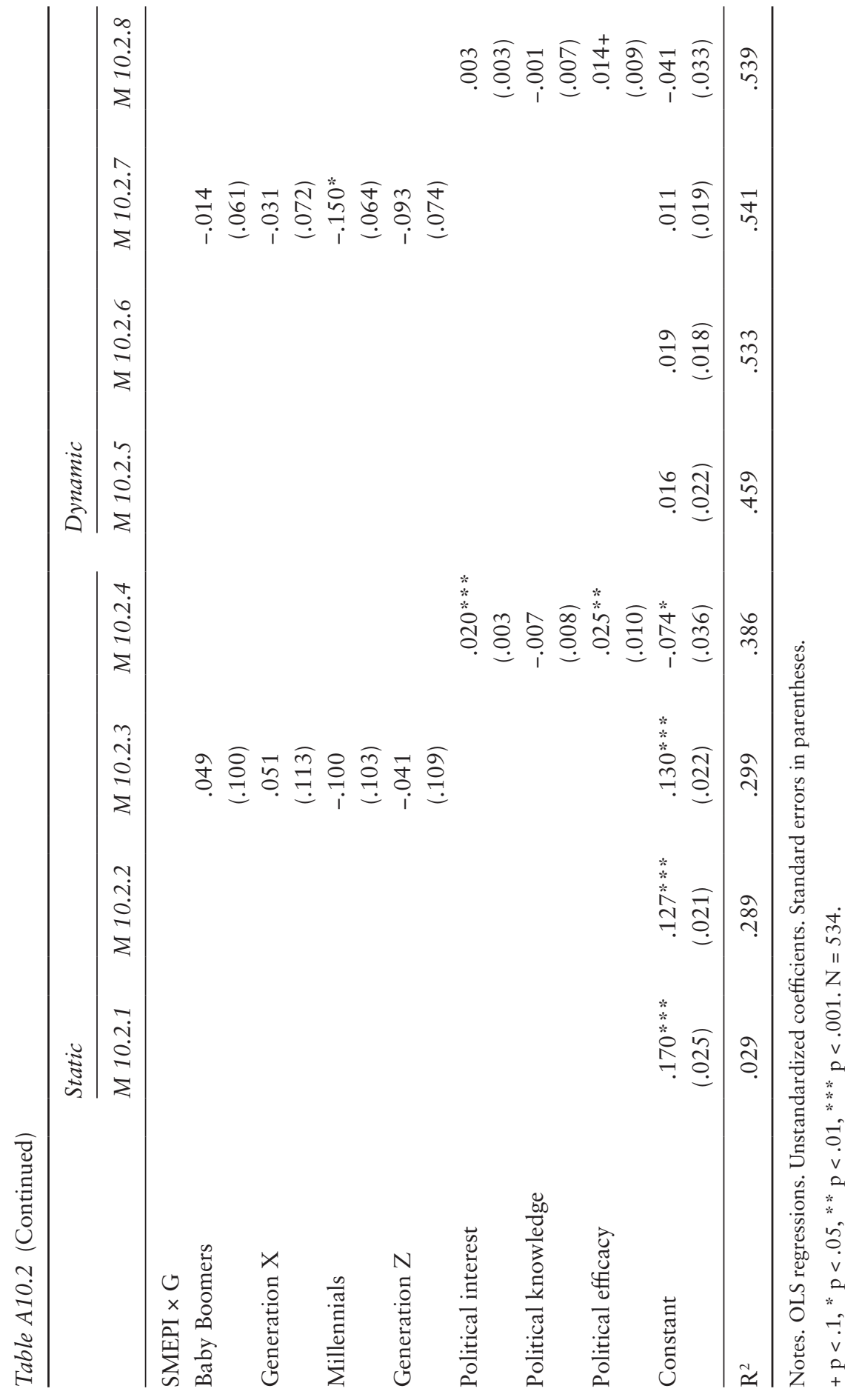




\section{References}

Aalberg, T., \& Curran, J. (2013). How media inform democracy: A comparative approach. New York: Routledge.

Aalberg, T., \& Jenssen, A. T. (2007). Do television debates in multiparty systems affect viewers? A quasi-experimental study with first-time voters. Scandinavian Political Studies, 30(1), 115-135. doi:10.1111/j.1467-9477.2007.00175.x

Abramson, P. R., \& Aldrich, J. H. (1982). The decline of electoral participation in America. American Political Science Review, 76(3), 502-521.

Acock, A. C. (2013). Discovering structural equation modeling using Stata. College Station, TX: Stata Press.

Andersen, J. (2011). Politisk interesse og selvtillid-fordelt på generationer. In A. Simonsen, M. Hedelund, \& J. N. Nielsen (Eds.), Demokrati for Fremtiden: Valgretskommissionens betonkning om unges demokratiske engagement (pp. 205220). Copenhagen: Valgretskommissionen. Retrieved from https://duf.dk/ fileadmin/user_upload/Editor/documents/Maerkesager/Valgret/PUB_2011-12-01_ Valgretskommissions_betaenkning_-_Demokrati_for_fremtiden.pdf

Andersen, K., Bjarnøe, C., Albæk, E., \& de Vreese, C. H. (2016). How news type matters: Indirect effects of media use on political participation through knowledge and efficacy. Journal of Media Psychology, 28(3), 111-122. doi:10.1027/18641105/a000201

Andersen, K., de Vreese, C. H., \& Albæk, E. (2016). Measuring media diet in a highchoice environment: Testing the list-frequency technique. Communication Methods and Measures, 10(2-3), 81-98. doi:10.1080/19312458.2016.1150973

Anduiza, E., Perea, E. A., Jensen, M. J., \& Jorba, L. (2012). Digital media and political engagement worldwide: A comparative study. New York: Cambridge University Press.

Arceneaux, K., \& Johnson, M. (2013). Changing minds or changing channels? Partisan news in an age of choice. Chicago, IL: University of Chicago Press.

Bakker, P. (2008). The simultaneous rise and fall of free and paid newspapers in Europe. Journalism Practice, 2(3), 427-443. doi:10.1080/17512780802281164

Bakker, T. P., \& de Vreese, C. H. (2011). Good news for the future? Young people, internet use, and political participation. Communication Research, 38(4), 451-470. doi:10.1177/0093650210381738

Balch, G. I. (1974). Multiple indicators in survey research: The concept "sense of political efficacy". Political Methodology, 1(2), 1-43.

Barabas, J., \& Jerit, J. (2009). Estimating the causal effects of media coverage on policy-specific knowledge. American Journal of Political Science, 53(1), 73-89. doi:10.1111/j.1540-5907.2008.00358.x 


\section{References}

Barabas, J., Jerit, J., Pollock, W., \& Rainey, C. (2014). The question(s) of political knowledge. American Political Science Review, 108(4), 840-855. doi:10.1017/ S0003055414000392

Beam, M. A., \& Kosicki, G. M. (2014). Personalized news portals filtering systems and increased news exposure. Journalism \& Mass Communication Quarterly, 91(1), 59-77. doi:10.1177/1077699013514411

Bennett, W. L. (Ed.). (2008). Civic life online: Learning how digital media can engage youth. Cambridge, MA: MIT Press.

Bennett, W. L., \& Iyengar, S. (2008). A new era of minimal effects? The changing foundations of political communication. Journal of Communication, 58(4), 707-731. doi:10.1111/j.1460-2466.2008.00410.x

Bennett, W. L., \& Segerberg, A. (2013). The logic of connective action: Digital media and the personalization of contentious politics. Cambridge, UK: Cambridge University Press.

Bhatti, Y., \& Hansen, K. M. (2012). The effect of generation and age on turnout to the European Parliament: How turnout will continue to decline in the future. Electoral Studies, 31(2), 262-272. doi:10.1016/j.electstud.2011.11.004

Binderkrantz, A. S., \& Christiansen, P. M. (2014). Making it to the news. Interest groups in the Danish media. In F. Oehmer (Ed.), Politische Interessenvermittlung und Medien: Funktionen, Formen und Folgen medialer Kommunikation von Parteien, Verbänden und Sozialen Bewegungen (pp. 201-219). Baden-Baden, Germany: Nomos Verlagsgesellschaft.

Bjarnøe, C., de Vreese, C. H., \& Albæk, E. (2020). The effect of being conflict nonavoidant: Linking conflict framing and political participation. West European Politics, 43(1), 102-128. doi:10.1080/01402382.2019.1572334

Blekesaune, A., Elvestad, E., \& Aalberg, T. (2012). Tuning out the world of news and current affairs: An empirical study of Europe's disconnected citizens. European Sociological Review, 28(1), 110-126. doi:10.1093/esr/jcq051

Bode, L. (2017). Gateway political behaviors: The frequency and consequences of low-cost political engagement on social media. Social Media + Society, 3(4). doi:10.1177/2056305117743349

Bos, L., Kruikemeier, S., \& de Vreese, C. (2016). Nation binding: How public service broadcasting mitigates political selective exposure. PLoS One, 11(5), e0155112. doi:10.1371/journal.pone.0155112

Boukes, M. (2019). Social network sites and acquiring current affairs knowledge: The impact of Twitter and Facebook usage on learning about the news. Journal of Information Technology \& Politics, 16(1), 36-51. doi:10.1080/19331681.2019.1 572568

Boulianne, S. (2011). Stimulating or reinforcing political interest: Using panel data to examine reciprocal effects between news media and political interest. Political Communication, 28, 147-162. doi:10.1080/10584609.2010.540305

Briggs, J. (2017). Young people and political participation. London: Palgrave Macmillan.

Brundidge, J. (2010). Encountering "difference" in the contemporary public sphere: The contribution of the internet to the heterogeneity of political discussion networks. Journal of Communication, 60(4), 680-700. doi:10.1111/j.1460-2466. 2010.01509.x

Cacciatore, M. A., Yeo, S. K., Scheufele, D. A., Xenos, M. A., Brossard, D., \& Corley, E. A. (2018). Is Facebook making us dumber? Exploring social media use as 
a predictor of political knowledge. Journalism \& Mass Communication Quarterly, 95(2), 404-424. doi:10.1177/1077699018770447

Campbell, A., Gurin, G., \& Miller, W. E. (1954). The voter decides. Oxford: Row, Peterson.

Chadwick, A. (2013). The hybrid media system: Politics and power. New York: Oxford University Press.

Chaffee, S. H., \& McLeod, J. M. (1973). Individual vs. social predictors of information seeking. Journalism Quarterly, 50(2), 237-245. doi:10.1177/10776990730 5000204

Cho, J., Shah, D. V., McLeod, J. M., McLeod, D. M., Scholl, R. M., \& Gotlieb, M. R. (2009). Campaigns, reflection, and deliberation: Advancing an O-S-R-O-R model of communication effects. Communication Theory, 19(1), 66-88. doi:10.1111/j.1468-2885.2008.01333.x

Christensen, H. S. (2011). Political activities on the internet: Slacktivism or political participation by other means? First Monday, 16(2). Retrieved from http://journals. uic.edu/ojs/index.php/fm/article/view/3336

Colwell Quarles, R. (1979). Mass media use and voting behavior: The accuracy of political perceptions among first-time and experienced voters. Communication Research, 6(4), 407-436. doi:10.1177/009365027900600402

Converse, P. E. (1964). The nature of belief systems in mass publics. In D. Apter (Ed.), Ideology and discontent (pp. 206-261). New York: Free Press.

Corrigall-Brown, C., \& Wilkes, R. (2014). Media exposure and the engaged citizen: How the media shape political participation. Social Science Journal, 51(3), 408-421. doi:10.1016/j.soscij.2014.03.009

Costera Meijer, I. (2007). The paradox of popularity: How young people experience the news. Journalism Studies, 8(1), 96-116. doi:10.1080/14616700601056874

Dahl, R. A. (1989). Democracy and its critics. New Haven, CT: Yale University Press.

Dalton, R. J. (2008). Citizenship norms and the expansion of political participation. Political Studies, 56(1), 76-98. doi:10.1111/j.1467-9248.2007.00718.x

Dalton, R. J. (2009). The good citizen: How a younger generation is reshaping American politics. Washington, DC: Sage.

Dalton, R. J. (2017). The participation gap: Social status and political inequality. Oxford: Oxford University Press.

Dalton, R. J., \& Wattenberg, M. P. (2002). Parties without partisans: Political change in advanced industrial democracies. Oxford: Oxford University Press.

Danish Ministry of Culture. (2015). Media development in Denmark 2017. Retrieved from https://mediernesudvikling.slks.dk/fileadmin/user_upload/dokumenter/ medier/Mediernes_udvikling/2015/Resume/PDF-filer_samlede_dokumenter/ Summary_2015_Final.pdf

Danish Ministry of Culture. (2017). Media development in Denmark 2017. Retrieved from https://mediernesudvikling.slks.dk/fileadmin/user_upload/dokumenter/ medier/Mediernes_udvikling/2017/Overblik_og_perspektivering/EN_Overblik_ og_perspektivering_2017.pdf

Danmarks Radio. (2014). Medieudviklingen 2014 [Media development 2014] (p. 74). Retrieved from www.dr.dk/NR/rdonlyres/6E40D722-3E66-4304-9800076F3F7C2FEE/6062535/DR_Medieudviklingen_2014.pdf

Danmarks Statistik. (2015). Turnout Danish election 2015. National Election Results. Retrieved from www.dst.dk/valg/Valg1487635/valgopg/valgopgHL.htm 


\section{References}

Davis, J. A. (2004). Did growing up in the 1960s leave a permanent mark on attitudes and values?: Evidence from the general social survey. Public Opinion Quarterly, 68(2), 161-183. doi:10.1093/poq/nfh010

De Graaf, R., \& van der Vossen, R. (2013). Bits versus brains in content analysis: Comparing the advantages and disadvantages of manual and automated methods for content analysis. Communications, 38(4), 433-443. doi:10.1515/commun2013-0025

Delli Carpini, M. X., \& Keeter, S. (1996). What Americans know about politics and why it matters. New Haven, CT: Yale University Press.

Dennis, J. (2019). Beyond slacktivism: Political participation on social media. Cham, Switzerland: Springer.

De Swert, K. (2012). Calculating inter-coder reliability in media content analysis using Krippendorff's alpha. Unpublished manuscript, Department of Political Communication and Journalism, University of Amsterdam, Netherlands. Retrieved November 1, 2019, from www.polcomm.org/wp-content/uploads/ICR01022012. pdf

de Vreese, C. H., \& Boomgaarden, H. (2006). News, political knowledge and participation: The differential effects of news media exposure on political knowledge and participation. Acta Politica, 41(4), 317-341. doi:10.1057/palgrave. ap. 5500164

de Vreese, C. H., Boukes, M., Schuck, A., Vliegenthart, R., Bos, L., \& Lelkes, Y. (2017). Linking survey and media content data: Opportunities, considerations, and pitfalls. Communication Methods and Measures, 11(4), 221-244. doi:10.108 0/19312458.2017.1380175

de Vreese, C. H., \& Neijens, P. (2016). Measuring media exposure in a changing communications environment. Communication Methods and Measures, 10(2-3), 69-80. doi:10.1080/19312458.2016.1150441

Dilliplane, S., Goldman, S. K., \& Mutz, D. C. (2013). Televised exposure to politics: New measures for a fragmented media environment. American Journal of Political Science, 57(1), 236-248. doi:10.1111/j.1540-5907.2012.00600.x

Dimitrova, D. V., Shehata, A., Strömbäck, J., \& Nord, L. W. (2014). The effects of digital media on political knowledge and participation in election campaigns evidence from panel data. Communication Research, 41(1), 95-118. doi:10.1177/ 0093650211426004

Dimock, M. (2018). Defining generations: Where Millennials end and post-Millennials begin. Pew Research Center. Retrieved from www.pewresearch.org/facttank/2018/03/01/defining-generations-where-millennials-end-and-post-millennialsbegin/

Dimock, M. (2019). Defining generations: Where Millennials end and Generation Z begins. Pew Research Center. Retrieved from www.pewresearch.org/facttank/2019/01/17/where-millennials-end-and-generation-z-begins/

Downs, A. (1957). An economic theory of democracy. New York: Harper.

Downs, A. (1972). Up and down with ecology - The "issue-attention cycle." Public Interest, 28, 38-50.

Druckman, J. N. (2005). Does political information matter? Political Communication, 22(4), 515-519. doi:10.1080/10584600500311444

Easton, D. (1953). The political system: An inquiry into the state of political science. New York: Knopf. 
Easton, D., \& Dennis, J. (1967). The child's acquisition of regime norms: Political efficacy. American Political Science Review, 61(1), 25-38. doi:10.2307/1953873

Edgerly, S. (2017). Seeking out and avoiding the news media: Young adults' proposed strategies for obtaining current events information. Mass Communication and Society, 20(3), 358-377. doi:10.1080/15205436.2016.1262424

Edgerly, S., Thorson, K., \& Wells, C. (2018). Young citizens, social media, and the dynamics of political learning in the U.S. Presidential primary election. American Behavioral Scientist, 62(8), 1042-1060. doi:10.1177/0002764218764236

Edgerly, S., \& Vraga, E. K. (2020). Deciding what's news: News-ness as an audience concept for the hybrid media environment. Journalism \& Mass Communication Quarterly, Advance online publication. doi:10.1177/1077699020916808

Edgerly, S., Vraga, E. K., Bode, L., Thorson, K., \& Thorson, E. (2018). New media, new relationship to participation? A closer look at youth news repertoires and political participation. Journalism \& Mass Communication Quarterly, 95(1), 192-212. doi:10.1177/1077699017706928

Ekström, M., Olsson, T., \& Shehata, A. (2014). Spaces for public orientation? Longitudinal effects of internet use in adolescence. Information, Communication \& Society, 17(2), 168-183. doi:10.1080/1369118X.2013.862288

Ekström, M., \& Östman, J. (2015). Information, interaction, and creative production: The effects of three forms of internet use on youth democratic engagement. Communication Research, 42(6), 796-818. doi:10.1177/0093650213476295

Elenbaas, M., de Vreese, C., Schuck, A., \& Boomgaarden, H. (2014). Reconciling passive and motivated learning the saturation-conditional impact of media coverage and motivation on political information. Communication Research, 41(4), 481-504. doi:10.1177/0093650212467032

Engel, B., \& Best, S. (2012). Stream, audio und page-die Rezeptionsformen in der konvergenten Medienwelt. Media Perspektiven, (2), 62-71.

Esser, F., de Vreese, C. H., Strömbäck, J., Van Aelst, P., Aalberg, T., Stanyer, J., . . . Reinemann, C. (2012). Political information opportunities in Europe: A longitudinal and comparative study of thirteen television systems. International Journal of Press/Politics, 17(3), 247-274. doi:10.1177/1940161212442956

Eveland, W. P., Hayes, A. F., Shah, D. V., \& Kwak, N. (2005). Understanding the relationship between communication and political knowledge: A model comparison approach using panel data. Political Communication, 22, 423-446. doi:10.1080/10584600500311345

Eveland, W. P., \& Scheufele, D. A. (2000). Connecting news media use with gaps in knowledge and participation. Political Communication, 17(3), 215-237. doi:10.1080/105846000414250

Fazekas, Z., \& Larsen, E. G. (2016). Media content and political behavior in observational research: A critical assessment. British Journal of Political Science, 46(1), 195-204. doi:10.1017/S000712341500006X

Finkel, S. E. (1985). Reciprocal effects of participation and political efficacy: A panel analysis. American Journal of Political Science, 29(4), 891-913. doi:10.2307/ 2111186

Finkel, S. (1995). Causal analysis with panel data. Beverly Hills, CA: Sage.

Flaxman, S., Goel, S., \& Rao, J. (2016). Filter bubbles, echo chambers, and online news consumption. Public Opinion Quarterly, 80(S1), 298-320. doi:10.1093/ poq/nfw006 


\section{References}

Fletcher, R., \& Nielsen, R. K. (2017). Are people incidentally exposed to news on social media? A comparative analysis. New Media \& Society, 20(7), 2450-2468. doi:10.1177/1461444817724170

Fournier, P., Nadeau, R., Blais, A., Gidengil, E., \& Nevitte, N. (2004). Time-ofvoting decision and susceptibility to campaign effects. Electoral Studies, 23(4), 661-681. doi:10.1016/j.electstud.2003.09.001

Fox, S. (2014). Is it time to update the definition of political participation? Parliamentary Affairs, 67(2), 495-505. doi:10.1093/pa/gss094

Franklin, M. N. (2004). Voter turnout and the dynamics of electoral competition in established democracies since 1945. Cambridge, UK: Cambridge University Press.

Gerber, A. S., Green, D. P., \& Shachar, R. (2003). Voting may be habit-forming: Evidence from a randomized field experiment. American Journal of Political Science, 47(3), 540-550. doi:10.1111/1540-5907.00038

Gibson, R., \& Cantijoch, M. (2013). Conceptualizing and measuring participation in the age of the internet: Is online political engagement really different to offline? Journal of Politics, 75(3), 701-716. doi:10.1017/s0022381613000431

Giddens, A. (1991). Modernity and self-identity: Self and society in the late modern age. Cambridge: Polity Press.

Gil de Zúñiga, H., Jung, N., \& Valenzuela, S. (2012). Social media use for news and individuals' social capital, civic engagement and political participation. Journal of Computer-Mediated Communication, 17(3), 319-336. doi:10.1111/j.1083-6101. 2012.01574.x

Gil de Zúñiga, H., Weeks, B., \& Ardèvol-Abreu, A. (2017). Effects of the news-findsme perception in communication: Social media use implications for news seeking and learning about politics. Journal of Computer-Mediated Communication, 22(3), 105-123. doi:10.1111/jcc4.12185

GLES. (2013). Documentation of questionnaire. Retrieved November 1, 2019, from http://info1.gesis.org/dbksearch/download.asp?id=62275

Grasso, M. T. (2016). Generations, political participation and social change in Western Europe. New York: Routledge.

Ha, L. S., Wang, F., Fang, L., Yang, C., Hu, X., Yang, L., . . . Morin, D. (2013). Political efficacy and the use of local and national news media among undecided voters in a swing state: A study of general population voters and first-time college student voters. Electronic News, 7(4), 204-222. doi:10.1177/1931243113515678

Hallin, D. C., \& Mancini, P. (2004). Comparing media systems: Three models of media and politics. New York: Cambridge University Press.

Hayes, A. F. (2013). Introduction to mediation, moderation, and conditional process analysis: A regression-based approach. New York: Guilford Press.

Held, D. (1987). Models of democracy. Stanford: Stanford University Press.

Holt, K., Shehata, A., Strömbäck, J., \& Ljungberg, E. (2013). Age and the effects of news media attention and social media use on political interest and participation: Do social media function as leveller? European Journal of Communication, 28(1), 19-34. doi:10.1177/0267323112465369

Howe, N., \& Strauss, W. (2007). The next 20 years: How customer and workforce attitudes will evolve. Harvard Business Review, 85(7 \& 8), 41-52.

Hurrelmann, K., \& Albrecht, E. (2014). Die heimlichen Revolutionäre: Wie die Generation $Y$ unsere Welt verändert [The hidden revolutionaries: How Generation $Y$ changes the world]. Weinheim, Germany: Beltz. 
Inglehart, R. (1990). Culture shift in advanced industrial society. Princeton, NJ: Princeton University Press.

Jennings, M. K., \& Markus, G. B. (1984). Partisan orientations over the long haul: Results from the three-wave political socialization panel study. American Political Science Review, 78(4), 1000-1018. doi:10.2307/1955804

Jerit, J., Barabas, J., \& Bolsen, T. (2006). Citizens, knowledge, and the information environment. American Journal of Political Science, 50(2), 266-282. doi:10.1111/j.1540-5907.2006.00183.x

Jung, N., Kim, Y., \& de Zúñiga, H. G. (2011). The mediating role of knowledge and efficacy in the effects of communication on political participation. Mass Communication and Society, 14(4), 407-430. doi:10.1080/15205436.2010.496135

Kahne, J., \& Bowyer, B. (2018). The political significance of social media activity and social networks. Political Communication, 35(3), 470-493. doi:10.1080/105846 09.2018.1426662

Kenski, K., \& Stroud, N. J. (2006). Connections between internet use and political efficacy, knowledge, and participation. Journal of Broadcasting \& Electronic Media, 50(2), 173-192. doi:10.1207/s15506878jobem5002_1

Kleinberg, M. S., \& Lau, R. R. (2019). The importance of political knowledge for effective citizenship. Public Opinion Quarterly, 83(2), 338-362. doi:10.1093/poq/ nfz025

Klinger, U., \& Svensson, J. (2015). The emergence of network media logic in political communication: A theoretical approach. New Media \& Society, 17(8), 12411257. doi:10.1177/1461444814522952

Konzelmann, L., Wagner, C., \& Rattinger, H. (2012). Turnout in Germany in the course of time: Life cycle and cohort effects on electoral turnout from 1953 to 2049. Electoral Studies, 31(2), 250-261. doi:10.1016/j.electstud.2011.11.006

Krippendorff, K. H. (2003). Content analysis: An introduction to its methodology. Thousand Oaks, CA: Sage.

Krosnick, J. A., \& Alwin, D. F. (1989). Aging and susceptibility to attitude change. Journal of Personality and Social Psychology, 57(3), 416-425. doi:10.1037/ 0022-3514.57.3.416

Kruikemeier, S., Sezgin, M., \& Boerman, S. C. (2016). Political microtargeting: Relationship between personalized advertising on Facebook and voters' responses. Cyberpsychology, Behavior, and Social Networking, 19(6), 367-372. doi:10.1089/ cyber.2015.0652

Kruikemeier, S., \& Shehata, A. (2017). News media use and political engagement among adolescents: An analysis of virtuous circles using panel data. Political Communication, 34, 221-242. doi:10.1080/10584609.2016.1174760

Lazarsfeld, P., Berelson, B., \& Gaudet, H. (1948). The people's choice: How the voter makes up his mind in a presidential campaign. New York: Columbia University Press.

Lecheler, S., \& de Vreese, C. H. (2017). News media, knowledge, and political interest: Evidence of a dual role from a field experiment. Journal of Communication, 67(4), 545-564. doi:10.1111/jcom.12314

Lee, N.-J., Shah, D. V., \& McLeod, J. M. (2012). Processes of political socialization: A communication mediation approach to youth civic engagement. Communication Research, 40(5), 669-697. doi:10.1177/0093650212436712

Lee, S., \& Xenos, M. (2019). Social distraction? Social media use and political knowledge in two U.S. Presidential elections. Computers in Human Behavior, 90, 18-25. doi:10.1016/j.chb.2018.08.006 


\section{References}

Leighley, J. E. (1995). Attitudes, opportunities and incentives: A field essay on political participation. Political Research Quarterly, 48(1), 181-209. doi:10.1177/ 106591299504800111

Lemert, J. B. (1984). News context and the elimination of mobilizing information: An experiment. Journalism \& Mass Communication Quarterly, 61(2), 243-259. doi:10.1177/107769908406100201

Levitsky, S., \& Ziblatt, D. (2018). How democracies die. New York: Crown.

Linssen, R., Schmeets, H., Scheeper, P., \& te Grotenhuis, M. (2014). Trends in conventional and unconventional political participation in Europe, 1981-2008. In C. Eder, I. Mochmann, \& M. Quandt (Eds.), Political trust and disenchantment with politics: International perspectives (pp. 31-58). Leiden, Netherlands: Brill.

Literat, I., Kligler-Vilenchik, N., Brough, M., \& Blum-Ross, A. (2018). Analyzing youth digital participation: Aims, actors, contexts and intensities. The Information Society, 34(4), 261-273. doi:10.1080/01972243.2018.1463333

Loader, B. D., Vromen, A., \& Xenos, M. A. (2014). The networked young citizen: Social media, political participation and civic engagement. Information, Communication \& Society, 17(2), 143-150. doi:10.1080/1369118X.2013.871571

Luskin, R. C. (1990). Explaining political sophistication. Political Behavior, 12, 331-361.

Mangelsdorf, M. (2014). Generation Y. Offenbach, Germany: Gabal.

Mangelsdorf, M. (2015). Von Babyboomer bis Generation Z: Der richtige Umgang mit unterschiedlichen Generationen im Unternehmen [From Baby Boomer to Generation Z: The correct handling of different generations in a company]. Offenbach, Germany: Gabal.

Mannheim, K. (1928). Das Problem der Generationen [The problem of generations]. Kölner Vierteljahreshefte Für Soziologie, (7), 157-185.

Markus, G. B. (1979). Analyzing panel data. Newbury Park, CA: Sage.

Marquart, F., Ohme, J., \& Möller, J. (2020). Following politicians on social media: Effects for political information, peer communication, and youth engagement. Media and Communication, 8(2), 197-207. doi:10.17645/mac.v8i2.2764

Matthes, J., \& Kohring, M. (2008). The content analysis of media frames: Toward improving reliability and validity. Journal of Communication, 58(2), 258-279. doi:10.1111/j.1460-2466.2008.00384.x

McLeod, D. M., Daily, K., Guo, Z., Eveland, W. P., Bayer, J., Yang, S., \& Wang, H. (1996). Community integration, local media use, and democratic processes. Communication Research, 23(2), 179-209. doi:10.1177/009365096023002002

McLeod, J. M., Scheufele, D. A., \& Moy, P. (1999). Community, communication, and participation: The role of mass media and interpersonal discussion in local political participation. Political Communication, 16(3), 315-336. doi:10.1080/ 105846099198659

Messing, S., \& Westwood, S. J. (2014). Selective exposure in the age of social media: Endorsements trump partisan source affiliation when selecting news online. Communication Research, 41(8), 1042-1063. doi:10.1177/0093650212466406

Messing, S., Westwood, S. J., \& Lelkes, Y. (2011, April). Online media effects: Social, not political, reinforcement. Paper presented at the annual meeting of the Midwestern Political Science Association, Chicago, IL. Retrieved from www.stanford. edu/ messing/PopRecSrcNews2.pdf

Micheletti, M., Stolle, D., \& Follesdal, A. (2004). Politics, products, and markets: Exploring political consumerism past and present. New Brunswick, NJ: Transaction. 
Milkman, R. (2017). A new political generation: Millennials and the post-2008 wave of protest. American Sociological Review, 82(1), 1-31. doi:10.1177/000312241 6681031

Mill, J. S. (1861). Considerations on representative government. London: Parker, Son, and Bourn.

Mill, J. S. (1912). On Liberty: Representative government: The subjection of women: Three essays. London: Oxford University Press.

Miller, A. H., Goldenberg, E. N., \& Erbring, L. (1979). Type-set politics: Impact of newspapers on public confidence. American Political Science Review, 73(1), 67-84. doi:10.2307/1954731

Mindich, D. T. Z. (2005). Tuned out: Why Americans under 40 don't follow the news. New York: Oxford University Press.

Moeller, J., \& de Vreese, C. H. (2019). Spiral of political learning: The reciprocal relationship of news media use and political knowledge among adolescents. Communication Research, 46(8), 1078-1094. doi:10.1177/0093650215605148

Moeller, J., de Vreese, C. H., Esser, F., \& Kunz, R. (2014). Pathway to political participation: The influence of online and offline news media on internal efficacy and turnout of first-time voters. American Behavioral Scientist, 58(5), 689-700. doi:10.1177/0002764213515220

Moeller, J., Kühne, R., \& de Vreese, C. (2018). Mobilizing youth in the 21st century: How digital media use fosters civic duty, information efficacy, and political participation. Journal of Broadcasting \& Electronic Media, 62(3), 445-460. doi:10. 1080/08838151.2018.1451866

Morozov, E. (2009). From slacktivism to activism. Foreign Policy. Retrieved from https:/foreignpolicy.com/2009/09/05/from-slacktivism-to-activism/

Neundorf, A., Smets, K., \& García-Albacete, G. M. (2013). Homemade citizens: The development of political interest during adolescence and young adulthood. Acta Politica, 48, 92-116. doi:10.1057/ap.2012.23

Newman, N., Fletcher, R., Kalogeropoulos, A., Levy, D., \& Nielsen, R. K. (2017). Reuters institute digital news report 2017. Retrieved from http:/www.digitalnewsreport. org/survey/2017/

Newman, N., Fletcher, R., Kalogeropoulos, A., Levy, D., \& Nielsen, R. K. (2018). Reuters institute digital news report 2018. Retrieved from http://www.digitalnewsreport.org/survey/2018/

Newman, N., Fletcher, R., Levy, D., \& Nielsen, R. K. (2016). Reuters institute digital news report 2016. Retrieved from http://www.digitalnewsreport.org/survey/ 2016/

Newman, N., Levy, D., \& Nielsen, R. K. (2015). Reuters institute digital news report 2015. Retrieved from https://reutersinstitute.politics.ox.ac.uk/our-research/ digital-news-report-2015-0

Newton, K. (1999). Mass media effects: Mobilization or media malaise? British Journal of Political Science, 29(4), 577-599.

Niemi, R. G., Craig, S. C., \& Mattei, F. (1991). Measuring internal political efficacy in the 1988 national election study. American Political Science Review, 85(4), 1407-1413. doi:10.2307/1963953

Niemi, R. G., \& Hepburn, M. A. (1995). The rebirth of political socialization. Perspectives on Political Science, 24(1), 7-16. doi:10.1080/10457097.1995.9941860

Norris, P. (2000). A virtuous circle: Political communications in postindustrial societies. Cambridge, UK: Cambridge University Press. 


\section{References}

Ohme, J. (2019). When digital natives enter the electorate: Political social media use among first-time voters and its effects on campaign participation. Journal of Information Technology \& Politics, 16(2), 119-136. doi:10.1080/19331681.2019.1613279

Ohme, J., Albæk, E., \& de Vreese, C. H. (2016). Exposure research going mobile: A smartphone-based measurement of media exposure to political information in a convergent media environment. Communication Methods and Measures, 10(2-3), 135-148. doi:10.1080/19312458.2016.1150972

Ohme, J., de Vreese, C. H., \& Albæk, E. (2017). Practical guidelines for developing a smartphone-based survey instrument. Paper presented at the 72nd annual conference of the American Association for Public Opinion Research, New Orleans, LA. Retrieved from www.researchgate.net/publication/334770127_Practical_ Guidelines_for_Developing_a_Smartphone-Based_Survey_Instrument

Ohme, J., de Vreese, C. H., \& Albæk, E. (2018a). From theory to practice: How to apply van Deth's conceptual map in empirical political participation research. Acta Politica, 53(3), 367-390. doi:10.1057/s41269-017-0056-y

Ohme, J., de Vreese, C. H., \& Albæk, E. (2018b). The uncertain first-time voter: Effects of political media exposure on young citizens' formation of vote choice in a digital media environment. New Media \& Society, 20(9), 3243-3265. doi:10.1177/1461444817745017

Ohme, J., \& Mothes, C. (2020). What affects first- and second-level selective exposure to journalistic news? A social media online experiment. Journalism Studies, 1-23. doi:10.1080/1461670X.2020.1735490

O'Keefe, G. J., \& Liu, J. (1980). First-time voters: Do media matter? Journal of Communication, 30(4), 122-129. doi:10.1111/j.1460-2466.1980.tb02024.x

Osborne, D., Sears, D. O., \& Valentino, N. A. (2011). The end of the solidly democratic South: The impressionable-years hypothesis. Political Psychology, 32(1), 81-108. doi:10.1111/j.1467-9221.2010.00796.x

Palfrey, J., \& Gasser, U. (2010). Born digital: Understanding the first generation of digital natives. New York: Basic Books.

Pitti, I. (2018). Unconventional political participation: An overview. In I. Pitti (Ed.), Youth and unconventional political engagement (pp. 7-21). doi:10.1007/ 978-3-319-75591-5_2

Pollock, P. H. (1983). The participatory consequences of internal and external political efficacy: A research note. Western Political Quarterly, 36(3), 400-409. doi:10.1177/106591298303600306

Portney, K. E., \& O'Leary, L. (2007). Civic and political engagement of America's youth: A report from the Tisch College National Survey of Civic and Political Engagement of Young People. Medford, MA: Tufts University, Tisch College.

Prensky, M. (2001). Digital natives, digital immigrants, part 1. On the Horizon, 9(5), 1-6. doi:10.1108/10748120110424816

Prior, M. (2005). News vs. entertainment: How increasing media choice widens gaps in political knowledge and turnout. American Journal of Political Science, 49(3), 577-592. doi:10.2307/3647733

Prior, M. (2007). Post-broadcast democracy: How media choice increases inequality in political involvement and polarizes elections. New York: Cambridge University Press.

Prior, M. (2010). You've either got it or you don't? The stability of political interest over the life cycle. Journal of Politics, 72, 747-766. doi:10.1017/s0022381610000149 
Prior, M. (2018). Hooked: How politics captures people's interest. New York: Cambridge University Press.

Putnam, R. D. (2000). Bowling alone: The collapse and revival of American community. New York: Simon \& Schuster.

Quintelier, E. (2007). Differences in political participation between young and old people. Contemporary Politics, 13(2), 165-180. doi:10.1080/13569770701562658

Ratto, M., \& Boler, M. (2014). DIY citizenship: Critical making and social media. Cambridge, MA: MIT Press.

Reichert, F., \& Print, M. (2019). Participatory practices and political knowledge: How motivational inequality moderates the effects of formal participation on knowledge. Social Psychology of Education, 22(5), 1085-1108. doi:10.1007/ s11218-019-09514-5

Rijpkema, B. (2018). Militant democracy: The limits of democratic tolerance. London: Routledge.

Scharkow, M., \& Bachl, M. (2016). How measurement error in content analysis and self-reported media use leads to minimal media effect findings in linkage analyses: A simulation study. Political Communication, 34(3), 323-343. doi:10.1080/1058 4609.2016.1235640

Schattschneider, E. E. (1975). The semisovereign people: A realist's view of democracy in America. Hinsdale, IL: Dryden Press.

Schuck, A. R. T., Vliegenthart, R., \& de Vreese, C. H. (2016). Matching theory and data: Why combining media content with survey data matters. British Journal of Political Science, 46(1), 205-213. doi:10.1017/S0007123415000228

Schumpeter, J. A. (1942). Capitalism, socialism, and democracy. New York: Harper $\&$ Brothers.

Sears, D. O., \& Valentino, N. A. (1997). Politics matters: Political events as catalysts for preadult socialization. American Political Science Review, 91(1), 45-65. doi:10.2307/2952258

Shah, D. V., Cho, J., Eveland, W. P., \& Kwak, N. (2005). Information and expression in a digital age modeling internet effects on civic participation. Communication Research, 32(5), 531-565. doi:10.1177/0093650205279209

Shah, D. V., McLeod, D. M., Rojas, H., Cho, J., Wagner, M. W., \& Friedland, L. A. (2017). Revising the communication mediation model for a new political communication ecology. Human Communication Research, 43(4), 491-504. doi:10.1111/hcre.12115

Shah, D. V., McLeod, D. M., \& Yoon, S.-H. (2001). Communication, context, and community: An exploration of print, broadcast, and internet influences. Communication Research, 28(4), 464-506. doi:10.1177/009365001028004005

Shah, D. V., Watts, M. D., Domke, D., \& Fan, D. P. (2002). News framing and cueing of issue regimes. Public Opinion Quarterly, 66(3), 339-370. doi:10.1086/341396

Shani, D. (2009). On the origins of political interest. Ph.D. dissertation, Princeton University.

Sharpe, L. J. (1970). Theories and values of local government. Political Studies, 18(2), 153-174. doi:10.1111/j.1467-9248.1970.tb00867.x

Shehata, A. (2016). News habits among adolescents: The influence of family communication on adolescents' news media use: Evidence from a three-wave panel study. Mass Communication and Society, 19(6), 758-781. doi:10.1080/1520543 6.2016.1199705 


\section{References}

Shehata, A., \& Amnå, E. (2017). The development of political interest among adolescents: A communication mediation approach using five waves of panel data. Communication Research, 46(8), 1055-1077. doi:10.1177/0093650217714360

Shehata, A., \& Strömbäck, J. (2018). Learning political news from social media: Network media logic and current affairs news learning in a high-choice media environment. Communication Research, 0093650217749354. doi:10.1177/ 0093650217749354

Shoemaker, P. J., \& Cohen, A. A. (2006). News about the world: Content, practitioners, and the public. New York: Routledge.

Slater, M. D. (2004). Operationalizing and analyzing exposure: The foundation of media effects research. Journalism \& Mass Communication Quarterly, 81(1), 168-183. doi:10.1177/107769900408100112

Slater, M. D. (2007). Reinforcing spirals: The mutual influence of media selectivity and media effects and their impact on individual behavior and social identity. Communication Theory, 17(3), 281-303. doi:10.1111/j.1468-2885.2007.00296.x

Slater, M. D. (2015). Reinforcing spirals model: Conceptualizing the relationship between media content exposure and the development and maintenance of attitudes. Media Psychology, 18(3), 370-395. doi:10.1080/15213269.2014.897236

Stolle, D., Hooghe, M., \& Micheletti, M. (2005). Politics in the supermarket: Political consumerism as a form of political participation. International Political Science Review, 26(3), 245-269. doi:10.1177/0192512105053784

Strömbäck, J. (2005). In search of a standard: Four models of democracy and their normative implications for journalism. Journalism Studies, 6(3), 331-345. doi:10.1080/14616700500131950

Strömbäck, J. (2008). Four phases of mediatization: An analysis of the mediatization of politics. The International Journal of Press/Politics, 13(3), 228-246. doi:10.1177/1940161208319097

Strömbäck, J., Djerf-Pierre, M., \& Shehata, A. (2013). The dynamics of political interest and news media consumption: A longitudinal perspective. International Journal of Public Opinion Research, 25, 414-435. doi:10.1093/ijpor/eds018

Strömbäck, J., \& Shehata, A. (2010). Media malaise or a virtuous circle? Exploring the causal relationships between news media exposure, political news attention and political interest. European Journal of Political Research, 49(5), 575-597. doi:10.1111/j.1475-6765.2009.01913.x

Strömbäck, J., \& Shehata, A. (2018). The reciprocal effects between political interest and TV news revisited: Evidence from four panel surveys. Journalism \& Mass Communication Quarterly, 96(2), 473-496. doi:10.1177/1077699018793998

Stubager, R., \& Hansen, K. M. (2013). Social baggrund og partivalg [Social background and party choice]. In R. Stubager, K. M. Hansen, \& J. G. Andersen (Eds.), Krisevalg (pp. 61-88). Copenhagen: Djøf Forlag.

Teorell, J., Torcal, M., \& Montero, J. R. (2007). Political participation: Mapping the terrain. In J. van Deth, J. R. Montero, \& A. Westholm (Eds.), Citizenship and involvement in European democracies: A comparative perspective (Vol. 17, pp. 334-357). Retrieved from http://lup.lub.lu.se/record/778040

Theocharis, Y. (2015). The conceptualization of digitally networked participation. Social Media + Society, 1(2). doi:10.1177/2056305115610140

Theocharis, Y., \& van Deth, J. W. (2016). The continuous expansion of citizen participation: A new taxonomy. European Political Science Review, 10(1), 139-163. doi:10.1017/S1755773916000230 
Thomas, M. (Ed.). (2011). Deconstructing digital natives: Young people, technology, and the new literacies. New York: Routledge.

Thorson, K., \& Wells, C. (2016). Curated flows: A framework for mapping media exposure in the digital age. Communication Theory, 26(3), 309-328. doi:10.1111/ comt.12087

Thorson, K., Xu, Y., \& Edgerly, S. (2018). Political inequalities start at home: Parents, children, and the socialization of civic infrastructure online. Political Communication, 35(2), 178-195. doi:10.1080/10584609.2017.1333550

Towner, T. L., \& Muñoz, C. L. (2018). Baby boom or bust? The new media effect on political participation. Journal of Political Marketing, 17(1), 32-61. doi:10.1080/ 15377857.2016.1153561

Turner, A. (2015). Generation Z: Technology and social interest. Journal of Individual Psychology, 71(2), 103-113. doi:10.1353/jip.2015.0021

Valeriani, A., \& Vaccari, C. (2016). Accidental exposure to politics on social media as online participation equalizer in Germany, Italy, and the United Kingdom. New Media \& Society, 18(9), 1857-1874. doi:10.1177/1461444815616223

Valkenburg, P. M., \& Peter, J. (2013). The differential susceptibility to media effects model. Journal of Communication, 63, 221-243. doi:10.1111/jcom.12024

Van Aelst, P., \& De Swert, K. (2009). Politics in the news: Do campaigns matter? A comparison of political news during election periods and routine periods in Flanders (Belgium). Communications, 34(2), 149-168. doi:10.1515/COMM.2009.011

Van Aelst, P., Strömbäck, J., Aalberg, T., Esser, F., de Vreese, C., Matthes, J., . . . Stanyer, J. (2017). Political communication in a high-choice media environment: A challenge for democracy? Annals of the International Communication Association, 41(1), 3-27. doi:10.1080/23808985.2017.1288551

Van der Brug, W., \& Kritzinger, S. (2012). Generational differences in electoral behaviour. Electoral Studies, 31(2), 245-249. doi:10.1016/j.electstud. 2011.11.005

Van Deth, J. W. (1990). Interest in politics. In M. K. Jennings \& J. W. van Deth (Eds.), Continuities in political action: A longitudinal study of political orientations in three Western democracies (pp. 275-312). Berlin: De Gruyter.

Van Deth, J. W. (2014). A conceptual map of political participation. Acta Politica, 49(3), 349-367. doi:10.1057/ap.2014.6

Van Deth, J. W., \& Elff, M. (2004). Politicisation, economic development and political interest in Europe. European Journal of Political Research, 43(3), 477-508. doi:10.1111/j.1475-6765.2004.00162.x

van Spanje, J., \& Azrout, R. (2019). Tainted love: How stigmatization of a political party in news media reduces its electoral support. International Journal of Public Opinion Research, 31(2), 283-308. doi:10.1093/ijpor/edy009

Verba, S., \& Nie, N. (1972). Participation in America: Political democracy and social equality. New York: Harper and Row.

Verba, S., Schlozman, K. L., \& Brady, H. E. (1995). Voice and equality: Civic voluntarism in American politics. Cambridge, MA: Harvard University Press.

Vissers, S., \& Stolle, D. (2014). Spill-over effects between Facebook and on/offline political participation? Evidence from a two-wave panel study. Journal of Information Technology \& Politics, 11(3), 259-275. doi:10.1080/19331681.2014.888383

Vraga, E. K., Bode, L., Smithson, A.-B., \& Troller-Renfree, S. (2016). Blurred lines: Defining social, news, and political posts on Facebook. Journal of Information Technology \& Politics, 13(3), 272-294. doi:10.1080/19331681.2016.1160265 


\section{References}

Walczak, A., Van Der Brug, W., \& de Vries, C. E. (2012). Long- and short-term determinants of party preferences: Inter-generational differences in Western and East Central Europe. Electoral Studies, 31(2), 273-284. doi:10.1016/j.electstud. 2011.11.007

Wass, H. (2007). The effects of age, generation and period on turnout in Finland 1975-2003, Electoral Studies, 26(3), 648-659. doi:10.1016/j.electstud.2007.06.002

Williams, B. A., \& Delli Carpini, M. X. (2011). After broadcast news: Media regimes, democracy, and the new information environment. New York: Cambridge University Press.

Woodstock, L. (2014). The news-democracy narrative and the unexpected benefits of limited news consumption: The case of news resisters. Journalism, 15(7), 834-849. doi:10.1177/1464884913504260

World Bank. (2018). Individuals using the internet (\% of population). Denmark. Retrieved from https://data.worldbank.org/indicator/IT.NET.USER.ZS?locations=DK

Xenos, M., Vromen, A., \& Loader, B. D. (2014). The great equalizer? Patterns of social media use and youth political engagement in three advanced democracies. Information, Communication \& Society, 17(2), 151-167. doi:10.1080/13691 18X.2013.871318

Yndigegn, C., \& Levinsen, K. (2015). Unge og politisk deltagelse i Danmark Ungdomspolitiske overvejelser på baggrund af MYPLACE projektet [Adolescents and political participation in Denmark: Youth policy recommendations on the basis of MYSPACE Project]. Retrieved from https://docplayer.dk/9434083-Unge-og-politiskdeltagelse-i-danmark-ungdomspolitiske-overvejelser-paa-baggrund-af-myplaceprojektet.html

Zakaras, A. (2007). John Stuart Mill, individuality, and participatory democracy. In N. Urbinati \& A. Zakaras (Eds.), J. S. Mill's political thought (pp. 200-220). doi:10.1017/CBO9780511618734.009

Zaller, J. (1992). The nature and origins of mass opinion. New York: Cambridge University Press.

Zaller, J. (2003). A new standard of news quality: Burglar alarms for the monitorial citizen. Political Communication, 20(2),109-130. doi:10.1080/10584600390211136

Zukin, C., Keeter, S., Andolina, M., Jenkins, K., \& Delli Carpini, M. X. (2006). A new engagement?: Political participation, civic life, and the changing American citizen. New York: Oxford University Press. 


\section{Index}

ability see Opportunity-MotivationAbility (OMA) framework active: election campaign participation 120-123; generations, politically 76-80, 92-93, 96, 131-134; participation 15; participation and social media 109-111 activism 132-133 affordances, of social media 1(?) 140 algorithmic media 140 algorithmic personalization 140 audience fragmentation 3 automated content analysis 30 , 34-35, 44

Baby Boomers 7-9, 24, 40-41, 46, 54-56, 58-59, 88, 92-93, 107, 111-117, 122-124, 131-134, 155-184

Bennett, Lance 22, 34, 136

Black Lives Matter 5

Boomers see Baby Boomers

Boulianne, Shelley 20

boycotting 4-5, 9, 15-16, 90-92, 129, 149, 152-153

Brady, Henry E. 15

buycotting see boycotting

campaign participation $39,119-128$, 133, 147, 154, 181, 183

Chadwick, Andrew 37

civic engagement 17, 39

Civic Voluntarism Model 102

clothing badges $92,149,152-153$

cohort effect 22-23, 26, 42, 48, 78, 87, $98,102,117,131,134-136$

collective action 82,136

collectivistic participation 5

Communication Mediation Model 17 community building 82

competitive democracy 4-5

consumer activism see boycotting crowdfunding 5, 83, 149, 151, 153

current affairs knowledge see political knowledge

Dalton, Russel J. 15, 22-23, 94, 120

Danish national election 30

Delli Carpini, Michael X. 11, 20, 61, 65

demand side of media system 3

democracy models 4-5, 8, 11-14, 140

demonstrations 11, 15-16, 73-74, 135, $139,142,149,151,153$

Denmark 32, 136, 150; and the media system 7, 28-29; news usage 28-29; political participation 8, 29; turnout 140

Dennis, James 91, 94

digital natives 25,120

disinformation 142

donations 73-74

Downs, Anthony 44, 80

dynamic analysis models 41

Easton, David 13, 16, 20, 35, 72

Edgerly, Stephanie 13, 23, 44, 100

election campaign 44-48, 65-66, $68-69,75,120-123,128$

election times 119-120; and media exposure during 45-48, 120-132

election turnout see turnout

elite-directed participation 16, 72

Engagement-Participation-InformationGeneration (EPIG) Model 11-12, 26-27, 126

entertainment news see soft news EPI framework 12, 21, 26 
EPIG Model see Engagement-

Participation-Information-Generation (EPIG) Model

equalizer perspective 131

European Social Survey 8-9

Facebook 1-2, 16, 44, 92, 148, 152

Finkel, Steven E. 41, 61

first-time voters 32,128

Fridays for Future 5, 129

fundraising 139

Generation X 7-9, 24, 40-41, 46, 54-56, 58-59, 88, 92-93, 107, 111-117, 122-124, 131-134, 155-184

Generation Y see Millennials

Generation Z 7-9, 24, 40-41, 46, 54-56, 58-59, 88, 92-93, 107, 111-117, 122-124, 131-134, 155-184

generational differences $7,22,29$; in news consumption $7,45-48,99,120$, 126,134 ; in political efficacy $68-71$; in political interest $62-65$; in political knowledge 65-68; in political participation 73-78, 82-87, 91-96, 108-113, 121-126, 131-134, 133

Hayes, Andrew F. 21, 41

heartbeat democracy 139

hibernation democracy 140

high-choice media environment 18, 34

hybrid media system 37

hyperlocal news media 137

inadvertent news exposure see incidental news exposure incidental news exposure 59 individualistic participation 140 inequalities: in media use 23 ; in participation 23, 132

Infomedia 35

information ecology 1-2, 142

Inglehart, Ronald 16, 23, 72, 94

institutionalized participation 16, 72

Kruikemeier, Sanne 3, 19-21, 62, 121

learning see political knowledge

Levitsky, Steven 141

life-cycle effect 6, 22-23, 26, 42, 118, 123, 134-135

local community 56-59, 81-89 local participation see political participation targeting the local community (PP III)

media: demand side of 3

media choice see high-choice media environment

media diets 2, 11, 43, 101

media effects $17,62,65,68,138$; and reciprocal 21

media environment 13, 18-19, 25, 34-35, 117

media exposure see political information exposure

media life histories 2

media literacy see social media literacy

\#MeToo 5

Mill, John Stuart 4-5, 81

Millennials 7-9, 24, 40-41, 46, 54-56, 58-59, 88, 92-93, 107, 111-117, 122-124, 131-134, 155-184

misinformation crisis 3

mobile media diary 30, 33

mobilization, political 99, 123, 126, 131, 133, 136

Moeller, Judith 14-15, 20-21, 101, 120

motivation see OpportunityMotivation-Ability (OMA) framework

neighborhood meetings $81-82$

news avoidance 44

news avoiders see news avoidance

news curation 101, 117

news exposure see political news

exposure; social media news

exposure

news networks 117

newspaper subscriptions 3,87

news seeking preference $18,43-44$

Norris, Pippa 14, 20

opinion expression 39, 92, 149, 151-154

opportunity see Opportunity-MotivationAbility (OMA) framework

Opportunity-Motivation-Ability

(OMA) framework 17-18

opportunity structures $2-7,10,15$, 74, 101

Orientations-Stimulus-ReasoningOrientations-Response (O-S-R-O-R) Model 17 
panel survey design 44

participation, political 4, 11-17, 22-27, 54-60, 109-111, 114-118, 119-121, 130-136, 153; and globalization of 91 ; levels of 107-109; passive 15 ; politically motivated but nonpolitical (PP IV) 39, 49, 90-97, 147, 152, 170, 179; targeting the local community (PP III) 39, 49, 81-89, 146, 151, 68, 177; targeting the political system (PP II) 38, 49, 73-79, $146,151,166,175$

participatory democracy 4-5, 139

party orientation 120

peer networks 128

petitions $5,9,16,73-74$

political discussion 16-17, 151-152

political efficacy 14-15, 38, 54, 68-70, $146,151,165,174$; and the effects on campaign participation 126-127; effects on political (social) media exposure 51-54, 114-116; effect on political participation $78-79,87-88$, 96-97

political engagement 11, 13-14, 17-22, 38-41, 48-49, 61-62, 99-107, 114-118, 127-128, 130-133

political information 2-6, 13, 18-22, 25-27, 43-60, 63-70, 101-102, 116-118, 132-136, 146, 172-177, 179, 183; and the amount of in news media 34-38, 44-54, 130-132, 146, $155,163-166,181$

political interest $14,20,38,49-54$, 62-65, 87-89, 96-97, 102-107, 114-116, 163, 172; and decline 3; effects on campaign participation 126-127; effects on political (social) media exposure 51-54, 114-116; effects on political participation 78-79, 87-88, 96-97

political involvement 2, 11-23, 26, 29-31, 100-102, 132, 134

political knowledge 14, 38, 51-54, $65-68,116,150,164,173$; and effects on campaign participation 126-127; effects on political (social) media exposure 51-54, 114-116; effects on political participation 78-79, 87-88, 96-97

political learning see political knowledge political mobilization $126,131-136$ political news exposure 13, 34, 46-49, 62, 133; and generational differences in campaign participation 120,128 ; political efficacy 49-54, 69-71, 87-89; political interest 49-54, 62-63, 87-89; political knowledge 49-54, 66, 87-89; political participation $56-59,76,78,85$, 94-96

political parties 4,44

political polarization 3,142

political socialization $23,73,96$, 135-136

political social media exposure 8 , 13, 34, 37, 47, 99-101, 133; and generational differences in campaign participation 121-123, 127; political efficacy 54, 107, 114-116; political interest 54, 107, 114-116; political knowledge 54, 107, 114-116; political participation 56-59, 107-111, 116-118

political statements 91-93

political system 14, 16, 81-82, 91, 120, 139; and participation targeting 29, 54-59, 72-80, 92, 108-111, $114-117,131$

print news 1, 7, 29, 148

Prior, Markus 2, 11, 14, 18-19, 34, 43, 61-62, 65, 117

private online platforms 1-3

public good 82

recall bias 32

recruitment see Civic Voluntarism Model

resources see Civic Voluntarism Model 'rich-get-richer' perspective 130

Rijpkema, Bastiaan 141

Schlozman, Kay L. 15

Schumpeter, Joseph A. 4

Shah, Dhavan V. 17, 21, 25, 35, 82, 85,128

Shehata, Adam 14, 18-21, 38-39, 62, 94, 100, 126, 135, 138

short-term activists 132-133

short-term media exposure 37

sinus curve 139

slacktivism 91

smartphone diary see mobile media diary

smartphones 1, 30, 33, 36 
Snapchat 1,141

social capital 82

social cues 101-102

social endorsements see social cues

social media literacy 102

social media use see political social media exposure

social utility 102

soft news 2

spiral of maintenance 137

static analysis models $41,49-51,66$, $69,76-78,85,94-96$

street art 83, 149, 152-153

Strömback, Jesper 4-5, 13, 18, 20-21, $49,62,65,94,100,120,126,140$

structural equation modeling $78,87,96$

supply side of media system 18 , $137-138$

surveillance knowledge see political knowledge

television news usage 8

Theocharis, Yannis 5, 39, 73, 91

Thorson, Kjerstin 23, 44, 100-101

Traditionalists 7-9, 24, 40-41, 51-54, $76,97,107-117$

trust in news 3 turnout 4,128

Twitter 2, 99-100, 148

unconventional participation 39, 91

urban gardening 82, 149, 153

van Deth, Jan 5, 15-16, 38, 39, 62, 81, 90-91, 120

vegetarianism see boycotting

Verba, Sidney 15, 62, 80, 82, 102, 117,120

virtuous cycle 139

vote advice application 121-122

vote decision 4, 120

voter volatility 120

voting experience 48

WhatsApp see private online platforms

$\mathrm{X}$, Generation see Generation X

Xenos, Mike 6, 12, 90, 94, 100, 126, 131

YouTube 99, 107, 148

Z, Generation see Generation Z

Ziblatt, Daniel 141 